\title{
Agroecología Experiencias comunitarias para la agricultura familiar en Colombia
}

Álvaro Acevedo Osorio Nathaly Jiménez Reinales

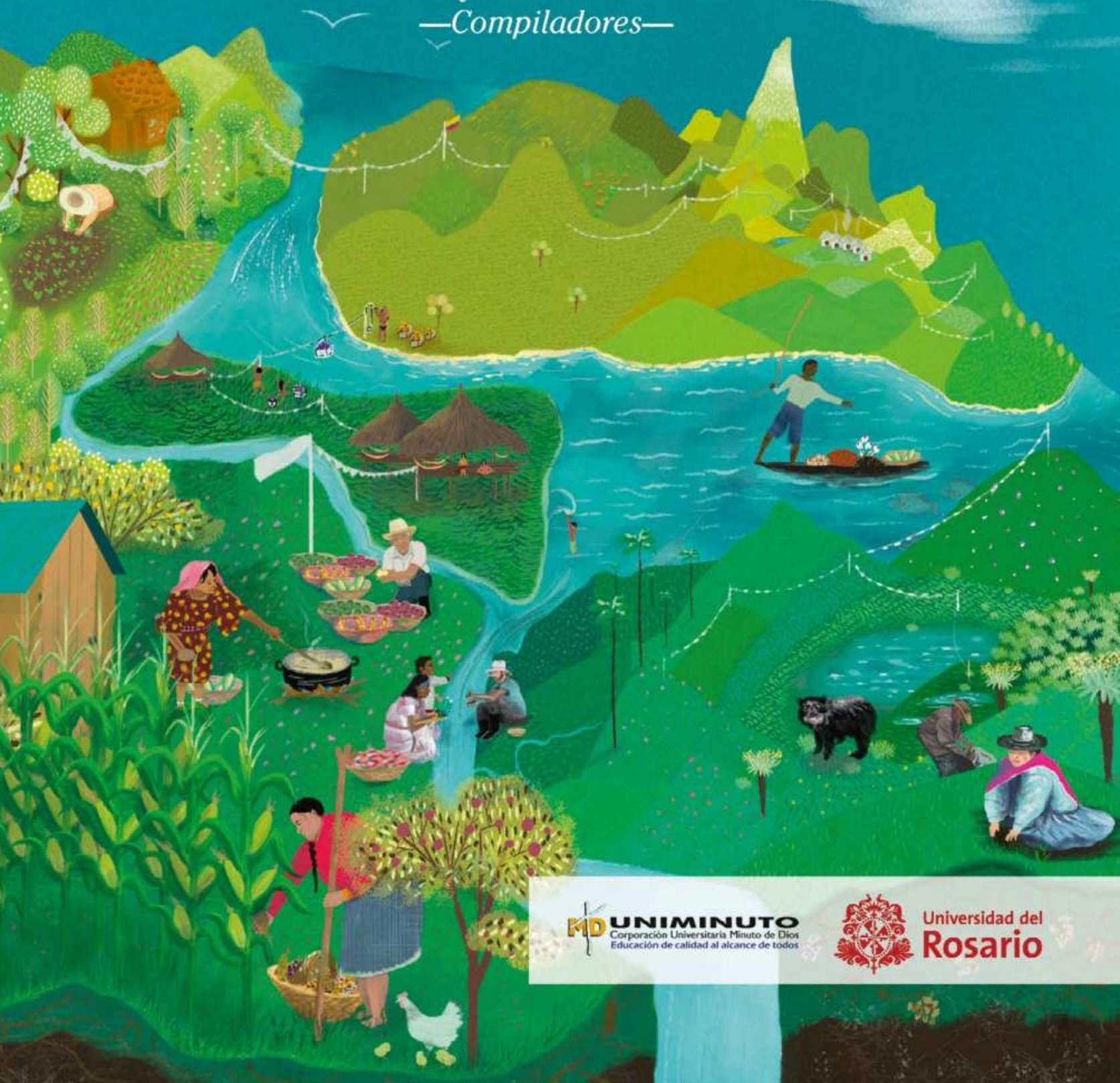



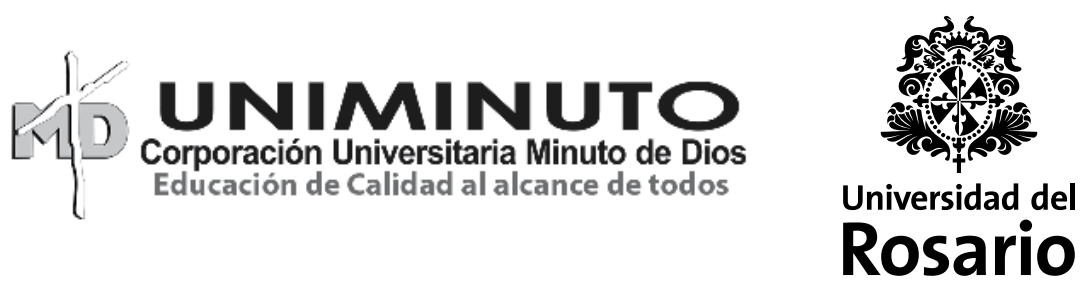
K4 - Corporación Universitaria Minuto de Dios

Presidente del Consejo de Fundadores

P. Diego Jaramillo Cuartas, cjm

Rector General Corporación

Universitaria Minuto de Dios -

UNIMINUTO

P. Harold Castilla Devoz, cjm

Vicerrectora General Académica

Marelen Castillo Torres

Rector Sede Principal

Jefferson Enrique Arias Gómez

Directora General de Investigaciones

Amparo Vélez Ramírez

Vicerrector Académico Sede Principal

Nelson Iván Bedoya Gallego

Director de Investigación Sede Principal

Alirio Raigoso Camelo

Directora General de Publicaciones

Rocío del Pilar Montoya Chacón 


\author{
AGROECOLOGÍA \\ EXPERIENCIAS COMUNITARIAS \\ PARA LA AGRICULTURA FAMILIAR \\ EN COLOMBIA
}




\title{
Agroecología. Experiencias comunitarias para la agricultura familiar en Colombia
}

\section{Resumen}

Los territorios rurales en Colombia enfrentan retos actuales relacionados no sólo con los aspectos sociales fundamentales para la paz, sino, también con las condiciones productivas y ambientales necesarias para avanzar hacia modelos de desarrollo rural sostenibles. Objetivos como alcanzar soberanía alimentaria, luchar contra la pobreza rural, adaptar la agricultura a riesgos emergentes y mitigar el efecto del cambio climático, proteger los recursos naturales especialmente suelo, agua y agrobiodiversidad, asegurar la prestación de servicios ecosistémicos, atender a la creciente demanda de alimentos, entre otros, requieren reconfigurar los sistemas agroalimentarios. Simultáneamente, la agricultura familiar viene siendo promovida por movimientos sociales que reconocen el papel esencial que cumplen de producir alimentos y cuidar la naturaleza y exigen el reconocimiento de su rol y políticas diferenciales que les permitan reproducir dignamente sus condiciones sociales de vida. Fortalecer las distintas formas de agricultura campesina, familiar y comunitaria, requiere de nuevos paradigmas científicos y prácticos en el desarrollo rural; uno de estos es la Agroecología, reconocido como el enfoque científico que mejor reconoce el potencial de la agricultura familiar para ayudar a enfrentar los retos mencionados. La Agroecología en Colombia ha sido promovida desde la década de 1980 por ONG's y la Iglesia, y más recientemente por las universidades. La práctica agroecológica ha permitido el surgimiento de innovaciones que han logrado niveles importantes de madurez. Desde la perspectiva de la transición hacia una agricultura sustentable, estas iniciativas comunitarias, reconocidas como "nichos sociotécnicos", se constituyen en espacios protegidos en los cuales se gestan y desarrollan estas innovaciones hasta lograr que se consoliden y generen cambios consistentes en las condiciones de vida de estas comunidades. El propósito de este libro es analizar algunas de estas experiencias agroecológicas desarrolladas por organizaciones de agricultores familiares en distintos lugares del país, nichos sociotécnicos, donde se generaron aprendizajes prácticos con potencial para fortalecer programas de agricultura campesina, familiar y comunitaria.

Palabras clave: Agroecología, Agricultura Familiar, Nichos sociotécnicos, Campesinado.

\section{Agroecology. Community Experiences for Family Farming in Colombia}

\begin{abstract}
Rural territories in Colombia currently face challenges to the peace process, not only in terms of social aspects but also with regards to the agricultural and environmental conditions necessary to move toward sustainable rural development models. Objectives including achieving food sovereignty, fighting rural poverty, adapting agriculture to emergent risks and mitigating the effects of climate change, protecting natural resources especially soils, water and agrobiodiversity, assuring the benefits of ecosystem services, responding to the growing demand for food, among others, require a reconfiguration of the food system. Concurrently, social movements are increasingly promoting family agriculture as a response to the aforementioned challenges. They affirm the essential role of food production in caring for conserving the environment and call for differential political agendas that encourage a dignified social reproduction of livelihoods for family farmers. Strengthening the distinct forms of peasant, family and communal agriculture requires new scientific paradigms as well as new practices of rural development; one of these is Agroecology, the scientific focus that best recognizes the potential of family agriculture to confront present day social-environmental challenges. Since the 1980s, Colombian NGO's and the Catholic Church, and more recently universities, have promoted agroecology. Agroecological practice has led to the emergence of solid innovations. From the perspective of sustainable agriculture, these community-based initiatives, recognized as "social-technical niches", are established within protected spaces. Communities create and develop such innovations until they become established and successfully generate consistent changes in the livelihoods of these communities. The goal of this volume is to analyze some of the agroecological experiences developed by groups of family farmers in different areas of the country, especially those from social-technical niches that generated practices with the potential to strengthen agricultural programs for peasant, family and communal producers.
\end{abstract}

Keywords: agroecology, family farming, socio-technical niches, campesinado.

¿Cómo citar este libro? / How to cite this book?

Acevedo, Á., y Jiménez, N. (comps). (2019). Agroecología. Experiencias comunitarias para la agricultura familiar en Colombia. Bogotá: Corporación Universitaria Minuto de Dios - UNIMINUTo; Editorial Universidad del Rosario.

Doi: doi.org/10.12804/tp9789587842326 


\section{AGROECOLOGÍA}

EXPERIENCIAS COMUNITARIAS

PARA LA AGRICULTURA FAMILIAR EN COLOMBIA

ÁLVARO ACEVEDO OSORIO
NATHALY JIMÉNEZ REINALES

-Compiladores- 
Agroecología. Experiencias comunitarias para la agricultura familiar en Colombia / Compiladores, Álvaro Acevedo Osorio, Nathaly Jiménez Reinales; Prólogos, Darío A. Fajardo Montaña y Tomás León Sicard. -- Bogotá: Editorial Universidad del Rosario, Corporación Universitaria Minuto de Dios, 2019.

xxi, 260 páginas.

Incluye referencias bibliográficas.

1. Ecología agrícola. 2. Granjas familiares. 3. Agricultura sostenible. 4. Agricultores. 5. Campesinos I. Osorio, Álvaro Acevedo. II. Jiménez Reinales, Nathaly. III. Fajardo Montaña, Darío A. IV León Sicard, Tomás. V. Universidad del Rosario. VI. Corporación Universitaria Minuto de Dios. VII. Título.

Compiladores

Álvaro Acevedo Osorio y Nataly Jiménez Reinales

(c) Varios autores

Prólogos

Darío A. Fajardo Montaña y Tomás León Sicard

En el marco de la "Cátedra Unesco en Desarrollo Sostenible", la Universidad del Rosario y la Universidad Minuto de Dios han unido esfuerzos para elaborar este libro fruto de la investigación que los autores han producido y la valiosa experiencia de los agricultores familiares protagonistas de estas contribuciones.

Corrección de estilo

Héctor Gómez

Diagramación

Martha Echeverry

Imagen de portada

Lorena Cifuentes

Diseño de portada

Juan Ramírez

Impresión

Xpress. Estudio Gráfico y Digital, S.A.S.

Impreso en Colombia - Printed in Colombia

Primera edición: abril, 2019

200 ejemplares
Corporación Universitaria Minuto de Dios

Educación de calidad al alcance de todos

\author{
(C) Universidad del Rosario \\ (c) Editorial Universidad del Rosario \\ Teléfono 2970200 , extensión 3114 \\ Carrera 7\# 12B-41, oficina 501 \\ Bogotá D. C., Colombia \\ editorial@urosario.edu.co
}

(c) Corporación Universitaria Minuto de Dios -

UNIMINUTO

Calle 81 B \# 72B-70

Bogotá D. C., Colombia

ISBN: 978-958-784-231-9 (impreso)

ISBN: 978-958-784-232-6 (ePub)

ISBN: 978-958-784-233-3 (pdf)

DOI: doi.org/10.12804/tp9789587842326

Esta publicación es el resultado del proyecto de la investigación Aporte de la agroecología al fortalecimiento de la agricultura familiar en colombia; caso de la Asociación de productores agroecológicos de la cuenca del río Anaime-apacra y la Asociación red agroecológica campesina La Pradera-Arac, financiado por la VI Convocatoria Sexta convocatoria para el fortalecimiento de grupos de investigación del Sistema uniminuto.

Corporación Universitaria Minuto de Dios - uniminuto. Todos los capítulos publicados en "La agroecología. Experiencias comunitarias para la agricultura familiar en Colombia", son seleccionados por el Comité Editorial de acuerdo con criterios establecidos. Están protegidos por el Registro de Propiedad Intelectual. Los conceptos expresados en los artículos competen a sus autores, son su responsabilidad y no comprometen la opinión de UNIMINUTO. Se autoriza su reproducción parcial en cualquier medio, incluido electrónico, con la condición de ser citada clara y completamente la fuente, siempre y cuando las copias no sean usadas para fines comerciales. 


\section{Contenido}

Agradecimientos........................................................................................ xiii

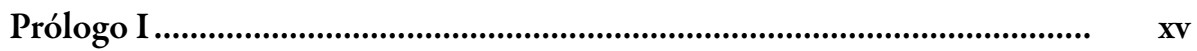

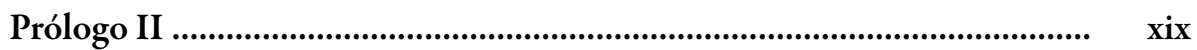

Tomás León Sicard

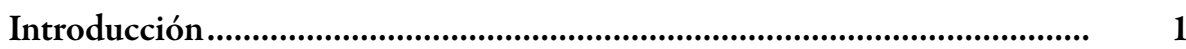

Referentes metodológicos.............................................................................. $\quad 7$

Referencias ..................................................................................... 11

\section{Capítulo 1}

Ideas para la transición hacia la sostenibilidad del sistema

agroalimentario: agricultura familiar, agroecología y nichos

sociotécnicos

Álvaro Acevedo Osorio

Jenny Paola Cruz Suárez

Julia Katharina Waeger

1. Características de la agricultura familiar.

15

2. Agroecología y agricultura familiar........................................................... 20

3. Nichos de innovación sociotécnica ............................................................. 24

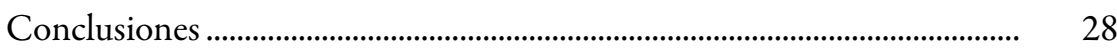

Referencias …………………………………………………………….... 29 


\section{Capítulo 2}

Agroecología, seguridad y soberanía alimentaria.

El caso de los agricultores familiares de Tibasosa, Turmequé

y Ventaquemada en Boyacá

Neidy Lorena Clavijo Ponce

Hellen Mireya Sánchez Gil

1. Introducción

37

2. Resultados y discusión.

40

3. Conclusiones ................................................................................................ 54

Agradecimientos .................................................................................... 55

Referencias

\section{Capítulo 3}

Conservación de suelos por agricultores campesinos en la cuenca

del rio Las Ceibas, Neiva, Huila

Juvenal Ruiz Pérez

Vladymeer León Cuellar

1. Introducción

61

2. El suelo y la agricultura.

62

3. Resultados y discusión. 65

4. Conclusiones ................................................................................................ 78

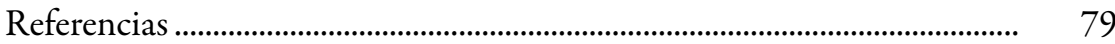

\section{Capítulo 4}

Construcción de casas comunitarias de semillas nativas - criollas con sistemas participativos de garantía de calidad en Colombia

Tarsicio Aguilar Gómez

Mauricio de Jesús García Álvarez

Ana Maria Garcia Hoyos

1. Introducción

2. Resultados

3. Discusión 106

4. Conclusiones 108

Agradecimientos. 109

Referencias 


\section{Capítulo 5}

Importancia de la agrobiodiversidad y agregación de valor a productos agroecológicos en la asociación APACRA en Cajamarca, Tolima

Astrid Ximena Cortés Lozano

Álvaro Acevedo Osorio

Cielo Esperanza Báez Mojica

1. Introducción

2. Resultados

3. Discusión

4. Conclusiones

Agradecimientos

Referencias

\section{Capítulo 6}

Sistemas agroecológicos de producción de gallinas criollas orientados a la sustentabilidad de la agricultura familiar campesina

Arlex Angarita Leiton

Fernando Castrillón Zapata

1. Introducción

2. Resultados y discusión 140

3. Conclusiones 153

Referencias

\section{Capítulo 7}

Construyendo desde la base una opción de vida: experiencia de la Red de Mercados Agroecológicos Campesinos del Valle del Cauca-REDMAC

Diego Iván Ángel Sánchez

Carlos Arturo Aristizábal Rodríguez

Red de Mercados Agroecológicos Campesinos del Valle del Cauca, REDMAC

1. Introducción

2. Resultados

3. Discusión 
4. Conclusiones ...................................................................................... 175

Agradecimientos ............................................................................................. 176

Referencias ........................................................................................... 176

\section{Capítulo 8}

Fondos autogestionados para la transición agroecológica:

el caso de ASproinca, Riosucio, Caldas.

Álvaro Acevedo Osorio

Julia Katharina Waeger

Willington Ortiz Orozco

1. Introducción

2. Resultados

3. Discusión

4. Conclusiones

Agradecimientos. 198

Referencias 198

\section{Capítulo 9}

Formación agroecológica en la experiencia de las "escuelas agroambientales" del Comité de Integración del Macizo Colombiano (CIMA)

Gustavo Adolfo Alegría Fernández

William Bernardo Macias Orozco

1. Introducción 203

2. Resultados 207

3. Discusión 217

4. Conclusiones 219

Agradecimientos. 220

Referencias 221 


\section{Capítulo 10}

Gestión de la cadena de valor de café agroecológico en ciclo

económico completo desde la economía social y solidaria

en ASOPECAM - Tuluá, Valle del Cauca

Álvaro Idárraga Quintero

Gloria Inés Cárdenas Grajales

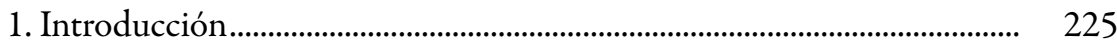

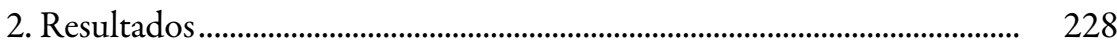

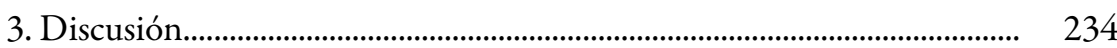

4. Conclusiones .......................................................................................... 242

Agradecimientos ........................................................................................ 243

Referencias .............................................................................................. 243

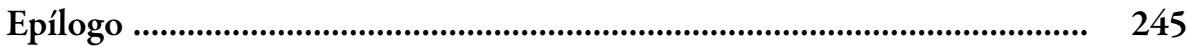

Álvaro Acevedo Osorio

Jenny Paola Cruz Suárez

Julia Katharina Waeger

El potencial de la agroecología para fortalecer los procesos

de transición hacia la sustentabilidad........................................................... 246

Referencias ................................................................................................... 250

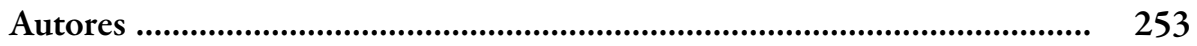





\section{Agradecimientos}

Los compiladores de este libro manifiestan su sentido agradecimiento a las organizaciones de productores rurales que, de manera sencilla y generosa, han compartido sus experiencias innovadoras; ellos son realmente los protagonistas de este libro:

A la Asociación de Productores de Cacao Ecológico de la cuenca del río Las Ceibas (ASPROCAECO) de Neiva - Huila. A las familias criadoras de gallina criolla en Natagaima - Tolima. A la Asociación de Pequeños Caficultores del corregimiento La Marina (Asopecam) en Tuluá, Valle del Cauca. A la Red de Mercados Agroecológicos Campesinos del Valle del Cauca (REDMAC). A las familias campesinas de Turmequé, Ventaquemada y Tibasosa en Boyacá. A la Asociación de Productores Agroecológicos de la Cuenca del Río Anaime (APACra) en Cajamarca - Tolima. A la Asociación de Productores Indígenas y Campesinos de Riosucio, Caldas (ASPROINCA). A los cerca de 800 custodios de semillas de las casas de semillas y Red de Semillas Libres de Colombia de diferentes regiones del país. Al Comité de Integración del Macizo Colombiano (CIMA).

Así mismo un agradecimiento especial por el compromiso y rigurosidad mostrado por los equipos académicos de profesores-investigadores que coordinaron el trabajo de sistematización de experiencias en las distintas regiones del país y documentaron los resultados de su trabajo en estos capítulos.

A La Red Nacional de Agricultura Familiar (RENAF) que nos anima a renovar nuestro compromiso como investigadores para trabajar en favor de la Agricultura Familiar. A su empeño y solidaridad con las organizaciones rurales del país.

A las editoriales Uniminuto (especialmente a Pilar Montoya y Jonathan Mora) y Universidad del rosario (Juan Felipe Córdoba), por su trabajo coordinado en el contexto de la CATEDRA UNESCO EN DESARROLLO SOSTENIBLE, para desarrollar el proceso editorial que da como resultado la publicación de esta obra

A Gabriela González y Megan Baumann por su apoyo en traducción.

Finalmente una dedicación especial a todos los Agricultores Campesinos, Familiares y Comutarios del país, por su trabajo silencioso y abnegado de producir alimentos y cuidar la naturaleza. 



\section{Prólogo I}

En su libro Agroecología. Ciencia y política Peter Rosset y Miguel Altieri destacan varios atributos de esta propuesta, hoy ampliamente diseminada en los campos del conocimiento y de la práctica: hace posible la agricultura "sin usar productos químicos peligrosos", proporciona una alternativa para comenzar a resolver las necesidades alimentarias de la población mundial, así como para enfrentar las destructivas amenazas de los modelos agrícolas impulsados por las empresas transnacionales. Es una iniciativa que responde a la tarea de la ciencia: "conocer para transformar".

En tal dirección, la oportuna compilación que preceden estas líneas, nos ofrece experiencias y testimonios sistemáticamente ordenados, que ilustran cómo productores y académicos han avanzado en la apropiación de este saber que hoy bien puede guiar las tareas de la reconstrucción pacífica de nuestro país. Dejar atrás la guerra es un propósito construido a lo largo de los años y bien podríamos decir que, desde cuando ella empezó, para las gentes del campo, sus primeras y más numerosa víctimas ha sido un propósito, un sueño, la posibilidad real de existir. Hoy, a pesar de la obstinación de quienes se han beneficiado del despojo y la muerte, Colombia comienza a asomarse hacia esa posibilidad.

Una de las huellas más profundas que ha dejado esta confrontación en nuestra sociedad ha sido el éxodo de millones de compatriotas, acumulado durante décadas y acompañado por la pérdida de vidas, la destrucción de comunidades campesinas originarias, mestizas, negras, la pérdida de sus tierras, territorios y patrimonios. Bien conocemos los resultados de esa "guerra para la usurpación" en la concentración y uso inadecuado de la tierra, el empobrecimiento de las gentes del campo y, por extensión, de las ciudades, las carencias de vías y demás condiciones indispensables para una vida medianamente digna en el mundo agrario. Pero, ante estas circunstancias vemos también experiencias que alumbran las posibilidades de un rumbo distinto: son las que nos presenta esta compilación, cuya llegada no es súbita ni sorprendente: sus contenidos 
han sido construidos a los largo de varios años y por tanto es esperada; más aún, necesitada, como lo veremos a continuación.

Las experiencias compiladas en esta colección responden a condiciones conocidas. A más de los efectos ya mencionados de la guerra, forman parte del pasado cercano las capacidades demostradas por las agriculturas campesinas, familiares y comunitarias para atender la demanda de alimentos del país. Conviene tener presente los resultados de un estudio sobre el desarrollo de la agricultura realizado por el gobierno colombiano a finales de la década de 1980. En él se estableció que, a pesar de las difíciles condiciones que rodean la existencia del campesinado, para entonces contribuía de manera destacada en hacer de Colombia un país autosuficiente en términos de su abastecimiento alimentario básico: cereales, tubérculos, frutales, hortalizas, carnes, lácteos. Su participación era de un 60 a 70\% de la oferta, condición que ya hemos perdido al pasar a importar cerca de 15 millones de toneladas, las cuales equivaldrían a más del 30\% de lo que consumimos. Este efecto lo ha hecho notar el Plan de desarrollo 2018-2022, al señalar cómo en los últimos años el nivel de precios de los alimentos ha sido mayor al nivel de precios de la canasta básica total. Estamos pagando los costos de haber permitido la destrucción de las comunidades campesinas y de sus aportes a la sociedad.

Varios caminos nos llevaron a esas pérdidas. A la guerra se sumó el enganche de Colombia con el narcotráfico, asociado al desmantelamiento de las comunidades y de sus prácticas productivas. Un país considerado por los especialistas como uno de los centros históricos en la domesticación de plantas habría de ser afectado por varios embates ocurridos a lo largo de nuestra historia. Desde la destrucción de cultivos y la demonización de muchos de ellos durante la conquista española como técnica de guerra y de control de la población hasta la implantación del modelo tecnológico de la "revolución verde”, el cual abriría espacios a la imposición de las variedades desarrolladas por las corporaciones transnacionales, eliminando a las agriculturas campesinas, a sus ecosistemas y patrimonios genéticos, con el apoyo de la propia guerra para la usurpación.

El panorama de las movilizaciones agrarias, en especial desde el paro agrario de 2013 y expresiones organizativas como la Federación Nacional de Sindicatos Agrarios (Fensuagro), el Consejo Regional Indígena del Cauca (CRIC), el Comité de Integración del Macizo Colombiano (CIMA), la Cumbre Agraria, la Coordinadora de Cultivadores de Coca, Amapola y Marihuana (Coccam), el Proceso de Comunidades Negras (PCN) y varias otras no solamente denuncian los incumplimientos del Estado ante los pactos alcanzados en las movilizaciones y las acciones represivas contra las dirigencias comunitarias, sino que manifiestan su voluntad de resistir los impulsos de los centros del poder para asegurar su debilitamiento económico, político y social. Esta voluntad se ha ido 
tejiendo desde lo local, proceso representativo de la gestión campesina y popular de los territorios manifiesta en las distintas experiencias documentadas en esta compilación.

Los estudios y testimonios acá recogidos presentan una sistematización rigurosa de experiencias locales y regionales de carácter estratégico para el fortalecimiento del arraigo y articulación de las comunidades con sus territorios y sus entornos, construidas sobre el denominador común de la agroecología. En términos geográficos, temáticos, organizativos y temporales, contemplan varias dimensiones: actúan en una amplia porción de la región central del país representada por municipios y localidades de Boyacá, Caldas, Cauca, Nariño, Tolima, Valle; comprenden la formación de redes para construir soberanía alimentaria apoyada en el desarrollo de circuitos productivos (mercados de cercanías); varias de ellas, sostenidas en mercados regionales, representan una ruta central para la reconstrucción económica y social de los territorios y el mejoramiento sustancial de las condiciones de vida de las mayorías rurales y urbanas con logros sostenibles como la reconstrucción de mercados de cercanías y el fortalecimiento del arraigo de las comunidades rurales y urbanas. Se encuentran igualmente experiencias en conservación de suelos mediante prácticas agroecológicas en cuencas estratégicas y altamente degradadas; manejo de semillas nativas y tradicionales a través de prácticas comunitarias para la recolección y distribución de material garantizado por las mismas comunidades; producción y reproducción de variedades criollas de aves domésticas; redes de escuelas agroecológicas, creación y gestión de un fondo rotatorio para el apoyo solidario a familias campesinas e indígenas, organización de pequeños productores para la producción agroecológica y comercialización de café en sistemas de comercio justo. Su espectro cubre iniciativas de grupos de familias y comunidades organizadas que construyen puentes entre "veredas y barrios", entre el campo y las ciudades para llevar alimentos a nuestras mesas, en una significativa bandeja de intervenciones, en un arco temporal que, en uno de los casos alcanza a cubrir 50 años de experiencias.

A propósito de los temas abordados, todas y cada una de estas iniciativas apuntan a problemas críticos que debe resolver la sociedad colombiana y que remiten a la reconstrucción de la ruralidad, a la recuperación del arraigo de las comunidades, de las condiciones alimentarias del país y de buena parte de su patrimonio ambiental. Ilustran opciones para superar los efectos del conflicto armado y sus secuelas en el destierro de millones de campesinos, los principales productores de alimentos así como los efectos de los pactos internacionales del comercio de bienes agrícolas, a los cuales Colombia ha cedido sus mercados en detrimento de los propios campesinos y de los consumidores en general. 
La conformación físico geográfica del país le ha otorgado su megadiversidad, pero la otra cara de la moneda es la vulnerabilidad de muchos de sus ecosistemas, profundamente maltratados en la actualidad; los alcances del manejo que se les ha proporcionado están dramáticamente representados en las condiciones que ofrece la cuenca del río Las Ceibas, escenario de una de las experiencias documentadas en esta colección y fuente del acueducto de Neiva, Huila, capital permanente amenazada en su abastecimiento a consecuencia del devastador manejo recibido por parte de sus habitantes.

Las normas sobre comercio y trasiego de semillas y especies tradicionales impuestas al país amenazan destruir su patrimonio genético y otro tanto ocurre con la postergación de una reforma agraria y rural que ha profundizado el empobrecimiento de las gentes del campo y desatado el arrasamiento de sus bosques, páramos, ciénagas y humedales. No sobra subrayar entonces la importancia dela recuperación, protección y defensa del patrimonio genético del país ante la ofensiva de los tratados de libre comercio de bienes agrícolas, en particular y la cesión de sus mercados hecha por el gobierno colombiano en detrimento de los productores y de los consumidores en general.

Una tarea central en la reconstrucción del país es la recuperación y el fortalecimiento de los vínculos entre las comunidades. A lo largo de la historia han sido vulnerados y sistemáticamente golpeados desde los centros del poder, en particular los de carácter interétnico, como parte de las estrategias de la guerra. Se ha tratado de debilitarlas generando y estimulando recelos, prevenciones, roces y confrontaciones entre ellas, dado el significado que sus alianzas pueden tener en la gestión pacífica y democrática de los territorios.

Cada una de las experiencias acá expuestas propone un punto de partida y una ruta para la solución de una dimensión de la encrucijada del país. Significa la posibilidad de incidir en sectores sociales y espacios más amplios, atributo que se magnifica al considerar que ellas están localizadas en donde está ubicada la mayor parte de la población y en inmediaciones de sus ecosistemas estratégicos. Contamos con esta publicación con una oportuna guía para la réplica sistemática de estas experiencias a través de su incorporación en los procesos de planificación local y regional para la gestión de los territorios: cada una de ellas puede traducirse en la posibilidad cierta de un mejoramiento efectivo de la calidad de vida y de las condiciones alimentarias de las comunidades, de recuperación de sus ecosistemas, de construcción participativa y democrática del país. 


\section{Prólogo II}

En el ejercicio de escribir, creo que no hay nada más difícil que prestarle la voz de las palabras de uno a la voz de las palabras de los otros. Esto, porque parece una empresa de enormes dificultades situarse en el ser, en las circunstancias y en los espacios múltiples, es decir, en los espacios domésticos, sociales, políticos, económicos, simbólicos o materiales de aquellos a quienes se interpreta. Y ese querer interpretar o ese querer prestar la voz resulta aún más complejo cuando se trata de grupos sociales heterogéneos, dibujados en estereotipos que perviven en los imaginarios de la gente y que distorsionan a los seres humanos que viven detrás de esas visiones, de esos modelos mentales que nos hemos forjado a lo largo de nuestras vidas. En ocasiones, algunos de esos estereotipos los anclamos desde la ignorancia y entonces nos resulta indiferente su suerte o su destino, pero en otras oportunidades tratamos de despejar estas incógnitas con o sin mucho conocimiento de los sujetos a quienes queremos interpretar o a quienes queremos visibilizar o reivindicar.

Esto es lo que pasa con el campesinado colombiano. Alguna vez le oí decir, a un excelente investigador universitario, que no había cosa más difícil de realizar que la de definir al campesino. Y no porque no hubiera acuerdos desde hace mucho tiempo entre los académicos sobre algunos rasgos socioeconómicos que los definen, tanto en lo que atañe al uso de mano de obra familiar o a su relación con la tierra, el terruño o el suelo como con sus actuaciones como agentes económicos, sino porque detrás de esa palabra existen millones de rostros, de historias, de intereses, de cualidades, virtudes, defectos, deseos, inclinaciones, gestos, lazos, aspiraciones y cuerpos y almas y espíritus, que individualizan y deslindan y limitan y hacen difícil de agrupar, al campesino solo, al hombre o la mujer, al niño, al joven o al anciano que vive de su tierra, que huele a frutos, que siembra y cosecha en distintas ocasiones y bajo soles y lunas diferentes. En una palabra, detrás del concepto campesino, se esconde la vida humana en toda su complejidad y esa complejidad de individuos difícilmente se puede traducir en una etiqueta, en una sílaba o, si se quiere, en uno o en cientos de libros. 
Por eso es que la obra que precede estas líneas, escrita por investigadores comprometidos con la vida misma, más que con la vida con etiquetas, es una obra llena de valor y de esperanzas. De valor, porque se trata, justamente, de interpretar a esos millones de seres humanos que, en el imaginario de los colombianos urbanos, se presta para múltiples interpretaciones, en alguna de las cuales el campesino es una figura que debiera desaparecer, que no es viable, que no es moderna, que representa el atrás, el pasado, la ineficiencia o la ignorancia. Y hay que tener valor para rebatir esas ideas y para defender a esos que no tienen voz, en los debates académicos y en los recintos del poder económico y político. Valor para interpretar a los hombres y a las mujeres de manos callosas y dedos gruesos y rostros de sal, y para mostrar que de ellos viene la luz y la comida, la savia que debiera nutrir a nuestros hijos, el agua que bebemos a diario, las fibras que visten nuestros cuerpos de ciudadanos urbanos. Porque hay quienes quieren fijarlos a ellos (a los y las campesinas en su monumental heterogeneidad), como rígidas fichas sin derechos o como empresarios del campo, productivos y acumuladores de capital, generadores de empleo, exportadores de bienes consumibles.

Desterrar esta idea y ganarle la partida a la indiferencia y quizás mostrar con la mayor honestidad posible algunos de los rostros y facetas humanas de algunos campesinos y campesinas en distintas regiones del país, es parte de los atributos no confesados que poseen los artículos escritos por los colegas en este libro. Escritos que quieren mostrar la diversidad enorme de estos seres humanos ligados a la tierra, especialmente en estos Andes colombianos, tan caros a varios de quienes nos dedicamos a ese otro campo diverso de estudios: la agroecología.

Y entonces los colegas que escribieron sus múltiples experiencias en distintos ámbitos de la geografía nacional sobre las familias campesinas agroecológicas, también nos presentan una obra llena de esperanza. De esperanza, porque relatan cómo, pese a la naturaleza humana que a todos nos permea por igual, en el campesinado colombiano existen potencialidades, posiciones filosóficas, actuaciones políticas, conocimientos nuevos y rutas diversas para continuar labrando la tierra entre arreglos amables (de plantas y humanos), entre una agrobiodiversidad exuberante, entre amigos que comparten sus excedentes y sus conocimientos, entre agricultores que le apuestan a un mejor vivir, a enfriar el planeta, a producir alimentos sanos para todos y a dejar los suelos, el agua y la biodiversidad aún en mejores condiciones que en las que las recibieron en préstamo, porque ellos (los campesinos), se saben mortales y pasajeros, mortales y responsables del futuro de todos nuestros hijos. 
Y entonces la esperanza que representa este libro y sus autores y sus desconocidos actores, nos da pistas sobre distintas maneras de habitar la tierra, de vivir los años que la biología o Dios nos han concedido, pero de una manera tal que la producción de alimento se torne no en una meta productivista y de acumulación de capital, sino en una vía de alegría y de amor por todo lo viviente. Y seamos o no campesinos y seamos o no académicos de carrera, lo que los colegas de este libro nos dejan y nos invitan a sentir, impulsados en buena parte por el entusiasmo de nuestro querido colega Álvaro Acevedo, son páginas que relatan y le dan nombre propio a las vidas de los cientos de agricultores familiares campesinos agroecológicos que pueden reconocerse en cada uno de los artículos escritos en este libro magnífico. Detrás de cada texto o párrafo pueden percibirse los seres humanos ligados a la tierra en su diario vivir, que nos legan cosas como la preservación del patrimonio genético de tubérculos andinos, la conservación de suelos y de semillas nativas, las discusiones sobre las transiciones de modelos agrarios, el cuidado de la agrobiodiversidad, el manejo de gallinas criollas, los mercados campesinos y los fondos auto gestionados para la transición agroecológica, la formación agroecológica o la gestión de la cadena de valor de productos agroecológicos, temas suficientes para entusiasmarnos con la esperanza del buen vivir y para ir desterrando los estereotipos nacidos en la ignorancia y la indiferencia. 



\section{Introducción}

El campesinado colombiano vive actualmente un momento histórico transcendental para su fortalecimiento. Las condiciones sociopolíticas del posconflicto configuran un escenario favorable para repensar el papel de este sector y su potencial, asimismo, para enfrentar los retos actuales y futuros, relacionados no sólo con los aspectos sociales fundamentales para la paz, sino, también con las condiciones productivas y ambientales necesarias para avanzar en el propósito de una transición hacia modelos de desarrollo rural sostenibles.

Algunos de los retos para la agricultura del futuro enunciados en estudios internacionales, como la Evaluación Internacional del Papel del Conocimiento, la Ciencia y la Tecnología en el Desarrollo Agricola (International Assessment of Agricultural Knowledge, Science and Technology for Development - IAASTAD, 2009), son: la seguridad y soberanía alimentaria, la lucha contra la pobreza rural, la adaptación y mitigación de la agricultura al cambio climático, la protección de los recursos naturales especialmente recursos fitogenéticos, asegurar la prestación de servicios ecosistémicos, atender a la creciente demanda de alimentos y los cambios de hábitos alimenticios de la sociedad urbana, entre otros. Además de los retos antes mencionados, es vital importancia generar las condiciones necesarias para que el sector rural colombiano pueda alcanzar la paz.

Muchas de estas condiciones han sido ampliamente debatidas por los sectores sociales con consignas como la necesidad de concretar políticas diferenciales para el progreso del campo y la democratización del acceso a la tierra. A lo anterior, hay que sumarle los argumentos de la producción sostenible, los mercados de proximidad, las tecnologías apropiadas, la economía solidaria y otros enfoques, en los cuales las mismas organizaciones, con apoyo de las ONG y de la iglesia, han logrado desarrollar experiencias locales de gran potencial transformador.

No obstante, la capacidad de transformar la ruralidad, no obedece solo a la inicitiva de las organizaciones sociales, ya que el rol institucional es determinante 
en dicha transformación. Una serie de acontecimientos recientes, configuran en buena medida la ruralidad colombiana del posconflicto y se relacionan directamente con la posibilidad transformadora de la ruralidad: anivel mundial y nacional el creciente interés por la agenda 2030 o los Objetivos de Desarrollo Sostenible (oDs) se pone sobre la mesa para el sector rural del país, puesto que, algunos de los objetivos trazados atañen directamente al campo y, especialmente, a las agriculturas en pequeña escala, ya que han sido responsables en buena medida de la producción de alimentos. Igualmente, a nivel internacional la campaña del Foro Rural Mundial y movimientos sociales como la Vía Campesina, en favor de la Agricultura Familiar que tuvo como hito importante la celebración del Año Internacional de la Agricultura Familiar determinado por la ONU a través de la FAO en 2014 (FAO, 2014). Estas circunstancias de orden institucional, representan oportunidades importantes que, al ser capitalizadas por los gobiernos y las organizaciones, permitirían cambios significativos en el sector y particualrmente, en las condiciones de vida de los agricultores del campesinado.

En Colombia, después de un largo período de profundización de las políticas económicas neoliberales que debilitaron al sector de la economía campesina y agudizaron los conflictos sociales y ambientales (Fajardo, 2014), se abren nuevas perspectivas para la agricultura del campesinado a partir de la firma de los acuerdos de paz entre la guerrilla de las FARC-EP y el gobierno Colombiano en diciembre de 2016. Este acuerdo está compuesto por propuestas que vienen a fortalecer las demandas que ya estaban construyendo los movimientos sociales del país, pero con la ventaja de ubicarse ahora en un nuevo contexto, el del posconflicto, que renueva el interés en los temas rurales, posibilitando al campo como escenario para alcanzar la paz. En este camino, la resolución 464 de diciembre de 2017 del Ministerio de Agricultura recoge, en buena medida, planteamientos de los acuerdos de paz y constituye, tal vez, la primera norma en el país en proponer una política diferenciada para la agricultura en pequeña escala denominada en esta obra como Agricultura Campesina, Familiar y Comunitaria que cuenta con la participación de diversos sectores sociales.

Como categoría sociopolítica de la ruralidad, la agricultura familiar viene siendo promovida por movimientos sociales que piden el reconocimiento del papel fundamental que cumplen en la soberanía alimentaria y conservación del patrimonio cultural y natural, para lo cual exigen políticas públicas específicas que les aseguren mejores condiciones de vida y permanencia en sus territorios. De alguna manera, este debate renovado sobre el campesinado también contribuye a enfrentar 
los riesgos a que están sometidos los líderes sociales que defienden reivindicaciones a favor de sus comunidades.

Un concepto general sobre la agricultura familiar ha sido acuñado desde la sociología rural como aquella manera particular de trabajo, producción y organización desarrollada por familias rurales dentro de un contexto social y económico particular (Schneider, 2016). Esto incluye familias campesinas de muy diversas condiciones y características: desde aquellas que están más vinculadas con los mercados y el uso de paquetes tecnológicos fomentados por la Revolución Verde, hasta las comunidades que producen lo esencial para la subsistencia en los territorios en los que existe poca articulación con los circuitos de comercialización; pasando por miles de familias que usan tecnologías tanto tradicionales (derivadas de la cultura y el pensamiento de las comunidades rurales) como convencionales (derivadas de paquetes tecnológicos) y que se vinculan de manera adaptativa a los mercados dependiendo del contexto en el que viven. Dentro de esta categoría se incluyen aquellas familias que no tienen tierra, pescadores, grupos étnicos, neorurales, agricultores urbanos, etc.

Uno de los enfoques relevantes para fortalecer las distintas formas de agricultura campesina, familiar y comunitaria (como ha sido acogida la categoría en Colombia) es la Agroecología. Aunque no se plantea como la única estrategia, sí es el enfoque científico que mejor reconoce el potencial de la agricultura familiar para ayudar a enfrentar los retos de la agricultura, especialmente, por su capacidad para proveer alimentos suficientes, sanos y culturalmente apropiados.

El movimiento agroecológico colombiano surgió a finales de la década de 1980, promovido por las ONG, organizaciones campesinas, programas de la Iglesia, líderes ambientalistas y algunas instituciones públicas (León-Sicard, Sánchez de Prager y Acevedo-Osorio, 2017) en medio de confusiones con el pensamiento de la agricultura orgánica y ecológica. No obstante, la evolución de las prácticas y conceptos de la agroecología en el país han trascendido como una forma de agricultura sostenible, con propósitos no sólo de carácter ambiental sino también sociales y políticos cada vez más claros.

Sobresalen en esta historia de la agroecología en Colombia, los desarrollos tecnológicos y organizativos logrados a partir de la innovación popular y la adaptación a las condiciones tanto productivas como sociales; razón por la cual, se ha generado un silencioso proceso de transición hacia el desarrollo rural sostenible desde la práctica agroecológica campesina. Se usará el concepto de "nichos de innovación sociotécnica” de Frank Geels (2011) como marco teórico para tratar 
de analizar la manera cómo se han creado estas innovaciones agroecológicas y han logrado niveles importantes de madurez. Desde la perspectiva de la transición hacia una agricultura sustentable, los nichos sociotécnicos se constituyen en espacios relativamente protegidos en los cuales se gestan estas innovaciones y son desarrolladas bajo ciertas condiciones necesarias para lograr que se consoliden y generen cambios consistentes en las condiciones de vida de los productores innovadores, asimismo, en los contextos parcialmente aislados del régimen sociotécnico dominante.

Se ha dado paso también a un proceso participativo de construcción de políticas públicas para la agroecología en Colombia, que parte de reconocer la Resolución 464 como norma referente y, reconoce también el papel fundamental de las organizaciones campesinas que han venido trabajando desde mucho antes, bajo el enfoque agroecológico. El reto, en estos tiempos de institucionalización de la agroecología (Holt-Giménez y Altieri, 2012), es no caer en la trampa de organismos multilaterales y gobiernos que intentan coaptar los principios de la agroecología para integrar, de manera forzada, a los agricultores familiares en la lógica de la empresarización ecologista y responder a las demandas de un sector orgánico del mercado global. Por esta razón, la idea de lo local y la cooperación, según Robert y Rahnema (2015, como se citó en Giraldo, 2018), debe primar en el concepto de agroecología familiar y comunitaria:

... lejos de insertar a las poblaciones a la vida económica del mercado y a sus lógicas basadas en la racionalidad económica, lo que urge en estos tiempos aciagos es actuar con base en la localidad, la auto-organización, la auto-gestión y auto-consumo; la reciprocidad, la redistribución social de los beneficios económicos; el intercambio en relaciones cercanas, y reavivar las múltiples vías que tenían los pueblos para llevar una vida compartida, simple y diversa. (p. 143).

El propósito de este libro es analizar una serie de experiencias agroecológicas desarrolladas por organizaciones de agricultores familiares en distintos lugares del país, que constituyen en sí, nichos sociotécnicos, donde se generaron aprendizajes prácticos con potencial para fortalecer programas de agricultura familiar en la nación.

Al presentar dichas experiencias se intenta recalcar las posibilidades que pueden ofrecer estas innovaciones agroecológicas, y así se conviertan en referentes para la agricultura campesina, familiar y comunitaria, asimismo, puedan aportar en la construcción de programas que fomenten estas prácticas agricolas. 
Más allá de poner todas las esperanzas en tratar de posicionar la agroecología y los procesos de transición por la vía de la institucionalidad gubernamental hacia una ruralidad sostenible, el propósito de este libro es afianzar la importancia de la construcción y consolidación de programas concretos y experiencias gratificantes desde abajo (campo) y hacia arriba (Estado), que partan de principios como la creatividad, solidaridad y respeto por la vida.

El primer capítulo de la presente obra propone tres enfoques centrales que permiten el abordaje teórico de las experiencias analizadas, estos son: la agricultura familiar, la agroecología y los nichos de innovación sociotécnica. La agricultura familiar es planteada como categoría política que renueva el pensamiento sobre el campesinado y lo impulsa hacia nuevos escenarios en la que la soberanía alimentaria, las nuevas relaciones de mercados y la agricultura sostenible se constituyan en factores centrales de nuevos procesos de desarrollo rural. La agroecología es propuesta como enfoque científico y metodológico para fortalecer las distintas formas de agricultura familiar. Finalmente, se propone que los procesos de transición hacia la agroecología basados en el redescubrimiento de conocimientos y prácticas tradicionales y locales, asimismo, en la mejora de los saberes científicos que pueden ser entendidos más ampliamente a través de la teoría de los nichos de innovación sociotécnica, que comprenden prácticas, intervenciones, productos, redes, entre otros factores, que se originan bajo las condiciones locales en espacios parcialmente protegidos del modelo convencional de transferencia.

El segundo capítulo resume los resultados de un estudio de caso con 25 familias agricultoras en los municipios de Turmequé, Ventaquemada y Tibasosa en el Departamento de Boyacá, que evidencia los aportes de la agricultura familiar, con enfoque agroecológico, a la seguridad y soberanía alimentaria en los Andes colombianos. A partir del desarrollo de procesos de investigación participativa, se expone información sobre la trayectoria productiva de estas familias durante los últimos 50 años; así como las características de sus sistemas de producción, las prácticas de manejo que llevan a cabo al interior de la finca, las dinámicas de su alimentación y los circuitos que tienen sus productos agropecuarios.

La conservación de suelos bajo esquemas agroecológicos de producción y conservación son abordados en el tercer capítulo. Se muestra la experiencia de la Asociación de Productores de Cacao Ecológico de la cuenca del río Las Ceibas (ASPRocaeCo), que adopta una propuesta de producción sostenible de alimentos a partir del desarrollo de sistemas agrícolas con mínima afectación al suelo y promoción del uso racional 
del agua en desarrollo del Plan de Ordenación y Manejo de la Cuenca Hidrográfica (POMCA) del río Las Ceibas en Neiva (Huila).

El capítulo cuarto está centrado en el manejo de las semillas criollas y nativas, mediante la estrategia de instalar casas comunitarias de semillas para la colección y distribución, así como los sistemas participativos de garantía para asegurar su calidad. Se presenta el caso de las redes articuladas a la "Campaña Semillas de Identidad" con más de 100 organizaciones en 20 departamentos de Colombia y 70 casas comunitarias de semillas que articulan a 800 custodios, constituyendo la más grande experiencia de conservación de semillas de origen agroecológico en el país.

Articulada con esta experiencia de redes de semillas, el capítulo quinto muestra la experiencia basada en manejo de agrobiodiversidad desarrollada por integrantes de la Asociación de Productores Agroecológicos de la Cuenca del Río Anaime (APACRA) en Cajamarca, Tolima, que no sólo han construido una estrategia para suplir las necesidades productivas y comerciales de las familias productoras, sino que, han establecido relaciones socioeconómicas dinámicas con mercados de Cajamarca e Ibagué, ejerciendo así acciones de conservación de ecosistemas, garantía de su seguridad alimentaria y aporte al desarrollo local sustentable.

La experiencia relatada en el sexto capítulo, corresponde a una iniciativa de producción pecuaria adelantada por familias del municipio de Natagaima, en el sur del Tolima, que han adecuado los sistemas agrícolas de sus fincas para la producción de gallina criolla, a partir de estrategias agroecológicas como la selección de razas criollas, el adecuado manejo productivo, reproductivo y, especialmente, de la alimentación balanceada a partir de recursos forrajeros del trópico bajo.

En el séptimo capítulo se expone la experiencia de la Red de Mercados Agroecológicos Campesinos del Valle del Cauca (REDMAC) compuesta por alrededor de 60 organizaciones de 23 municipios de los departamentos del Valle del Cauca y Cauca, que hacen presencia en mercados campesinos ubicados en los municipios de Andalucía, Buga, Cali, Dagua, Guacarí, Palmira, Restrepo, Roldanillo, Sevilla y Tuluá. Se resalta la particular manera cómo han establecido un Sistema Participativo de Garantías (SPG), que responde a las expectativas de calidad de los alimentos y la confianza construida entre productores y consumidores.

Una experiencia de más de 20 años de administración de un fondo autogestionado para la transición agroecológica de fincas de familias agricultoras es presentada en el capítulo octavo. El capítulo resalta como, a partir del enfoque de la economía social y solidaria, más de 300 familias se han beneficiado de un fondo rotatorio que es gestionado y manejado por la Asociación de Productores Indígenas 
y Campesinos de Riosucio, Caldas (ASPROINCA), y que financia la transformación ambiental, productiva y genera calidad de vida a las familias que están asociadas a dicha organización.

El capítulo noveno analiza una experiencia de educación rural de base agroecológica. Se trata de la propuesta educativa de las Escuelas Agroambientales impulsadas por el Comité de Integración del Macizo Colombiano (CIMA) que propone una formación de arraigo y defensa territorial. Se destaca de esta experiencia, la perspectiva integral de la agroecología plasmada en la propuesta educativa dirigida a niños, niñas y jóvenes campesinos, en la que no sólo se aborda la preocupación productiva y ambiental, sino que, se pretende entender la política y la economía, además de su interrelación con los sistemas agroecológicos desde el nivel básico y concreto de la finca.

El último capítulo destaca una reconocida experiencia de producción agroecológica de café, ligada a la idea del comercio justo. La Asociación de Pequeños Caficultores del corregimiento La Marina (ASOPECAM) en Tuluá, Valle del Cauca, desde 1993, ha consolidado una estrategia de producción y comercialización del producto insignia de la agricultura colombiana. En esta oportunidad se muestra cómo esta propuesta ha evolucionado hacia esquemas de escalamiento, economía social y solidaria en ciclo económico completo y modelo multiactor, que han permitido a la asociación evolucionar en su autonomía en la toma sus decisiones y en la gestión económica y social.

\section{Referentes metodológicos}

Cada una de las experiencias recogidas en este libro fue analizada detalladamente por equipos interdisciplinarios de investigación pertenecientes a diversas instituciones académicas, ONG y organizaciones rurales. Cada equipo de trabajo usó la misma metodología propuesta para la descripción y análisis de una experiencia seleccionada con base en su trayectoria en agroecología y la representatividad temática de la misma, tratando de abarcar algunas de las más relevantes dimensiones del trabajo agroecológico nacional.

La metodología empleada fue la de Sistematización de experiencias planteada por Chávez-Tafur (2006), diseñada para realizar ejercicios rigurosos de documentación de experiencias rurales adelantadas por comunidades de productores para obtener aprendizajes y, por lo tanto, nuevo conocimiento, que puede estar disponible para el mejoramiento de futuras experiencias. Las experiencias analizadas y su ubicación geográfica se relacionan en la figura 1 . 
Figura 1. Ubicación de las experiencias sistematizadas.

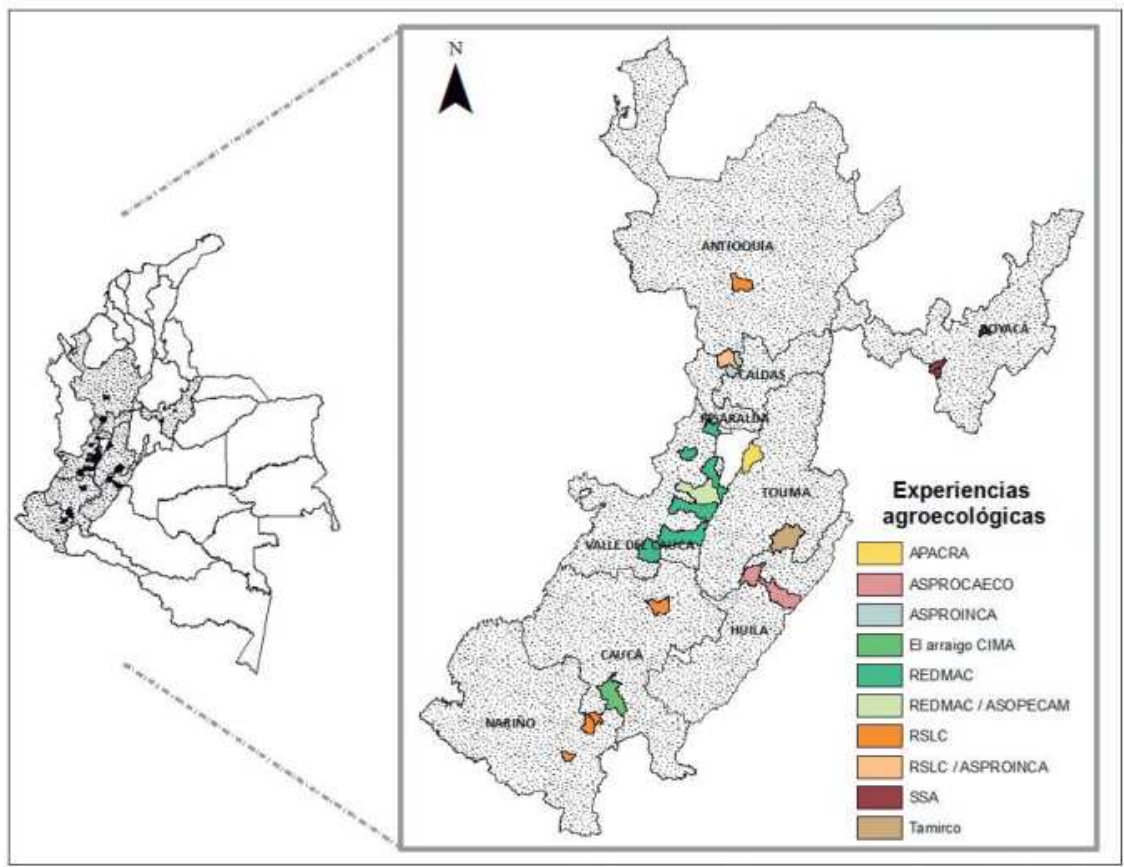

Fuente: Becerra (2018).

La sistematización de cada una de las experiencias se desarrolló en seis momentos, se emplearon matrices para la recoleccción de la información obtenida tanto de la documentación existente, como de aquella que se generó al utilizar distintos instrumentos de investigación definidos para este fin.

El primer momento correspondió a la definición del punto de partida, esto implicó conformar el equipo de trabajo, clarificar las intenciones, beneficiarios y objetivos de la sistematización, así como caracterizar a la organización que desarrolló la experiencia, identificar la documentación disponible y acordar la coordinación, los recursos y los tiempos para el desarrollar cada uno de los momentos del proceso (Chavez-Tafur, 2006; Eizaguirre, Urrutia y Askuze, 2004).

El segundo momento fue la delimitación de la sistematización. Esta etapa consistió en delimitar espacial y temporalmente la experiencia. Igualmente, se definieron los indicadores para los parámetros desde los cuales se realizaría el análisis de la experiencia (figura 2). 
Figura 2. Matriz de delimitación de la experiencia. Basada en Aprender de la experiencia. Una Metodología para la sistematización.

\begin{tabular}{ccccccc}
\hline Título & $\begin{array}{c}\text { Ámbito de } \\
\text { intervención } \\
\text { (localización) }\end{array}$ & $\begin{array}{c}\text { Grupo meta } \\
\text { (participantes) }\end{array}$ & $\begin{array}{c}\text { Fechade } \\
\text { inicioy } \\
\text { duración }\end{array}$ & Objetivos & $\begin{array}{c}\text { Enfoque/ } \\
\text { estrategia }\end{array}$ & Componentes \\
\hline
\end{tabular}

Fuente: tomado de Chávez-Tafur (2006).

El tercer momento consistió en la reconstrucción ordenada de la experiencia, identificando sus etapas, componentes, actividades, materiales y recursos utilizados, logros, dificultades, resultados obtenidos y resultados no esperados. Este proceso se realizó simultáneamente con cada uno de los equipos de sistematización de las organizaciones (figura 3).

Figura 3. Matriz de reconstrucción de la experiencia. Basado en Aprender de la experiencia.

Una Metodología para la sistematización.

\begin{tabular}{lccccc}
\hline Componentes & Actividades & $\begin{array}{c}\text { Materiales y } \\
\text { recursos }\end{array}$ & $\begin{array}{c}\text { Principales } \\
\text { logros }\end{array}$ & $\begin{array}{c}\text { Dificultades } \\
\text { encontradas }\end{array}$ & $\begin{array}{c}\text { Resultados no } \\
\text { esperados }\end{array}$ \\
\hline
\end{tabular}

a)

b)

c)

d)

Fuente: tomado de Chávez-Tafur (2006).

El cuarto momento de la sistematización fue el análisis. Este consistió en el análisis, síntesis e interpretación crítica de la experiencia en sus distintos componentes, desde lo particular y lo colectivo, enfocado en la búsqueda y comprensión de los factores claves de la experiencia y de su lógica interna. En ese momento se definieron atributos de análisis e indicadores de estos, que incluyeron toda la experiencia desde 
una perspectiva tanto cualitativa como cuantitativa. Los indicadores fueron construidos con los equipos de sistematización de cada experiencia y sobre cada uno de ellos se recopilaron evidencias. Asimismo, se analizaron los aspectos positivos, negativos y desconocidos de la experiencia, así como las causas que generaron los resultados obtenidos y recogidos en el momento anterior (figura 4) (Chávez-Tafur, 2006).

Figura 4. Matriz de análisis de la experiencia.

\begin{tabular}{llll}
\hline Dimensión & & \\
\hline Atributo & $\begin{array}{l}\text { Indicadores (medidas - } \\
\text { evidencias) }\end{array}$ & Fortalezas del atributo & $\begin{array}{l}\text { Oportunidades de } \\
\text { mejorar }\end{array}$ \\
\hline 1. & $\mathrm{I}_{1}$ & \\
\cline { 2 - 3 } & $\mathrm{I}_{\mathrm{n}}$ & \\
\hline 3. & $\mathrm{I}_{1}$ & \\
\hline $\mathrm{I}_{\mathrm{n}}$ & $\mathrm{I}_{1}$ & \\
\hline & $\mathrm{I}_{\mathrm{n}}$ & \\
\hline
\end{tabular}

Fuente: adaptado de Aprender de la experiencia. Una Metodología para la sistematización, Chávez-Tafur (2006).

El quinto momento fue el proceso de sistematización. Consistió en compartir los resultados con las familias agricultoras y otros actores involucrados en el proceso de sistematización. Además, se realizó la presentación de los resultados a los miembros de cada una las organizaciones para su realimentación. Este momento fue aprovechado para construir las conclusiones sobre los aprendizajes obtenidos del proceso.

El sexto momento consistió en la elaboración del documento síntesis de la experiencia para ser publicado en este volumen, además de otras publicaciones que permitieran la difusión de los conocimientos generados. La documentación fue elaborada sobre la idea de generar lecciones obtenidas de cada una de las experiencias sistematizadas e identificar "gérmenes de generalización" que permitieran "servir para experiencias similares, así como a la hora de formular políticas concretas o reconceptualizar la teoría desde las propias prácticas, o al menos suscitar nuevas inquietudes o preguntas para su elaboración teórica" (Eizaguirre, Urrutia y Askuze, 2004, p. 53). 


\section{Referencias}

Chávez-Tafur, J. (2006). Aprender de la experiencia. Una metodologia para la sistematización. Lima: Asociación ETC Andes y Fundación ILEIA. Recuperado de http:// www.leisa-al.org/web/images/stories/Materialinteres/ sistematizacion. pdf

Eizaguirre, M., Urrutia, G., y Askunze, C. (2004). La sistematización, una nueva mirada de nuestras prácticas. Bilbao: Alboan, HEGOA e Instituto de Derechos Humanos Pedro Arrupe. Recuperado de http://www.dhl.hegoa.ehu.es/ ficheros/0000/0728/Guia_Sistematizaci_n_2004.pdf

Fajardo, D. (2014). Las guerras de la agricultura colombiana 1980 - 2010. Bogotá: Instituto Latinoamericano para una Sociedad y un Derecho Alternativos-ILSA. FAO. (2014). Agricultura familiar en América Latina y el Caribe. Recomendaciones de politica. Eds. S. Salcedo y L. Guzmán. Santiago: FAO. Recuperado de http:// www.fao.org/docrep/019/i3788s/i3788s.pdf

Geels, F. (2011). The multi-level perspective on sustainability transitions: Responses to seven criticisms. Environmental Innovations and Societal Transitions, 1, 24-40. Doi: http://dx.doi.org/10.1016\%2Fj.eist.2011.02.002

Giraldo, O. F. (2018). Ecología politica de la agricultura. Agroecología y posdesarrollo. Chiapas: Ecosur.

Holt-Giménez, E., y Altieri, M. A. (2012). Agroecology, food sovereignty and the new green revolution. Agroecology and Sustainable Food Systems, 37(1), 90-102.

International Assessment of Agricultural Knowledge, Science and technology for Development - IAASTD. (2009). Agriculture at a crossroads. Global report. Washington: IAASTD, UNDP, FAO, UNEP y UNESCO. Recuperado de https:// www.weltagrarbericht.de/fileadmin/files/weltagrarbericht/IAASTDBerichte/ GlobalReport.pdf

León-Sicard, T., Sánchez De Prager M., y Acevedo-Osorio, Á. (2017) Toward a history of agroecology in Colombia, Agroecology and Sustainable Food Systems, 41(3-4), 296-310. Doi: http://dx.doi.org/10.1080/21683565.2017.1285843

Ministerio de Agricultura y Desarrollo Rural. (2017). Resolución 464. Recuperado de https://www.minagricultura.gov.co/Normatividad/Resoluciones/ Resoluci\%C3 \%B3n\%20No\%20000464\%20de\%202017.pdf

Schneider, S. (2016). Family farming in Latin America and the Caribbean: looking for new paths of rural development and food security. Working Paper No. 137. Brasilia: FAO y UNDP. Recuperado de http://www.fao.org/3/a-i5534e.pdf 



\title{
Capítulo 1
}

\section{Ideas para la transición hacia la sostenibilidad del sistema agroalimentario: agricultura familiar, agroecología y nichos sociotécnicos}

Ideas for transition towards the agri-food system sustainability: family farming, agroecology and socio-technical niches

\author{
Álvaro Acevedo Osorio* \\ Jenny Paola Cruz Suárez** \\ Julia Katharina Waeger***
}

\section{Cómo citar}

\begin{abstract}
APA
Acevedo, Á. Cruz, J., y Waeger, J. (2019). Ideas para la transición hacia la sostenibilidad del sistema agroalimentario: agricultura familiar, agroecología y nichos socio-técnicos. En Á. Acevedo-Osorio y N., Jiménez-Reinales (comps.). La agroecología. Experiencias comunitarias para la Agricultura Familiar en Colombia. (pp. 13-34). Bogotá: Corporación Universitaria Minuto de Dios-UnIMINUTO, Editorial Universidad del Rosario.
\end{abstract}

\section{Chicago}

Acevedo Osorio, Álvaro Cruz y Waeger, Julia. "Ideas para la transición hacia la sostenibilidad del sistema agroalimentario: agricultura familiar, agroecología y nichos socio-técnicos". En La agroecología. Experiencias comunitarias para la Agricultura Familiar en Colombia, comps.

* Facultad de Ciencias Agrarias. Universidad Nacional de Colombia. aacevedoo@unal.edu.co

** Facultad de Ciencias. Universidad de Quebec, Montreal, Canadá. cruz.jenny_paola@courrier.uqam.ca

*** Instituto de Manejo y Tecnología de Recursos en los Trópicos y Subtrópicos. Universidad de Ciencias Aplicadas, TH Köln, Colonia, Alemania. julia.waeger@gmail.com 
Álvaro Acevedo-Osorio y Nathaly Jiménez-Reinales. Bogotá: Corporación Universitaria Minuto de Dios-UnIMINUTO, Editorial Universidad del Rosario, 2019.

\section{MLA}

Acevedo Osorio, Álvaro, Cruz, Jenny y Waeger, Julia. "Ideas para la transición hacia la sostenibilidad del sistema agroalimentario: agricultura familiar, agroecología y nichos socio-técnicos" En La agroecología. Experiencias comunitarias para la Agricultura Familiar en Colombia. En Á. Acevedo-Osorio y N., Jiménez-Reinales (comps.) Bogotá: Corporación Universitaria Minuto de Dios-UnIMINUTO, Editorial Universidad del Rosario, 2019, pp. 13-34.

\section{Resumen}

Este capítulo introductorio abordará los enfoques teóricos centrales en el desarrollo de la presente obra: la agricultura familiar, la agroecología y los nichos sociotécnicos como base conceptual para analizar el potencial de distintas experiencias de tipo agroecológica para fortalecer la categoría de la agricultura campesina, familiar y comunitaria. Las discusiones en el campo político y académico sobre agricultura familiar surgen de la creciente preocupación mundial por la soberanía alimentaria, las nuevas relaciones de mercados, la agricultura sostenible y los nuevos procesos de desarrollo rural. En Colombia, este debate ha tenido aportes importantes de las organizaciones sociales, a partir de la necesidad de diferenciarla de la agricultura industrial o patronal. La construcción participativa en el país dio origen al concepto de agricultura campesina, familiar y comunitaria como una categoría integral que reconoce los múltiples aportes de este sector social. El pensamiento agroecológico se ha construido sobre el conocimiento tradicional campesino, asimismo, se propone en la actualidad como el enfoque científico más promisorio para fortalecer las distintas formas de agricultura campesina, familiar y comunitaria. La transición de las formas tradicionales o convencionales de producción hacia la agroecología puede ser entendido a través del análisis de innovaciones, originadas bajo condiciones locales en espacios parcialmente protegidos llamados nichos de innovación sociotécnica. Los enfoques presentados se articulan en este libro para entender el potencial de las experiencias analizadas para fortalecer distintas formas de agricultura familiar en Colombia.

Palabras clave: agricultura familiar, agricultura comunitaria, agroecología, nichos sociotécnicos

\section{Abstract}

This introductory chapter will address the theoretical central approaches in the development of the present work: family farming, agroecology and socio-technical niches as a conceptual basis to analyze the potential of different agroecological experiences to strengthen the category of peasant agriculture, family and community. Discussions in the political and academic field on family farming arise from the growing global concern for food sovereignty, new market relations, sustainable agriculture and new processes of rural development. 
In Colombia, this debate has had important contributions from social organizations, from the need to differentiate it from industrial or employer agriculture. The participatory construction in the country gave rise to the concept of peasant, family and community agriculture as an integral category that recognizes the multiple contributions of this social sector. Agroecological thinking has been built on traditional peasant knowledge and its germ. It is also proposed as the most promising scientific approach to strengthen the different forms of peasant, family and community agriculture. The transition from traditional or conventional forms of production to agroecology can be understood through the analysis of innovations, originated under local conditions in partially protected spaces called niches of socio-technical innovation. The approaches presented are articulated in this book to understand the potential of the experiences analyzed to strengthen different forms of family farming in Colombia.

Keywords: family farming, community agriculture, agroecology, socio-technical niches.

\section{Características de la agricultura familiar}

\subsection{Surgimiento de la categoría a nivel internacional}

Los debates mundiales de la última década relacionados con la soberanía alimentaria, los nuevos mercados que acercan a productores y consumidores en formas alternativas en la distribución de alimentos, la agricultura sostenible y los nuevos procesos de desarrollo rural han revivido el interés por el tema del campesinado (Milone, Ventura y Ye, 2015). En este contexto surge la categoría de la agricultura familiar, que en América Latina es promovida, fuertemente, desde las políticas de Brasil y del Mercosur. El concepto de agricultura familiar no tiene una definición concreta aún y representa más bien a un grupo diverso y heterogéneo (Medina, Almeida, Novaes, Godar y Pokorny, 2015) siendo un fenómeno tanto del hemisferio sur como norte (FAO, 2018). Varias actividades e iniciativas muestran un gran interés en el tema, ejemplo de esto son: la "Plataforma de conocimientos sobre agricultura familiar” de la Organización de la Naciones Unidas para la Alimentación y la Agricultura (FAO, 2018), la celebración del año internacional de la agricultura familiar en 2014 según la FAO, el primer congreso sobre los derechos de los pequeños productores (International Congress Global Peasants' Rights, 2018), igualmente, contribuyendo a esto se encuentra la "Declaración sobre los derechos de pequeños productores y otras personas trabajando en zonas rurales" de la ONU (2013) y la larga experiencia de la organización Via Campesina (La Via Campesina, 2018) por nombrar algunos. También en la ciencia es notable una creciente 
tendencia a más publicaciones específicas que se enfocan en la agricultura familiar. Sin embargo, la categoría claramente no es nueva.

La historiografía del campesinado tiene sus raíces en el siglo XIX (Myrdal, 2015), asimismo, el discurso sobre el modelo de la producción agrícola de los pequeños productores tampoco es nuevo. La novedad se manifiesta en la percepción y la valoración de lo que en la actualidad se llama agricultura familiar. Entre las décadas 1950 y 1980 el paradigma de la modernización expresado por medio de la Revolución verde y las reformas Mansholt, declaró a la agricultura familiar como irrelevante, refiriéndose a esta forma de trabajo campesino en términos de descampesinización (Van der Ploeg, 2009). Por el contrario, actualmente existen varios ejemplos en Brasil, regiones de América Latina, países de la antigua Unión Soviética, e incluso, Europa muestran una "recampesinización” de la agricultura familiar (Van der Ploeg, 2009). Por esta razón, el investigador Jan Douwe Van der Ploeg subraya, en su texto "Peasant agriculture" (2009), que la agricultura familiar no solamente revive y da beneficios tanto a los productores como consumidores, sino también, refleja una expresión inicial de un nuevo paradigma de la agricultura al nivel global. Toader y Roman (2015) argumentan que la agricultura familiar ofrece soluciones a los mayores desafíos del siglo XXI, además apelan a que los gobiernos y la cooperación internacional deben enfocarse en la agricultura familiar como un nuevo paradigma agrícola.

\subsection{La agricultura familiar en Colombia}

Colombia es esencialmente un país rural. Según el Informe de Desarrollo Humano del Programa de las Naciones Unidas para el Desarrollo - PNUD (2011) estima que el 75,5\% de los municipios son rurales, ocupan un 94,4\% de la superficie nacional y albergan el 31,6\% de la población. Sobre un total de 2370099 unidades de producción agropecuaria, el Censo Nacional Agropecuario del 2014 (DANE, 2016) estimó que el $81,1 \%$ de estas unidades son predios menores de 10 hectáreas, es decir que, un total de 1922150 predios se podrían considerar parte del grupo total de familias agricultoras del país. Esta Proporción de la ruralidad nacional, es proveedora de alimentos básicos para la población Colombiana y demanda del Estado la atención debida.

La campaña desarrollada desde la ONG internacional Foro Rural Mundial y organizaciones campesinas de gran fuerza mundial como la Vía Campesina, tuvieron influencia en Colombia desde 2012 para visibilizar la agricultura familiar y promover políticas diferenciadas. Un ejemplo de esto es la Red Nacional de Agri- 
cultura Familiar (RENAF), que ha logrado incidir en escenarios políticos donde se han tomado decisiones para posicionar esta categoría como parte importante campesinado colombiano. Muestra de su importancia está el apoyo proporcionado para que mediante la resolución 464 de 2017 del Ministerio de Agricultura y Desarrollo Rural, se diera los lineamientos de una política sobre agricultura familiar. Adicionalmente, la RENAF ha promovido la investigación, las estrategias de divulgación para visibilizar y búsqueda del compromiso social con este sector que es responsable en buena medida de la producción de alimentos; la conservación de paisajes, recursos naturales y biodiversidad; igualmente, impulsa la preservación del legado cultural rural, que constituye la base sobre la cual se ha construido la identidad nacional.

La conceptualización sobre el término agricultura familiar en Colombia ha tenido aportes importantes de la academia y las organizaciones sociales. En las discusiones, ha estado clara la necesidad de diferenciar este concepto respecto al de agricultura industrial o patronal, y otorgarle un carácter holístico, alejándola de la condición meramente comercial que pudiera darse, sí se considera sólo como una categoría económica. La construcción participativa del concepto oficial que toma la Resolución 464 contempla la siguiente definición:

...sistema de producción y organización gestionado y operado por mujeres, hombres, familias y comunidades campesinas, indígenas, negras, afrodescendientes, raizales y palenqueras que conviven en los territorios rurales del país. En este sistema se desarrollan principalmente actividades de producción, transformación y comercialización de bienes y servicios agrícolas, pecuarios, pesqueros, acuícolas y silvícolas; que suelen complementarse con actividades no agropecuarias. Esta diversificación de actividades y medios de vida se realiza predominantemente a través de la gestión y el trabajo familiar, asociativo o comunitario, aunque también puede emplearse mano de obra contratada. El territorio y los actores que gestionan este sistema están estrechamente vinculados y coevolucionan combinando funciones económicas, sociales, ecológicas, políticas y culturales. (Ministerio de Agricultura y Desarrollo Rural, 2017, p. 36).

Este concepto integra al menos 3 enfoques: el territorial que contempla que los territorios son espacios social e históricamente construidos (Sepúlveda, Rodríguez, Echeverri y Portilla, 2003; PNUD, 2011), el de la pluriactividad, que resalta el carácter multiactivo y diverso de los esquemas de producción y economía de las familias 
rurales (Schneider, 2009) y el de la multifuncionalidad que reconoce que la agricultura cumple múltiples propósitos, uno de los cuales es la producción de alimentos y materias primas, pero que además es responsable por la conservación del patrimonio cultural, de los recursos naturales, ocupación de territorios, cohesión social, entre otras (IAASTD, 2009; Renting et al., 2009; Acevedo-Osorio, 2016).

Para lograr el propósito de mejorar las condiciones de vida de las familias rurales del país, la Resolución 464 propone 19 estrategias para tal fin, entre ellas algunas están orientadas a la educación y la extensión rural pertinentes; dotar de servicios básicos como agua y saneamiento; incentivar la producción sostenible mediante la agroecología, las semillas del agricultor y el manejo sostenible de los recursos naturales; permitir el acceso a la tierra; impulsar la participación y la organización comunitaria; promover relaciones justas con los mercados mediante el acceso a mercados locales, sistemas participativos de garantía, compras públicas locales y posicionamiento de productos de la agricultura familiar; promover estrategias solidarias de financiación y mercadeo de productos; entre otras.

\subsection{Acciones necesarias para fortalecer la agricultura familiar}

La última década ha mostrado un alto desarrollo de la agricultura familiar y un cambio en la perspectiva sobre el concepto. Varios ejemplos a nivel global reflejan que la agricultura familiar se expande y crece tanto en número como en reconocimiento (Graeub et al., 2015). Por otro lado, el nuevo discurso también da lugar a una reflexión crítica del concepto. Para varios científicos fundamentalmente la crítica se centra en el rechazo de un preconcepto de la agricultura familiar que se puede aplicar a cualquier contexto y dinámica. Por ejemplo, Van der Ploeg (2017) señala cambios y soluciones que se unen en un "planteamiento universal". Por otro lado, según Medina et al. (2015), la falta de consideración de los contextos específicos pueden crear expectativas confusas con respecto a los potenciales y las capacidades de la agricultura familiar. Asimismo, Cabral, Favareto, Mukwereza y Amanor (2016) confirman esta crítica basándose en el intento de transferir exitosas experiencias en Brasil a lugares de África y reclaman que deben considerarse las realidades socio-políticas de estas regiones como la contextualización histórica y geográfica necesaria a tener en cuenta, para la tranferencia de estas experiencias de agricultura familiar. Van Vliet et al. (2015) subrayan que, no solo se deben concentrar la crítica en el término, sino que, se debe centrar su mirada en el enfoque potencial transformativo que tiene la agricultura familiar. 
Por estas razones, un actor central en el tema del fortalecimiento de la agricultura familiar es el Estado. Puesto que, en el apoyo a este plan por medio de créditos, la asistencia técnica y la comercialización de productos, el estado brasileño dio un ejemplo de cómo se puede crear un entorno favorable para la agricultura familiar (Medina et al., 2015). En especial, el acceso a los recursos económicos suele limitar a la agricultura familiar, ya que pequeños productores no disponen de los requisitos de acceso. Por ello, un aporte estatal en esta dimensión es necesario y debería ser diseñado a favor de los pequeños productores (Van der Ploeg, 2017). El nuevo paradigma de familias "pluri-activas" (Schneider, 2009) implica que parte de la familia trabaje fuera de la finca, esta acción describe una posibilidad de fortalecer los recursos económicos en cada una de estas zonas de producción. Sin embargo, un punto débil de esto es que, este tipo de trabajo no es accesible siempre y, a la vez, permite que la fuerza laboral disminuya para la finca (Medina et al., 2015).

Al mismo tiempo de fortalecer su producción agrícola, los productores tienen mucha autonomía e influencia para mejorar su propia realidad social y económica. En este sentido, la idea de Van der Ploeg (2017) en la que, la propuesta individual parece insignificante, el plan colectivo puede formar una importante fuerza sociopolítica. La agrupación de productores individuales aumenta la seguridad, la organización social y, a su vez, facilita la logística fortaleciendo la posición mercantil de estas organizaciones (Medina et al., 2015).

En resumen, la agricultura familiar enfrenta una larga serie de retos económicos, políticos, sociales y ambientales (Suess-Reyes y Fuetsch, 2016). Algunos de esto son: en lo económico, necesita recursos como el de financiamiento, los terrenos necesarios para la actividad y el apoyo con tecnologías adecuadas que respeten prácticas agrícolas tradicionales. En lo político, requiere el respaldo y apoyo estatal adecuado, reconociendo a los agricultores familiares como ciudadanos con derechos y políticas diferenciadas para afianzar su trabajo. En lo social, se requiere fortalecer las distintas formas de organización, recomponer y consolidar las redes comunitarias y familiares con programas diversos que reconozcan a las mujeres y jóvenes como parte activa de la agricultura familiar y, además, generar posibilidades reales para su bienestar. Desde lo ambiental, fomentar el trabajo coordinado para la defensa de sus ecosistemas y la permanencia en sus territorios con autonomía para el manejo de sus bienes comunes. Sólo con este reconocimiento de los agricultores familiares y un respaldo decidido se puede evolucionar por vías razonables de desarrollo (Medina et al., 2015). 


\section{Agroecología y agricultura familiar}

\subsection{Agroecología como ciencia y movimiento social}

Desde el punto de vista científico, la agroecología se enfocó inicialmente en el análisis de los agroecosistemas, concentrándose en la comprensión de las relaciones ecológicas que se dan entre los componentes involucrados en la producción agropecuaria (Hecht, 1999). El interés fue descubrir las relaciones de sinergia, complementariedad, comunalismo, entre otras, que tuvieran un alto potencial para incrementar la producción de alimentos sanos de alto valor nutricional. Esta visión ecologista de la agroecología, se estructuró en la década de 1980 y, a partir de entonces, ha crecido el interés de otras disciplinas distintas a la ecología y agronomía el aportar en su estudio. La incursión de las ciencias sociales marcó el inicio de un enfoque distinto en la agroecología, llevándola a su connotación más política y holística, trascendiendo el conocimiento científico para valorar el enorme potencial de las sabidurías tradicionales en su estructuración.

En la actualidad se consideran al menos tres enfoques de la agroecología a nivel mundial: el científico, el práctico y el político (Wezel et al., 2009). A nivel científico, crece la cantidad de programas académicos en educación superior que abordan la agroecología como objeto de estudio. En Colombia, programas de pregrado y posgrado, al lado de programas de educación media y colegios de básica secundaria, estructuran sus proyectos educativos institucionales a partir del enfoque y práctica agroecológica. Las investigaciones relacionadas al análisis de los fenómenos ecológicos en la parcela de cultivo y otros, que incluyen la perspectiva social, crecen con el avance de programas académicos de educación superior.

En el nivel práctico, la agroecología es el enfoque predominante en programas adelantados por ONG y proyectos de pastoral de la Iglesia desarrollados con comunidades rurales en todo el país. Según Acevedo-Osorio (2013) la larga tradición de escuelas campesinas en agroecología basadas en estrategias de educación popular de adultos y la investigación acción participativa han impulsado fuertemente la agroecología en el país, su aplicación práctica ha sido evidente con los aportes en la generación de capacidades y la transformación productiva de las fincas, lo anterior se intentará demostrar en este libro con la presentación de las experiencias.

Finalmente, en el nivel sociopolítico, los principios de la agroecología han sido tomados como fundamentos de los movimientos rurales del mundo, especialmente, del grupo La Vía Campesina que abarca unas 150 organizaciones en 70 países y representa a cerca de 200 millones de agricultores en defensa de la agricultura con 
base en la agroecológica comunitaria y la construcción de la soberanía alimentaria (Sevilla y Woodgate, 2013). En Colombia, la Vía Campesina está representada por FENSUAGRO, pero, adicionalmente, las Zonas de Reserva Campesina han optado por la agroecología como su estrategia política y productiva, esto queda expresado en sus documentos oficiales. Como estas, muchas asociaciones rurales en el país defienden la agroecología como plataforma política y estrategia práctica para el mejoramiento de sus fincas, asimismo, preconizan la agroecología como la forma real para la transformación de las condiciones de vida de la población rural, por argumentos como: la protección de los ecosistemas o bienes naturales, el reconocimiento de las culturas locales y sus formas propias de conocimiento, la participación y organización comunitaria, el acceso a la tierra, la defensa de los derechos de los campesinos y de otras comunidades rurales.

\subsection{El valor del conocimiento campesino en la agroecología}

"El conocimiento acumulado de millones de agricultores de pequeña escala en todo el mundo tiene mucho que ofrecer a la ciencia moderna de la agroecología (Vandermeer y Perfecto, 2013, p. 61). Lo anterior, se puede traducir en que el pensamiento agroecológico se ha construído sobre la base del conocimiento tradicional campesino. Como ciencia interdisciplinaria, la agroecología se ha aproximado a muchas disciplinas enriqueciendo sus planteamientos y prácticas para la transformación productiva de las fincas agricultoras, pero al mismo tiempo, como ciencia transdisciplinaria, la agroecología reconoce el valor intrínseco del conocimiento tradicional, que tiende a compaginarse con el conocimiento científico de las distintas disciplinas, con el fin de lograr abordajes holísticos o complejos de los sistemas y procesos agroalimentarios.

Como ningún otro enfoque científico, la agroecología está logrado la revalorización del bagaje cultural de los campesinos alrededor del mundo. En su racionalidad, los agricultores utilizan estrategias de uso múltiple (Toledo, 1993) que otorgan a sus recursos la mayor cantidad posible de funciones, utilizando y reutilizando los recursos en una lógica de "no botar nada" (Milone et al., 2015), para cerrar ciclos biológicos y hacer más eficiente el sistema ecológico-productivo. Esta lógica se contrapone a la lógica lineal de la agricultura especializada, que integra a la naturaleza una cantidad abundante de insumos sintéticos y genera consecuencias negativas. Mientras tanto si se atiende a la lógica campesina, la agroecología promueve una agricultura de bajos insumos intensificando los procesos de coproducción con la naturaleza, generando autonomía de insumos a los 
Figura 1. Los sistemas diversificados de producción en pequeña escala representan una de las estrategias de producción sustentable en sistemas agroecológicos. Huerta de Don Pedro González. ARAC. Subachoque-Cundinamarca.

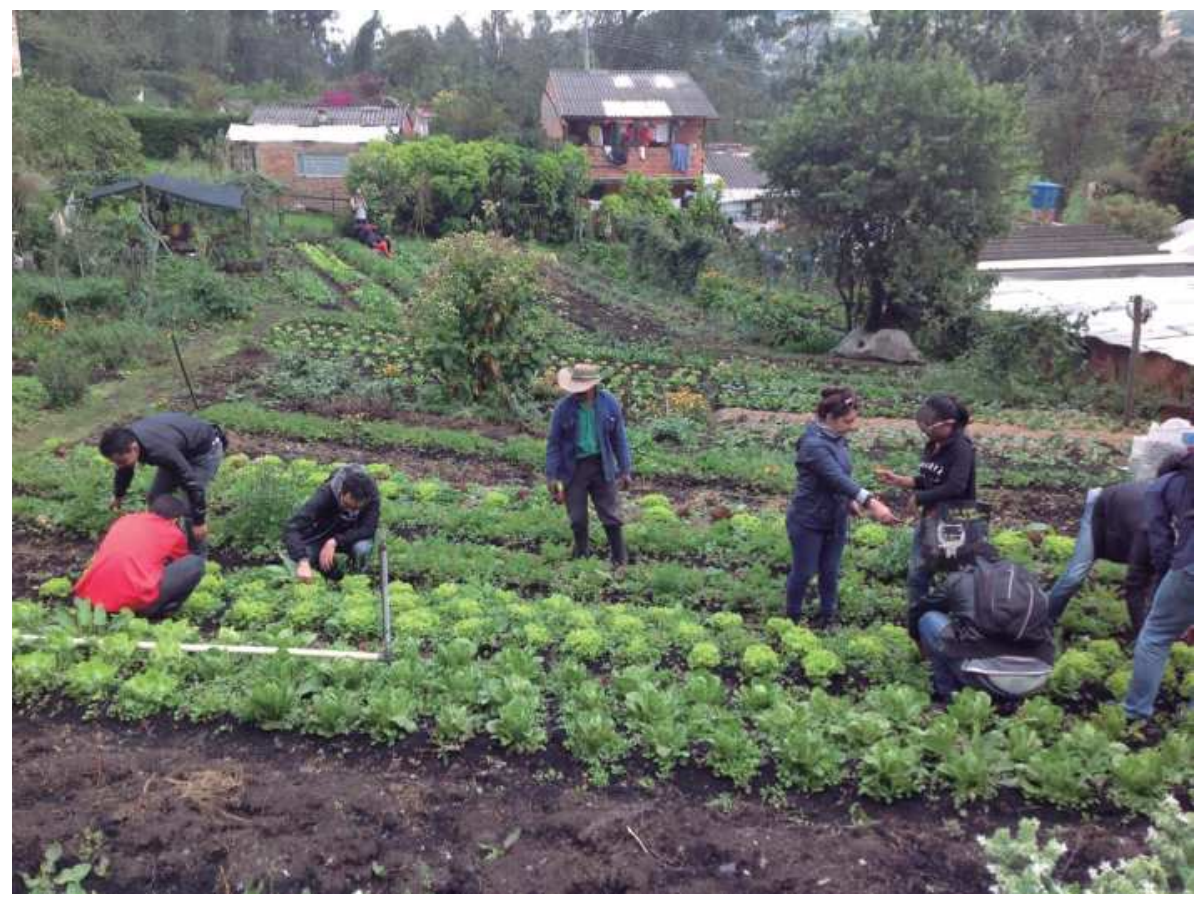

Fuente: Acevedo (2018).

agricultores, desligándolos de la onerosa dependencia del mercado de insumos y reduciendo las externalidades negativas externas.

La agroecología ha reconocido la capacidad de muchas comunidades de agricultores tradicionales para desarrollar sistemas productivos complejos con alto grado de adaptación a las condiciones locales. Estos sistemas locales de agricultura tradicional son catalogados como "sistemas de patrimonio agrícola" con una gran significancia global (Koohafkan y Altieri, 2011). Dichos sistemas están caracterizados por los altos niveles de biodiversidad y diseños productivos basados en innovaciones tecnológicas propias del conocimiento tradicional. Estas comunidades rurales, que aún hoy viven en territorios de agricultura tradicional, albergan un gran potencial para ofrecer alternativas a la producción agrícola y manejo de recursos frente a problemas emergentes como el cambio climático (Koohafkan y Altieri, 2011). 


\subsection{Agricultura familiar y agroecología}

Durante siglos, los agricultores tradicionales han reformulado sus modelos de producción y la forma de como se relaciona con la naturaleza, resistiendo, modificando y reajustando sus formas de producción y reproducción social (Milone et al., 2015), de acuerdo con las condiciones que el entorno social, productivo y ambiental les exigen. Cada vez más la agroecología representa la oportunidad más clara de repensar y ajustar los sistemas tradicionales de producción potenciándolos hacia nuevas trayectorias, en las que revalorar su conocimiento, mejorar sus condiciones de vida, fortalecer la relación productor-consumidor y contribuir a procesos de transición hacia la sustentabilidad, sean los nuevos escenarios de actuación familiar y comunitaria de las comunidades rurales. La categoría agricultura familiar permite justamente este tránsito de las agriculturas tradicionales para transformarlas, partiendo de lo que han sido hasta la actualidad, pero, al mismo tiempo, para realzarlas e impulsarlas hacia nuevas relaciones con la sociedad y la naturaleza.

En una declaración pública con motivo del foro internacional sobre agroecología realizado por la organización La Vía Campesina en Malí, en el 2015, este movimiento ratificó que:

ya hemos avanzado significativamente en la definición de la Soberanía Alimentaria como nuestra bandera común de lucha por la justicia y como marco general para la Agroecología. Hemos desarrollado nuestros sistemas de producción ancestralmente a lo largo de milenios, definidos con el término de agroecología en los últimos 30-40 años. Nuestra agroecología incluye prácticas éxitosas y productivas, procesos de campesino a campesino y territoriales, escuelas de formación y sofisticadas formulaciones teóricas, técnicas y políticas". (La Vía Ccampesina, 2015, p. 64).

Esta declaración ratifica a la agroecología como el enfoque científico que mejor representa los intereses y aspiraciones de miles de comunidades rurales en todo el mundo.

Las características propias de los agricultores familiares dejan entrever la necesidad de crear programas integrales, que vayan más allá de generar nuevas y mejores condiciones en la articulación con el mercado. Esta afirmación interpela a los programas convencionales y jerárquicos de extensión rural, que con el propósito de empresarizar y articular competitivamente a los agricultores familiares con los mercados globales, solamente los ven como actores económicos, desconociendo 
la multidimensionalidad en la que se estructura su estilo de vida. En el diseño de nuevos programas rurales, los agricultores familiares tienen la capacidad suficiente para liderar procesos de transformación agroproductiva a partir de la innovación y el trabajo colectivo, es necesario dejar de lado la arrogancia del conocimiento científico y de los programas verticales y descontextualizados, para dar paso a una mayor participación y protagonismo de los agricultores: “[...] imaginamos un futuro en el que los pequeños agricultores tendrán el control de sus propios sistemas de producción, lo que significaría que alcanzarían la plena soberanía alimentaria, y seguirían desarrollando su propia ciencia” (Vandermeer y Perfecto, 2013, p. 61).

\section{Nichos de innovación sociotécnica}

En el marco del proceso de transición rural y agrícola desde la agroecología, los agricultores familiares son agentes de cambio y líderes potenciales en la creación de escenarios propicios para alcanzar un desarrollo rural sustentable. Como modelo de desarrollo rural alternativo, la agricultura familiar reconcilia, de manera innovadora, dimensiones olvidadas por los modelos de desarrollo tradicional en la que la dimensión económica y productiva prima sobre las demás. La agroecología proporciona las condiciones necesarias para fortalecer la agricultura familiar, al potenciar los cambios a nivel técnico, pero también social, político y ambiental, por medio de un proceso de transición rural que esta estrechamente ligado a la innovación. Autores como Piraux, Silveira, Diniz y Duque (2010) señalan que este proceso de transición progresiva desde la agroecología, basado en el redescubrimiento de conocimiento tradicionales, plasmado en prácticas y conocimientos locales y en saberes científicos, puede ser entendido más ampliamente por medio de las teorías de la innovación. Desde estas teorías la transición es multinivel, flexible y este cambio no se reduce a través de las innovaciones en el plano productivo y económico, sino en todo el sistema social en el que se encuentra implicado (de allí el término de inno-vaciones sociotécnicas). Las innovaciones comprenden prácticas, intervenciones, productos, redes, entre otros, que se originan, se desarrollan, se prueban y se ajustan a las condiciones locales en espacios parcialmente protegidos del modelo convencional, denominados: nichos de innovación sociotécnica.

\subsection{Concepto de nicho de innovación sociotécnica en el ámbito rural}

Poco se ha estudiado en el ámbito rural, los nichos de innovación socio técnica (llamados en adelante nichos), estos son espacios autónomos, relativamente protegidos y aislados en donde tienen lugar innovaciones radicales a nivel técnico, social, institucional, estructural, cultural, entre otros. (Geels, 2002; Raven, 2006; 
Schot y Geels, 2008; Darnhofer, 2015). Con una gran diversidad de actores, estos espacios de "blindaje" operan bajo sus propios criterios, se alejan, normalmente, de los criterios del modelo rural convencional dominante en el que están inmersos. Los nichos funcionan como una "incubadora" de nuevas ideas, son espacios de aprendizaje colectivo y de construcción de redes sociales que eventualmente impulsan las innovaciones desde lo local hacia lo global (Geels, 2002, 2004; Smith, Voß y Grin, 2010). Inicialmente, los proyectos de innovación rural al interior de los nichos son heterogéneos, van en diferentes direcciones, emergen bajo reglas poco articuladas y son menos estables y rentables que aquellos que dominan los sistemas convencionales (Geels, 2002). Sin embargo, al desarrollarse y madurar, estas "semillas de cambio" dejan atrás el nicho para dar inicio a la transición desde lo local y lo colectivo, esto permite que eventualmente se expandan, se generalicen y se adopten a nivel global, llegando incluso, potencialmente, a transformar el modelo agrícola y rural convencional (Rip, Kemp y Kemp, 1998; Smith, 2007; Geels y Schot, 2007).

Las innovaciones agrícolas son extremadamente variadas, van desde el desarrollo de nuevas tecnologías de producción hasta el desarrollo de nuevas formas de organización social (Sutherland, Wilson y Zagata , 2015; Darnhofer, 2015). Karanikolas, Vlahos y Sutherland,(2015) mencionan algunas iniciativas como la producción de biogás y de energía eólica en las fincas, la integración del turismo rural y la producción local, las certificaciones participativas y locales, los circuitos cortos de comercialización, las acciones colectivas para el manejo de recursos, etc. Además de la agroecología, ejemplos de nichos potenciales en el sector agrícola incluyen la agricultura orgánica, biodinámica, de conservación, entre otros.

\subsection{Características de los nichos de innovación socio técnica}

Los nichos tienen el gran reto de estimular las innovaciones, de vincularlas y de favorecer el intercambio entre ellas a nivel local para potencializar, finalmente, la transición global. El éxito de un nicho depende de diferentes factores y más precisamente de las características y los procesos ocurridos al interior de éstos (Audet, 2015; Geels 2002). Ortiz, Vilsmaier y Acevedo-Osorio, (2017) proponen cuatro características centrales para entender los nichos: protección, coevolución, los procesos de construcción interna y el desarrollo en dos niveles.

1. La característica principal de un nicho es brindar un espacio de protección y flexibilidad con respecto al régimen convencional para las innovaciones 
radicales. La protección puede darse a través del establecimiento de mecanismos como la venta de productos en mercados locales, la financiación de proyectos mediante subsidios públicos o medios culturales específicos (Geels, 2004; Raven 2006; Smith et al., 2010).

2. Otra característica fundamental de los nichos es que permiten la coevolución en dos niveles: entre las dimensiones socio técnicas, es decir, entre la innovación tecnológica y el ambiente social en el que se desarrolla y; la coevolución del nicho con relación al régimen convencional dominante. Si bien las innovaciones emergen como alternativas al marco del régimen, éstas no siempre compiten con él, pueden reemplazar todas sus dimensiones, pero también pueden coevolucionar incorporándose y transformando solo ciertas dimensiones; de hecho, el nivel de cercanía al régimen condiciona la radicalidad de la innovación, cuanto más se aleje del régimen, más radical será la innovación (Geels, 2004; Schot y Geels, 2008).

3. Tres procesos internos le permiten al nicho desarrollarse y consolidarse: (i) la articulación de expectativas y la creación de visiones compartidas entre los actores; (ii) la construcción y ampliación de redes sociales para facilitar la interacción entre los diferentes actores y; (iii) los procesos de aprendizaje compartido en múltiples dimensiones (técnica, de mercado, cultural y simbólica, de infraestructura, etc.) (Schot y Geels, 2008).

4. El desarrollo progresivo en dos niveles simultáneos caracterizan un nicho de innovación. El nivel de proyectos o fase local en el que algunos proyectos son llevados a cabo en las redes locales están sometidos bajo reglas más difusas, amplias e inestables. Pero una vez que los actores y sus proyectos aislados empiezan a agregarse para generar espacios, elaborar ideas y construir proyectos conjuntos, bajo reglas más elaboradas, alcanzan un segundo nivel o fase global. En este nivel, el nicho es más estable, con reglas más definidas, más sólido y se comparten reglas, normas y rutinas que eventualmente puede llevar a la transición (Schot y Geels, 2008; Raven, 2006).

\subsection{Casos reconocidos en el ámbito rural}

Muchas innovaciones y nichos, potencialmente viables, desaparecen o no llegan a madurar lo suficiente, como para potenciar el proceso de transición. La transición hacia la sustentabilidad no ocurre fácilmente, es difícil transformar y sobre todo sustituir modelos convencionales que tienen gran estabilidad en el ámbito rural. Para que esto ocurra, deben existir condiciones internas y externas propicias, no 
sólo para que las iniciativas innovadoras y alternativas se relacionen entre sí y se fortalezcan, sino para que los nichos afiancen sus procesos internos y su capacidad de generar e integrar redes, de crear, de reproducir y de difundir proyectos, discursos, prácticas, entre otras capcidades (Schot y Geels, 2008; Audet, 2015).

A pesar de los obstáculos, diferentes estudios como el de Piraux et al., (2010) ilustran el éxito en el desarrollo y consolidación de nichos de innovación a nivel local y su rol potencial en la transición rural. En muchos lugares del mundo, agricultores familiares han logrado establecer prácticas agrícolas ecológicamente sustentables, con bajos insumos y en las que se basan en una mezcla de cultivos nativos e introducidos. El análisis del nicho muestra cómo en medio de un régimen dominado por la agricultura intensiva de cultivos introducidos, las iniciativas territoriales soportadas en tecnologías locales son económicamente viables, ecológicamente sostenibles, permiten conservar la cultura y tradiciones locales, la mediación con otros actores y facilitan el aprendizaje de campesino a campesino y del colectivo por medio de proyectos como las huertas comunales. En América Latina, en donde pocos estudios han usado el enfoque de los nichos de innovación sociotécnica como base conceptual, Vila y Marín (2017) señalan como la cooperativa argentina de pequeños agricultores, "Cooperación Solidaria” dedicada a la apicultura orgánica, correspondería a un nicho de innovación local emergente que desafía la lógica del sistema dominante, porque tiene como objetivo la protección del medio ambiente, emplea a productores de bajos recursos de la zona, ofrece estabilidad de precios y favorece las dinámicas locales, entre otros propósitos.

Estos ejemplos ilustran nichos emergentes o en etapas tempranas de desarrollo, con propuestas alternativas puntuales a escala local; sin embargo, pocas investigaciones presentan nichos de innovación rural desarrollados y en etapa de consolidación en su fase global (escala nacional) como es el caso del trabajo de Ortiz et al., (2017). Los investigadores analizan en Colombia un conjunto amplio de experiencias de agricultura familiar agroecológica a nivel nacional, sugiriendo que estas conforman un nicho de un nivel maduro de desarrollo y en vía de consolidación. Se destacan las múltiples iniciativas y trayectorias de innovación en áreas como la transferencia de conocimientos especialmente de campesino a campesino, los procesos de aprendizaje colectivo, la replicación de experiencias a nivel nacional, la innovación en las técnicas de producción y la construcción de redes entre la academia, las asociaciones de productores y las organizaciones de soporte. Uno de los resultados destacados de este estudio es la fortaleza del nicho en las innovaciones sociales, en términos de los procesos organizativos que, más allá de lo comercial, se 
sustentan en valores solidarios. Los autores hacen énfasis en el enorme y prometedor potencial de la agricultura familiar agroecológica y en la contribución a la transición y, posteriormente, consolidación de una agricultura sostenible en Colombia.

\section{Conclusiones}

Este capítulo presentó tres enfoques teóricos centrales en el desarrollo de la presente obra: la agricultura familiar, la agroecología y los nichos sociotécnicos en su fundamentación conceptual para analizar las experiencias de base agroecológica incluidas en este libro.

El debate político y académico sobre agricultura familiar surge recientemente y está vinculado a los nuevos procesos de desarrollo rural, relacionados especialmente al interés por la soberanía alimentaria, las nuevas relaciones campo-ciudad, los mercados de cercanía, la agricultura sostenible y, en el caso particular de Colombia, la búsqueda de la paz en tiempo del posacuerdo alcanzado.

El debate en el país ha tenido aportes importantes de las organizaciones sociales, especialmente, de la Red Nacional de Agricultura Familiar (RENAF), con el fin depoder diferenciarla de la agricultura del agronegocio. Así surge el concepto de agricultura campesina, familiar y comunitaria que reconoce la multifuncionalidad de la agricultura en el ámbito sociocultural, político y ambiental, además del productivo.

La agroecología, por su parte, constituye un enfoque científico, práctico y político que se ha construido sobre la base del conocimiento tradicional campesino y se propone, en la actualidad, como el enfoque más promisorio para fortalecer la agricultura familiar. Por su carácter interdisciplinario, la agroecología es el enfoque que mejor permite comprender e intervenir la compleja realidad que implica la producción agropecuaria en manos de comunidades de agricultores en pequeña y mediana escala. Al ser no sólo un enfoque teórico-práctico, sino también político, la agroecología ha facilitado a las organizaciones de productores un proceso sistemático de incidencia, en favor de sus derechos y de los derechos de la sociedad en general.

El proceso de transición hacia la agroecología, basado en el redescubrimiento de conocimientos tradicionales, en prácticas y conocimientos locales y en saberes científicos, puede ser entendido más ampliamente a través de las teorías de la innovación, puesto que estas comprenden prácticas, intervenciones, productos, redes, entre otros, que se originan, se desarrollan, se prueban y se ajustan a las condiciones locales; en espacios parcialmente protegidos del modelo convencional, denominados: nichos de innovación sociotécnica. 
A partir de estos enfoques teóricos, este libro permite comprender mucho más las características de los agricultores familiares del país y cómo sus experiencias de origen agroecológica, nacidas de su propia innovación, constituyen un invaluable aporte a la construcción de alternativas que puedan ser llevadas a una mayor escala, con el fin de fortalecer a una base social determinante en la edificación de una ruralidad más productiva, más justa y sustentable.

\section{Referencias}

Acevedo-Osorio, Á. (2013). Escuelas de agroecología en Colombia. La construcción del conocimiento agroecológico en manos campesinas. En M. Altieri, S. Sarandón, C. F. Morales, F. Funes y S. Siura (eds.), Congreso Latinoamericano de agroecología articulos completos, Sociedad Cientifica Latinoamericana de Agroecologia (SOCLA). Lima: Recuperado de http://orgprints.org/25086/

Acevedo-Osorio, Á. (2016). Monofuncionalidad, multifuncionalidad e hibridación de funciones de las agriculturas en la cuenca del río Guaguarco, sur del Tolima. Revista Luna Azul. 43, 251-285. doi: 10.17151/luaz.2016.43.12

Audet, R. (2015). Le champ des sustainability transitions: origines, analyses et pratiques de recherche. Cahiers de recherche sociologique, 58, 73-93. doi: https:// doi.org/10.7202/1036207ar

Cabral, L., Favareto, A., Mukwereza, L., y Amanor, K. (2016). Brazil's agricultural politics in Africa: more food international and the disputed meanings of " $\mathrm{fa}$ mily farming”. World Development, 81,47-60. doi: https://doi.org/10.1016/j. world dev.2015.11.010

Darnhofer, I. (2015). Socio-technical transitions in farming: key concepts. En L.A. Sutherland, I. Darnhofer, G. Wilson y L. Zagata (eds.), Transition pathways towards sustainability in European agriculture. Case studies from Europe, (pp. 17-31). Oxfordshire: CABI International. Recuperado de http://www.academia.edu/23851453/Socio-technical_transitions_in_farming_key_concepts

Departamento Administrativo Nacional de Estadística - DANE. (2016). Tercer censo nacional agropecuario 2014. Recuperado de https://www.dane.gov.co/index. $\mathrm{php} /$ estadisticas-por-tema/agropecuario/censo-nacional-agropecuario-2014 (acceso 17.07.2016)

FAO. (2018). Plataforma de conocimientos sobre agricultura familiar. Recuperado de http://www.fao.org/family-farming/background/es/ 
Geels, F. W. (2002). Technological transitions as evolutionary configuration processes: a multi-level perspective and a case-study. Research Policy, 31(8-9), 1257-1274. doi: https://doi.org/10.1016/S0048-7333(02)00062-8

Geels, F. (2004). From sectoral systems of innovation to socio-technical systems. Insights about dynamics and change from sociology and institutional theory. Research Policy, 33, 897-920. doi: https://doi.org/10.1016/j.respol.2004.01.015

Geels, F. W., y Schot, J. (2007). Typology of sociotechnical transition pathways. Research Policy, 36(3), 399-417. doi: https://doi.org/10.1016/j.respol.2007. 01.003

Graeub, B., Chappell, M., Wittman, H., Ledermann, S., Bezner, R., y Gemmill-Herren, B. (2015). The state of family farms in the world. World Development, 87, 1-15. doi: https://doi.org/10.1016/j.worlddev.2015.05.012

Hecht, S. B. (1999). Evolución del pensamiento agroecológico. pp. 11-28. CLADES. Curso de educación a distancia Agroecología y Desarrollo Rural. Lima: CLADES, CIED. Recuperado de https://www.minagricultura.gov.co/ Normatividad/ Resoluciones/Resoluci\%C3\%B3n\%20No\%20000464\%20de\%202017.pdf

International Assessment of Agricultural Knowledge, Science and technology for Development - IAASTD. (2009). Agriculture at a crossroads. Global report. Washington: IAASTD, UNDP, FAO, UNEP y UNESCO. Recuperado de https:// www.weltagrarbericht.de/fileadmin/files/weltagrarbericht/IAASTDBerichte/ GlobalReport.pdf

International Congress Global Peasants' Rights. (2017). Congress “Global Peasants Rights”. Recuperado de http://global-peasants-rights.com/index.php/es/

Karanikolas, P., Vlahos, G., y Sutherland, L. A. (2015). Utilising the multi-level perspective in empirical field research: methodological considerations. En L.-A. Sutherland, I. Darnhofer, G. A. Wilson y L. Zagata (eds.), Transition pathways towards sustainability in European agriculture: case studies from Europe (pp. 51-66). Oxfordshire: CABI International.

Koohafkan, P., y Altieri, M. A. (2011). Globally important agricultural heritage systems. A legacy for the future. Roma: FAO. Recuperado de http://www.fao.org/filead$\mathrm{min} /$ templates/giahs/PDF/GIAHS_Booklet_EN_WEB2011.pdf

La Vía Campesina. (2015). Agroecología campesina: por la soberanía alimentaria y la madre tierra. Experiencias de la Via Campesina. (Cuaderno 7). Argentina: Ministerio de Agricultura, Ganadería y Pesca de la República de Argentina. Recuperado de https://viacampesina.org/es/wp-content/uploads/sites/3/2015/ 11/CUADERNO\%207\%20LVC\%20ESPANOL.compressed.pdf 
La Vía Campesina. (2018). La V'a Campesina. Movimiento Campesino Internacional. Recuperado de https://viacampesina.org/es/

Medina, G., Almeida, C., Novaes, E., Godar, J., y Pokorny, B. (2015). Development conditions for family farming: lessons from Brazil. World Development, 74, 386-396. Doi: 10.1016/j.worlddev.2015.05.023

Milone, P., Ventura, F., y Ye, J. (2015). Constructing a new framework for rural development. Research in Rural Sociology and Development, 22, 1-16.

Ministerio de Agricultura y Desarrollo Rural. (Diciembre 29 2017). Resolución 494 por la cual se adoptan los lineamientos estratégicos de política pública para la agricultura campesina, familiar y comunitaria. Recuperado de https://www. minagricultura.gov.co/Normatividad/Resoluciones/Resoluci\%C3\%B3n\%20 No\%20000464\%20de\%202017.pdf

Myrdal, J. (2015). Peasants and rural societies in history (agricultural history). En J. Wright (ed.), International encyclopedia of the social y behavioral sciences (2. ${ }^{a} \mathrm{ed}$.), (pp. 669-675). doi: https://doi.org/10.1016/B978-0-08-097086-8.62019-6 Organización de la Naciones Unidad - ONU. (2013). Declaración sobre los derechos de los campesinos y de otras personas que trabajan en las zonas rurales. Recuperado dehttps://www.ohchr.org/Documents/HRBodies/HRCouncil/wg Pleasants/ A-HRC-WG-15-1-2_sp.pdf

Ortiz, W., Vilsmaier, U., y Acevedo-Osorio, Á. (2018). The diffusion of sustainable family farming practices in Colombia: an emerging sociotechnical niche? Sustainability Science, 13(3), 829-847. doi: https://doi.org/10.1007\%2Fs11625 $-017-0493-6$

Piraux, M., Silveira, L., Diniz, P., y Duque, G. (2010). La transition agroécologique comme une innovation socio-territoriale. En E. Coudel, H. Devautour, C. Soulard, B. Hubert (eds.), Innovation and sustainable development in agriculture and food - ISDA. Montpellier. Recuperado de https://hal.archives-ouvertes. $\mathrm{fr} / \mathrm{hal}-00512788 / \mathrm{fr} /$

Programa de las Naciones Unidas para el Desarrollo - PNUD. (2011). Colombia rural. Razones para la esperanza. Informe Nacional de Desarrollo Humano 2011. Bogotá: PNUD. Recuperado de http://www.undp.org/content/dam/ colombia/ docs/DesarrolloHumano/undp-co-ic_indh2011-parte1-2011.pdf

Raven, R. P. J. M. (2006). Towards alternative trajectories? Reconfigurations in the Dutch electricity regime. Research Policy, 35(4), 581-595. http://doi:10.1016/j. respol.2006.02.001 
Renting, H., Rossing, W. A., Groot, J. C., Van der Ploeg, J. D., Laurent, C., Perraud, D., Stobbelaar, D. J., y Van Ittersum, M. K. (2009). Exploring multifunctional agriculture. A review of conceptual approaches and prospects for an integrative transitional framework. Journal of Environmental Management, 90, S112-S123. doi: https://doi.org/10.1016/j.jenvman.2008.11.014

Rip, A., Kemp, R. P. M., y Kemp, R. (1998). Technological change. En S. Rayner y E. L. Malone (eds.), Human choice and climate change (vol. 2), (pp. 327-399). Columbus: Battelle Prêss.

Schneider, S. (2009). A pluriactividade na agricultura familiar. (2. ${ }^{\text {a }}$ ed.). Porto Alegre: UFRGS.

Schot, J., y Geels, F. (2008). Strategic niche management and sustainable innovation journeys: theory, findings, research agenda and policy. Technology Analysis y Strategic Management, 20(5), 537-554. doi:10.1080/0953732080 2292651

Sepúlveda, S., Rodríguez, A., Echeverri, R., y Portilla, M. (2003). El enfoque territorial del desarrollo rural. San José: Instituto Latinoamericano de Cooperación para la Agricultura. Recuperado de http://orton.catie.ac.cr/ repdoc/A3045e/ A3045e.pdf

Sevilla, E., y Woodgate, G. (2013). Agroecología: fundamentos del pensamiento social agrario y teoría sociológica. Revista Agroecología, 8(2), 27-34. Recuperado de https://revistas.um.es/agroecologia/article/view/212161

Smith, A. (2007). Translating sustainabilities between Green Niches and SocioTechnical Regimes. Technology Analysis and Strategic Management, 19(4), 427-450. doi:10.1080/09537320701403334

Smith, A., Voß, J. P., y Grin, J. (2010). Innovation studies and sustainability transitions: the allure of the multi-level perspective ant its challenges. Research Policy, 39, 435-448. doi: https://doi.org/10.1016/j.respol.2010.01.023

Suess-Reyes, J., y Fuetsch, E. (2016). The future of family farming: a literature review on innovative, sustainable and succession-oriented strategies. Journal of Rural Studies, 47, 117-140. doi: https://doi.org/10.1016/ j.jrurstud.2016.07.008

Sutherland, L. A., Wilson, G., y Zagata, L. (2015). Introduction. En L.A. Sutherland, I. Darnhofer, G. Wilson y L.Zagata (eds.), Transition pathways towards sustainability in European agriculture: case studies from Europe (pp. 2-16). Oxfordshire: CABI International.

Toader, M., y Roman, G. V. (2015). Family farming. Examples for rural communities development. Agriculture and agricultural science procedia, 6, 89-94. doi: https://doi.org/10.1016/j.aaspro.2015.08.043 
Toledo, V. M., (1993). La racionalidad ecológica de la producción campesina. En E. Sevilla, M. González (eds.), Ecología, campesinado e historia (pp. 197-218). Madrid: La Piqueta.

Vandermeer, J., y Perfecto, I. (2013). Tradiciones complejas: intersección de marcos teóricos en la investigación agroecológica. Revista Agroecología, 8(2), 55-63. Recuperado de https://revistas.um.es/agroecologia/article/view/212191

Van der Ploeg, J. D. (2009). Peasant agriculture. En R. Kitchin y N. Thrift (eds.), International encyclopedia of human geography (pp. 108-113). Doi: https://doi. org/10.1016/B978-008044910-4.00894-4

Van der Ploeg, J. D. (2017). The importance of peasant agriculture: a neglected truth. Wageningen, Netherlands: Wageningen University and Research. Recuperado de http://edepot.wur.nl/403213

Van Vliet, J. A., Shut, A. G. T., Reidsma, P., Descheemaeker, K. K. E. Slingerland, M. A., van de Ven, G. W., y Giller, K. E. (2015). De-mystifying family farming: features, diversity and trends across the globe. Global Food Security, 5, 11-18. doi: https://doi.org/10.1016/j.gfs.2015.03.001

Vila, M., y Marin, A. (2017). Transiciones hacia una agricultura sostenible: el nicho de la apicultura orgánica en una cooperativa Argentina. Mundo Agrario, 18(37), 1-18. doi: https://doi.org/10.24215/15155994e049

Wezel, A., Bellon, S., Doré, T., Francis, C., Vallod, D., y David, C. (2009). Agroecology as a science, a movement and a practice. A review. Agronomy for Sustainable Development, 29(4), 503-515. doi: http://dx.doi.org/10.1051/agro/2009004 



\title{
Capítulo 2
}

\section{Agroecología, seguridad y soberanía alimentaria. El caso de los agricultores familiares de Tibasosa, Turmequé y Ventaquemada en Boyacá}

\author{
Agroecology, food security and sovereignty. The case of the family \\ farmers of Tibasosa, Turmequé and Ventaquemada in Boyacá
}

\author{
Neidy Lorena Clavijo Ponce* \\ Hellen Mireya Sánchez Gil**
}

\section{Cómo citar}

\section{APA}

Clavijo, N., y Sánchez, H. (2019). Agroecología, seguridad y soberanía alimentaria. El caso de los agricultores familiares de Tibasosa, Turmequé y Ventaquemada en Boyacá. En Á. Acevedo-Osorio y N., Jiménez-Reinales (comps.). La agroecología. Experiencias comunitarias para la Agricultura Familiar en Colombia. (pp. 35-58). Bogotá: Corporación Universitaria Minuto de Dios-UNIMINUTO, Editorial Universidad del Rosario.

\section{Chicago}

Clavijo Ponce, Neidy y Sánchez Gil, Hellen. "Agroecología, seguridad y soberanía alimentaria. El caso de los agricultores familiares de Tibasosa, Turmequé y Ventaquemada en Boyacá". En La agroecología. Experiencias comunitarias para la Agricultura Familiar en Colombia, comps. Álvaro Acevedo-Osorio y Nathaly Jiménez-Reinales. Bogotá: Corporación Universitaria Minuto de Dios-UNIMINUTO, Editorial Universidad del Rosario, 2019.

* Pontificia Universidad Javeriana. n.clavijo@javeriana.edu.co

** Pontificia Universidad Javeriana. hellensanchez@javeriana.edu.co 


\section{MLA}

Clavijo Ponce, Neidy. y Sánchez Gil, Hellen. "Agroecología, seguridad y soberanía alimentaria. El caso de los agricultores familiares de Tibasosa, Turmequé y Ventaquemada en Boyacá". En La agroecología. Experiencias comunitarias para la Agricultura Familiar en Colombia. En Á. Acevedo-Osorio y N., Jiménez-Reinales (comps.) Bogotá: Corporación Universitaria Minuto de Dios-UNIMINUTO, Editorial Universidad del Rosario, 2019, pp. 35-58.

\section{Resumen}

La creciente dificultad para acceder de manera estable a alimentos diversos, nutritivos y saludables se ha convertido en un reto creciente, pues el sistema agroalimentario globalizado, proveedor de la mayor parte de alimentos que se consumen, se fundamenta primordialmente en la generación de productos altamente procesados, cuya materia prima se obtiene de pocas especies vegetales producidas bajo el modelo de agricultura industrializada. Lo anterior, implica un detrimento considerable en la disponibilidad de alimentos frescos, saludables y locales, así como, un general deterioro de la soberanía alimentaria. Frente a este panorama, organizaciones sociales, algunos sectores de la academia y la FAO hacen un llamado sobre la importancia sustancial que tienen los sistemas agroalimentarios sostenibles, como estrategia de conservación de recursos naturales y del suministro de alimentos. Así, la agricultura familiar aparece como la mejor opción, sobre todo aquella que tiene una clara orientación agroecológica. Por esta razón, en aras de proporcionar evidencia empírica que visibilice los aportes de la agricultura familiar, con enfoque agroecológico a la seguridad y soberanía alimentaria en los Andes colombianos, esta investigación llevó a cabo un estudio de caso con 25 familias agricultoras en los municipios de Turmequé, Ventaquemada y Tibasosa en el Departamento de Boyacá. En esta se aplicó herramientas de investigación participativa, con el fin de obtener información en lo referente a la trayectoria productiva de estas familias durante los últimos 50 años; las características de sus sistemas de producción; las prácticas de manejo que llevan a cabo al interior de la finca; las dinámicas de su alimentación y los principales destinos que tienen sus productos agropecuarios. Los resultados muestran agroecosistemas familiares diversos, con huertas escalonadas que proporcionan una producción constante de alimento, permiten su acceso y disponibilidad durante todo el año tanto para autoconsumo como para el mercado local. Su manejo es predominantemente agroecológico, como respuesta a procesos de transición que han sido acompañados por capacitación e innovación local. La diversidad histórica productiva, así como una alimentación diversa, equilibrada y culturalmente adecuada, junto con la promoción de circuitos cortos de comercialización son evidencias, entre otras, del fomento de la soberanía alimentaria en estas zonas, resultado de la agricultura familiar con enfoque agroecológico.

Palabras clave: agricultura familiar, agrobiodiversidad, seguridad alimentaria y soberanía alimentaria. 


\begin{abstract}
The growing difficulty of accessing nutritious, diverse and healthy foods in a stable way has become a growing challenge, since the globalized agrifood system, which supplies most of the food consumed, is primarily based on the generation of highly processed products. Whose raw materials are obtained from few vegetable species produced under the model of industrialized agriculture. This implies a considerable detriment in the availability of fresh, healthy and local foods, as well as a general deterioration of food sovereignty. Against this background, social organizations, some sectors of the academy and FAO are calling for the substantial importance of sustainable agrifood systems, as a strategy for the conservation of natural resources and the supply of food. In this scenario family farming appears as the best option, especially one that has a clear agroecological orientation. For this reason, in order to provide empirical evidence that highlights the contributions of family farming, with an agroecological approach to food security and sovereignty in the Colombian Andes, this research carried out a case study with 25 farming families in the municipalities of Turmequé, Ventaquemada and Tibasosa in the Department of Boyacá. The participatory research tools were applied in order to obtain information regarding the productive trajectory of these families over the past 50 years; the characteristics of their production systems; the management practices that they carry out inside the farm; the dynamics of their diet and the main destinations of their agricultural products. The results show diverse family agroecosystems with stepped orchards that provide a constant production of food, allow their access and availability throughout the year both for self-consumption and for the local market. Its management is predominantly agroecological in response to transition processes that have been accompanied by training and local innovation. Historical productive diversity, a diverse, balanced and culturally adequate diet, and the promotion of short marketing circuits are, among others, evidence of the promotion of food sovereignty in these areas, thanks to the result of family farming with an agroecological approach.
\end{abstract}

Keywords: family farming, agrobiodiversity, food security and food sovereignty.

\title{
1. Introducción
}

La crisis alimentaria ocasionada por el modelo agroindustrial y promovida por la Revolución Verde establece una forma capitalista de apropiación de la naturaleza, esto a conllevado a supeditar la producción alimentaria a la racionalidad del lucro y transgrediendo de manera irreversible su renovabilidad (Alonso y Sevilla, 1995; Naredo, 2006; Sevilla, 2006; López, 2012).

De acuerdo con la Organización de la Naciones Unidas para la Alimentación y la Agricultura (FAO por su siglas en inglés), el actual sistema agroalimentario, en el marco de la economía globalizada, incide directamente en el incremento de las cifras de mal nutrición en el mundo, ya que ha contribuido al cambio de hábitos 
alimenticios menos saludables, estos productos son altamente procesados, cuya materia prima la constituyen pocas especiesvegetales que son cultivadas de forma intensiva en vastas áreas a lo largo del planeta. Lo anterior, ha afectado considerablemente no solo la seguridad alimentaria y nutricional de gran parte de la población, sino también la soberanía alimentaria (FAO, FIDA, OMS, PMA y UNICEF, 2017).

El presente escrito acoge la definición de seguridad alimentaria consignada en el documento Conpes Social 113 de 2008, la cual describe a este concepto como

... la disponibilidad suficiente y estable de alimentos, el acceso y el consumo oportuno y permanente de los mismos en cantidad, calidad e inocuidad por parte de todas las personas, bajo condiciones que permitan su adecuada utilización biológica, para llevar una vida saludable y activa. (DNP, 2007, p. 3).

Si bien esta definición reconoce el derecho humano que tiene la población a no padecer hambre y a tener una alimentación adecuada, su concepción deja por fuera otros elementos igual de importantes e indispensables para cumplir con tales propósitos. Por esta razón, la organización Vía Campesina plantea la necesidad de abordar el concepto de "soberanía alimentaria, entendida como el derecho de todos los pueblos a alimentos nutritivos y culturalmente adecuados, accesibles, producidos de forma sostenible y ecológica, y su derecho a decidir su propio sistema alimentario y productivo". (2007, p. 1).

En Colombia, la última Encuesta Nacional de Situación Nutricional (Ministerio de Salud y Protección Social, 2015) evidenció que la prevalencia de inseguridad alimentaria y hambre fue de 54.2\%. Particularmente, en el departamento de Boyacá, considerado la despensa alimentaria de Bogotá, la cifra corresponde a $52 \%$ y al rededor de $37 \%$ de sus municipios presentan altos niveles de desnutrición. Tal problemática trae la necesaria discusión sobre las alternativas que se puedan otorgar a las poblaciones para el acceso a alimentos sanos, inocuos, diversos y, culturalmente, apropiados, los cuales no pueden ser obtenidos por la agricultura industrializada, sino por medio sistemas de producción sostenibles y diversificados. Es así que, en el año 2013, la FAo planteó la necesidad de considerar a los sistemas alimentarios saludables como una alternativa para mitigar el problema de inseguridad alimentaria en el mundo, asimismo, dentro de las comunidades campesinas y algunos sectores de la academia resaltan el papel que, en esta tarea, cumple la agricultura familiar con enfoque agroecológico (Morales, 2013; Cuellar, Calle y Gallar , 2013). 
La agroecología propende a construir una agricultura sobre la base de la conservación de los recursos naturales, de la agricultura tradicional, local y familiar, que a la par dialoga con las innovaciones de la ciencia moderna (Guzmán y Morales, 2012).En este sentido, la agricultura familiar, con enfoque agroecológico, conserva y fomenta la biodiversidad a través de diseños estratificados con distinto grado de complejidad, en los cuales pueden coexistir cultivos, animales, árboles, arbustos y arvenses. En la agroecología es indispensable el fomento de la fertilidad del suelo por medio del uso de distintos tipos de abonos orgánicos (Gliessman, 2002). Además, prioriza la producción de alimentos frescos y diversos por encima de la producción de materias primas orientadas, netamente, al mercado convencional, en ella es una prioridad el abastecimiento de alimentos a la familia, vecinos y mercados locales mediante la articulación de circuitos cortos de comercialización (Morales, 2011; Chaparro, 2014).

En el departamento de Boyacá, en los municipios de Tibasosa, Turmequé y Ventaquemada, estudios realizados por Blanco (2012), Cadavid (2012), reportaron indicios de una agricultura familiar agrodiversa, llevada a cabo en mini y microfundios, proveen sus propios ingresos y alimentos, en los cuales, se siembran cultivos tradicionales con prácticas agroecológicas. En 25 de estos sistemas de producción, el presente estudio de caso procuró, a través del uso de herramientas de investigación cualitativa, encontrar evidencias empíricas que permitan determinar la contribución cotidiana que estos sistemas puedan hacer, no sólo a la seguridad alimentaria, sino también, a la soberanía alimentaria. Para esto la investigación acogió la siguiente pregunta como orientadora:

¿Cómo contribuye la agricultura familiar agroecológica a la seguridad y soberanía alimentaria de los municipios de Tibasosa, Turmequé y Ventaquemada del departamento de Boyacá?

Para dar respuesta a esta pregunta, con cada familia se llevó a cabo la reconstrucción de una línea de tiempo desde la llegada de paquetes tecnológicos de la Revolución verde al territorio en el año de 1970, hasta el año 2017, con el fin de comprender los cambios y persistencias de cultivos a lo largo del tiempo. Esta información que nos permitió dilucidar patrones históricos de producción y autoconsumo familiar. También se aplicaron entrevistas semiestructuradas que incluían tanto variables socioeconómicas y ambientales, que ayudaron a identificar características biofísicas de los predios, así como prácticas e insumos agrícolas utilizados; además, ayudó a indagar actuales procesos de consumo alimentario, e intercambio monetario y no monetario de sus productos. Lo anterior fue complementado con visitas periódicas que dieron lugar a un ejercicio de observación participante. Los datos se analizaron 
mediante un proceso de triangulación metodológica que contrastó la información generada entre lasdistintas herramientas, así como con información secundaria consultada durante los dos años de estudio.

\section{Resultados y discusión}

\subsection{Trayectoria productiva de las familias campesinas de las tres zonas de estudio durante los últimos 50 años}

A mediados de los años de 1970, un nuevo modelo de agricultura fundamentado en el monocultivo de pocas especies, el uso de fertilizantes de síntesis química y la artificialización de los procesos productivos, conocido como Revolución Verde, este se hizo presente en la zona de estudio. Evidencias reportadas por Raymond (1990), Forero (1999), Benzing (2001), León (2007), Saavedra (2010), entre otros, dan cuenta que en Boyacá existen extensas áreas con monocultivos de papa, pastos, cebolla, maíz, fríjol, frutales y hortalizas, caracterizados por el alto uso de agroquímicos, maquinaria agrícola e importantes inversiones de dinero; cuyo propósito principal es su venta en mercados urbanos, especialmente en capitales de provincia y departamentos.

Los aparentes beneficios, de esta forma de agricultura, se plasmaron en incrementos de la productividad de ciertos cultivos generados por tal mejora agrícola, pero, este aumento vino acompañado con problemas e impactos negativos de igual o mayor magnitud, entre los que se pueden citar: la degradación del suelo, el gasto excesivo, la pérdida y contaminación del agua, la contaminación del ambiente, la dependencia de insumos externos, la pérdida de diversidad genética, la pobreza y, por supuesto, la baja seguridad alimentaria (Pengue, 2005; Roberts, 2009; Fajardo, 2014).

En consecuencia, resulta una generalidad que las fincas visitadas, hacia las décadas de 1980 y 1990, fueran menos agrodiversas, ya que la mayor parte de sus áreas estaban destinadas a cultivos comerciales, bajo el modelo de monocultivo o tenían presencia de pastos para el levante de ganado.

Este hecho obedeció al modelo de desarrollo acogido por el Estado, en ese entonces, en el cual el país debía responder al incremento del PIB agrícola que inducía la expansión del área productiva y la intensificación de las zonas tradicionales (Machado, 1998). Para ello, el programa de Desarrollo Rural Integral (DRI), el cual a través del atractivo de créditos subsidiados y programas de asistencia técnica, indujo a los campesinos a sustituir sus cultivos por una canasta reducida de productos que se comercializaba en los mercados, a fin de ponerse a tono con lo que venía ocurriendo con la gran propiedad. Aquellos grandes productores, que por su disponibilidad de 
recursos, ya habían introducido con éxito y en menor tiempo, estos cambios técnicos, con el fin de insertarse en mercados nacionales y extranjeros (Fajardo, 2009).

Si bien con los nuevos insumos químicos y la aplicación de novedosas técnicas de cultivo, el rendimiento por área en sus campos se incrementó en su momento, a finales de la década de 1990, la débil participación en el mercado de las familias agricultoras las puso en desventaja. Puesto que la dependencia del intermediario, el surgimiento de plagas y enfermedades y, los rendimientos decrecientes de sus monocultivos que exigían cada vez más la compra de insumos químicos, los cuales no se hicieron esperar, tuvo como resultado serios problemas para continuar con el trabajo agricola.

Es por esto que, como primera estrategia para solventar estas dificultades, optaron por sustituir algunos de sus cultivos por más pastizales. Lo anterior, reduciría la mano de obra familiar, ya que debían, de ahora en adelante, ocuparse en otras actividades para aportar ingresos adicionales a los hogares, los cuales, para ese entonces, se veían seriamente endeudados y sin flujo de caja para adquirir alimentos en el mercado.

Más tarde, al ver que no había posibilidad de cambio, la mayoría de los agricultores tomaron algunas decisiones, como: vender parte de su tierra para subsanar deudas, emplearse como mano de obra en otras actividades y reconfigurar sus sistemas de producción volviendo a su esquema de policultivo con uso de abonos orgánicos. Esta última, según ellos, fue una estrategia que por los menos les aportaría sustento diario para alimentación de su familia. De este modo, sin abandonar del todo los cultivos principales con uso de agroquímicos, decidieron retomar cultivos y prácticas de antaño destinando un área importante de su finca para ello. Así, como las primeras evidencias del proceso de transición hacia la agroecología, reaparecen nuevamente el uso de las abonaduras orgánicas, los cultivos tradicionales y las especies menores. La huerta familiar, lentamente, se reactiva y empieza a reconfigurarse como una incipiente despensa.

Los primeros agricultores que optaron por dejar paulatinamente la agricultura con el enfoque de la Revolución Verde aducen que el proceso de cambio de modelo productivo no fue difícil, toda vez que, para hacerlo, tuvieron que recurrir a las enseñanzas de sus padres y abuelos, quienes otrora, llevaban a cabo este tipo de prácticas y, en cuyos complejos diseños productivos, se incorporaban toda clase de cultivos de los cuales se alimentaron en su niñez. De esta manera, para la segunda década del siglo XXI, las huertas familiares se ampliaron, la diversidad cultivada se incrementó y aunque la papa no dejó de ser importante en sus fincas, los frutales empezaron a repuntar como cultivos principales, entre ellos los caducifolios y la curuba (Passiflora tripartita var. mollissima). 
Los agricultores mencionan que, para esta época, tener acceso y disponibilidad para la compra de alimentos ya no estaban supeditados, únicamente, al ingreso obtenido por la venta de sus cosechas, sino que, ahora su alimentación empezaba a abasteserce poco a poco de la producción de sus fincas, aunque continuaban adquiriendo varios productos en los mercados regionales.

Sin embargo, el paro nacional agrario suscitado en el año 2013 fue un hito que, para las familias de la zona de estudio, reafirmó la vulnerabilidad que los sistemas de producción tienen. Puesto que, por un lado, dependían del acceso a sus alimentos de los mercados urbanos y, por el otro, para la venta de su producción estaban en manos de los intermediarios que la venden en las grandes ciudades ${ }^{1}$.

A partir de este momento, los procesos de intercambio local, monetario y no monetario se fortalecieron. El Paro Agrario ratificó el hecho que la dependencia hacia el mercado de Tunja, Duitama, Sogamoso y Bogotá no era ya la mejor y única opción. Así se hicieron más frecuentes lo trueques entre vecinos y familiares, y, junto con ellos, se reavivaron los procesos de recuperación e intercambio de semillas y cultivos nativos; además se dejó atrás en gran medida el uso de agroquímicos y maquinaria agrícola. La diversidad cultivada empieza a ser el eje central de las fincas visitadas y la coexistencia se reafirma con los espacios naturales como los bosques nativos y los páramos.

Como podrá apreciarse más adelante, el proceso de reconversión hacia una agricultura con enfoque agroecológico continúa consolidándose y hoy, se expresa en sistemas de producción agrodiversos que, a pesar de ser mini y microfundios, consiguen abastecer en gran medida de alimentos a las familias, vecinos y mercados locales.

\footnotetext{
${ }^{1}$ Este hecho movilizó a miles de campesinos del país en aras de reclamar por los altos costos de los insumos agrícolas, la necesidad de subsidios, el acceso a crédito, la falta de asistencia técnica, entre otros motivos, suspendió por semanas la movilidad en las vías en el departamento de Boyocá, restringió no solo el transporte de alimentos que salían de Tibasosa, Turmequé y Ventaquemada hacia las ciudades principales, sino también al interior del sector rural. A la par, cargas de alimentos represados se perdieron, la leche del ganado que no pudo salir se consumía, se regalaba, se daba a los animales y hasta se botaba. Hectáreas de cultivos de papa listos para la cosecha tuvo que dejarse en los campos y luego voltearse nuevamente en la tierra para que terminará de descomponerse. Más información en Salcedo, L; Pinzón, R y Duarte, D (2013). El paro nacional agrario: un analisis de los actores agrarios y los procesos organizativos del campesinado colombiano. Recuperado de https:// www.javerianacali.edu.co/sites/ujc/files/node/field-documents/field_document_file/el_paro_nacional_ agrario-_un_analisis_de_los_actores_agrarios_y_los_procesos_organizativos_del_campesinado_colombiano._centro_de_estudios_interculturales._pdf
} 


\subsection{Características de los sistemas de producción de agricultura familiar campesina}

\subsubsection{Caracterización de los sistemas de producción}

Las 25 familias campesinas que contribuyeron a esta investigación son propietarias de sus unidades productivas. La estructura de la propiedad está conformada por microfundios cuyos predios son menores de 3 hectáreas (22 predios) y minifundios que oscilan entre 3 a 8 hectáreas ( 3 predios). En la tabla 1 se presenta el tamaño de los predios por municipio.

Tabla 1. Tamaño de la propiedad.

\begin{tabular}{lcccc}
\hline \multicolumn{5}{c}{ Tamaño de la finca } \\
\hline Municipio & $<1$ ha & $1-3$ ha & $3.1-6$ ha & $6-8$ ha \\
\hline Tibasosa & 5 & 1 & 1 & 1 \\
\hline Turmequé & 1 & 7 & 1 & 0 \\
\hline Ventaquemada & 4 & 4 & 0 & 0 \\
\hline Total & 10 & 12 & 2 & 1 \\
\hline
\end{tabular}

Fuente: elaboración propia.

En los predios se identificaron dos subsistemas básicos: el agrícola y el pecuario; asimismo, en seis de las 25 fincas se encontró un tercer componente compuesto por un relicto de bosque nativo. En la mayoría de ellas, también se resalta un cuarto componente seminatural, donde se incluyen cercas vivas y árboles dispersos, instalados durante el proceso de transición hacia prácticas agroecológicas y de policultivo, con el fin de mejorar la diversidad y estructura de las fincas.

a) El componente agrícola. Esta presente en todas las fincas, posee dos tipos de subcomponentes: cultivos de tipo comercial y cultivos para autoconsumo (las huertas caseras). Se resalta que las 25 fincas poseen gran variedad de especies cultivadas ya sean nativas o, también, de especies introducidas. Entre ellas, se destacan en su orden de riqueza funcional: medicinales $30 \%$, hortalizas $29.3 \%$, frutas $24 \%$, tubérculos y raíces $6 \%$, cereales $5 \%$, especias $4 \%$ y leguminosas $2 \%$ (tabla 2 ).

Dentro de los cultivos destinados a la comercialización sobresalen, principalmente: la papa, los frutales, el frijol, el maíz, la arveja y las habas. Estos cultivos son transitorios y están planificados por el agricultor dentro de un espacio determinado de su propiedad, generalmente, se encuentran en monocultivos, pero también pueden estar asociados con otras especies. Las especies vegetales rotan de acuerdo a un tiempo determinado, prácticas que le aseguran al agricultor una producción sostenida a lo largo del año. 
Figura 1. Agroecosistema familiar en Tibasosa, Boyacá.

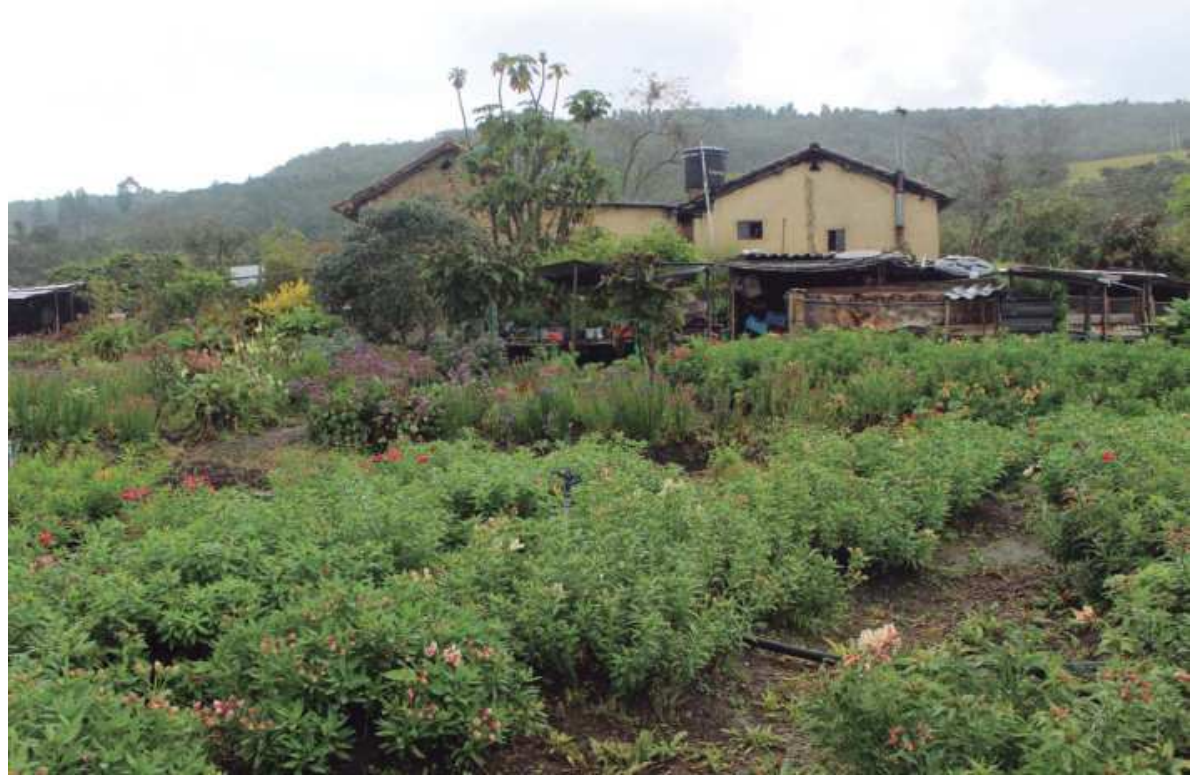

Fuente: Clavijo (2018).

Tabla 2. Especies cultivadas en los sistemas agrícolas familiares con enfoque agroecológico en Turmequé, Ventaquemada y Tibasosa. 2017

\begin{tabular}{|c|c|c|}
\hline Cultivo & Especies & Nombre científico \\
\hline \multirow{14}{*}{ Frutales } & Papayuela & Vasconcellea pubescens, A.DC. \\
\hline & Fresa & Fragaria spp \\
\hline & Mora & Rubus glaucus, B. \\
\hline & Tomate de árbol & Solanum betaceum, Cav. \\
\hline & Lulo & Solanum quitoense, Lamarck \\
\hline & Uchuva & Physalisperuviana. L. \\
\hline & Feijoa & Acca sellowiana, B. \\
\hline & Ciruela & Prunus domestica, $\mathrm{L}$. \\
\hline & Durazno & Prunus pérsica, L. \\
\hline & Curuba & Passiflora tripartita, J. \\
\hline & Breva & Ficus carica, $\mathrm{L}$. \\
\hline & Manzana & Malus domestica, $\mathrm{B}$. \\
\hline & Chirimoya & Annona cherimola, $\mathrm{L}$. \\
\hline & Pepino de guiso & Solanum muricatum, A. \\
\hline
\end{tabular}




\begin{tabular}{|c|c|c|}
\hline Cultivo & Especies & Nombre científico \\
\hline \multirow{13}{*}{ Hortalizas } & Acelga & Beta vulgaris, $\mathrm{L}$ \\
\hline & Lechugas & Lactuca sativa, $\mathrm{L}$ \\
\hline & Repollo & Brassica oleraceae, $\mathrm{L}$. \\
\hline & Tomate & Solanum lycopersicum, L. \\
\hline & Remolacha & Beta vulgaris, $\mathrm{L}$. \\
\hline & Pepino de rellenar & Cyclanthera pedata, $\mathrm{L}$. \\
\hline & Zanahoria & Daucus carota, L. \\
\hline & Espinaca & Spinacia oleracea, L. \\
\hline & Cebolla larga & Allium fistolosum, L. \\
\hline & Rábano & Raphanus sativus, L. \\
\hline & Brócoli & Brassica oleracea, $\mathrm{L}$. \\
\hline & Coliflor & Brassica oleracea, $\mathrm{L}$. \\
\hline & Cilantro & Coriandrum sativum, L. \\
\hline \multirow{8}{*}{$\begin{array}{l}\text { Tubérculos y } \\
\text { raíces andinas }\end{array}$} & Variedades de papa comercial & Solanum sp \\
\hline & Variedades de papa Nativa & Solanum sp \\
\hline & Variedades de papa criolla & Solanum sp \\
\hline & Rubas & Ullucus tuberosus, $C$. \\
\hline & Cubios & Tropoaelum tuberosum, R\&P. \\
\hline & Ibias & Oxalis tuberosa, M. \\
\hline & Arracacha & Arracacia xanthorriza, Bancr. \\
\hline & Yacón & Smallanthus sonchifolius (P\&E) \\
\hline \multirow{4}{*}{ Cucurbitáceas } & Ahuyama & Cucurbita máxima, D. \\
\hline & Calabaza & Cucurbita moschata, D. \\
\hline & Calabacín & Cucurbita pepo, L. \\
\hline & Pepino & Cucumis sativus, $\mathrm{L}$ \\
\hline \multirow{3}{*}{ Leguminosas } & Variedades de frijol & Phaseolussp \\
\hline & Arveja & Pisum sativum, $\mathrm{L}$. \\
\hline & Haba & Vicia faba, L. \\
\hline \multirow{5}{*}{ Cereales } & Maíz & Zea mayz, L. \\
\hline & Quinua & Chenopodium quinoa, W. \\
\hline & Trigo & Triticum sativum, Lam. \\
\hline & Avena & Avena sativa, $\mathrm{L}$ \\
\hline & Linaza & Linum usitatissimum, L. \\
\hline
\end{tabular}




\begin{tabular}{|c|c|c|}
\hline Cultivo & Especies & Nombre científico \\
\hline \multirow{20}{*}{ Aromáticas } & Orégano & Origanum vulgare, $\mathrm{L}$. \\
\hline & Yerbabuena & Mentha viridis, $\mathrm{L}$. \\
\hline & Menta & Mentha piperita, $\mathrm{L}$. \\
\hline & Manzanilla & Matricaria chamomilla, $\mathrm{L}$. \\
\hline & Romero & Rosmarinus oficinales, $\mathrm{L}$. \\
\hline & Toronjil & Melissa officinalis, $\mathrm{L}$. \\
\hline & Caléndula & Calendula officinalis, $\mathrm{L}$. \\
\hline & Tomillo & Thymus vulgaris, $\mathrm{L}$. \\
\hline & Laurel & Laurus nobilis, L. \\
\hline & Cedrón & Aloysia citrodora, $\mathrm{P}$. \\
\hline & Ruda & Ruta graveolens, $\mathrm{L}$. \\
\hline & Borraja & Borrago officinalis, $\mathrm{L}$. \\
\hline & Hinojo & Foeniculum vulgare, Mill. \\
\hline & Mejorana & Origanum majorana, $\mathrm{L}$. \\
\hline & Altamisa & Artemisia vulgaris, $\mathrm{L}$. \\
\hline & Perejil & Petroselinum crispum, Mill. \\
\hline & Ajenjo & Artemisia absinthium, $\mathrm{L}$. \\
\hline & Árnica & Arnica montana, $\mathrm{L}$. \\
\hline & Chipaca & Bidenspilosa, $\mathrm{L}$. \\
\hline & Albahaca & Ocimum basilicum, $\mathrm{L}$. \\
\hline
\end{tabular}

Fuente: elaboración propia.

b) Componente pecuario. 22 fincas visitadas poseen especies animales menores y mayores (figura 2). En cuanto al uso que se les da a los animales es diferente dependiendo de la especie, por ejemplo: las aves son destinadas para la alimentación de las familias, al igual que el ganado caprino (cabrasy ovejas) y los peces; mientras que los conejos y curíes son tanto para autoconsumo como para su comercialización. Respecto al ganado vacuno se destina tanto para la producción de leche en los municipios de Tibasosa y Ventaquemada, como para doble propósito en el municipio de Turmequé. Estos productos son comercializados en los mercados locales y en menor medida se utiliza para autoconsumo. 
Figura 2. Número de fincas con componente pecuario por municipio.

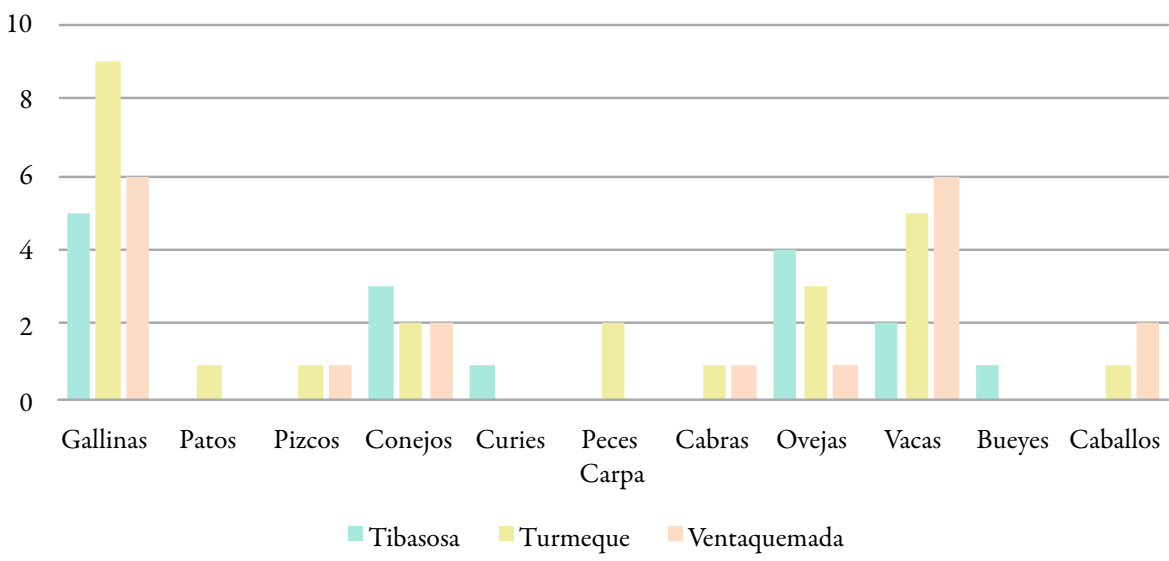

Fuente: elaboración propia.

c) Componente bosque. Como se indicó anteriormente, seis fincas presentaron relictos de bosque nativo incluidos dentro de sus predios, dosde ellas localizadas en Tibasosa, tres en Turmequé y una en Ventaquemada. Cabe mencionar que, debido a la conciencia ecológica fomentada durante el proceso de transición hacia la agroecología, en los últimos diez años ha aumentado la conservación de estos relictos de bosque nativo, en palabras de los agricultores, ellos reconocen que es un componente crucial en la conectividad de su finca con el paisaje. Además, destacan que su presencia dentro de la finca les permite tener mayor diversidad no solo de plantas, sino también de insectos, sobre todo los benéficos para su terreno.

d) Componente espacio natural. En 23 fincas se han plantado algunas especies arbóreas y arbustivas. La plantación de estas especies se ha realizado tanto en cercas vivas como en barreras rompevientos y árboles dispersos, asociados no sólo con los cultivos agrícolas, sino también con las áreas pecuarias o de pastoreo. De esta manera, es posible afirmar que las familias campesinas con los años han incorporado en el diseño de sus sistemas productivos, un importante subsistema agroforestal, bajo la misma lógica que impulsa la conservación de los relictos de bosques: conectividad e incremento de la biodiversidad. Ambos aspectos claves en sistemas de producción con enfoque agroecológico (Gliessman, 2002; Altieri y Nicholls, 2007; León-Sicard, 2014). 


\subsubsection{Prácticas de manejo en los cultivos}

Figura 3. Cosecha manual de tubérculos andinos en Ventaquemada, Boyacá.

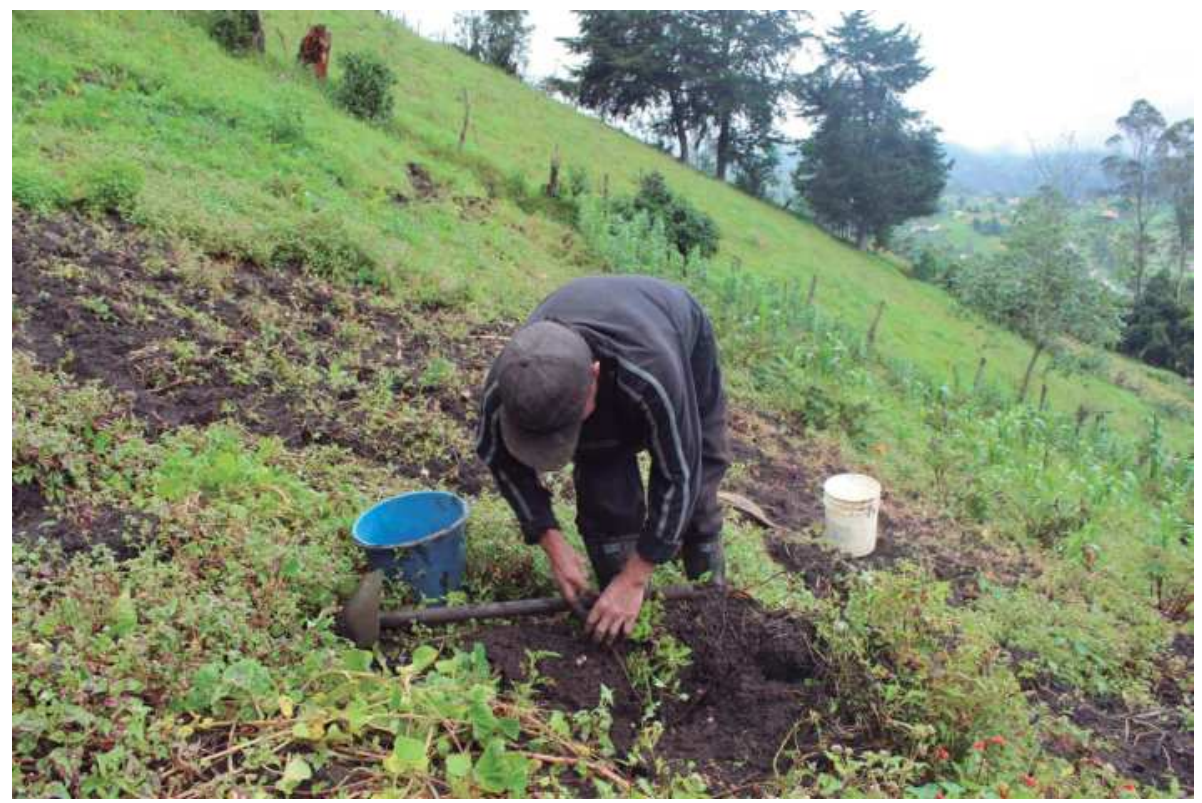

Fuente: Clavijo (2018).

$\mathrm{Al}$ considerar que el destino de la producción tiene una fuerte orientación hacia el autoconsumo, en su mayoría, las técnicas e insumos utilizados para el manejo de estos cultivos están asociadas a los principios que se orientan desde la agroecología. No obstante, a lo anterior, hay que reflexionar que en los sistemas productivos pensados desde la agroecología todavía resulta importante la presencia de monocultivos comerciales y, por esta razón, aún se evidencia el uso en estos de algunos productos de síntesis química, algunos de ellos como: molusquicidas, herbicidas, insecticidas y fertilizantes de síntesis química. La tabla 3 proporciona un panorama de lo enunciado. 
Tabla 3. Prácticas de manejo realizadas en cada municipio.

\begin{tabular}{|c|c|c|c|}
\hline & Tibasosa & Turmequé & Ventaquemada \\
\hline $\begin{array}{l}\text { Preparación } \\
\text { del suelo }\end{array}$ & $\begin{array}{l}\text { Manual. } \\
\text { Yunta de bueyes. } \\
\text { Arado de disco. } \\
\text { Rotobo. }\end{array}$ & $\begin{array}{l}\text { Manual. } \\
\text { Arado de cincel. } \\
\text { Arado de chuzo. } \\
\text { Arado de disco. }\end{array}$ & $\begin{array}{l}\text { Manual. } \\
\text { Arado con caballos. }\end{array}$ \\
\hline $\begin{array}{l}\text { Época de } \\
\text { siembra }\end{array}$ & $\begin{array}{l}\text { Huerta permanente. } \\
\text { Invierno. }\end{array}$ & $\begin{array}{l}\text { Huerta permanente. } \\
\text { Cultivos de frutales } \\
\text { permanentes. } \\
\text { Invierno. }\end{array}$ & $\begin{array}{l}\text { Huerta permanente. } \\
\text { Invierno. }\end{array}$ \\
\hline $\begin{array}{l}\text { Época de } \\
\text { cosecha }\end{array}$ & $\begin{array}{l}\text { Huerta permanente. } \\
\text { Cultivos: enero - abril, junio } \\
\text { - octubre y diciembre. }\end{array}$ & $\begin{array}{l}\text { Huerta permanente } \\
\text { Cultivos de frutales } \\
\text { permanentes. } \\
\text { Cultivos: enero - mayo, junio } \\
\text { - septiembre y diciembre. }\end{array}$ & $\begin{array}{l}\text { Huerta permanente. } \\
\text { Cultivos: febrero - marzo, } \\
\text { junio - julio y noviembre - } \\
\text { diciembre. }\end{array}$ \\
\hline $\begin{array}{l}\text { Origen de la } \\
\text { semilla }\end{array}$ & $\begin{array}{l}\text { Centros agrícolas en: Nobsa, } \\
\text { Tocogua y } \\
\text { Duitama. } \\
\text { Alcaldía de Tibasosa } \\
\text { Intercambio con miembros } \\
\text { de Asomercampo. }\end{array}$ & $\begin{array}{l}\text { Centros agrícolas en: } \\
\text { Garagoa, Universidad Jorge } \\
\text { Tadeo Lozano, Red de } \\
\text { semillas, intercambio con } \\
\text { socios de AITAB. }\end{array}$ & $\begin{array}{l}\text { Centros agrícolas en: Nobsa, } \\
\text { Samacá, Capellanía. } \\
\text { Fincas agroecológicas } \\
\text { en la sabana de Bogotá, } \\
\text { Universidad Jorge Tadeo } \\
\text { Lozano, intercambio con } \\
\text { Granja Victoria. }\end{array}$ \\
\hline Fertilización & $\begin{array}{l}\text { Orgánicos: compostaje, } \\
\text { estiércol de animales, } \\
\text { microorganismos efectivos. } \\
\text { Síntesis química: Triple 15, } \\
\text { Cal, Nutrimon, Triple 18, } \\
\text { Abocol y Yara. }\end{array}$ & $\begin{array}{l}\text { Orgánicos: compostaje, } \\
\text { lombricompostaje, estiércol } \\
\text { de animales, bioles. } \\
\text { Síntesis química: Triple 15, } \\
\text { Triple 18, Súper 4, Cal y } \\
\text { Urea. }\end{array}$ & $\begin{array}{l}\text { Orgánicos: compostaje, } \\
\text { lombricompostaje, estiércol } \\
\text { de animales, bioles. } \\
\text { Síntesis química: Triple } 15 \text {, } \\
\text { Cal y Urea }\end{array}$ \\
\hline $\begin{array}{l}\text { Equipos } \\
\text { utilizados al } \\
\text { momento de } \\
\text { cosechar }\end{array}$ & Manual. & $\begin{array}{l}\text { Manual. } \\
\text { Motocultor. }\end{array}$ & Manual. \\
\hline $\begin{array}{l}\text { Manejo de } \\
\text { enfermedades, } \\
\text { plagas y } \\
\text { arvenses }\end{array}$ & $\begin{array}{l}\text { Matababosa química, control } \\
\text { manual de babosa y caracol, } \\
\text { cerveza, cal viva, manzate. } \\
\text { Arvenses: manual y glifosato }\end{array}$ & $\begin{array}{l}\text { Control biológico, trampas } \\
\text { biológicas, repelentes y } \\
\text { fungicidas e insecticidas de } \\
\text { origen vegetal. } \\
\text { Arvenses: guadaña, glifosato } \\
\text { y gramoxone. }\end{array}$ & $\begin{array}{l}\text { Control biológico, trampas } \\
\text { biológicas. } \\
\text { Alelopatía: plantas } \\
\text { acompañantes a los } \\
\text { cultivos que ayudan a } \\
\text { repeler y controlar plagas y } \\
\text { enfermedades. } \\
\text { Repelentes de origen vegetal: } \\
\text { ajo, ají, chipaca, ajenjo. } \\
\text { Síntesis química: sulfato de } \\
\text { cobre y cal. } \\
\text { Arvenses: manual y glifosato. }\end{array}$ \\
\hline
\end{tabular}

Fuente: elaboración propia. 
Al respecto Gliessman (2002) refiere que, en los procesos de transición desde una agricultura con enfoque de Revolución Verde hacia una con enfoque agroecológico, puede presentarse coexistencia de prácticas e insumos orgánicos y de síntesis química, sobre todo en sus primeras etapas mientras se concreta el proceso de rediseño del sistema productivo ${ }^{2}$.

\subsection{Contribución de la agricultura familiar con enfoque agroecológico a la seguridad y soberanía alimentarias}

Las 25 fincas mantienen huertas escalonadas, que proporcionan una producción constante de alimento durante todo el año. Con relación al menú diario, se encontró que todas las familias consumen tres comidas al día: desayuno, almuerzo y cena. Mientras que más de la mitad de ellas, incorporan a su dieta un refrigerio de media mañana y otro a media tarde.

Por tratarse de familias campesinas de los Andes colombianos, estas mantienen una tradición agrícola y alimentaria similar en su menú diario, dentro del cual los carbohidratos constituyen la principal fuente de alimentación. El almuerzo representa para ellos la comida principal del día, allí se identifican claramente seis grupos alimenticios:

i) Carbohidratos representados por papas, arroz, tubérculos andinos, arracacha y pasta.

ii) Granos como alverja, habas, lentejas y, a veces, fríjoles.

iii) También están los cereales como el maíz y el arroz. El segundo se adquiere en el mercado y es el plato fuerte de todas las comidas. Mientras que del maíz se preparan sopas, arepas, envueltos y demás amasijos.

iv) Las proteinas animales no suelen ser frecuentes, se consumen en promedio dos veces por semana. La carne de animales como gallinas, conejos, cerdos o curíes se crían en las mismas fincas para su autoconsumo. Mientras que la carne de res o de cordero se compra ocasionalmente en mercados locales. La leche y sus derivados, al igual que los huevos, son también parte de este grupo alimentario.

\footnotetext{
${ }^{2}$ De otra parte, Clavijo (2010), y Altieri y Toledo (2011) también anotan que, pese a que los agricultores cuentan ya con conocimiento ecológico de base, su evaluación de riesgo los impulsa a optar por la utilización de agroquímicos en sus cultivos comerciales, como un anclaje seguro para obtener ingresos para su familia, hasta tanto, en la zona, no se cuente con mercados agroecológicos que retribuyan el valor real de su producción.
} 
Figura 4. Cocido boyacense. Turmequé, Boyacá.

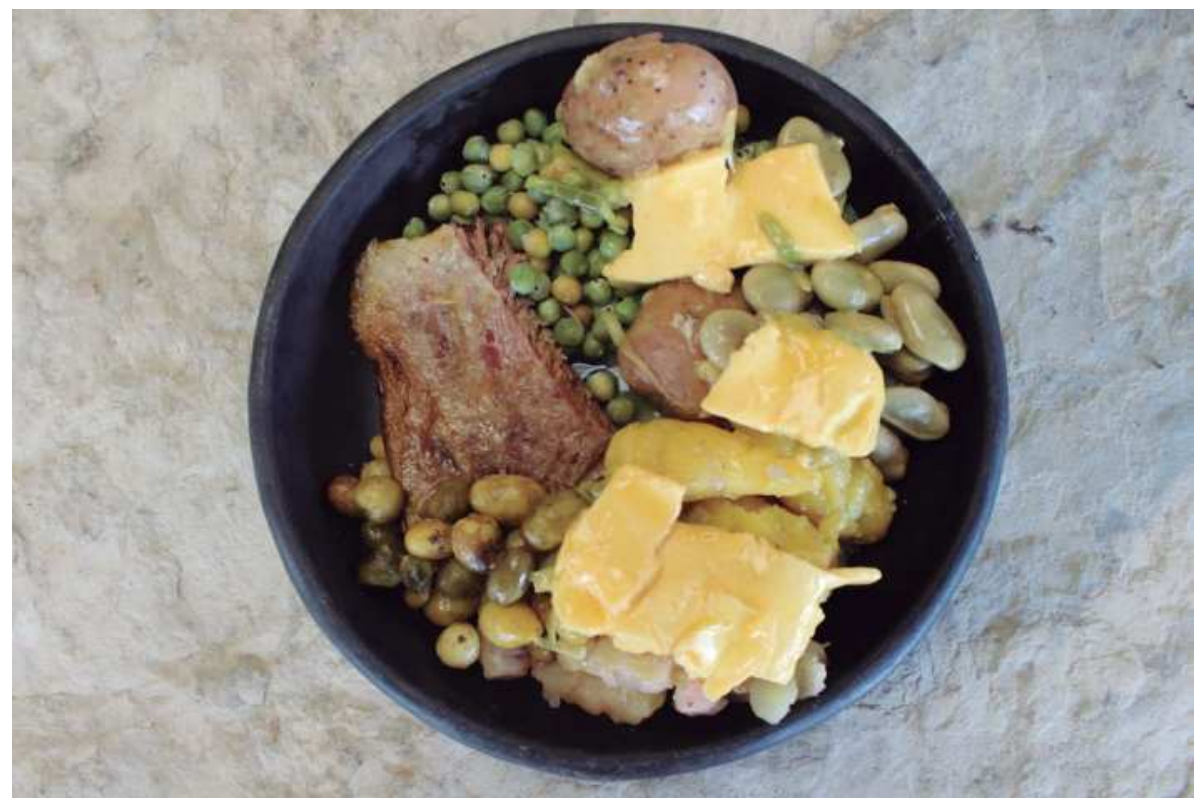

Fuente: Clavijo (2018).

v) Las frutas se consumen en el jugo y otrascomo el mango, la papaya o la piña, en ocasiones, se compran en el mercado.

vi) El consumo de hortalizas suele ser en cremas o sopas, muy poco en ensaladas.

vii) Las grasas en su mayoría provienen de aceites y mantecas.

\subsubsection{Seguridad alimentaria}

Con base en la información que proporciona la caracterización de los sistemas de producción, las especies cultivadas, las horas de alimentación y el tipo de productos consumidos por las familias, se pudo establecer algunos hallazgos en torno a los cuatro componentes de la seguridad alimentaria.

\section{a) Disponibilidad}

- En cuanto a la producción promedio de alimento, se registró cerca de 100 especies cultivadas para el caso de Tibasosa, 95 en Turmequé y 93 en Ventaquemada. Aunque, la producción no es constante durante todo el año, debido a las épocas de cosecha que tiene cada cultivo y a los factores 
bioclimáticos, la época de invierno o de verano, las familias campesinas producen cerca del $60 \%$ de los alimentos que consumen.

- Su energía alimentaria proviene de cereales, raíces y tubérculos. Las familias tienen como base de su alimentación los cereales, como el arroz, trigo y maíz; igualmente, están los tubérculos representados en los cubios, las papas y, en menor medida, las rubas, las ibias, la arracacha y el yacón.

- El suministro de proteínas de origen vegetal proviene de las especies cultivadas como las leguminosas. En cuanto a las proteínas de origen animal, el consumo de carne no es frecuente y sólo se limita a una o dos veces por semana o en ocasiones especiales. Se incluye en este grupo el consumo de huevos, leche y sus derivados.

b) Acceso

- El acceso a los alimentos para las familias estudiadas de los tres municipios se dá por dos vías: autoconsumo y compra.

- El 60\% de los alimentos producidos en las fincas son utilizados para la alimentación de las familias. No obstante, el $40 \%$ restante no se producen en las fincas. Este es el caso de productos como la azúcar, la panela, el café, el chocolate, la pasta, el arroz, los granos secos, el aceite y, ocasionalmente, algunas frutas y enlatados.

- La venta de los excedentes de sus cosechas y el dinero que reciben por actividades fuera de la finca, les proporcionan a las familias la posibilidad de adquirir productos faltantes de su dieta para su consumo, en los mercados locales.

\section{c) Estabilidad}

- En condiciones generales, la constante producción agrícola y pecuaria en los sistemas familiares aseguran el abastecimiento y el acceso a los alimentos que necesitan, esto relativamente contínuo, salvo en aquellas épocas en las cuales ocurren eventos bioclimáticos o comerciales inesperados. $\mathrm{O}$ casos o eventos esporádicos como paros o manifestaciones que restringen el transporte de productos complementarios para su dieta.

- Tanto la estabilidad como el acceso están directamente relacionados con las épocas de cosecha y los ciclos fisiológicos de los cultivos. Por ejemplo, el consumo de frutas como caducifolios están sujetos a la época de producción y cosecha en la zona, la cual ocurre dos veces al año. Lo mismo 
pasa con ciertas especies como las ibias, cuyo ciclo de cultivo puede durar hasta siete meses.

\section{d) Utilización biológica}

- Almacenamiento: en la mayoría de las fincas los alimentos son almacenados en despensas, para ello se usa bolsas de polietileno o de plástico, sacos de fique, cajas de cartón o canastillas plásticas. Estas son ubicadas en los zarzos (si la casa tiene alguno) o en algún sitio de la cocina. Estas prácticas aceleran el deterioro de los alimentos, por lo tanto, los alimentos deben consumirse rápido, venderse, intercambiarse por otros alimentos o utilizarlos como alimento para los animales de cría.

- Procesamiento y preparación de los alimentos: como todas las fincas cuentan con servicio de acueducto veredal, sus alimentos son lavados y procesados en las cocinas. La mayoría de los alimentos, con excepción de las frutas y algunas hortalizas, suelen consumirse cocidos, por lo tanto, se disminuye el riesgo de contraer enfermedades debido a la descomposición de los alimentos. Para su preparación se utiliza tanto estufas con leña, como estufas que requieren gas propano para su funcionamiento.

\subsubsection{Soberanía alimentaria}

Se resumen algunos aspectos de la soberanía alimentaria en la zona de estudio, para ello se utiliza seis de las variables sugeridas por Binimelis et al., (2013).

a) Diversidad histórica productiva en el ámbito regional. En los últimos 50 años la producción de alimentos ha estado restringida tanto a las condiciones del mercado como a las preferencias de los agricultores a la hora de consumir alimentos. Con lo anterior, fue posible establecer una variedad importante de alimentos que las familias cultivan, cerca de 80 especies en promedio, entre ellas especies nativas que retornaron con fuerza a las huertas familiares en el proceso de reconversión hacia la agroecología.

b) Alimentación sana, equilibrada y culturalmente adecuada. Este aspecto se evidencia en el consumo de productos originados en su propia finca, que provienen en su mayoría de las huertas agroecológicas. El acceso y disponibilidad de frutas, grasas, proteina animal, entre otros grupos alimentarios, dan la pauta para pensar que las familias agricultoras podrían aproximarse a una alimentación saludable, aunque el consumo de carbohidratos, en 
mayor proporción, deja un precedente y un llamado de atención, porque es el principal grupo alimenticio en sus preparaciones. Gran parte de las especies cultivadas y consumidas son locales y elaboradas de acuerdo con las tradiciones propias de la cultura gastronómica boyacense como amasijos (arepas, almojábanas y garullas); sopas (cuchucos, mazamorras y cremas); sudados y guisos; piquetes; cocidos; entre otroas preparaciones.

c) Circuitos cortos y de proximidad. Si bien los alimentos producidos en las fincas descritas son en principio para el autoconsumo, también suelen ser intercambiados entre familias y vecinos mediante los trueques o, simplemente, son un regalo que se otorga como gesto de amabilidad. Los excedentes de la producción se ofertan en los mercados locales el mismo día que se cosechan, generalmente los días de feria y en ocasiones por encargo de algún restaurante o de consumidores que ya tiene identificados estos productos por la calidad en su producción.

d) Educación para la soberanía alimentaria. Los agricultores de los tres municipios han recibido capacitaciones para el establecimiento de huertas caseras agroecológicas, alimentación saludable, conservación y uso de especies nativas y prácticas culinarias.

e) Medio rural vivo y productivo. La principal ocupación de las familias campesinas está en el sector primario, en la produción de alimentos frescos y diversos, a la vez que coexisten con los espacios naturales como bosques nativos, cercas vivas y árboles dispersos. Aún no han llevado a cabo procesos de transformación ni agregación de valor a sus productos, tarea que muchos de ellos consideran una meta a mediano plazo.

f) Minimización de residuos. El manejo que se le da a los residuos de las fincas, por general, es el mismo en los tres municipios. En las 25 fincas se separan los residuos entre orgánicos e inorgánicos. En el caso de los residuos orgánicos estos se utilizan para el compostaje de los cultivos y en las fincas que tienen ganado ovino, vacuno y equino los residuos de los alimentos se los dan para el consumo de este.

\section{Conclusiones}

Esta investigación evidencia la contribución de la agricultura familiar con enfoque agroecológico a la seguridad y soberanía alimentaria de los casos estudiados. Puesto que la producción diversificada de sus pequeños predios actualmente garantiza, en su mayoría, elementos de acceso, disponibilidad, estabilidad y utilización biológica 
de alimentos diversos, frescos y culturalmente apropiados, a través de prácticas agroecológicas que recogen el conocimiento local de sus antepasados, como una estrategia clara de subsistencia frente a un panorama económico nacional y global adverso.

Lo anterior, les ha permitido adoptar a lo largo del tiempo modalidades de uso, posesión y control de sus sistemas agroalimentarios hasta el punto de recobrar además de especies nativas, ya olvidadas, insumos orgánicos y prácticas de intercambio no monetario como trueques, donaciones y regalos, que actualmente ayudan a solventar la alimentación de sus vecinos y familiares. De igual manera, el abastecer directamente a los mercados locales, fomenta circuitos cortos de comercialización en la zona, con esto se promueve el fortalecimiento de las relaciones de confianza entre familias y vecinos de productores y comercializadores.

Tanto la trayectoria productiva como la caracterización de los sistemas de producción otorgan evidencias que los sistemas de agricultura familiar son dinámicos, complejos y adaptativos, al punto de generar estrategias que fomentan su persistencia a través del tiempo, mediante la toma de decisiones coyunturales, como lo es la transición hacia la agroecología.

\section{Agradecimientos}

A las familias campesinas de los municipios de Turmequé, Ventaquemada y Tibasosa en el departamento de Boyacá, quienes de forma muy comprometida y voluntaria accedieron participar en este ejercicio de investigación. A los miembros de la Confederación Agrosolidaria y la Fundación Semillas en Tibasosa; a la Asociación Innovadora de Tubérculos Andinos de Boyacá (AITAB) y ASOAgroTURMEQUe en Turmequé y a la Junta de Acción Comunal de la Vereda Supatá en Ventaquemada. A la Pontificia Universidad Javeriana por financiar este trabajo de investigación a través de la convocatoria interna Laudato si.

\section{Referencias}

Alonso, A., y Sevilla, E. (1995). El discurso ecotecnocrático de la sostenibilidad. En A. Cadenas (ed.), Agricultura y Desarrollo Sostenible (pp. 91-119). Madrid: Ministerio de Agricultura, Pesca y Alimentación.

Altieri, M., y Nichols, C. (2007). Biodiversidad y manejo de plagas en agroecosistemas. (trad. Miguel Altieri). Barcelona: Editorial ICARIA. Recuperado de https:// www.socla.co/wp-content/uploads/2014/BiodiversidadAltieriNicholls .pdf Altieri, M., y Toledo, V. (2011). La revolución agroecológica en América Latina-rescatar la naturaleza, asegurar la soberanía alimentaria y empoderar a los campesinos. 
The Journal of Peasant Studies, 38(3), 587-612. Recuperado de https://www.ucm. es/data/cont/media/www/pag-104576/3.\%20La\%20revoluci \%C3\%B3n\%20 agroecol\%C3\%B3gica\%20en\%20Latinoam\%C3\%A9rica\%20(M\%20iguel\%20 Altieri\%20y\%20Victor\%20Toledo).pdf

Benzing, A. (2001). Agricultura orgánica. Fundamentos para la región andina. Alemania: Neckar-Verlag, Villingen Schwenningen.

Binimelis, R., Tendero, G., Vadal, M., Heras, M., Gamboa, G., Ortega, M., y RiveraFerre, M. (2013). La necesidad de indicadores para construir la soberanía alimentaria. En M. Cuellar, A. Calle y D. Gallar (eds.), Procesos hacia la soberania alimentaria. Perspectivas y prácticas desde la agroecología politica (pp. 153-166). Barcelona: Icaria Editorial.

Blanco, D. (2012). Influencia del enfoque agroecológico en el trabajo comunitario de Agrosolidaria en Tibasosa, Boyacá (trabajo de grado). Recuperado de https:// repository.javeriana.edu.co /bitstream/handle/10554/12455/BlancoBetancourtDianaMarcela2012.pdf ? sequence $=1$ \&isAllowed $=y$

Cadavid, I. (2012). Conservación de agrobiodiversidad por familias campesinas de los andes colombianos: estudio de caso en los municipios de Ventaquemada y Turmequé, departamento de Boyacá (trabajo de grado).

Clavijo, N., Barón, M. y Combariza, J. (2015). Tubérculos andinos. Conservación y uso desde una perspectiva agroecológica. Bogotá: Editorial Pontificia Universidad Javeriana.

Chaparro, A. (2014). Sostenibilidad de la agricultura campesina. Cómo evaluarla y cómo promoverla (2. ${ }^{\text {a }}$ ed.). Bogotá: Ediciones de la U.

Cuellar, M., Calle, A., y Gallar, D. (2013). Procesos hacia la soberanía alimentaria. Perspectivas y prácticas desde la agroecología politica. Barcelona: Icaria editorial s.A.

Departamento Nacional de Planeación-DNP. (2007). Documento Conpes Social 113. Política Nacional de Seguridad Alimentaria y Nutricional (PSAN). Recuperado dehttps://www.minsalud.gov.co/Documentos\%20y\%20Publicaciones/POL\% C3\%8DTICA\%20NACIONAL\%20DE\%20SEGURIDAD\%20ALIMENTARIA\%20 Y\%20NUTRICIONAL.pdf

Fajardo, D. (2009). Territorios de la agricultura colombiana. Bogotá: Universidad Externado de Colombia.

Fajardo, D. (2014). Las guerras de la agricultura colombiana 1980-2010. Bogotá: ILSA. FAO, FIDA, OMS, PMA y UNICEF. (2017). El estado de la seguridad alimentaria y la nutrición en el mundo 2017. Fomentando la resiliencia en aras de la paz y la seguridad alimentaria. Roma: FAO. Recuperado de http://www.fao.org/3/a-I7695s.pdf 
Forero, J. (1999). Economía y sociedad rural en los Andes colombianos. Bogotá: Editorial Pontificia Universidad Javeriana,

Gliessman, S. (2002). Agroecología: procesos ecológicos en agricultura sostenible. Costa Rica: Turrialba. Recuperado de https://biowit.files.wordpress.com /2010/11/ agroecologia-procesos-ecolc3b3gicos-en-agricultura-sostenible-stephen-rgliessman.pdf

Guzmán, G., y Morales, J. (2012). Agroecología y agricultura ecológica. Aportes y sinergias para incrementar la sustentabilidad agraria. Agroecología 6: 55-62. Recuperado de https://revistas.um.es/agroecologia/article/view/160671

León, T. (2007). Medio ambiente, tecnologia y modelos de agricultura en Colombia. Hombre y arcilla. Bogotá: Ecoe Ediciones y Universidad Nacional de Colombia. León-Sicard, T. (2014). La perspectiva ambiental agroecología: la ciencia de los agroecosistemas. Series IDEAs 23. Bogotá: Instituto de Estudios Ambientales -IDEA, Universidad Nacional de Colombia.

López, D. (2012). Hacia un modelo europeo de extensión rural agroecológica. Praxis participativas para la transición agroecológica. Un estudio de caso en Morata de Tajuñ, Madrid (tesis doctoral, Universidad Internacional de Andalucía, Baeza, España). Recuperado de http://hdl.handle.net/10334/1949

Machado, A. (1998). La cuestión agraria en Colombia a fines del milenio. Bogotá: El Ancora Editores.

Ministerio de Salud y Protección Social. (2015). Encuesta Nacional de Situación Nutricional (ENSIN). Recuperado de https://www.minsalud.gov.co/salud/ publica/ epidemiologia/Paginas/encuesta-nacional-de-situacion-nutricional-ensin.aspx Morales, J. (coord.). (2011). La agroecología en la construcción de alternativas hacia la sustentabilidad rural. México D.F.: Instituo Tecnológico de estudios Superiores de Occidente y Siglo xxi Editores.

Morales, J. (2013). Las agriculturas sustentables y los pasos hacia la soberanía alimentaria: Una experiencia en Jalisco, México. En M. Cuellar, A. Calle y D. Gallar (eds.), Procesos hacia la soberania alimentaria. Perspectivas y prácticas desde la agroecología politica (pp. 103-125). Barcelona: Icaria editorial s.A.

Naredo, J. (2006). Raíces económicas del deterioro ecológico y social: más allá de los dogmas. Siglo XXI de España Editores.

Pengue, W. (2005). Agricultura industrial y transnacionalización en América Latina. ¿La transgénesis de un continente? México: ONU, GEPEMA, PNUMA.

Raymond, P. (1990). El lago de Tota ahogado en cebolla: estudio socioeconómico de la cuenca cebollera del Lago de Tota. Bogotá: Pontificia Universidad Javeriana. 
Roberts, P. (2009). El hambre que viene: la crisis alimentaria y sus consecuencias. (Trad, Gotzone Pérez). Barcelona: Ediciones B.

Saavedra, D. (2010). Análisis de la dinámica de adopción de las prácticas convencionales deprevención y control fitosanitario del cultivo de cebolla cabezona (Allium cepa l.). Estudio de caso con pequeños agricultores del municipio de Tibasosa en el departamento de Boyacá (tesis de maestría). Recuperado de https://repository.javeriana. edu.co/bitstream/handle/10554/663/eam26.pdf ?sequence=1\&isAllowed=y

Salcedo, L., Pinzón, R., y Duarte, D. (2013). El paro nacional agrario: un análisis de los actores agrarios y los procesos organizativos del campesinado colombiano Recuperado de https://www.javerianacali.edu.co/sites/ujc/files/node/fielddocuments/field_document_file/el_paro_nacional_agrario-_un_analisis_de_l os_actores_agrarios_y_los_procesos_organizativos_del_campesinado_colombiano._centro_de_estudios_interculturales._pdf

Sevilla, E. (2006). Agroecología y agricultura ecológica: hacia una "re"construcción de la soberania alimentaria. Agroecología, 1, 7-18. Recuperado de https://helvia.uco. es/handle/10396/2221

Vía Campesina. (2007). Declaración de Nyéléni. Recuperado de https://nyeleni.org / IMG/pdf/DeclNyeleni-es.pdf 


\title{
Capítulo 3
}

\section{Conservación de suelos por agricultores campesinos en la cuenca del rio Las Ceibas, Neiva, Huila}

\author{
Soil conservation by peasant farmers in Las Ceibas river basin, \\ Neiva, Huila
}

\author{
Juvenal Ruiz Pérez* \\ Vladymeer León Cuellar**
}

\section{Cómo citar}

\begin{abstract}
APA
Ruiz, J., y León, V. (2019). Conservación de suelos por agricultores campesinos en la cuenca del rio Las Ceibas, Neiva, Huila. En Á. Acevedo-Osorio y N. Jiménez-Reinales (comps.). En La agroecología. Experiencias comunitarias para la Agricultura Familiar en Colombia. (pp. 59-82). Bogotá: Corporación Universitaria Minuto de Dios-UNIMINUTO, Editorial Universidad del Rosario.
\end{abstract}

\section{Chicago}

Ruiz Pérez, Juvenal y León Cuellar, Vladymeer. "Conservación de suelos por agricultores campesinos en la cuenca del rio Las Ceibas, Neiva, Huila”. En La agroecología. Experiencias comunitarias para la Agricultura Familiar en Colombia, comps. Álvaro Acevedo-Osorio y Nathaly Jiménez-Reinales. Bogotá: Corporación Universitaria Minuto de Dios-UNIMINUTO, Editorial Universidad del Rosario, 2019.

* Corporación Autónoma Regional del Alto Magdalena (CAM) juvenalruizperez@gmail.com

** Fundación Universitaria Navarra. vladymeer.leon@uninavarra.edu.co 


\section{MLA}

Ruiz Pérez, Juvenal y León Cuellar, Vladymeer. "Conservación de suelos por agricultores campesinos en la cuenca del rio Las Ceibas, Neiva, Huila". En La agroecología. Experiencias comunitarias para la Agricultura Familiar en Colombia. En Á. Acevedo-Osorio y N., JiménezReinales (comps.) Bogotá: Corporación Universitaria Minuto de Dios-UNIMINUTO, Editorial Universidad del Rosario, 2019, pp. 59-82.

\section{Resumen}

La conservación de los suelos está pasando de ser una iniciativa meramente técnica a un accionar urgente de importancia mundial mediante el diseño y la aplicación de instrumentos políticos, para responder al crecimiento exponencial de la demanda de alimentos cada año. El presente capítulo describe como la Asociación de Productores de Cacao Ecológico de la cuenca del río Las Ceibas (ASPROCAECO), en el marco de la implementación del Plan de Ordenación y Manejo de la Cuenca Hidrográfica (POMCA) del río Las Ceibas, adopta una propuesta de producción sostenible de alimentos a partir del desarrollo de sistemas agrícolas con mínima afectación al suelo y promoción del uso racional del agua, con el acompañamiento de la Corporación Autónoma Regional del Alto Magdalena (CAM). El objetivo del estudio fue reconocer el desarrollo de las prácticas de conservación de suelos y su implicación en la dimensión económica, productiva, política, financiera, social e institucional, al diagnósticar las características de los huertos mixtos de frutales de ASPROCAECO como estrategia que contribuye a la seguridad alimentaria de sus familias. El estudio se desarrolló como investigación semi cuantitativa empleando instrumentos como la observación participante en campo, revisión de documentos institucionales y de la asociación, entrevistas semiestructuradas dirigidas a integrantes de la asociación y actores institucionales. Los resultados obtenidos reconocen la importancia, en la economía familiar agropecuaria y en los alcances de un POMCA, de los "huertos mixtos de frutales para la seguridad alimentaria y acciones en pro de la conservación de suelos a nivel predial y de cuenca", a partir del empleo de tecnologías apropiadas que evitan el deterioro del suelo, manteniendo su capacidad productiva y calidad del mismo, para el uso en actividades diversas a nivel productivo, asimismo, para el acceso y oferta hídrica y edáfica de forma permanente.

Palabras clave: Conservación de suelos, fortalecimiento organizativo, plan de ordenación y manejo de cuencas hidrográficas, producción agropecuaria sostenible, seguridad alimentaria.

\section{Abstract}

Taking into account the exponential growth of the demand for food every year, soil conservation is changing from a purely technical initiative to an urgent action of global importance through the design and application of political instruments. This chapter describes how the Association of Organic Cacao Producers of the Las Ceibas river basin (ASPROCAECO), in the framework of the implementation of the Plan for the Ordination and Management of the Hydrographic Basin (POMCA) of the Las Ceibas River, adopts a proposal of sustainable food production from the development of agricultural systems with minimal impact on the 
soil and promotion of the rational use of water, with the support of the Regional Autonomous Corporation of the Alto Magdalena (CAM). The objective of the study was to recognize the development of soil conservation practices and their implication in the economic, productive, political, financial, social and institutional dimensions, when diagnosing the characteristics of the mixed fruit orchards of ASPROCAECO as a strategy that contributes to the food security of their families. The study was developed as semi-quantitative research using instruments such as participant observation in the field, review of institutional documents and the association, semi-structured interviews aimed at members of the association and institutional actors. The results obtained recognize the importance, in the farming family economy and in the scope of a POMCA, of the "mixed orchards of fruit trees for food security and actions in favor of soil conservation at the farm and basin level", starting of the use of appropriate technologies that prevent the deterioration of the soil, maintaining its productive capacity and its quality, for use in diverse activities at a productive level, also, for access and water supply and soil permanently.

Keywords: Soil conservation, organizational development, river basin ordination and management plan, sustainable agricultural production, food security.

\section{Introducción}

Los suelos cumplen con funciones vitales para el mantenimiento de los ecosistemas y el sostén de la vida humana, igualmente, realiza el papel de ser el soporte y sustento para los cultivos y vegetación natural, ayuda a la infiltración y retención de agua, la captura de carbono y es el apoyo a la vida de los microorganismos, entre otros aspectos. Sin embargo, estas funciones son poco reconocidas por la sociedad, lo que ha derivado en su descuido, abandono y consecuente deterioro (Cotler et al., 2007). La relevancia dada por el hombre al agua y al bosque ha generado un inequitativo balance sin percatarse del acelerado deterioro del suelo, principalmente, por la erosión en zonas de ladera, situación adversa a la demanda de alimentos y la regulación hídrica. Los cambios en las propiedades del suelo, provocados por la erosión, producen alteraciones en el nivel de fertilidad del suelo y, consecuentemente, en su capacidad de sostener una agricultura productiva (do Prado y da Veiga, 1994).

Casi todas las zonas altas tropicales sufren degradación del suelo, especialmente, de erosión hídrica, entre media y muy alta. Estudios han demostrado que la gestión del suelo se ha convertido en una parte inherente del sistema de cultivo en montañas tropicales, además que es posible revertir la degradación ambiental de estas áreas, a través de una política activa de conservación de suelos y agua, pero el eje de esta debe ser el agricultor, que a largo plazo, puede proporcionar servicios ecosistémicos a la sociedad (Nyssen, Poesen y Deckers, 2009). 
La formulación y aplicación de un enfoque integrado de la conservación del suelo y el agua puede reportar enormes beneficios, cuando es entendido a nivel de microcuenca y se formulan políticas y programas agrícolas adecuados (Benites, 2004).

De ahí, la necesidad de recuperar y proteger con tecnologías apropiadas el suelo y el agua, como lo propone la Asociación de Productores de Cacao Ecológico de la cuenca del río Las Ceibas (ASPROCAECO), para la producción de alimentos en el marco del Plan de Ordenamiento y Manejo de la cuenca abastecedora del acueducto de Neiva: el río Las Ceibas.

Para la consecución y sistematización de la información de esta experiencia, se realizaron entrevistas a cada familia de la asociación, con un formato semiestructurado para hacer la caracterización predial y reconocer el sistema productivo en su integralidad, también para resaltar aspectos relacionados con prácticas de conservación de suelos que se vienen apropiando, así como los impactos a nivel productivo, social, ambiental y económico generados por dichas prácticas. Asimismo, se hicieron visitas a las parcelas de conservación de suelos, aprovechando las giras académicas de varias universidades que iban a conocer la experiencia. Igualmente, se estructuraron entrevistas dirigidas a actores institucionales de manera personalizada.

\section{El suelo y la agricultura}

\subsection{El suelo y sus procesos degradativos}

El suelo es un bien natural finito y componente fundamental del ambiente, constituido por minerales, aire, agua, materia orgánica, macro y microorganismos que desempeñan procesos permanentes de tipo biótico y abiótico, cumpliendo funciones y prestando servicios ecosistémicos vitales para la sociedad y el planeta (Ministerio de Ambiente y Desarrollo Sostenible, 2016, p. 17). Asimismo, "es una parte esencial del paisaje y el escenario de las actividades y de la supervivencia humana, así como de las relaciones sociales". Igualmente, el suelo "es un medio multifuncional que constituye la base del $90 \%$ de los alimentos humanos, el forraje, la fibra y los combustibles, y ofrece otros servicios que van más allá de aquellos asociados a la producción" (Brissio, 2005, como se citó en Ministerio de Ambiente y Desarrollo Sostenible, 2016).

En términos generales y según Organización de las Naciones Unidas para la Alimentación y la Agricultura (FAO por sus siglas en inglés), la degradación del suelo provoca alteraciones en su fertilidad y consecuentemente en su capacidad de sostener 
una agricultura productiva (FAO, 1994). Gran parte de la degradación de los suelos es ocasionada por la erosión (aunque existen otros procesos degradativos como la salinización, sodización, compactación, sellamiento y remoción masal) ligada a factores geológicos, geomorfológicos, antrópicos, hídricos o eólicos. Las partículas son desprendidas y arrastradas por agua de escorrentía que posteriormente sedimentan en áreas bajas y depresionales o son conducidas al mar (Núñez, 2001).

La reducción de la productividad, debido a la erosión del suelo, se presenta por la disminución de los contenidos de materia orgánica y de nutrientes, degradación de la estructura del suelo con la consecuente disminución de la capacidad de retención de agua (do Prado y da Veiga, 1994), a la vez, que se presenta pérdida de la capacidad de mitigación del cambio climático por la disminución considerable de captura de carbono (Ministerio de Ambiente y Desarrollo Sostenible, 2016, p. 46, como se citó en FAO, 2007).

Una práctica aún arraigada en la cuenca alta del río Magdalena, que hace parte de la preparación de suelos, es la quema agrícola, esta provoca efectos negativos en los suelos de similares características, además con el tiempo y en los continentes, estos efectos se relacionan a continuación: el aumento de la escorrentía e inundaciones, mayor pérdida de suelo por erosión, reducción de la materia orgánica, pérdida de nutrientes y aumento del $\mathrm{pH}$ dado que aportan bases intercambiables de elementos (Ca, Mg, K, Na) (Granjed, 2011).

Existe el concepto de pérdidas tolerables de suelo, este estima la máxima cantidad de suelo que se puede perder por erosión sin sufrir degradación excesiva, a pesar de que se explote agrícolamente de forma continua; sin embargo, los niveles aceptables o límites tolerables de erosión están en función del proceso de formación de suelos, para una región específica (Núñez, 2001). Cuando los descriptores se encuentran entre erosión baja a alta, los grados de erosión natural no deben exceder 1 tonelada por hectárea y año y mantenerse entre valores de 1 a 10 toneladas por hectárea año, según Gómez, 1.982 como se citó en Núñez, 2001).

De otro lado, las tierras montañosas juegan un papel clave en los sistemas económicos y ambientales de muchos países tropicales. En América Latina y el Caribe estas ocupan más del 25\% del área total de tierra, y en Colombia representan el 27\% de la extensión del país (30 millones de hectáreas) (Obando, 2012). Desde la perspectiva de la clasificación de tierras por capacidad de uso, los suelos que tiene una pendiente se han considerado como un limitante para la producción agropecuaria por los riesgos de degradación que suponen las tierras con pendientes mayores al $12 \%$, las cuales se consideran tierras no mecanizables, entre el $13 \%$ y $60 \%$ con uso 
restrictivo y mayor al 60\% se recomiendan para vegetación natural y prácticas de restauración vegetal (Shaxon, 1999 como se citó en Obando, 2012).

Las cifras sobre erosión, se muestran en crecimiento alarmante. La investigadora Claudia Mendoza (2011) indica que

La erosión del suelo es una forma severa de degradación física, se estima que cerca del $80 \%$ de la tierra agrícola en el mundo sufre erosión moderada a severa y el 10\% erosión ligera a moderada (Lal y Stewart, 1995). El 40\% del territorio colombiano presenta erosión de ligera a severa y la zona andina es la más afectada, con el 88\% del área en estado de erosión hídrica. (Olmos y Montenegro, 1987, p. 81).

En este mismo sentido, es importante señalar los resultados obtenidos en el estudio de la línea base (2010-2011), hecho por el IDEAM y el Ministerio del ambiente en 2014, para el monitoreo y seguimiento de la degradación de los suelos por erosión en territorio continental a escala 1:100.000, el 42\% del territorio continental nacional presenta algún grado de degradación de suelos distribuido de la siguiente manera: con predominio de erosión ligera del 20\%; erosión moderada el $16,8 \%$; entre severa y muy severa el $2.9 \%$ del territorio continental y el $2.3 \%$ corresponde a otras coberturas terrestres distintas al suelo (zonas urbanas, afloramientos rocosos, cuerpos de agua, etc.) (Ministerio de Ambiente y Desarrollo Sostenible, 2016, p. 44).

En la mayoría de los casos, la erosión es muy variable en el tiempo y ocurre mayormente durante eventos extraordinarios de precipitación de corta duración y alta intensidad, cuando el suelo no está protegido por una cobertura vegetal o la pendiente del terreno es fuerte (según Larson y Col, 1983 como se citó en Pla Sentis, 2006).

\subsection{Manejo y conservación de suelos}

Para enfrentar la degradación de suelos de manera efectiva se debe incentivar el uso de prácticas de conservación sencillas, de bajo costo y que puedan mejorar la productividad de la tierra. Los puntos principales de dicha estrategia son: el mejoramiento del uso de la tierra, la concentración de la producción en menor área y aumento de la productividad, el aumento de la cobertura vegetal, el aumento de la infiltración de agua, el control de la escorrentía, la reducción de la pendiente 
y la participación de los agricultores en todo el proceso de la planificación de la conservación de suelos (FAO, 1994).

Del mismo modo, Roose considera que "el mantenimiento de la productividad del suelo para lograr una producción agrícola sostenida y un uso más eficiente del agua requiere de prácticas de conservación, siendo las agronómicas las de más fácil aceptación por los productores" (Roose como se citó en Andrade y Rodríguez, 2002, p. 123).

Es así que, la vegetación puede actuar como una barrera protectora entre el suelo y los elementos naturales que estimulan la erosión o el movimiento de masas. Las plantas exhiben muchas formas y estructuras diferentes, pero, en general, los elementos que pueden ser útiles en soluciones ecotecnológicas para la estabilidad de la pendiente son: Raíces, para proporcionar anclaje y absorber agua y nutrientes del suelo, para soportar las partes anteriores y capturar el suelo erosionado y; Hojas, para interceptar la precipitación e iniciar la evapotranspiración que conduce a la disminución de los niveles de humedad del suelo (Stokes et al., 2008).

Entre las prácticas de conservación de suelos se pueden mencionar: barreras vivas, abonos verdes y cultivos de cobertura, cobertura muerta y los sistemas agroforestales, entre otros; las cuales son de fácil adaptación y adopción en los sistemas agropecuarios campesinos que se distinguen por tener fuertes pendientes; suelos con fertilidad media; limitado acceso a agua de riego, pero disponibilidad permanente de mano de obra, estos sistemas caracterizan, en buena medida, la agricultura que se realiza en los Andes colombianos.

\section{Resultados y discusión}

\subsection{La Asociación ASPROCAECO}

La Asociación de Productores de Cacao Ecológico de la cuenca del río Las Ceibas (ASPROCAECO) se conformó por iniciativa de una Escuela de Campo para Agricultores (ECA) para el rejuvenecimiento de las labranzas de cacao, liderada por el equipo del Plan de Ordenamiento y Manejo de la Cuenca Hidrográfica del río Las Ceibas, coordinado por la Organización de Naciones Unidas para la Alimentación y Agricultura (FAO), mediante el desarrollo de mingas en las que se ponían en práctica los aprendizajes avanzandos en cada una de las fincas de los cacaoteros de la cuenca. 
En marzo del 2010, obtienen la personería jurídica con el propósito de mejorar la calidad de vida de los asociados, asimismo, a propender por la protección y conservación del medio ambiente, fomentar y fortalecer el bienestar comunitario a través de la ejecución de proyectos ambientales, productivos y de comercialización de productos agroecológicos. En la actualidad cuenta con 26 socios activos.

La asociación ASPROCAECO tiene dentro de sus propósitos de mediano y largo plazo seguir incursionando en mercados justos y socialmente aceptados y reconocidos, además, de incentivar y planear el agroturismo, establecer la tienda del cacao y de otros productos del campo, tanto en la zona rural como en la capital del Huila.

Los integrantes de ASPROcaeco habitan en la cuenca del río Las Ceibas, se localiza al oriente de la cabecera municipal de Neiva, departamento del Huila, sobre la vertiente occidental de la cordillera oriental (figura 1), delimitada por accidentes geográficos muy definidos, en especial las altas montañas que hacen colindar al municipio con el departamento del Caquetá al oriente y al occidente la desembocadura del río Magdalena, en un área aproximada de 31128 ha, que

Figura 1. Mapa de ubicación de ASPROcaEco en la cuenca del río Las Ceibas, Neiva, Huila.
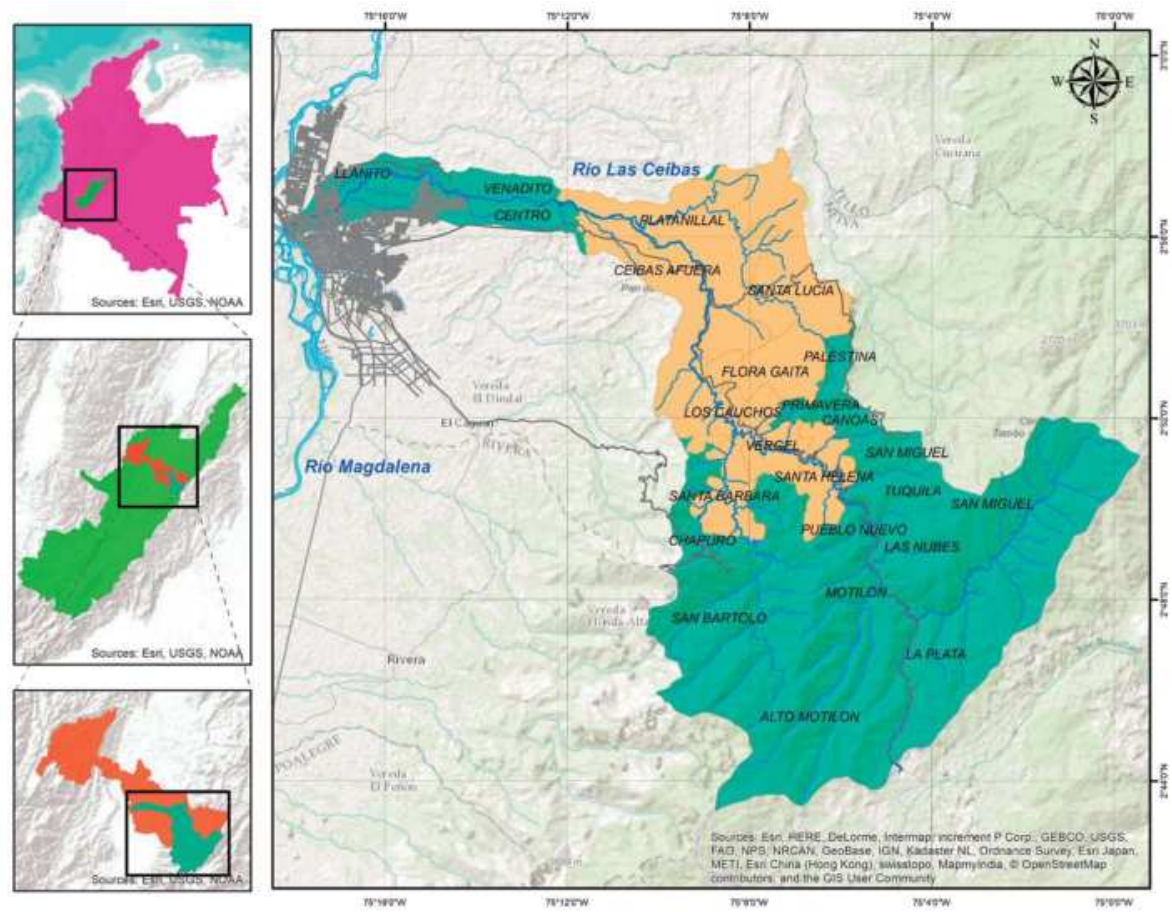

Fuente: elaboración propia. 
representa el 18.3\% del municipio de Neiva (Corporación Autónoma Regional del Alto Magdalena, 2006).

El río Las Ceibas es la única fuente hídrica de donde se abastece el acueducto de la ciudad de Neiva, su cauce principal nace en el cerro Santa Rosalía y desemboca en el río Magdalena después de un recorrido de $63 \mathrm{~km}$. La cuenca alcanza una altura máxima de 3150 m s. n. m. en los ecosistemas estratégicos Santa Rosalía (costado nororiental de la cuenca) y La Siberia y la cota más baja está a una altura de $430 \mathrm{~m} \mathrm{s.} \mathrm{n.} \mathrm{m.} \mathrm{en} \mathrm{la}$ desembocadura sobre el río Magdalena, al terminar su paso por la zona urbana de la ciudad de Neiva (Corporación Autónoma Regional del Alto Magdalena, 2006).

\subsection{Caracterización de los sistemas productivos en ASPROCAECO}

De acuerdo a la caracterización de las tipologías de los predios de los agricultores de la cuenca del río Las Ceibas, los predios son de 16 ha en promedio; pueden o no tener un área en potreros. Aproximadamente, cuentan con 2 a 4 ha de cacao (Theobroma cacao), hasta 0.5 ha en caña (Saccharum officinarum), 0.5 ha de banano (Musa paradisiaca) o frutales, principalmente cítricos, y de yuca (Manihot sculenta) que están asociadas a las labranzas del cacao. Poseen hasta el 10\% del área de los predios en bosques, que se limitan a franjas altamente intervenidas y angostas en los bordes de las quebradas.

El propietario vive con su familia en la finca, su nivel académico no sobrepasa tercero de primaria en los adultos mayores y quinto de primaria en los mayores de 35 años. Hay un mínimo porcentaje de integrantes de la asociación que cuentan con formación técnica del sENA (Servicio Nacional de Aprendizaje) en conservación de los recursos naturales.

El cacao es establecido, por lo general, en las vegas del río Las Ceibas y sus afluentes, con gran ventaja por tener la posibilidad de aprovechar el nivel freático en época de verano. Sin embargo, con la implementación del POMCA del río Las Ceibas, se han estado instalando sistemas de riego, principalmente, por microtubo en terrenos con topografía quebrada.

Antes del POMCA, se acostumbraba a emplear la quema agrícola en la renovación de pasturas cada tres o cuatro años incluso para la siembra de cualquier cultivo; situación que aprovechaban algunos campesinos para sembrar fríjol arbustivo.

Frente a los impactos ambientales generados por esta tipología, que actualmente son mínimos, se está logrando el aumento en los rendimientos de los cultivos por el rejuvenecimiento de plantaciones, la siembra de cacao con sombrío, la promoción 
de la diversificación y, asimismo, la siembra tradicional de fríjol con quemas agrícolas ha disminuido con respecto a años anteriores; por estas razones, la reconversión de las fincas hacia un manejo sostenible se está dando de manera satisfactoria.

Las siembras de cacao en su mayoría están ubicadas en las riberas del río Las Ceibas y sus afluentes, esto contribuye a la protección de las rondas hídricas; no obstante, el tipo de riego más generalizado es por gravedad generando erosión en los terrenos más pendientes y provocando conflictos por el uso del agua en verano porque los primeros usuarios acaparan el poco caudal disponible y los usuarios de las partes bajas quedan sin agua disponible afectándose sus cultivos.

\subsection{Conservación de suelos por ASPROCAECO}

Con el fin de disminuir el aporte de sedimentos al río Las Ceibas y sus afluentes, además, de subsanar el manejo inadecuado de los suelos y mejorar las condiciones de seguridad alimentaria de los habitantes de la cuenca, fueron establecidos durante el primer semestre del 2015, en el seno de ASPROCAECO, cinco huertos mixtos de frutales, uno de ellos comunitario, en el que se integraron 20 de sus asociados (figura 2). Cada huerto consta de 0.25 ha, fueron diseñados con prácticas de conservación de suelos para que mejorarán las características físicas, químicas y biológicas de los suelos y, que por supuesto, contribuyeran a la diversificación del autoconsumo con frutas y cultivos de pancoger $^{1}$, cuyos excedentes se comercializan para la generación de ingresos adicionales.

Como prácticas de conservación de suelos utilizadas por la asociación se encuentran las barreras vivas de pasto vetiver (Chrysopogon zizanioides), el abono verde forestal como cámbulo (Erythrina poeppigiana) y el árbol matarratón (Gliricida sepium) que atraviesan el lote desde la parte alta hasta la parte baja del predio, con el fin de disminuir la velocidad del agua de escorrentía y promover el reciclaje de nutrientes con biomasa rica en nitrógeno (de los árboles leguminosos) mezclada con material lignificado (del vetiver) para mejorar el contenido de materia orgánica del suelo (figuras 3 y 4 ).

En los callejones del abono verde se sembraron frutales como papayo (Carica papaya), cítricos (Citrus spp) principalmente, y en algunos casos, se estableció guanábano (Annona muricata), aguacate (Persea americana), maracuyá (Passiflora edulis), banano (Musa paradisiaca) y yuca (Manihot esculenta). Mientras que se

\footnotetext{
${ }^{1}$ Los cultivos de pancoger corresponden a especies cultivas propias de cada región que hacen parte de la cultura alimentaria local y que se cultivan de manera escalonada para su permanente cosecha y consumo.
} 
Figura 2. Trazado de lote en curvas de nivel con apoyo del agronivel. Parcela comunitaria de ASPROCAECO, vereda Los Cauchos.

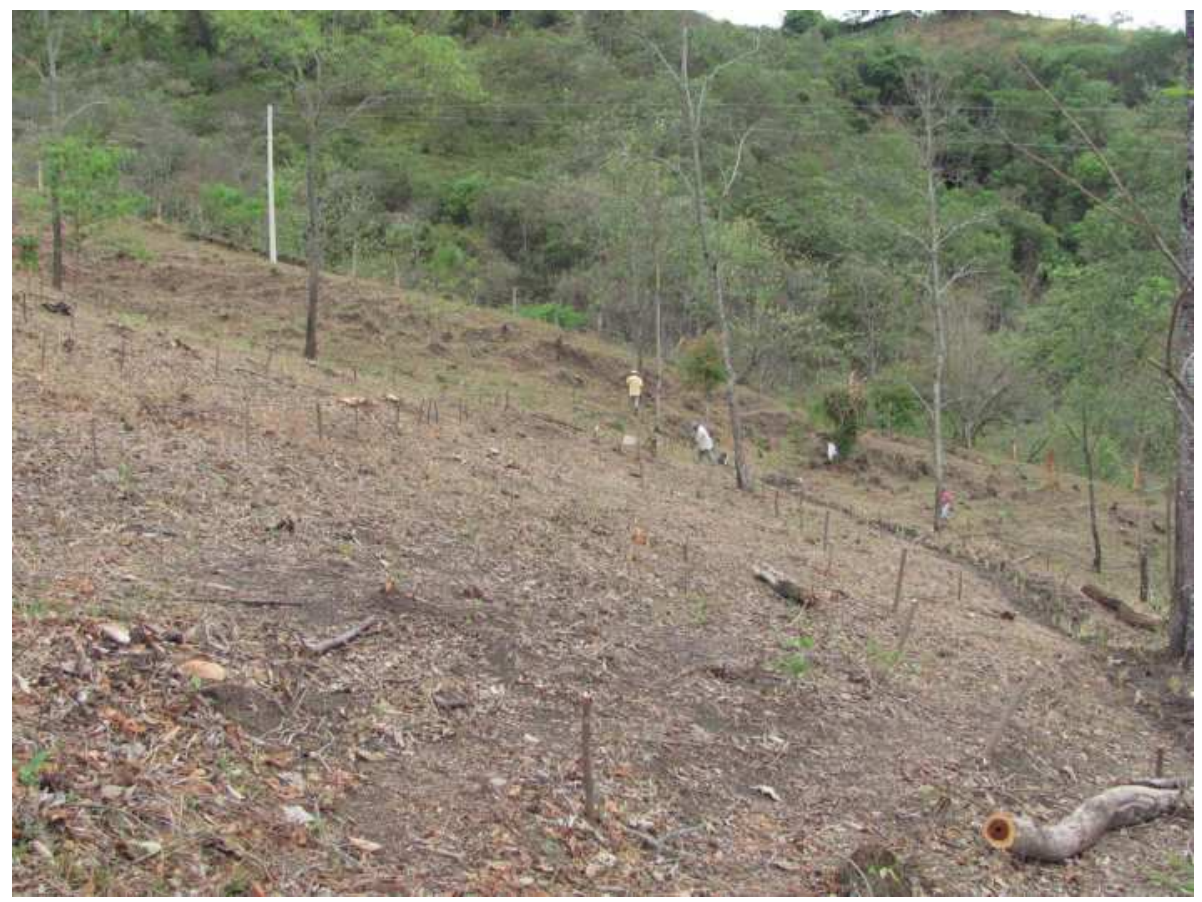

Fuente: Ruíz (2018).

Figura 3. Barreras vivas de vetiver (Chrysopogon zizanioides). Parcela comunitaria de ASPROCAECO, vereda Los Cauchos.

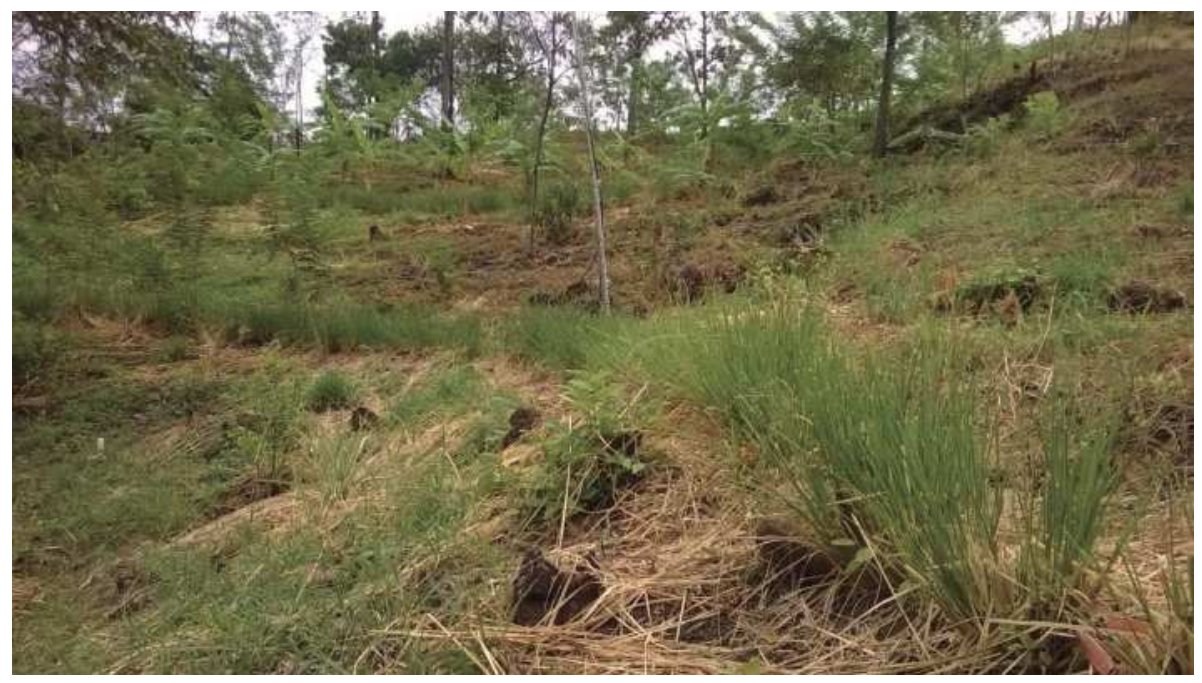

Fuente: Ruíz (2018). 
Figura 4. Aporte de abono verde de matarratón (Gliricida sepium) y vetiver (Chrysopogon zizanioides). Parcela comunitaria de ASPRocaEco, vereda Los Cauchos.

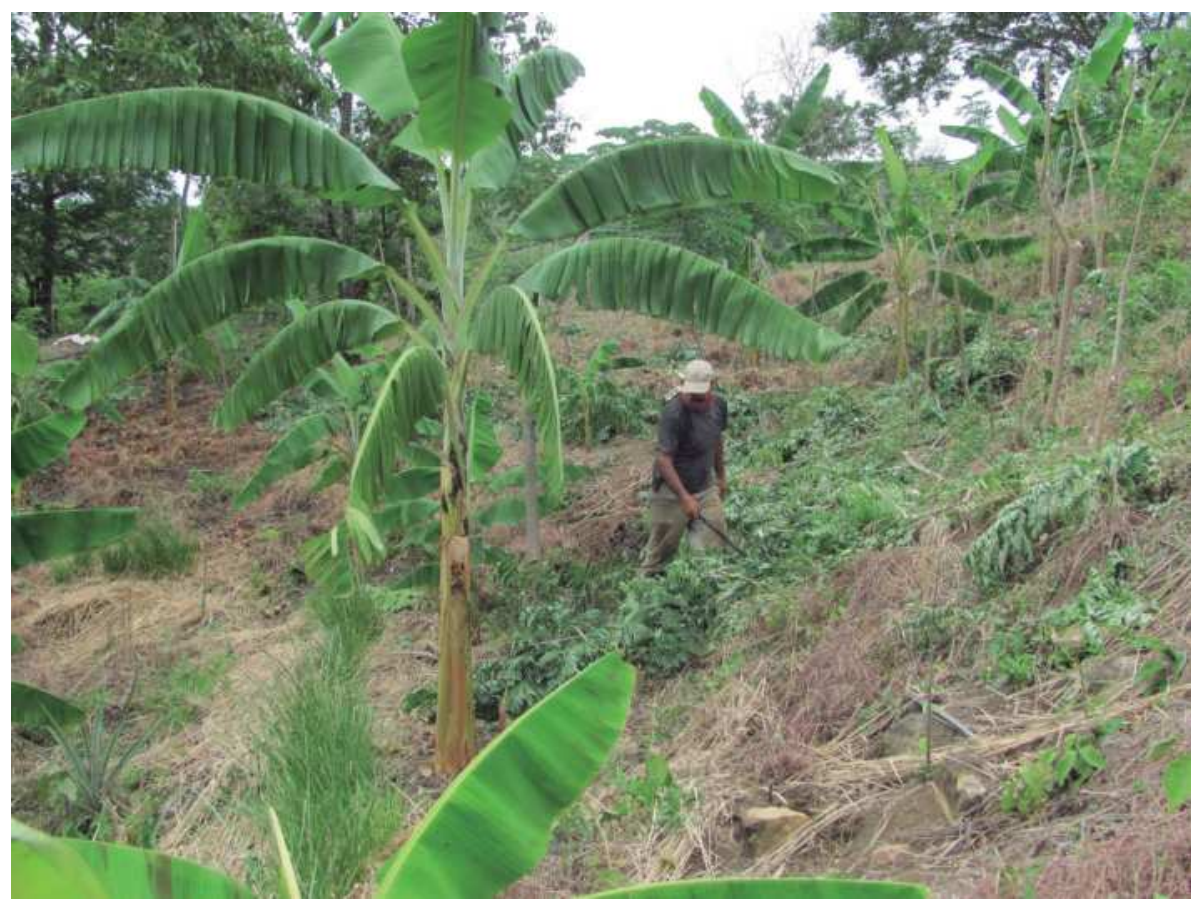

Fuente: Ruíz (2018).

desarrollan los frutales en los callejones, fue sembrado para autoconsumo frijol (Phaseolus vulgaris) y maíz (Zea mays) (figura 5 y 6). La cosecha de papaya y maracuyá en su momento fueron comercializadas en las mismas veredas y en el mercado campesino Mercalixto de Neiva. Los otros frutales como cítricos, guanábano y aguacate avanzan en su desarrollo.

Cada parcela cuenta con un diseño sencillo de riego por goteo para contribuir al uso eficiente del agua, a partir de la oferta limitada de este recurso en la región.

\subsection{Impacto de la conservación de suelos y agua en los sistemas productivos}

La adopción de prácticas de conservación de suelos en parcelas de seguridad alimentaria generó cambios en los sistemas productivos de ASPROCAECO que serán explicados a través de los atributos de las diferentes dimensiones de la sustentabilidad. 
Figura 5. Distribución espacial de los componentes en parcela de conservación de suelos.

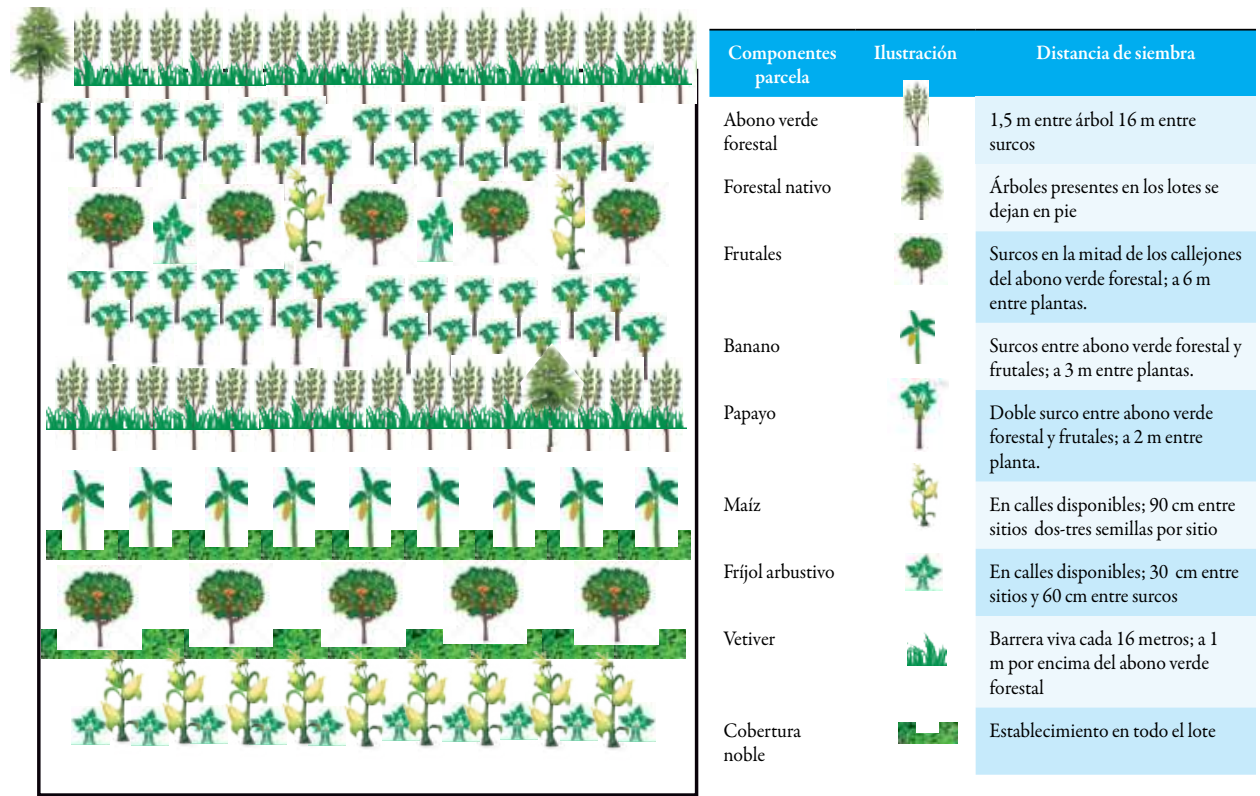

Fuente: Ruíz (2018).

Figura 6. Callejón sembrado con maíz (Zea mays), fríjol arbustivo (Phaseolus vulgaris) y cítricos (Citrus spp), delimitado en la parte alta por una barrera viva de vetiver (Chrysopogon zizanioides) y surco de abono verde forestal de matarratón (Gliricida sepium). Parcela comunitaria de ASPRocaEco, vereda Los Cauchos

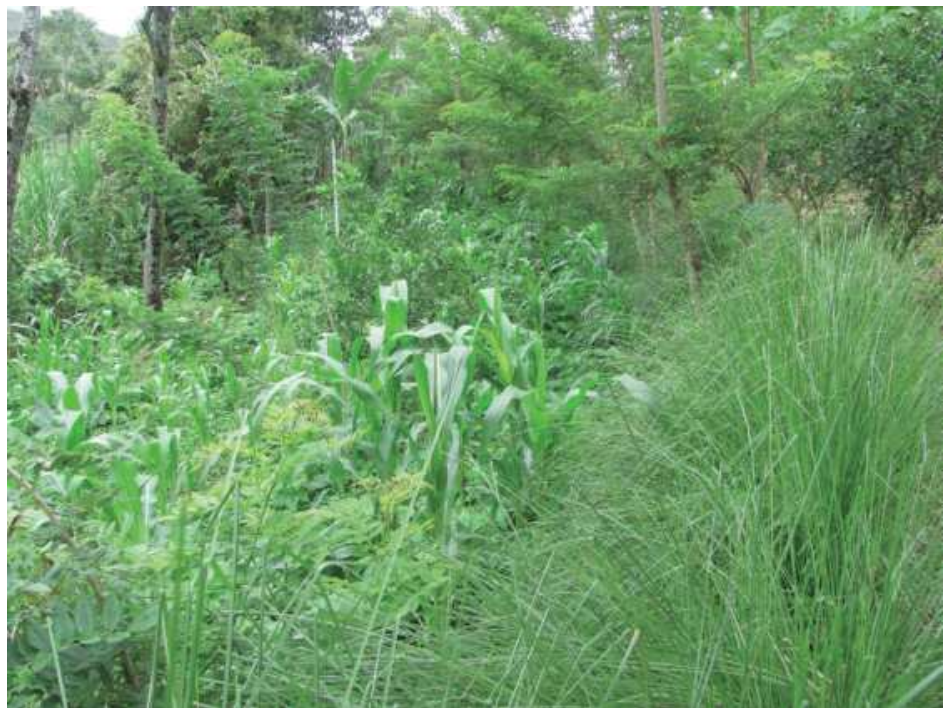

Fuente: Ruíz (2018). 


\section{Dimensión productiva}

- Aumento en la producción de alimentos. Se destinó un área para la siembra de frutales adaptados a la oferta ambiental de la zona: cítricos, aguacate, guanábano, uva, maracuyá y papaya, con una distribución espacial en el lote que facilitó las labores culturales y la cosecha, motivó el cuidado del suelo que, a su vez, garantizó la oferta de alimentos para el consumo familiar. Mientras la cosecha de fríjol y banano se han orientado al autoconsumo solamente, la de maracuyá y sobre todo la de papaya requirieron espacios de comercialización que se dieron en la zona, en la caseta de mercados verdes de la Corporación Autónoma Regional del Alto Magdalena (CAM) y en el mercado campesino del barrio Calixto, espacio con años de tradición en la ciudad de Neiva. Los cítricos con un mejor comportamiento, comparado con el resto de los frutales, avanzan en su desarrollo para ofrecer próximamente producto para la comercialización en la estrategia de Mercados Verdes de la Corporación. En este momento, el concepto de producción en menor área a la acostumbrada, anteriormente, empieza a dar resultados con la eficiencia en el manejo de los recursos disponibles en la economía campesina: tierra, mano de obra y capital, tan limitados en este grupo de agricultores.

- Aprendizaje en manejo técnico de cultivos. Conceptos como patrones, injertos, micorrizas, podas, distancias de siembra, abonamiento, manejo fitosanitario, sistemas agroforestales, distribución espacial, consumo de agua son conocimientos relativamente nuevos que se están volviendo rutinarios por el cuidado que demanda la parcela en su desarrollo. Asimismo, nociones como humedad del suelo, compactación del suelo, reciclaje de nutrientes y $\mathrm{pH}$ empiezan a ser concepciones que se tienen en cuenta en la toma de decisiones para la implementación de nuevas áreas cultivables.

- Adopción de prácticas de conservación de suelos. Los agricultores apropiados del proceso aplican una o varias tecnologías de conservación de suelos en la finca, por lo tanto, paulatinamente se ha ido aumentando el área con prácticas de conservación de suelos en sus predios, superando actualmente el cuarto de hectárea inicial hasta llegar a una hectárea, en promedio.

Las nuevas siembras en estos predios conllevan a la ampliación en el empleo de las prácticas de conservación de suelos, como por ejemplo: 1.5 ha de banano con cobertura noble de hierba coneja (Commelina sp), incluso la siembra de coberturas nobles, en la etapa de vivero de banano propagado bajo cámara térmica, facilita su multiplicación en el lote para adicionar una 
1 ha más; mientras que las calles se aprovechan para el sembrando de fríjol con labranza mínima o para sembrar guandú (Cajanus cajan) en las calles de frutales para la fijación de nitrógeno y autoconsumo, lo que correspondería a una media hectárea más (figura 7).

Figura 7. Incremento de área de cultivos manejados con prácticas de conservación de suelos a nivel predial.

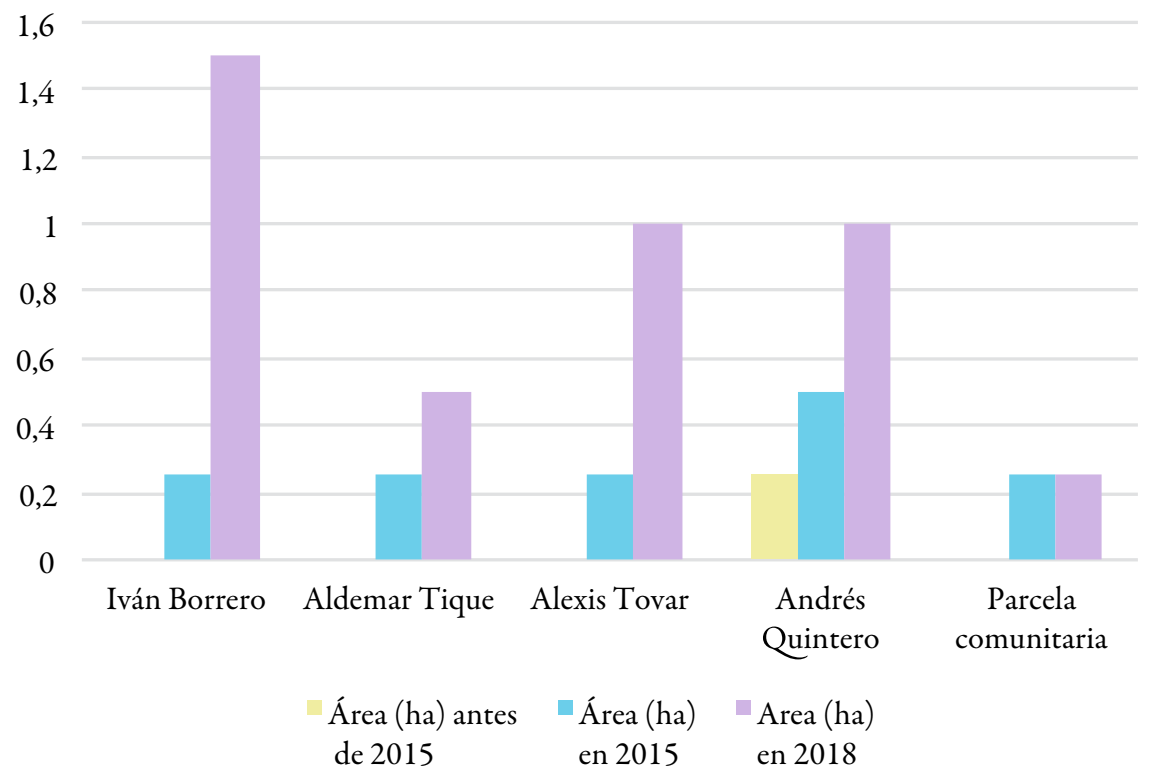

Fuente: elaboración propia.

\section{Dimensión ambiental}

- Tecnologías apropiadas de conservación de suelos. Al tener en cuenta que el sistema de suelo obedece a la interrelación de características físicas, químicas y biológicas, las prácticas de manejo deben ser diversas para que su aplicación conjunta conserve o recupere el suelo en su integridad. Emplear una práctica de conservación de suelos es valioso, pero la cantidad de prácticas intensificará su conservación, es así que, en la medida que se apliquen varias se podrá garantizar que el suelo conservará su capacidad productiva y el agricultor prolongará sus planes de producción en el tiempo, ya que la producción promedio de sedimentos por actividades agropecuarias en la cuenca del río Las Ceibas es baja (1.6 t.ha-1.año-1), pero presenta grandes variaciones ( 0 a 15 t.ha-1.año-1) dependiendo del porcentaje de 
pendiente del terreno, cobertura vegetal, características del suelo y manejo del mismo (Centro Internacional de Agricultura Tropical, 2007). Trazado en curvas a nivel, labranza mínima o en algunos casos cero, barreras vivas, abono verde, cultivos de cobertura, sombrío y micorrizas en su individualidad, son prácticas que contribuyen a conservar los suelos, pero su aplicación planificada y combinada con toda seguridad cambiará a corto plazo parámetros del suelo como: contenido de materia orgánica, capacidad de intercambio catiónico, $\mathrm{pH}$, densidad aparente, infiltración, humedad del suelo, biología del suelo, estabilidad, entre otros.

$\mathrm{Al}$ aumentar el empleo de la cobertura noble en los suelos de cultivos, se reduce la erosión laminar, pero en la medida que se multiplique esta práctica, la disminución en el aporte de sedimentos al río Las Ceibas y sus afluentes será significativa. Sin embargo, existen 10 agricultores con estos conocimientos en práctica, la visión busca que estos conceptos se vayan ampliando paulatinamente en sus predios y entre los vecinos. Es necesario cuantificar este impacto, aunque es poca área, es muy significativo el resultado; toda vez que las investigaciones reportan una disminución de arrastre de sedimentos hasta del 90\% (Gómez y Rivera, 1993) y más cuándo las pendientes pueden alcanzar el $70 \%$.

La figura 8 muestra ocho prácticas de conservación de las cuales, sobresale por su nivel de apropiación, el uso de sombrío con especies forestales nativas

Figura 8. Prácticas de conservación de suelos apropiadas por agricultores de ASPROCAECO.

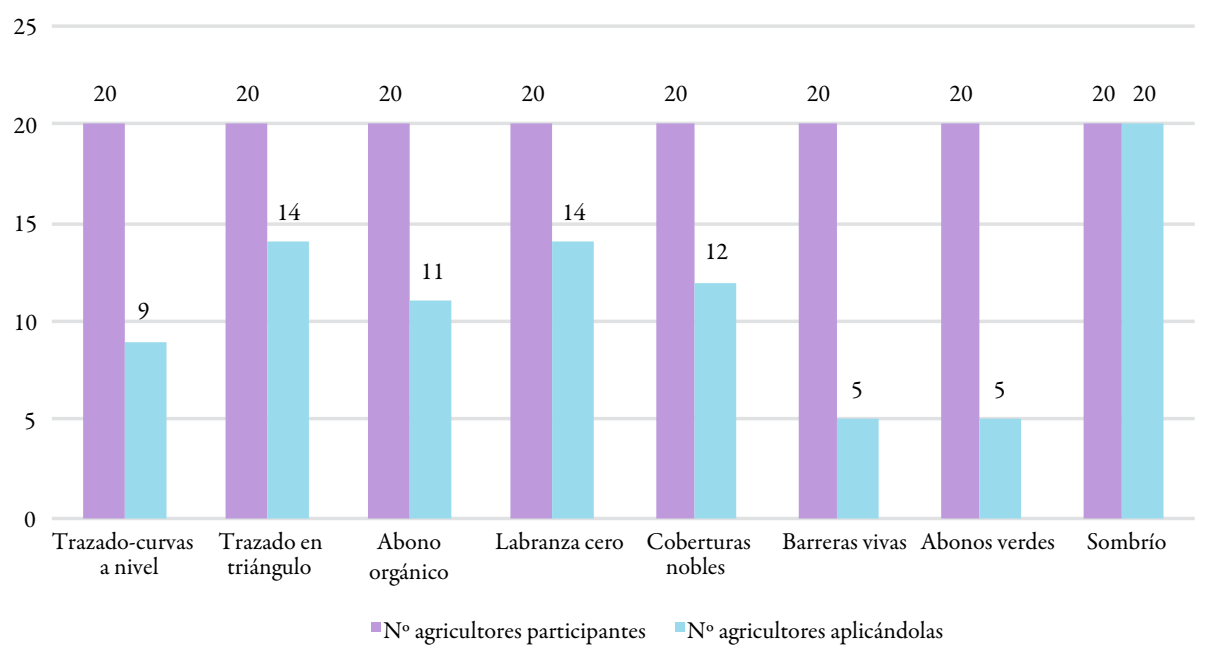

Fuente: elaboración propia. 
como el nogal (Cordia alliodora) e iguá (Pseudosamanea guachapele). El trazado en triángulo y la labranza cero también son de fácil aplicación y mayor aceptación. Los agricultores conocen el efecto del abono orgánico en las plantas, pero su preparación demanda un esfuerzo adicional que no todos están dispuestos a realizar de forma permanente. La adopción de otras prácticas como el trazado en curvas a nivel, uso de abonos verdes, así como barreras vivas y coberturas nobles es más lenta por el trabajo que demandan.

Por lo tanto, hay que destacar que la aceptabilidad de las prácticas está inversamente relacionada con el nivel de esfuerzo para desarrollarlas, es decir, entre menos esfuerzo, más fácil es su apropiación. Lo cual deja entrever que, aquellas que demandan mayor trabajo requieren de un incentivo para promover su ampliación y su permanencia en el tiempo a nivel predial, donde se garantizaría una mayor participación de más familias de la cuenca. Pero lo más importante es que así la adopción de las prácticas de conservación de suelos no sea de un $100 \%$ entre los campesinos, actualmente, ninguno recurre a las quemas agrícolas para la preparación del terreno o la renovación de las pasturas.

- Uso eficiente del agua. El empleo de las prácticas de conservación de suelos, entre ellas, las coberturas nobles contribuirán a la conservación de la humedad al disminuir la evapotranspiración, que bajo el trópico seco es una condición que se vuelve obligatoria, ya que la oferta de agua cada vez es más limitada. Un caudal de 0.03 l.s-1 que representa 25921 de agua en el día empleada para regar por gravedad, regaba aproximadamente $1 / 4$ ha de cacao durante la semana. Este mismo caudal permite regar por goteo esta misma área 2.5 veces a la semana, puesto que se aplica localizadamente y de acuerdo a las necesidades de las plantas. Ahora con tanques de $2000 \mathrm{l}$ inicialmente, pueden almacenar el poco caudal que les llega para aumentar su capacidad de riego y, por ende, mejorar la productividad.

\section{Dimensión sociocultural}

- Condiciones de administración del predio. La economía campesina se define por las siguientes características de sus unidades productivas: (a) la mano de obra familiar es la principal fuente de oferta laboral; (b) la agricultura es la principal fuente de ingreso; (c) la productividad es tan baja, que no hay capacidad de generación del excedente económico (Figueroa, 1998, p. 88). Los campesinos tienen como patrimonio la tierra, el capital y la mano de obra. 
La economía campesina opera bajo condiciones de incertidumbre (originadas por el clima, mercados, inestabilidad política, entre otros factores). Bajo este contexto, y dada la limitación de sus recursos, la lógica económica campesina es la de buscar la minimización de riesgos, pues su capacidad para absorber pérdidas es limitada. Una consecuencia empírica de esta lógica económica es que las unidades campesinas tendrían que diversificar sus actividades. Diversos estudios han mostrado, en efecto, una gran diversificación en la pequeña agricultura de América Latina y le dan sustento a la hipótesis de minimización de los riesgos (Figueroa, 1998).

Según Aramburu, González, Salazar y Winter, una de las barreras que limita la adopción tecnológica, por parte de los pequeños productores agropecuarios es el bajo nivel de capital humano (caracterizado por la baja educación y la falta de asistencia técnica). Esta barrera dificulta el uso adecuado de la tecnología y, por ende, la obtención de beneficios por la adopción de las mismas. (2014, p. 6 ).

Por esta razón, la mano de obra, la tierra y el capital son los recursos que posee la economía campesina en condiciones limitadas. Un punto particular sobre la mano de obra es que antes era el recurso que más abundaba, ahora la migración de los jóvenes a las ciudades debilita aún más la estabilidad de los sistemas productivos minifundistas. Es bajo estas condiciones donde el empleo de tecnologías apropiadas de mínima inversión financiera, que demanden básicamente una observación juiciosa de parte de los campesinos para comprobar su efectividad en campo, es lo que se debe promover, garantizando el acompañamiento técnico permanente para generar cambios en el manejo de los recursos naturales en la producción agropecuaria.

- Visitas a la experiencia o atención de giras técnicas. La visibilización de los campesinos como protagonistas de la protección del suelo y en el ordenamiento de cuencas ha despertado gran interés y ha generado que la experiencia de conservación de suelos sea una oportunidad de cambio en las prácticas agrícolas. Lo anterior, se debe a que esta inmerso en el marco de la implementación de un Plan de Ordenación y Manejo de la cuenca, el cual es pionero a nivel nacional por su integralidad, esquema administrativo y concertación participativa de las acciones a nivel predial. Esto mejoraría, sí además, se aplicarán medidas técnicas de conservación de suelos relacionadas con los manuales de agricultura de conservación y agroecología, pero su empleo es vago y, por ende, no gozan de aceptación por el esfuerzo adicional que pueden generar al momento de establecerse. Sin lugar a dudas, 
con mayor razón las universidades de la región quieren conocerlas y más cuando fueron reconocidas por Colciencias como una experiencia exitosa en ciencia, tecnología e innovación con enfoque comunitario.

- Aceptabilidad. El diseño de la parcela de seguridad alimentaria con prácticas de conservación de suelos fue socializado con la comunidad y si bien la distribución espacial de algunos elementos estaba preconcebida, permitió la inclusión de otros componentes sugeridos por ellos, algunos de estos fueron la yuca, el banano, el plátano, el maíz y la multiplicación de matarratón como abono verde forestal; esto se debió por su adaptación en la zona y su aceptación por la misma comunidad, ya que, esta última, es una especie multipropósito.

La variación de riego por goteo hacia aspersión, en algunos casos, facilitó también el establecimiento de las parcelas entre los integrantes de ASPROCAECO. Finalmente, el trabajo comunitario en el establecimiento de la parcela de la asociación permitió el intercambio de conocimientos y la identificación de liderazgos.

\section{Dimensión financiera}

- Aumento de ingresos. El establecimiento de las parcelas ha representado un aumento significativo en los ingresos anuales debido a los ingresos familiares por venta de servicios y productos.

- Ocho visitas en promedio por año, para desarrollar acciones de capacitación usando las fincas como espacios de aprendizaje. A nivel económico se perciben ingresos en las familias asociadas por la venta de productos de acuerdo al momento y la cosecha, como pollos, aguacate, cacao, naranjas, limones, guarapo y almuerzos en conjunto pueden representar $\$ 1000000$ anuales; además de la acción de capacitación que desarrollan los agricultores en la guianza, presentación de su sistema productivo y la experiencia de conservación de suelos a los grupos visitantes, que les representa un incentivo en promedio de $\$ 40000$ por visita.

\section{Dimensión legal}

- Adopción o aplicación de la normatividad de recuperación y conservación de suelos. El escenario futuro para ASPROCAECO es prometedor, porque sus acciones se adelantan en el marco de la implementación de un POMCA, que siendo una norma ambiental de alta jerarquía demanda la 
aplicación de otras normas que, complementarias, pretenden hacer una gestión articulada frente al manejo eficiente y el mejoramiento de la calidad del agua. Es así que, un primer avance en materia de leyesel Decreto 1640 de 2012 por medio del cual se reglamentan los instrumentos para la planificación, ordenación y manejo de las cuencas hidrográficas y acuíferos (MADS, 2012); y para el fortalecimiento de lo anterior, el Ministerio de Ambiente y Desarrollo Sostenible en 2016 formuló la Política para la gestión sostenible del suelo (MADs, 2016), que precisa la necesidad de mantener la capacidad productiva de los suelos dado el deterioro de los mismos en algunas regiones, asimismo, dispusó esta política previendo el potencial agropecuario de estos para el desarrollo del país.

Los Planes de Ordenamiento del Recurso Hídrico (PORH) guardan relación con el suelo, pues estos regular los usos del agua, entre ellos está el riego para la agricultura; por este motivo, se considera que el manejo adecuado del suelo hará más eficiente el empleo del agua. También guarda estrecha relación con la Resolución 3002 de 2017, por medio de la cual se establecen los requisitos para la Certificación en Buenas Prácticas Agrícolas (BPA) en producción primaria de vegetales y otras especies para consumo humano (ICA, 2017), hecho relevante, pues algunos de estos agricultores fueron certificados en BPA por el Instituto Colombiano Agropecuario (ICA) en el año de 2017.

\section{Conclusiones}

El auspicio institucional a la asociación ASPROCAECO, en el marco del POMCA del río las Ceibas, ha fortalecido las iniciativas con enfoque de agricultura familiar hacia la conservación de recursos vitales como el suelo y el agua. Los aprendizajes obtenidos por los miembros esta corporación hace que estos se caracterizen por poseer fortalezas en la apropiación de técnicas, conocimientos y gestiones interinstitucionales y comunitarias, asimismo, en el trabajo en equipo y, permite que haya un verdadero realce en la apropiación de la mano de obra familiar.

Los sistemas productivos, pese a las condiciones biofísicas y agroambientales de la zona, muestran posibilidades de desarrollo agropecuario con limitaciones evidentes, pero con diseños y realizaciones de mediano y largo plazo, que auguran sostenibilidad con enfoque conservacionista y de seguridad alimentaria familiar.

Las familias adscritas a ASPROCAECO han logrado poner en práctica un manejo adecuado y sostenible del suelo, en procesos de recuperación, reconversión 
y mantenimiento del recurso con fines agropecuarios sostenibles, aplicando varias prácticas, entre las que destacan: el manejo de barbecho, delineado y trazado del terreno; manejo de coberturas verdes y abonos verdes forestales; reincorporación de material vegetal al suelo; distribución espacial de especies vegetales nativas con múltiples propósitos; manejo de la fertilidad del suelo y optimización del agua para controlar procesos de pérdida del suelo en los cultivos. Es importante anotar el rol funcional de cada miembro de la familia para el desarrollo de las distintas actividades en el predio. Por último, se resalta el nivel organizacional tanto a nivel predial como de la asociación, ya que han logrado una multifuncionalidad de la agricultura a nivel familiar, pero con objetivos misionales como agrupación.

\section{Referencias}

Andrade, O., y Rodríguez, O. (2002). Evaluación de la eficiencia de barreras vivas como sistemas de conservación de suelos en ladera. Bioagro, 14(3), 123-133. Recuperado de http://www.ucla.edu.ve/bioagro/Rev14(3)/1.\%20Evaluaci\%C3 \%B3n\%20de\%20la\%20eficiencia.pdf

Aramburu, J., González, M., Salazar, L., y Winters, P. (2014). Cuando un análisis de corto plazo no es un enfoque cortoplacista: Impactos de la adopción tecnológica agropecuaria en Bolivia. La Paz: Banco Interamericano de Desarrollo-BID. Recuperado de https://publications.iadb.org/bitstream/handle/11319/6676/ IDB-wP-539-Cuando-un-analisis-de-corto-plazo-no-es-un-enfoque-cortoplacista.pdf ? sequence $=1$

Benites, J. R. (2004). Editorial. Manejo integrado del suelo y agua para un desarrollo agrí́cola sostenible en América Latina. LEISA, Revista de Agroecología, 19(4), 4-5. Recuperado de http://www.leisa-al.org/web/index.php/volumen-19-numero-4/2132-editorial-manejo-integrado-del-suelo-y-agua-para-un-desarrolloagricola-sostenible-en-america-latina

Centro Internacional de Agricultura Tropical - CiAT. (2007). Potencial de generar un sistema de compensación pos servicios ambientales: Estudio de caso cuenca río Las Ceibas. Santiago de Cali.

Corporación Autónoma Regional del Alto Magdalena, CAM. (2006). Diagnóstico cuenca hidrográfica del río Las Ceibas. Diagnóstico cuenca bidrográfica del rio Las Ceibas, 276. Neiva, Huila, Colombia.

Cotler, H., Sotelo, E., Domínguez, J., Zorrilla, M., Cortina, S., y Quiñones, L. (2007). La conservación de suelos: un asunto de interés público. Gaceta Ecológica, 83, 
5-71. Recuperado de http://www.academia.edu/11675281/La_conservaci \%C3\%B3n_de_suelos_un_asunto_de_inter\%C3\%A9s_p\%C3\%BAblico do Prado, L., y da Veiga, M. (1994). Tema 2. Erosión y pérdida de fertilidad del suelo. Relación entre erosión y pérdida de fertilidad del suelo. En FAO (eds.), Erosión de suelos en América Latina. Santiago de Chile: FAo Recuperado de http:// www.fao.org/docrep/t2351s/T2351S00.htm

Figueroa, A. (1998). Pobreza rural en los países andinos. En R. G. Echeverría y L. G. Reca (eds.), Agricultura, medio ambiente y pobreza rural en América Latina (pp. 85-120). Washington: Instituto Internacional de Investigaciones sobre Políticas Alimentarias y Banco Interamericano de Desarrollo. Recuperado de https://publications.iadb.org/en/publication/14211/agricultura-medioambiente -y-pobreza-rural-en-america-latina

Gómez, A., y Rivera, H. (1993). La conservación de los suelos y la sostenibilidad de la productividad en la zona cafetera. Avances Técnicos, Cenicafé, 190, 1-8. Recuperado de https://www.cenicafe.org/es/publications/avt0190.pdf

Granjed, A.J. (2011). Efectos a corto y largo plazo del fuego sobre algunas propiedades del suelo. Incendios naturales e incendios experimentales bajo condiciones de campo y laboratorio (tesis doctoral). Recuperado de https://idus.us.es/xmlui/bitstream/ handle/11441/72763/file_1.pdf ?sequence $=1$

Instituto Colombiano Agropecuario - ICA. (2017). Resolución 3002, Por medio del cualse establecen los requisitos para la Certificación en Buenas prácticas Agricolas en producción primaria de vegetales y otras especies para consumo humano. Recuperado de https://www.ica.gov.co/getattachment/9d8fe0fa-66d2-4feb-9513cbba30dc4844/2017R30021.aspx

Mendoza, C. (2011). Alternativas para el control de la erosión mediante el uso de coberturas convencionales, no convencionales y revegetalización. Ingeniería e investigación, 31(3), 80-90. Recuperado de http://www.scielo.org.co/pdf/ iei/v31n3/v31n3a09.pdf

Ministerio de Ambiente y Desarrollo Sostenible - MADs. (2012). Decreto 1640, por medio del cual se reglamentan los instrumentos para la planificación, ordanación y manejo de las cuencas hidrogéficas y acuiferos, y se dictan otras disposiciones. Recuperado de https://www.alcaldiabogota.gov. co/sisjur/normas/Norma1. jsp? $\mathrm{i}=49987$

Ministerio de Ambiente y Desarrollo Sostenible - MADs. (2016). Politica para la gestión sostenible del suelo. Bogotá: Ministerio de Ambiente y Desarrollo Sos- 
tenible. Recuperado de http://www.andi.com.co/Uploads/ Pol\%C3\%ADtica _para_la_gesti\%C3\%B3n_sostenible_del_suelo_fINAL.pdf

Núñez, J. (2001). Manejo y conservación de suelos. San José de Costa Rica: Editorial Universidad Estatal a Distancia.

Nyssen, J., Poesen, J., y Deckers, J. (2009). Land degradation and soil and water conservation in tropical highlands. Soil and Tillage Research, 103(2), 197-202. doi: http://dx.doi.org/10.1016/j.still.2008.08.002

Obando, F. (2012). Agricultura de conservación en tierras de ladera. En F. H. Acuña (ed.), Agricultura de conservación en tierras de ladera. Manizales: Universidad de Caldas.

Organización de las Naciones Unidas para la Alimentación y la Agricultura - FAO. (1994). Erosión de los suelos en América Latina. Santiago de Chile: FAO. Recuperado de http://www.fao.org/docrep/t2351s/T2351S00.htm

Pla Sentis, I. (2006). Problemas de degradación de suelos en América Latina: evalaución de causas y efectos. X Congreso Ecuatoriano de la Ciencia del Suelo, Ecuador.

Sandoval, J. E. (2017). Las quemas físicas y su efecto sobre la calidad del suelo. En A. T. Trujillo (ed.), Manejo sostenible y productivo del suelo. Neiva: Universidad Surcolombiana.

Stokes, A., Norris, J. E., van Beek, L. P., Bogaard, T., Cammeraat, E., Mickovski, S., Jenner, A., Di Iorio, A., y Fourcaud, T. (2008). How vegetation reinforces soil on slopes. En J. E. Norris, A. Stokes, S. B. Mickovski, E. Cammeraat, L. P. van Beek, B. C. Nicoll y A. Achim (eds.), Slope stability and erosion control: ecotechnological solutions. (pp. 65-118). Canadá: Springer.

Ruíz, J. (2017). Diseño de un modelo de optimización para promover cambios de uso del suelo en ecosistemas estratégicos. Estudio de caso: cuenca hidrográfica del río Las Ceibas, Neiva, Huila. 162. Neiva, Huila, Colombia. 



\title{
Capítulo 4
}

\section{Construcción de casas comunitarias de semillas nativas - criollas con sistemas participativos de garantía de calidad en Colombia}

Construction of community houses of native and creole seeds with participatory systems of quality assurance in Colombia

\author{
Tarsicio Aguilar Gómez* \\ Mauricio de Jesús García Álvarez** \\ Ana María García Hoyos ${ }^{* * *}$
}

\section{Cómo citar}

\begin{abstract}
APA
Aguilar, T. García, M. y García, A. (2019). Construcciones de casas comunitarias de semillas nativas - criollas con sistemas participativos de garantía de calidad en Colombia. En Á. Acevedo-Osorio y N. Jiménez-Reinales (comps.). La agroecología. Experiencias comunitarias para la Agricultura Familiar en Colombia. (pp. 83-112). Bogotá: Corporación Universitaria Minuto de Dios-UNIMINUTO, Editorial Universidad del Rosario.
\end{abstract}

\section{Chicago}

Aguilar Gómez, Tarsicio. García Álvarez, M. y García Hoyos, A. "Construcciones de casas comunitarias de semillas nativas - criollas con sistemas participativos de garantía de calidad en Colombia". En La agroecología. Experiencias comunitarias para la Agricultura Familiar en

* Red Colombiana de Agricultura Biológica, Antioquia. info@recab.org

** Campaña Semillas de Identidad. Fundación swissaId. mauricio.garcia2007@yahoo.es

*** University of Natural Resources and Life Sciences (boku), Austria. University of Hohenheim, Alemania. anagarcia321@hotmail.com 
Colombia, comps. Álvaro Acevedo-Osorio y Nathaly Jiménez-Reinales. Bogotá: Corporación Universitaria Minuto de Dios-UNIMINUTO, Editorial Universidad del Rosario, 2019.

\section{MLA}

Aguilar Gómez, Tarsicio, García Álvarez, M. y García Hoyos, A. "Construcciones de casas comunitarias de semillas nativas - criollas con sistemas participativos de garantía de calidad en Colombia". En La agroecología. Experiencias comunitarias para la Agricultura Familiar en Colombia. En Á. Acevedo-Osorio y N., Jiménez-Reinales (comps.) Bogotá: Corporación Universitaria Minuto de Dios-UNIMINUTO, Editorial Universidad del Rosario, 2019, pp. 89-112.

\section{Resumen}

Desde el Movimiento Agroecológico de América Latina y el Caribe (.MAELA) se impulsa el cambio de modelos productivos de una agricultura convencional a una agroecológica, hace más de 25 años en Colombia. Una de las dificultades encontradas han sido las limitaciones frente a la cantidad y calidad de semillas que permitan mantener una producción constante y con la abundancia requerida, para abastecer el mercado y garantizar la seguridad alimentaria a las familias rurales. Después de un largo trabajo para fortalecer las capacidades en los custodios de semillas y productores, este capítulo tiene por objetivo socializar la sistematización de las experiencias de las redes productoras de semillas y procesos adelantados, para garantizar la calidad de las semillas a partir de los Sistemas Participativos de Garantía (SPG). Para el presente trabajo, se realizaron visitas a las redes articuladas de la Campaña Semillas de Identidad en Colombia, para constatar el avance y las deficiencias en la producción de semillas. Se encontró que existen más de 100 organizaciones en 20 departamentos de Colombia, articuladas a la Red de Semillas Libres de Colombia y 70 casas comunitarias de semillas que vinculan a 800 custodios de semillas. Las casas comunitarias de semillas se encuentran vinculadas a procesos agrícolas de las comunidades campesinas e indígenas que se comprometieron con la producción de semillas criollas y nativas, para abastecer una demanda insatisfecha en Colombia. Con relación a la garantía de calidad de las semillas, las redes han constituido criterios más amplios de los que se trabajan en las semillas mejoradas, involucrando criterios técnicos, organizativos, culturales y ancestrales. Los Sistemas Participativos de Garantía constituyen la apuesta colectiva para garantizar la calidad declarada por las comunidades y se establece, como uno de los retos finales, fortalecer la organización para la incidencia política en defensa de las semillas nativas y criollas en Colombia.

Palabras clave: agroecología, calidad de semillas criollas, semillas nativas, Sistemas Participativos de Garantía para semillas.

\section{Abstract}

From the Agroecological Movement of Latin America and the Caribbean (MAELA), the change of productive models from conventional to agroecological agriculture has been promoted for more than 25 years in Colombia. One of the difficulties encountered has been the limitations 
on the quantity and quality of seeds that allow maintaining a constant production and with the abundance required, to supply the market and guarantee food security to rural families. After a long work to strengthen the capacities in the custodians of seeds and producers, this chapter aims to socialize the systematization of the experiences of the seed production networks and advanced processes, to guarantee the quality of the seeds from the Participatory Guarantee Systems (PGS). For the present work, visits were made to the articulated networks of the Identity Seeds Campaign in Colombia, to verify the progress and deficiencies in the production of seeds. It was found that there are more than 100 organizations in 20 departments of Colombia, articulated to the Free Seeds Network of Colombia and 70 community seed houses that link 800 seed custodians. Community seed houses are linked to agricultural processes of peasant and indigenous communities that are committed to the production of Creole and native seeds, to supply an unsatisfied demand in Colombia. With regard to the guarantee of quality of the seeds, the networks have constituted broader criteria than those that work on improved seeds, involving technical, organizational, cultural and ancestral criteria. The Participatory Guarantee Systems constitute the collective commitment to guarantee the quality declared by the communities and establish, as one of the final challenges, strengthen the organization for the political advocacy in defense Creole and native seeds in Colombia.

Keywords: agroecology, quality of Creole seeds, native seeds, Participatory Guarantee Systems for seeds.

\section{Introducción}

Como consecuencia de la Revolución Verde iniciada en los años 50, que se caracterizada por el desarrollo y uso de agroquímicos, fertilizantes inorgánicos, semillas híbridas y otros insumos agrícolas, las semillas han sido sujeto de múltiples trabajos de selección genética por parte de la empresa privada, esto generó así una élite de variedades comerciales con alto grado de uniformidad genética, la cual es la base de la agricultura industrial. La limitada base y uniformidad genética resultantes han generado una alta vulnerabilidad a enfermedades y plagas, evidente en la erosión genética (Ceccon, 2008).

Otro hecho que se suma a la erosión genética de las semillas es la reducción continua de variedades de alimentos consumidos por el ser humano. Se estima que dos siglos atrás los agricultores cultivaban alrededor de 300 plantas y todas de vital importancia para los mismos. En la actualidad, una familia puede alimentarse de 30 o menos plantas (Ceccon, 2008).

Contrario a las semillas producto de desarrollos tecnológicos, las semillas nativas y criollas $^{1}$, también llamadas locales, albergan una amplia gama de genes

\footnotetext{
${ }^{1}$ Semillas nativas: originadas en el lugar o región donde son cultivadas. Semillas criollas: semillas adaptadas y adoptadas por una comunidad como "propias" aunque tienen un lugar de orígen distinto (García, 2012).
} 
(Ceccon, 2008). Los agricultores, tradicionalmente, las han domesticado y elegido por razones sociales, culturales y agroecológicas, asimismo, por conocer el desempeño de las plantas, por lo que una variedad apta para una familia agricultora podrá no serlo para otra (Rivas-Platero, Rodríguez, Padilla, Hernández y Suchini, 2013). Sin embargo, estas semillas han sufrido los impactos de la Revolución Verde, primero por procesos de selección que dieron origen a semillas con una base genética estrecha y, por tanto, una disminución en la diversidad genética (Binimelis, 2004; Ceccon, 2008) y, posteriormente, por procesos de contaminación transgénica, lo cual ha generado una pérdida de zonas de producción agroecológica y ecológica/orgánica que plantea el cuestionamiento sobre la coexistencia de modelos de agricultura ecológica con aquella que esta basada en la Revolución Verde (Binimelis, 2004).

Así, el cambio en la utilización de semillas nativas y criollas por el uso de semillas de la Revolución Verde ha llevado a un cambio en los sistemas agrícolas manejados por familias campesinas, a uno controlado por la industria de agroquímicos, compañías de semillas y centros de investigación agrícola. Este cambio transformó los recursos básicos y libres de producción de las fincas con respecto a las semillas, y lo convirtió en un insumo costoso que debe ser comprado por las familias campesinas.

Lo anterior, fue posibilitado por los gobiernos de los distintos países que adoptaron el esquema productivo de la Revolución Verde, quienes propiciaron la difusión y adquisición de nuevas semillas por medio de créditos asumidos por los agricultores y gobiernos, además de implementar la capacitación y extensión de estas prácticas. De la misma manera, los Centros Internacionales de Agricultura adoptaron dichas semillas para ser reproducidas, cruzadas y multiplicadas y, luego, distribuidas en diversos países. Dichos procesos de innovación y desarrollo tecnológico llevaron al establecimiento de leyes de propiedad privada y patentes enfocadas en proteger los derechos individuales a costa de la omisión de los derechos colectivos como base de sustento (Shiva, 2016). De este modo, las semillas pasaron de ser bienes colectivos a bienes privados sobre los cuales se restringe la libre reproducción por los agricultores.

Bajo el esquema de producción de semillas, para una agricultura intensiva, surgió la clasificación de semillas certificadas y registradas, conceptos apropiados mundialmente en las políticas públicas (Shiva, 2016).

Referente a la normativa en Colombia, en la actualidad, se cuenta con legislación para las semillas producto del mejoramiento genético. La Resolución 3168 de 2015 del Instituto Colombiano Agropecuario (ICA) cuyo objeto es "Reglamentar y controlar la 
producción, importación y exportación de semillas producto del mejoramiento genético para la comercialización y siembra en el país, así como el registro de las unidades de evaluación agronómica y/o unidades de investigación en fitomejoramiento" (ICA, 2015, p. 2). Por otra parte, el Ministerio de Agricultura y Desarrollo Rural expidió la Resolución 464 de 2017 “por la cual se adoptan los lineamientos estratégicos de política pública para la Agricultura Campesina, Familiar y Comunitaria (ACFC)”, la cual establece en el artículo 9, numeral 10, el lineamiento sobre "Semillas del Agricultor". Dicho lineamiento define que se debe "establecer y apoyar circuitos y redes de conservación de semillas del agricultor como medida de resistencia a los efectos del cambio climático, afectación por plagas y enfermedades, preservación de la agrobiodiversidad, y de las prácticas y saberes tradicionales de la ACFC", como estrategia a ser liderada por dicho ministerio (Ministerio de Agricultura y Desarrollo Rural, 2017, p. 12).

En lo que respecta a las semillas certificadas, para el caso de Colombia, según el artículo la Mercado de semillas mueve más de \$ 200000 millones en Colombia (2018), la Asociación Colombiana de Semillas y Biotecnología (ACOSEMILlas) reportó en 2018 que las tasas de uso de semillas certificadas son bajas en el país (30\% en 2017 y 20\% en 2018 para el caso del arroz). Se reporta que en el año 2017 la producción de semillas fue de 36983 t y la importación de semillas por un valor de 68.8 millones de dólares, con un total de movimientos por \$ 222281 millones de pesos en el mercado de semillas de Colombia.

Los agricultores que practican agriculturas alternativas se abastecen de semillas de las empresas y de semillas nativas y criollas, pues en Colombia no hay empresas productoras de semillas ecológicas, ante la falta de políticas de fomento en este sentido. Por lo tanto, los agricultores se enfrentan al reto de autoabastecerse y de abastecer de semillas nativas, criollas y agroecológicas al país . Este reto, planteó al Movimiento Agroecológico de América Latina y el Caribe (MAELA, 2018) la necesidad de construir estrategias para la producción de semillas en conjunto con las organizaciones constituidas por agricultores familiares, campesinos y de comunidades étnicas con producción agroecológica, a partir de sus necesidades y conocimientos.

Como estrategia surgió la creación de Redes y Casas Comunitarias de Semillas (CCs) como acción concreta de las organizaciones de campesinos y comunidades étnicas, frente a la pérdida de la agrobiodiversidad y la contaminación por transgénicos, organizados en la Red de Semillas Libres de Colombia (RSLC). Esta estrategia se constituye en alternativa no solo para resolver la problemática de abastecimiento de semillas para los procesos agroecológicos, sino también, para alcanzar la seguridad y soberanía alimentaria de las comunidades de la agricultura familiar en general. 
Figura 1. Casa de semillas. Red de Guardianes de Semillas de Vida, Nariño.

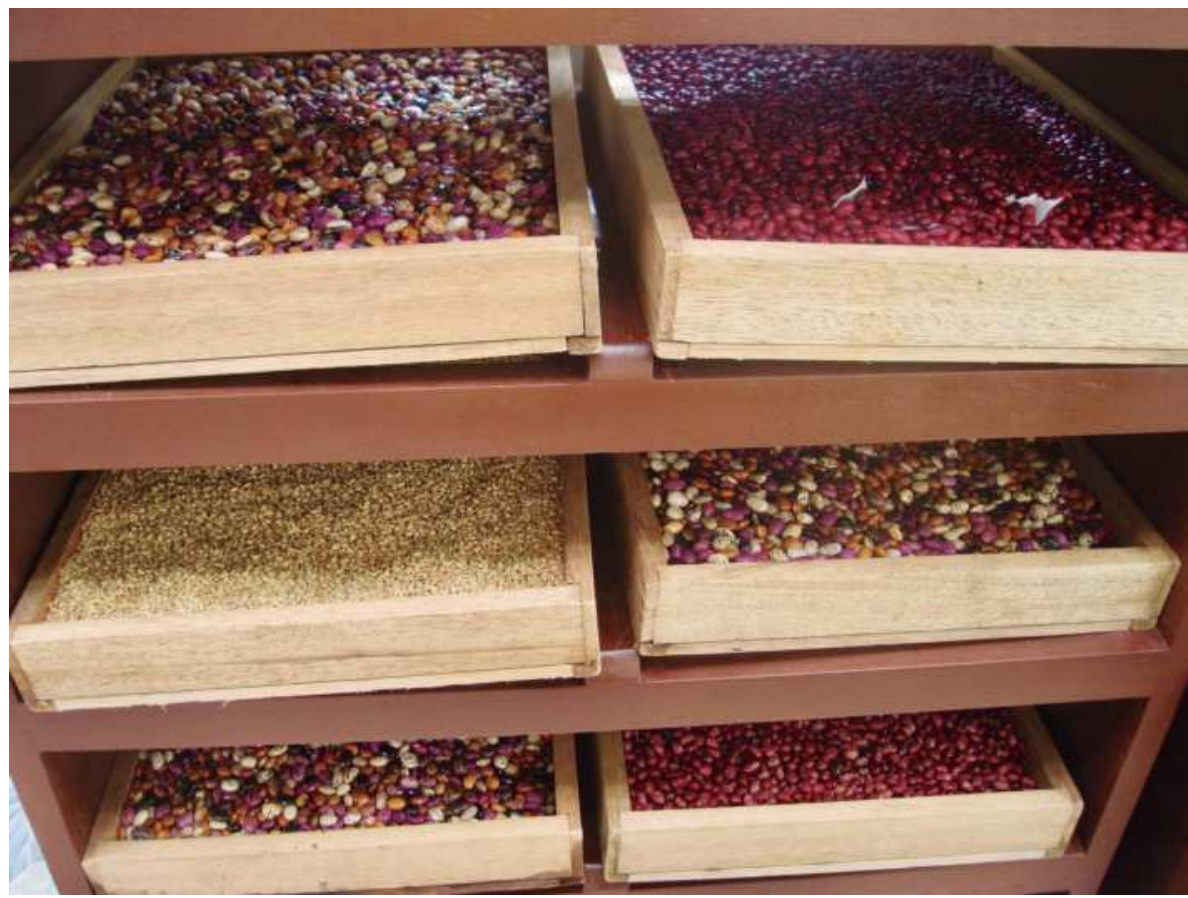

Fuente: García (2018).

La RSLC es un proceso abierto y descentralizado conformado por comunidades campesinas, indígenas y afrocolombianas de todo el país, ONG nacionales e internacionales y la academia que trabajan por la recuperación, conservación y defensa de las semillas criollas y nativas, guiados por los principios de la agroecología. Esta red se caracteriza por promover: 1) la conservación in situ de semillas en las fincas; 2) el cuidado de las semillas a través de guardianes o custodios de semillas; 3 ) las CCS como espacio para la recuperación, conservación e intercambio de semillas y; 4) la calidad de semillas criollas y nativas (Gutiérrez-Escobar, 2015).

Son varias las organizaciones y redes que conforman la RSLC, algunas de estas trabajan articuladamente y son apoyadas por la "Campaña Semillas de Identidad". La Campaña se origina en los años 2001 y 2002 en la región Caribe, impulsada por el "Programa de agroecología y gestión local" de la ONG SWISSAID y el Grupo Semillas, con el objetivo de apoyar a las organizaciones que salvaguardan las semillas nativas y criollas en Colombia, a través del fortalecimiento de capacidades técnicas, además del establecimiento y funcionamiento de las CCs. Lo anterior, 
está motivado, en un principio, por las preocupaciones frente a los efectos del uso de transgénicos, la pérdida de diversidad genética en los maíces y la defensa por la soberanía alimentaria y la agrobiodiversidad (García, 2012).

Desde las distintas redes de semillas que hacen parte de la Campaña Semillas de Identidad y con el apoyo de la Red Colombiana de Agricultura Biológica (RECAB) se vienen construyendo los conceptos sobre loscriterios de calidad de las semillas criollas y nativas que garantizarán el tránsito por las CCs. Estos criterios comprenden aspectos culturales, agronómicos y de sanidad, que se establecen como puntos de llegada y hoy forman parte de la construcción del Sistema Participativo de Garantía para semillas criollas y nativas en Colombia.

Los SPG son sistemas locales de garantía de la calidad de productos agroecológicos, conocidos también como certificación de confianza, construidos sobre la base de la confianza, la activa participación de los miembros del sistema y el intercambio de conocimientos (May, 2008).

La garantía sucede, entre otras cosas, por la revisión hecha por pares que realizan los productores entre sí y otros actores como consumidores, lo que reduce los costos en comparación con una certificación de tercera parte y fortalece el capital social. Aunque son sistemas diversos entre sí, pueden compartir ciertas características (May, 2008; Terramocha, 2012) (figura 2).

El SPG para semillas nativas y criollas nace a partir de las organizaciones de base y Redes de Semillas, estructurado en torno a las CCS, de tal manera que, estos espacios sean el lugar de tránsito de las semillas ya sea para venta, intercambio o donaciones y, en el cual, se verifica la calidad de estas. El SPG para la calidad de semillas podrá operar a nivel local, regional o nacional, dependiendo del lugar de actuación que tenga las CCs o las Redes de Semillas que adopten la metodología.

El proceso de construcción conjunta de un SPG para la calidad de semillas criollas y nativas ha tomado un camino constante desde el año 2014 en Colombia y, es de resaltar que en el mundo y en el país, existen diversos SPG para la garantía de la calidad agroecológica de productos para el consumo directo; sin embargo, a la fecha no se han reportado experiencias de SPG para semillas. 
Figura 2. Elementos comunes en los Sistemas Participativos de Garantía. Elaboración propia basado en PGS Guidelines. How participatory guarantee systems can develop and function por C. May, 2008; Los sistemas participativos de garantía.

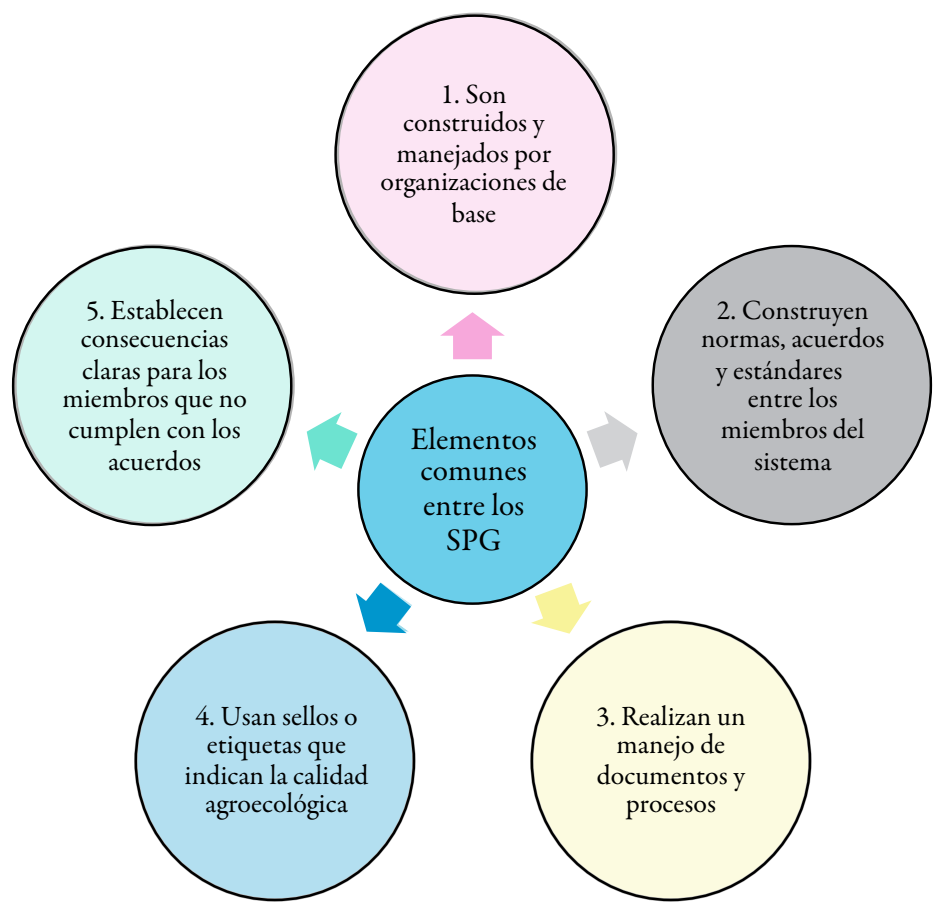

Fuente: herramientas de definición de estrategias agroecológicas por Terramocha (2012).

Por lo tanto, el propósito del presente capítulo es socializar los resultados de la sistematización del trabajo de las Redes de Semillas en Colombia, en los últimos tres años, en materia del SPG; basado en las siguientes preguntas de investigación:

- ¿Cómo se estructuran las Redes y Casas Comunitarias de Semillas nativas y criollas?

- ¿Qué actividades son fundamentales para el funcionamiento adecuado de las Casas Comunitarias de Semillas?

- ¿Qué caracteriza una Casa Comunitaria de Semillas?

- ¿Cuáles elementos definen la calidad de las semillas nativas y criollas para las organizaciones articuladas a la Red de Semillas Libres de Colombia?

- ¿Cómo se construye un SPG de semillas y qué elementos lo constituyen? 
- ¿Qué contribuciones hacen las casas de semillas y el SPG de semillas para la producción agroecológica y la agricultura familiar?

En este documento se mostrará el proceso de avance en el fortalecimiento de las experiencias de 15 redes de custodios y guardianes de semillas que han implementado Casas Comunitarias de Semillas en 10 departamentos de Colombia. Para ello, se definió una batería de indicadores de evaluación del SPG como instrumento, los cuales fueron construidos en dos momentos: el primero en 2016 y el segundo en 2017. Se espera que las redes de semillas puedan avanzar sobre la consolidación de aspectos sobre el conocimiento, producción, abastecimiento, almacenamiento y calidad de las semillas nativas y criollas; para, además, poder afrontar la problemática actual frente a la contaminación por semillas transgénicas y los efectos del cambio climático.

\section{Resultados}

\subsection{Redes y casas comunitarias de semillas}

En Colombia, los procesos de Redes y ccs se vienen consolidando desde hace más de 10 años, bajo la idea del aprovisionamiento, hacerle frente a la erosión genética, la alta dependencia de insumos externos en la agricultura, la pérdida de los conocimientos ancestrales y tradicionales y los efectos del cambio climático.

La Red Semillas Libres de Colombia (RSLC) articula alrededor de 100 organizaciones locales en 20 departamentos, las cuales están trabajando en diferentes niveles por construir estrategias de recuperación, intercambio y venta de semillas (Red de Semillas Libres de Colombia, 2015; Grupo Semillas, 2016). En el marco de este proceso, 15 redes de semillas apoyadas por la Campaña Semillas de Identidad han implementado 70 ccs que articulan cerca de 800 custodios y guardianes de semillas.

Para la conformación de las redes de custodios y guardianes de semillas, se han identificado tres etapas con múltiples acciones que se recomienda tener en cuenta para el establecimiento y consolidación de las mismas, entendiendo que cada proceso tendrá sus particularidades (Chacón y García, 2016) (tabla 1). 
Tabla 1. Etapas y acciones en el proceso de conformación y consolidación de redes de custodios y guardianes de semillas.

\begin{tabular}{ll}
\hline \multicolumn{1}{c}{ Etapa } & \multicolumn{1}{c}{ Acciones } \\
\hline Etapa 1. & - Definición de principios y objetivos del trabajo en red. \\
Creación de la red de & - Identificar los custodios o guardianes de semillas de la comunidad. \\
custodios & - Realizar el inventario de semillas por familia, por vereda o resguardo. \\
& - Realizar la caracterización participativa de las semillas nativas y criollas. \\
\hline & - Elaborar diagnósticos locales de semillas. \\
Etapa 2. & - Identificar e implementar sistemas tradicionales, locales y artesanales de \\
Crecimiento y & conservación y almacenamiento de semillas. \\
fortalecimiento & - Diseñar y promover campañas de rescate de semillas. \\
& - Socializar el conocimiento local sobre las semillas y promover intercambios, ferias \\
& de semillas y alimentos tradicionales a nivel local y regional. \\
\hline Etapa 3. & Elaborar diagnósticos locales de semillas. \\
Consolidación de & - Identificar e implementar sistemas tradicionales, locales y artesanales de \\
la red & conservación y almacenamiento de semillas. \\
& - Diseñar y promover campañas de rescate de semillas. \\
& Socializar el conocimiento local sobre las semillas y promover intercambios, ferias \\
\end{tabular}

Fuente: adaptado de Redes de custodios y guardianes de semillas y casas comunitarias de semillas nativas y criollas. Guía metodológica, por Chacón y García (2016).

Ahora bien, una de las estrategias ampliamente utilizadas por las redes de custodios y guardianes de semillas son las Casas Comunitarias de Semillas. El concepto es dinámico y, por tanto, está en permanente construcción acorde con los procesos sociales, culturales y demás. Esta noción es complementaria con los de Bancos Familiares de Semillas, Reservas Comunitarias de Semillas y se plantea:

como un conjunto de espacios donde pueden o no estar unidos y funcionan integral e interdependientemente al servicio de la Red de Custodios y Guardianes de Semillas con el objetivo de producir, reproducir, almacenar, seleccionar, mejorar, intercambiar y comercializar todas aquellas semillas de interés económico, cultural y ambiental de la comunidad. (Chacón y García, 2016, p. 24).

La CCS tiene como objetivo recuperar, producir, conservar y almacenar semillas nativas y criollas de las regiones donde existen y funcionan las redes de custodios de semillas. Adicionamente, la ccs busca suplir la demanda local de semillas por parte de los agricultores de la Red. También, se constituye como un esquema para prever problemas relacionados con el fenómeno de cambio climático, escasez de agua, emergencias ambientales y otras del territorio; igualmente, la ccs busca 
ser un espacio de encuentro e intercambio de experiencias y saberes de las comunidades sobre semillas criollas y nativas conservadas por estas colectividades. Al respecto del intercambio, hombres, mujeres y niños conocen y se capacitan sobre los procesos para mejorar la calidad y las técnicas de almacenamiento, selección y conservación de sus semillas.

La complejidad y diversidad que se presentan en las CCS responde al contexto del territorio. De igual forma, su ubicación difiere según las características de cada red de semillas, las hay en veredas y resguardos indígenas, integradas por pequeños grupos de familias, también conocidas como ccs familiares. Las CCs de este tipo manejan un volúmen de semillas pequeño, bajo el manejo de un custodio capacitado, previamente, para llevar los registros, determinar la calidad óptima de la semilla recibida en la CCS, establecer los porcentajes de germinación, entre otras actividades.

$\mathrm{Al}$ respecto del almacenamiento e intercambio de semillas, las cCs familiares se caracteriza por contar con un espacio para este acopio en frascos y canecas. Las semillas circulan a partir de sistemas de préstamo e intercambio, que varia según el contexto de cada Red. En la actualidad, en la mayoría de las ccs, las ventas se hacen en muy bajo volumen y a nivel local. Entre tanto, los registros y empaques especiales están en construcción.

De igual modo, como se han propuesto unas etapas para el establecimiento de las redes de custodios y guardianes de semillas, a continuación, se presentan los elementos para el desarrollo de una propuesta de una ccs enmarcados en cuatro aspectos claves: 1. Organización, 2. Administración, 3. Técnica y 4. Reglamento interno (Chacón y García, 2016) (tabla 2).

Tabla 2. Aspectos claves y elementos a desarrollar para una propuesta de Casa Comunitaria de Semillas.

\begin{tabular}{ll}
\hline Aspecto clave & \multicolumn{1}{c}{ Elementos por desarrollar } \\
\hline & Identificación de custodios(as) o guardianes(as) de semillas en la comunidad. \\
& Discusión sobre la necesidad y posibilidad de tener una ccs. \\
1. Organización & Ubicación de la(s) ccs: vías de acceso, centralidad. \\
& Designación de responsables del manejo de la ccs: coordinador y seguimiento administrativo. \\
& Espacios y tiempos de seguimiento y evaluación internos, con la red y la comunidad. \\
& Definición del responsable de administración. \\
& Definición del tipo de registros: entrada y salida de semillas, compras y ventas de semilla, \\
& gastos, horas de trabajo, contabilidad. \\
2. Administración & Organigrama de funcionamiento. \\
& Rendición de cuentas a la red y la comunidad. \\
& Gestión de recursos. \\
& Definición de precios: costos de producción.
\end{tabular}

(Continúa) 


\begin{tabular}{ll}
\hline \multicolumn{1}{c}{ Aspecto clave } & \multicolumn{1}{c}{ Elementos por desarrollar } \\
\hline \multirow{4}{*}{ 3. Técnica } & Tipo de construcción donde van a quedar las semillas. Que la temperatura sea baja y estable. \\
& Necesidades de acondicionamiento del espacio: para regular temperatura y humedad. \\
& Necesidades de equipos y mobiliario de acuerdo con el volumen y rotación de la semilla: \\
& frascos, canecas, silos, zarandas, grameras, pesos, nevera, computador, ventilador, secador, etc. \\
& Tratamiento de la semilla. \\
& Pruebas de calidad a realizar: porcentaje de germinación, secado, limpieza, daños por \\
& insectos y hongos. \\
\hline \multirow{4}{*}{ 4. Reglamento } & Elaboración de acuerdos escritos con propietarios del inmueble: convenio de uso, tiempo, \\
Interno & área, horarios, etc. \\
& Elaboración de protocolos de funcionamiento de la ccs. \\
& Elaboración de protocolos de producción de semillas nativas y criollas en la comunidad. \\
& Inventarios de semillas nativas y criollas de la comunidad. \\
& Acuerdos para préstamo, intercambio y venta \\
\hline
\end{tabular}

Fuente: adaptado de Redes de custodios y guardianes de semillas y casas comunitarias de semillas nativas y criollas. Guia metodológica, por Chacón y García (2016).

En la anterior tabla, se describieron los aspectos clave y elementos que aplican, en general, para las CCs. Sin embargo, en el país existen ccs de alcance regional, las cuales presentan características adicionales a las ccs de alcance local (figura 3).

Figura 3. Características de una Casa Comunitaria de Semillas regional.

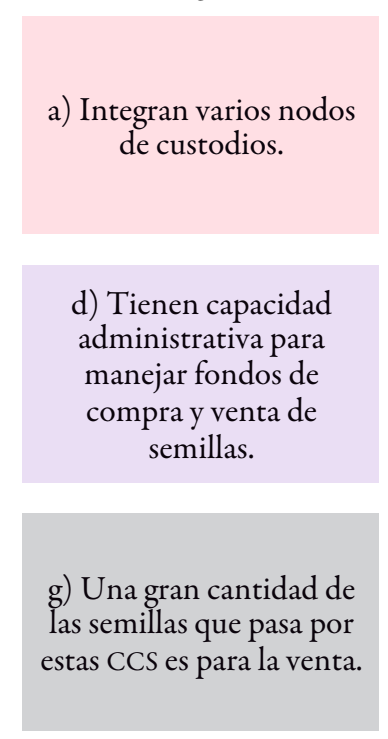

b) Manejan volúmenes más altos de semillas.

e) Están construyendo su Sistema Participativo de Garantía (SPG).

h) Están construyendo alternativas de sostenibilidad. c) Requieren de un equipo de personas con mayor dedicación para las tareas de recibir, registrar y cuidar las semillas.

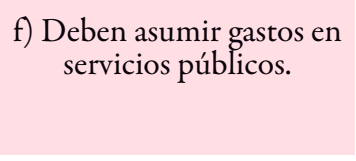

i) Manejan un empaque de semillas con información básica.

Fuente: elaboración propia. 
Un ejemplo de ccs regional es representado por el Centro de Semillas de la Red de Guardianes de Semillas de Vida (RGSv) en los municipios de Consacá, La Unión, San Lorenzo en Nariño; la ccs del Resguardo Indígena Cañamomo - Lomaprieta en Riosucio; la ccs de la Red de Semillas Libres de Antioquia en Medellín y la ccs de la Red de Custodios de Siberia - Caldono en el Cauca. Estas redes han logrado vender semillas a proyectos productivos de ONG, instituciones públicas y privadas a nivel local y regional.

En la Casa Comunitaria de Semillas se realizan diversas actividades orientadas a controlar y garantizar la calidad de las semillas criollas y nativas que transitan por esta, ilustradas en la figura 4. Es importante resaltar que, las semillas que se reciben en la cCs deben pertenecer a custodios o guardianes de semillas de la Red a los cuales se les hace un acompañamiento permanente.

Figura 4. Actividades realizadas en la ccs.

Llevar el registro de ingreso y salida de semillas. Evaluación de la calidad física de las mismas. Todas las semillas ingresan con pasaporte (etiqueta con nombre de custodio, nombre de la semilla, cantidad de semilla, lugar de producción, fecha de recolección) diligenciado por el guardián.
Elaborar e implementar protocolos de manejo y almacenamiento adecuado de semillas.

Realizar las
pruebas de
germinación a
todas las semillas
que ingresan a la
ccs y se lleva un
registro de las
mismos.

Realizar intercambios de semillas, conocimientos y experiencias.

Fuente: elaboración propia.

\subsection{Evaluación de la calidad de las semillas nativas y criollas: Sistema Participativo de Garantía}

Una condición necesaria para el fortalecimiento de los procesos de Redes y Casas Comunitarias de Semillas es la producción de semillas con buena calidad, lo cual se logra a partir de una serie de acciones organizativas de tipo formativo, de adecuación tecnológica e incidencia en las políticas públicas.

Desde la conceptualización de las Ccs, la calidad de la semilla se evalúa a partir de diferentes aspectos: culturales, agronómicos, de calidad física, genética y sanitaria. Para la sistematización de la calidad de las semillas se tomó el ejemplo de tres redes a nivel del país: la Red de Semillas de Riosucio - Caldas, en la región Caribe 
se encuentra la Red de Semillas de la Asociación de Productores Agropecuarios Alternativos (ASPROAL) y la Red se Semillas Libres de Antioquia.

En la práctica, las cCS realizan actualmente entre tres y cinco tipos de pruebas para permitir el tránsito de las semillas por las casas comunitarias. (Tabla 3)

Tabla 3. Pruebas realizadas a las semillas en tres ccs de la RSLC.

\begin{tabular}{|c|c|c|c|c|c|}
\hline $\begin{array}{l}\text { Casa de } \\
\text { semillas }\end{array}$ & $\begin{array}{c}\text { Calidad } \\
\text { sanitaria }\end{array}$ & Pureza física & Humedad & Germinación & Viabilidad \\
\hline ASPROAL & Sí & Sí & Sí & Sí & No \\
\hline Riosucio & Sí & Sí & Sí & Sí & No \\
\hline Antioquia & Sí & Sí & Sí & Sí & Sí \\
\hline Observación & $\begin{array}{l}\text { Se hace por } \\
\text { observación }\end{array}$ & Se hace manual & $\begin{array}{c}\text { Con la prueba } \\
\text { ancestral de la } \\
\text { sal tostada }{ }^{2}\end{array}$ & $\begin{array}{c}\text { Para todas las } \\
\text { especies }\end{array}$ & $\begin{array}{c}\text { Con la prueba } \\
\text { topógrafica por } \\
\text { Tetrazolio }^{3}\end{array}$ \\
\hline
\end{tabular}

Fuente: elaboración propia.

La cantidad de pruebas y la rigurosidad de ellas se dan de acuerdo con el grado de especialización de las ventas y del volumen de estas. En las CCs, donde priman los intercambios, se realizan pruebas de germinación, de sanidad física y la prueba de pureza física, como por ejemplo en las Redes de Los Palmitos, Red Agroecológica del Caribe (RECAR), la Red del Cauca, del Valle del Cauca y de Risaralda. En aquellas CCS con ventas sistemáticas, se han establecido protocolos con las pruebas de calidad de las semillas como el cultivo de patógenos y pruebas de viabilidad con tetrazolio, como en el caso de la Red de Semillas Libres de Antioquia, la Red de Riosucio - Caldas y la Red de la RGsv en Nariño.

Profundizando en una de las pruebas realizadas en las ccsanalizadas anteriormente, se presentan los resultados para las pruebas de germinación en tres

\footnotetext{
${ }^{2}$ Para semillas-grano se utiliza sal seca (ya sea seca al sol por 2 días o seca al fuego). Primero, se toma una botella de vidrio seca, allí se deposita un tercio del volumen en semillas. Posteriormente, se adicionan 20-30 g de sal, se tapa la botella y se sacude fuerte por un minuto. Se deja en reposo por 15 minutos y se agita de nuevo. Sí se adhiere la sal en las paredes de la botella, esto indica que el grano no ha alcanzado el porcentaje de secado óptimo para el almacenamiento.

3 "Es una prueba bioquímica para determinar la viabilidad de una semilla. [...] Diferencia los tejidos vivos de los muertos sobre la base de la actividad de enzimas deshidrogenasas (enzimas de la respiración). Al ser hidratadas las semillas, la actividad de las deshidrogenasas incrementa, resultando en la liberación de iones [de] hidrógeno, reduciendo el tetrazolio a formazán. Este tiñe a las células vivas de color rojo, en tanto que las muertas permanecen sin colorear. La viabilidad de las semillas se determina en función del patrón de tinción del embrión y la intensidad de la coloración”. (Ruíz, 2009, p. 7).
} 
CCs partícipes del proceso de construcción del SPG. Estos registros corresponden a valores y registros para la garantía de la calidad de semillas (tabla 4).

Tabla 4. Pruebas de germinación en tres casas de semillas entre los años 2013 y 2018.

\begin{tabular}{|c|c|c|c|c|c|c|c|}
\hline \multirow{2}{*}{$\begin{array}{c}\text { Casa de } \\
\text { Semillas } \\
\text { Comunitaria }\end{array}$} & \multicolumn{6}{|c|}{ Año } & \multirow[t]{2}{*}{ Observación } \\
\hline & 2013 & 2014 & 2015 & 2016 & 2017 & 2018 & \\
\hline ASPROAL & & & & & 6 & 13 & $\begin{array}{l}\text { Solo se realiza a maíces. Total: } 10 \text { variedades. } \\
\text { Porcentajes superiores al } 85 \% \text {. }\end{array}$ \\
\hline Riosucio & 5 & 6 & 4 & 4 & 16 & 7 & $\begin{array}{l}\text { Entre los años } 2013 \text { y } 2017 \text { se realizaron pruebas } \\
\text { principalmente a } 10 \text { variedades de frijoles, } 1 \\
\text { variedad de habichuela y } 5 \text { de maíces. En el año } \\
2017 \text { se inició la prueba con hortalizas, } 5 \text { especies. } \\
\text { En el } 2018 \text { se realizaron pruebas a } 4 \text { especies de } \\
\text { hortalizas, entre ellas a } 4 \text { variedades de tomate. }\end{array}$ \\
\hline Antioquia & & & & 21 & 38 & 135 & $\begin{array}{l}\text { Entre los años } 2016 \text { y } 2017 \text { se realizaron pruebas } \\
\text { a semilla de ahuyama, amaranto, arveja, cilantro, } \\
\text { frijol, girasol, guandú, habas, habichuela, lenteja, } \\
\text { maíz, manzanilla, papayuela, pepino, pimentón, } \\
\text { quinua y tomate. En el año } 2018 \text { se aumentaron } \\
\text { las pruebas a } 45 \text { especies vegetales más, entre las } \\
\text { que se encuentran } 20 \text { hortalizas. }\end{array}$ \\
\hline
\end{tabular}

Fuente: elaboración propia.

La evaluación de la calidad de semillas nativas y criollas se constituye como la base del SPG. La construcción del SPG de semillas se basó en la experiencia de la RECAB y el MAELA referente al instrumento de garantía de la calidad desarrollado (bien sea para alimentos agroecológicos o para la calidad de semillas). Los criterios o normas para el SPG se han construido de manera participativa por las organizaciones de la RSLC, a partir de talleres regionales realizados en los años 2015, 2016 y 2017. Posteriormente, el instrumento se ha ajustado con los promotores y redes que ya tienen implementado el SPG, sumado a otras acciones hasta la fecha (figura 5). Se espera que las evaluaciones que se registran de manera transparente sean una herramienta por utilizar en la incidencia política, frente a la normativa y políticas públicas para la producción, uso y comercialización de semillas criollas y nativas en Colombia 
Figura 5. Síntesis del proceso de construcción del SPG para la calidad de semillas desde el año 2015 hasta el año 2018.

- Primer taller sobre SPG en la zona Cafetera, zona Sur-occidente y zona Caribe.

- Definición de los SPG, sus características e importancia para la Red de Semillas Libres de Colombia.

2015
- Inicio del proceso de sistematización del proceso de creación de un spg para las redes de semillas en Colombia.

- Talleres de sensbilización sobre la estructura y normativa construida participativamente en la zona Cafetera, Sur-occidente y Caribe en el marco de los talleres de incidencia política y legal.

- Recolección de impresiones acerca de la normativa propuesta para el spg en el encuentro de Ecovida.
- Construcción participativa de un instrumento de evaluación para el spg de semillas criollas y nativas.

- Establecimiento de redes con otros actores importantes en el país y la visibilización para el establecimiento de diálogos con instituciones.

\section{8}

- Sistematización de la aplicación del instrumento de evaluación del SPG en dos experiencias regionales de la RSLC.

- Co-construcción del instrumento de evaluación para el SPG nacional.

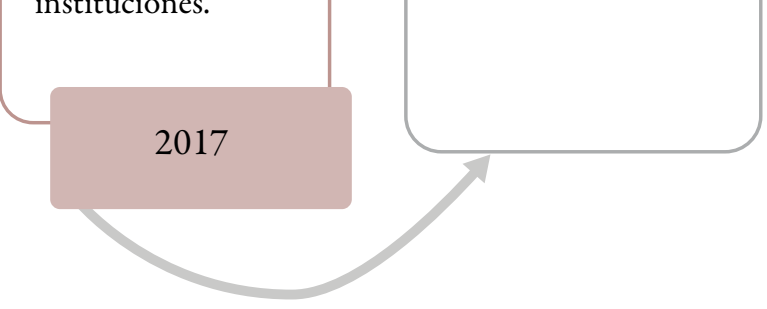


Como se ha mencionado, el SPG requiere de una normativa, acuerdos o criterios establecidos por los miembros del sistema o actores involucrados; así como de procedimientos de verificación o revisión por pares. Hasta el momento de construcción del instrumento, se ha identificado que los actores miembros son: custodios, productores campesinos, promotores campesinos, asesores, comité de aprobación del SPG, las redes y CCS y las organizaciones promotoras (tabla 5).

Tabla 5. Actores miembros del SPG para la calidad de semillas criollas y nativas.

\begin{tabular}{|c|c|c|}
\hline Actor & Descripción & Función \\
\hline Custodios* & $\begin{array}{l}\text { Son los hombres y mujeres que cuidan } \\
\text { las semillas criollas y nativas en sus } \\
\text { predios. Se encuentran articulados a } \\
\text { las organizaciones y a través de ellas a } \\
\text { las ccs. }\end{array}$ & $\begin{array}{l}\text { Rescatar, conservar, multiplicar y } \\
\text { usar las semillas criollas y nativas. Un } \\
\text { custodio se interesa por investigar y por } \\
\text { multiplicar ese conocimiento entre los } \\
\text { agricultores y otros custodios. }\end{array}$ \\
\hline $\begin{array}{l}\text { Productores } \\
\text { campesinos }^{* *}\end{array}$ & $\begin{array}{l}\text { Son productores de conocida } \\
\text { trayectoria de producción de semillas. } \\
\text { No siempre se encuentran articulados } \\
\text { a las ccs o a las organizaciones con } \\
\text { custodios. }\end{array}$ & $\begin{array}{l}\text { Proveer semillas en las épocas que se } \\
\text { requiera y en cantidad suficiente. Para } \\
\text { incorporarlos al sistema se requiere } \\
\text { de invitación y se debe aplicar los } \\
\text { formatos de registro y evaluación como } \\
\text { a cualquier otro custodio. }\end{array}$ \\
\hline Promotores & $\begin{array}{l}\text { Son campesinos que ejercen la labor de } \\
\text { promover los procesos agroecológicos } \\
\text { o campesinos en las organizaciones } \\
\text { articuladas a las Redes de Semillas y } \\
\text { otras propuestas campesinas. }\end{array}$ & $\begin{array}{l}\text { La función de los promotores es } \\
\text { acompañar los procesos productivos de } \\
\text { las semillas criollas y nativas y de hacer } \\
\text { seguimiento a las recomendaciones } \\
\text { del sPG; mantener informados sobre } \\
\text { el proceso a los encargados del sPG. En } \\
\text { algunos de los casos los promotores, } \\
\text { al igual que los custodios, ejercen una } \\
\text { función de revisión por pares en las } \\
\text { fincas en el marco del sPG y allí reciben } \\
\text { el nombre de promotores o evaluadores } \\
\text { del sPG. }\end{array}$ \\
\hline Asesores & $\begin{array}{l}\text { Son personas de formación técnica } \\
\text { o profesional en diferentes áreas de } \\
\text { conocimiento que acompañan los } \\
\text { procesos en las Redes y ccs. }\end{array}$ & $\begin{array}{l}\text { Apoyar la cualificación técnica y } \\
\text { organizativa de las ccs. En lo específico } \\
\text { del sPG acompañan el diseño, ajuste e } \\
\text { implementación del mismo. }\end{array}$ \\
\hline $\begin{array}{c}\text { Comité de aprobación } \\
\text { del SPG }\end{array}$ & $\begin{array}{l}\text { Constituido por al menos tres personas } \\
\text { de la Red y CCS: un representante de los } \\
\text { promotores, uno de los evaluadores y } \\
\text { una persona responsable de calidad }\end{array}$ & $\begin{array}{l}\text { Son los encargados de dar el dictamen } \\
\text { a cada custodio, en relación con el } \\
\text { cumplimiento de los procedimientos y } \\
\text { la norma o acuerdos. }\end{array}$ \\
\hline
\end{tabular}




\begin{tabular}{cll}
\hline Actor & \multicolumn{1}{c}{ Descripción } & \multicolumn{1}{c}{ Función } \\
\hline $\begin{array}{c}\text { Redes y Casas } \\
\text { Comunitarias de } \\
\text { Semillas }\end{array}$ & $\begin{array}{l}\text { Son las redes que se articulan a nivel } \\
\text { del país en torno a la recuperación, } \\
\text { multiplicación y reproducción de } \\
\text { semillas criollas y nativas, y que tienen }\end{array}$ & $\begin{array}{l}\text { Es en la ccs donde sucede la venta de } \\
\text { semillas y es allí donde cobra vigencia } \\
\text { realizar el sPG de semillas. Las semillas } \\
\text { intercambiadas o vendidas por los } \\
\text { custodios directamente en sus parcelas }\end{array}$ \\
& $\begin{array}{l}\text { de Semillas, por medio de las cuales } \\
\text { establecen el intercambio o venta de las } \\
\text { semillas. }\end{array}$ & $\begin{array}{l}\text { o los mercados no se rigen por el sPG } \\
\text { como instrumento de garantía. }\end{array}$ \\
& $\begin{array}{l}\text { Son las organizaciones que promueven } \\
\text { la producción campesina, agroecológica } \\
\text { yrganizaciones }\end{array}$ & $\begin{array}{l}\text { Estas organizaciones participan desde el } \\
\text { proceso de incidencia política y el apoyo } \\
\text { promotoras }\end{array}$ \\
& $\begin{array}{l}\text { yla producción de semillas criollas y } \\
\text { nativas, y su articulación en redes. }\end{array}$ & producción de semillas. \\
\hline
\end{tabular}

Fuente: ${ }^{*}$ Llamados guardianes de semillas. ${ }^{* *}$ Llamados cosecheros. Adaptado de Sistematización de dos procesos de Sistemas Participativos de Garantía (SPG) que adelanta la Red de Semillas Libres de Colombia (RSLC), por Aguilar-Gómez y GarcíaHoyos (2018).

Previamente, se ha definido que a partir del SPG como instrumento de garantía de la calidad, se evalúan las normas o los acuerdos para la producción de semillas criollas y nativas en las redes de semillas y, de esta forma, el SPG se configura como guía para los custodios, ya que orienta las formas de producción de semillas para constituir la calidad declarada de las mismas por las CCS, con base en los siguientes criterios técnicos:

I. Normas técnicas para asegurar que las semillas son agroecológicas y de polinización abierta.

II. Prácticas en el manejo de las semillas para asegurar su calidad no transgénica.

III. Procedimientos para el manejo de las semillas a fin de asegurar su calidad fisiológica, física y sanitaria.

IV. Prácticas de manejo de las semillas para asegurar su calidad criolla y nativa.

V. Procedimientos para el acompañamiento a fincas y administración de la casa de semillas.

A continuación, se ilustra el paso a paso del proceso de verificación de la calidad de semillas criollas y nativas que transitan por las CCS miembro del SPG, a nivel local (figura 6). 
Figura 6. Pasos en la verificación de calidad de semillas a nivel local.

Punto de partida: lista de custodios y

productores de semillas articulados a las cCs.

Para cada custodio y productor se llena una ficha inicial de diagnóstico que da cuenta de las prácticas bajo las que se producen las semillas y la articulación del mismo con las cCs.

El promotor evaluador compara lo encontrado en la finca con la norma o acuerdos y prepara una ficha de evaluación.
- Estos custodios y productores serán visitados a fin de garantizar la calidad de las semillas.

- Esta información es colectada y analizada por un promotor.

- La ficha de evaluación indicará al custodio o productor las recomendaciones.

El o los promotores preparan un informe con las fichas de todos los custodios para presentarlo al comité de aprobación.

Sí el custodio/productor
cumple con los acuerdos
pactados, se entrega un
certificado reconociendolo
como miembro activo del sPG.
Sí el custodio presenta alguna
dificultad o anomalía
justificada, podrá entregarse un
certificado condicionado al
mejoramiento.

- De no haber conformidad con la norma, habrá lugar a sanciones: 1) Advertencia de obligatorio cumplimiento, 2) suspensión temporal para entregar y recibir semillas en la cCs hasta que se verifique la correción, 3) Exclusión de la ccs.

A cada custodio se le dará un tiempo para subsanar la no conformidad. Sí al cabo de dicho tiempo el custodio y la organización no toman acciones al respecto, el comité de aprobación podrá suspender el spg (aval de confianza) y recomendar a la ccs no obtener semillas del custodio de referencia. Dicha información estará disponible en la ccs y fincas de los custodios como parte del proceso de garantía del SPG. 
Sumado a la definición conjunta de normas/acuerdos de calidad y de mecanismos de verificación, en la actualidad, se construye el SPG a fin de obtener un aval de la calidad de semillas criollas y nativas a nivel regional y nacional (figura 7).

Figura 7. Proceso de aval de calidad de semillas criollas y nativas a nivel regional y nacional.
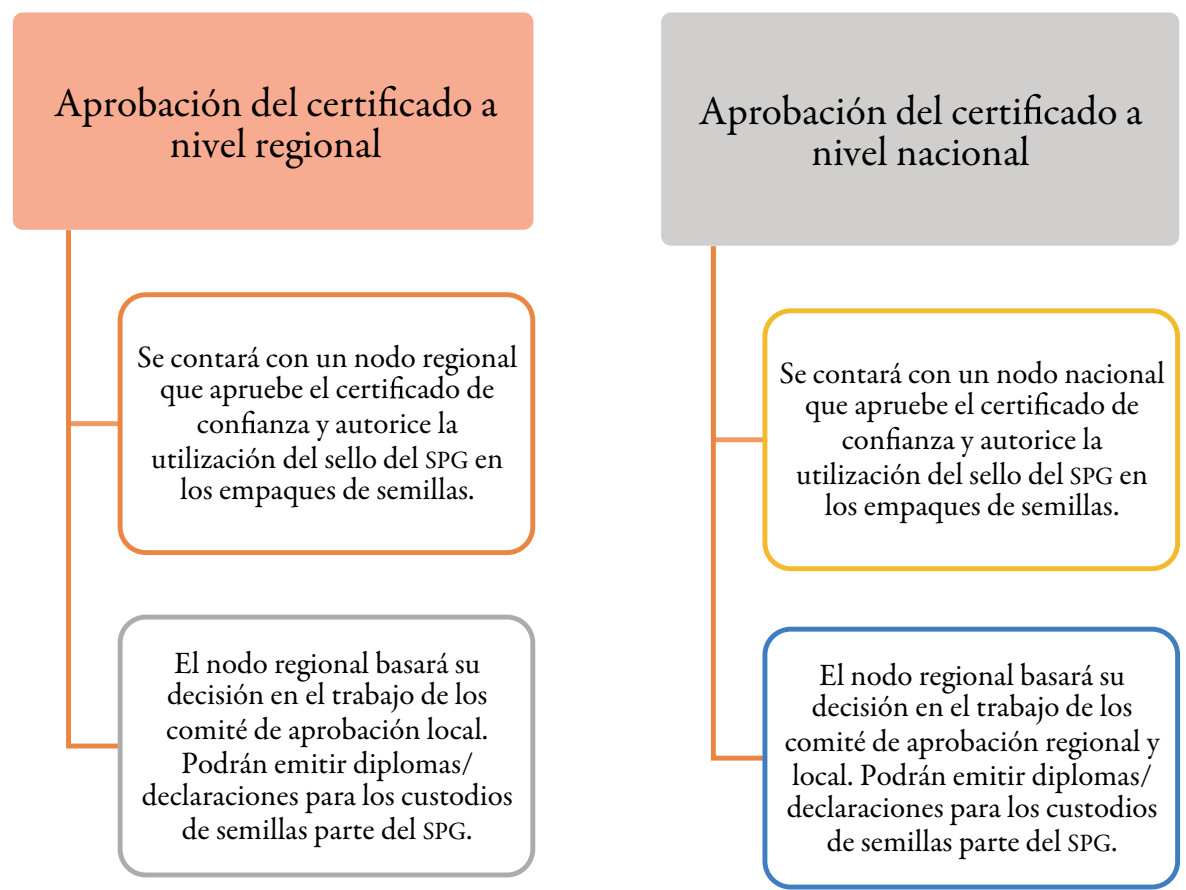

Fuente: elaboración propia.

\subsection{Resultados de la evaluación del SPG de calidad de semillas}

Para el año 2017 en las tres redes objeto de estudio de esta sistematización, se evaluaron parámetros de calidad a 31 custodios de semillas, diferenciados así: 5 en la costa caribe, 10 en Riosucio y 16 en Antioquia.

La evaluación del sistema se hace a partir de las visitas a la finca y la aplicación de un cuestionario que evalúa 14 normas en los 5 componentes. Cada pregunta tiene una única respuesta y su resultado lleva a una calificación numérica. Cada componente tiene un valor relativo de 1 , para que en total la máxima calificación sea de 5. Cabe resaltar, que no todos los aspectos tienen la misma importancia relativa, por eso, se trabaja en una calificación ponderada. Los resultados se pueden mostrar de manera individual o grupal. En el estudio de caso del presente capítulo, mostramos los resultados de manera individual dentro de cada región . 
Figura 8. Resultado de la evaluación del cumplimiento de parámetros de calidad en tres Redes de Semillas.

\begin{tabular}{|l|r|r|r|r|r|r|r|r|}
\hline \multicolumn{1}{|c|}{ Resultados Red de semillas libres Antioquia 2017 } & \multicolumn{7}{|c|}{ Custodios } \\
\hline & 1 & 2 & 3 & 4 & 5 & 6 & 7 & 8 \\
\hline $\begin{array}{l}\text { I. Criterios técnicos para asegurar que las semillas son } \\
\text { ecológicas y de polinización abierta }\end{array}$ & 0,68 & 0,51 & 0,58 & 0,5 & 0,285 & 0,755 & 0,725 & 0,505 \\
\hline $\begin{array}{l}\text { II. Manejo de las semillas para asegurar su calidad no } \\
\text { transgénica }\end{array}$ & 0,66 & 0,33 & 0,33 & 0,33 & 0,33 & 0,66 & 0,66 & 0,33 \\
\hline III. Manejo de las semillas para asegurar su calidad sanitaria & 0,2 & 0,4 & 1 & 0,2 & 0,2 & 0,8 & 0,6 & 0,6 \\
\hline $\begin{array}{l}\text { IV. Manejo de las semillas para asegurar su calidad Criolla } \\
\text { y Nativa }\end{array}$ & 0,25 & 0,25 & 0,25 & 0,25 & 0,5 & 0,5 & 0,5 & 0,75 \\
\hline $\begin{array}{l}\text { V. Acompañamiento a fincas y Administración de la casa } \\
\text { de semillas }\end{array}$ & 0,8 & 0,8 & 0,8 & 0,8 & 0,3 & 0,8 & 0,8 & 0,8 \\
\hline Total Puntaje acumulado & 2,59 & 2,29 & 2,96 & 2,08 & 1,615 & 3,515 & 3,285 & 2,985 \\
\hline Tipo sello & Criolla & Criolla & Criolla & Criolla & Criolla & Ecológica & Ecológica & Ecológica \\
\hline
\end{tabular}

\begin{tabular}{|c|c|c|c|c|c|c|c|c|}
\hline \multirow[t]{2}{*}{ Resultados Red de semillas libres Antioquia 2017} & \multicolumn{8}{|c|}{ Custodios } \\
\hline & 9 & 10 & 11 & 12 & 13 & 14 & 15 & 16 \\
\hline $\begin{array}{l}\text { I. Criterios técnicos para asegurar que las semillas son } \\
\text { ecológicas y de polinización abierta }\end{array}$ & 0,325 & 0,145 & 0,325 & 0,68 & 325 & 0,68 & 0,5 & 0,85 \\
\hline $\begin{array}{l}\text { II. Manejo de las semillas para asegurar su calidad no } \\
\text { transgénica }\end{array}$ & 0,66 & 0,33 & 0,66 & 0,66 & 0,33 & 0,66 & 0,33 & 0,33 \\
\hline III. Manejo de las semillas para asegurar su calidad sanitaria & 0,2 & 0 & 0,2 & 0,2 & 0 & 0 & 0,2 & 0,2 \\
\hline $\begin{array}{l}\text { IV. Manejo de las semillas para asegurar su calidad Criolla } \\
\text { y Nativa }\end{array}$ & 0,25 & 0 & 0 & 0 & 0 & 0,25 & 0,5 & 0,5 \\
\hline $\begin{array}{l}\text { V. Acompañamiento a fincas y Administración de la casa } \\
\text { de semillas }\end{array}$ & 0,3 & 0 & 0,5 & 0,3 & 0 & 0,5 & 0,5 & 0 \\
\hline Total Puntaje acumulado & 1,735 & 0,475 & 1,685 & 1,84 & 0,655 & 2,09 & 2,03 & 1,88 \\
\hline Tipo sello & Criolla & Criolla & Criolla & Ecológica & Criolla & Criolla & Criolla & Criolla \\
\hline
\end{tabular}

\begin{tabular}{|c|c|c|c|c|c|}
\hline \multirow[t]{2}{*}{ Resultados ASPROAL 2017} & \multicolumn{5}{|c|}{ Custodios } \\
\hline & 1 & 2 & 3 & 4 & 5 \\
\hline $\begin{array}{l}\text { I. Criterios técnicos para asegurar que las semillas son } \\
\text { ecológicas y de polinización abierta }\end{array}$ & 0,325 & 0,68 & 0,325 & 0,68 & 0,5 \\
\hline $\begin{array}{l}\text { II. Manejo de las semillas para asegurar su calidad no } \\
\text { transgénica }\end{array}$ & 0,66 & 0,66 & 0,33 & 0,66 & 0,33 \\
\hline III. Manejo de las semillas para asegurar su calidad sanitaria & 0,2 & 0,2 & 0 & 0 & 0,2 \\
\hline $\begin{array}{l}\text { IV. Manejo de las semillas para asegurar su calidad Criolla } \\
\text { y Nativa }\end{array}$ & 0 & 0 & 0 & 0,25 & 0,5 \\
\hline $\begin{array}{l}\text { V. Acompañamiento a fincas y Administración de la casa } \\
\text { de semillas }\end{array}$ & 0,5 & 0,3 & 0 & 0,5 & 0,5 \\
\hline Total Puntaje acumulado & 1,685 & 1,84 & 0,655 & 2,09 & 2,03 \\
\hline Tipo sello & Criolla & Criolla & Criolla & Criolla & Criolla \\
\hline
\end{tabular}

\begin{tabular}{|c|c|c|c|c|c|c|c|c|c|c|}
\hline \multirow[t]{2}{*}{ Resultados Riosucio 2017} & \multicolumn{10}{|c|}{ Custodios } \\
\hline & 1 & 2 & 3 & 4 & 5 & 6 & 7 & 8 & 9 & 10 \\
\hline $\begin{array}{l}\text { I. Criterios técnicos para asegurar que las semillas son } \\
\text { ecológicas y de polinización abierta }\end{array}$ & 0,895 & 0,965 & 0,895 & 0,86 & 0,895 & 0,965 & 0,72 & 0,72 & 0,72 & 0,965 \\
\hline $\begin{array}{l}\text { II. Manejo de las semillas para asegurar su calidad no } \\
\text { transgénica }\end{array}$ & 0,66 & 0 & 0 & 0 & 0 & 0 & 0 & 0 & 0 & 0 \\
\hline III. Manejo de las semillas para asegurar su calidad sanitaria & 1 & 1 & 1 & 1 & 1 & 1 & 1 & 1 & 1 & 1 \\
\hline $\begin{array}{l}\text { IV. Manejo de las semillas para asegurar su calidad Criolla } \\
\text { y Nativa }\end{array}$ & 0,5 & 0,75 & 0,5 & 0,75 & 0,5 & 0,75 & 0,75 & 0,5 & 0,75 & 0,75 \\
\hline $\begin{array}{l}\text { V. Acompañamiento a fincas y Administración de la casa } \\
\text { de semillas }\end{array}$ & 1 & 1 & 1 & 1 & 1 & 1 & 1 & 1 & 1 & 0,7 \\
\hline Total Puntaje acumulado & 4,055 & 3,715 & 3,395 & 3,61 & 3,395 & 3,375 & 3,47 & 3,22 & 3,47 & 3,415 \\
\hline Tipo sello & Criolla & Criolla & Criolla & Criolla & Criolla & Criolla & Criolla & Criolla & Criolla & Criolla \\
\hline
\end{tabular}

Fuente: elaboración propia. 
En la figura 8 se presenta el resultado de cada custodio y de cada componente, siendo el valor mayor por obtener el número 1. cada componente evaluado se encuentra sombreado por el color rojo, verde o amarillo, dependiendo de la condición sobre el cual se evalúa. Entonces, la calificación de cada componente nos da dos valores: la numérica y la de color. En relación con el color, el verde significa que todo el criterio evaluado se cumple. El color amarillo significa que se cumple parcialmente o se cumple condicionado a una tarea que debe completar por parte del custodio, en el periodo siguiente, entre la evaluación actual y la siguiente. El color rojo significa que no cumple el criterio y que tiene una tarea por corregir, ademas significa que la semilla no es ecológica.

Cada componente, mientras mas se acerque al numero 1 , significa que ha alcanzado a desarrollar la practica completa. La evaluación tambien puede darse a partir del total de los cinco componentes, en los cuales, el mayor puntaje es el de 5; significa entonces que, un custodio que este mas cercano a la calificación de 5, está con mayores practicas alcanzadas, por lo tanto, está más adelantado que uno que se encuentre con menor calificación. Este criterio no implica que mientras su calificación sea mas alta, se le reciba mas semillas, significa que es un custodio que tiene mayor aprendizaje y puede compartir con otros custodios.

Una vez revisado los resultados, cada custodio quedará en la categoria de producir semillas criollas y nativas de manera convencional o de manera ecológica. De esta manera, se entrega el sello para ser empleado en los sobres de venta de las semillas (figura 9).

Figura 9. Resultados graficos de la evaluación y sello de calificación del SPG de semillas.

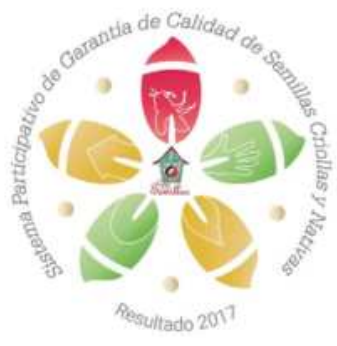

Resultado de la evaluación año 2017

Fuente: elaboración propia.

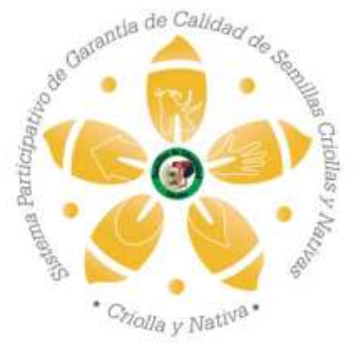

Sello de semilla criolla y nativa

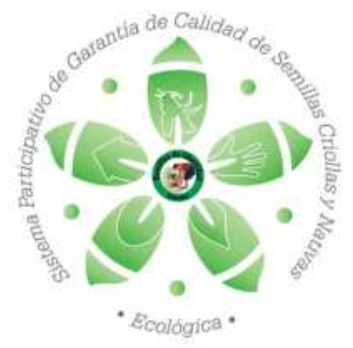

Sello semilla ecológica 
Los resultados finales se entregan con el sello que es una flor con 5 pétalos, cada uno representa los criterios evaluados. El criterio I esta simbolizado por una abeja, el criterio II por una mano, el criterio III por una hoja, el criterio IV por una semilla y, el criterio $v$ por una casa. La flor tiene en el centro el logo de la casa de semillas que hace el SPG y, si la semilla es ecológica, el logo es de color verde; asimismo, si la semilla es producida con productos de sintesis quimica, el logo es de color amarillo.

La calificación es una orientación sobre cómo se está llevando el trabajo y el seguimiento, pero, en definitiva, lo que impediría que se llevará semillas a la Casa Comunitaria de Semillas es que cumpla con algunos de los siguientes parámetros: no emplear semillas criollas, usar transgénicos que estas estén contaminadas o atacadas por insectos y enfermedades transmisibles y semillas con un porcentaje de germinación por debajo de las normas colombianas.

\subsection{Organización e incidencia}

Las Redes de Semillas con el apoyo técnico y financiero de SWISSAID y de las mismas organizaciones se articulan a procesos de incidencia y organización a nivel nacional desde la Campaña Semillas de Identidad y a la RSLC.

Varios aspectos unen a las redes, entre estas, la intención de fortalecer capacidades productivas, el apoyo mutuo y la organización para la incidencia política. Desde estos colectivos, se ha conformado la Alianza Multisectorial por la Salvaguarda de la Agrobiodiversidad, la Soberanía Alimentaria y el Derecho Humano a la Alimentación Adecuada, que es quizás, el espacio en el que se puede tener una mayor proyección del trabajo de las Redes de Semillas, al tener articulación con otros movimientos.

La conformación de esta Alianza Multisectorial propone un plan de incidencia con el fin de propiciar un diálogo político en tres escenarios: primero, en el que las normas favorecen un modelo agroindustrial basado en semillas certificadas, cultivos transgénicos y el uso intensivo de los recursos naturales; segundo, en el que las normas y políticas públicas no reconocen ni protegen los derechos de las comunidades a la soberanía alimentaria; y tercero, en donde la falta de aplicación de instrumentos legales nacionales e internacionales y de normas constitucionales no garantizan el derecho a una alimentación adecuada y la información suficiente al consumidor sobre los alimentos, de manera que, se proteja la soberanía y autonomía alimentaria.

Un tema crucial, desde un principio del movimiento de las redes de semillas, ha sido el de la venta de semillas en las ccs. Si bien este no ha sido el principal 
objetivo, ha sido importante discutirlo con las redes como mecanismo para generar sostenibilidad económica. Algunas organizaciones se han negado a la comercialización de las semillas, lo que se ha respetado, dando impulso al préstamo e intercambio local de semillas. En una consulta a varias redes nacionales e internacionales sobre el tema de venta de semillas, un gran número de custodios y sus organizaciones manifestaron estar de acuerdo con la posibilidad de vender las semillas. La comercialización de semillas criollas y nativas ha sido un derecho de las familias custodias de semillas, este se ha visto limitado por las empresas, la normativa nacional y la carencia de una política pública en esta materia. Aunque, las redes utilizan diferentes mecanismos para circular las semillas como son el préstamo, intercambio y venta, han declarado no ceder ante la exigencia del derecho a la libre comercialización de las semillas recuperadas, conservadas y multiplicadas.

\section{Discusión}

Por cientos de años, las semillas han sido esenciales para el manejo de cultivos y diversificación de la agricultura, así como el principal mecanismo por medio del cual los cultivos son distribuidos en el tiempo y espacio (Hermann, Amaya, Latournerie y Castiñeiras, 2009). Tradicionalmente, los agricultores han conservado, recuperado y dinamizado las semillas que producen, llevando a la conformación de los sistemas locales de semillas. Los sistemas locales de semillas son una práctica fundamental para los pequeños productores y, desde el punto de vista de su rol económico y social, constituyen un elemento clave para abordar los retos y necesidades en materia de producción y seguridad alimentaria (Almekinders, Louwaars y de Bruijn, 1994; Badstue, 2007).

Si bien es cierto que, recientemente se habla de la multifuncionalidad de la agricultura campesina como enfoque de análisis, la agricultura se ha constituido, a lo largo de la historia, como la base esencial del sustento alimentario y económico de la mayoría de las familias campesinas, indígenas y afrodescendientes de Colombia, a través de sistemas productivos basados en la diversificación.

Altieri (2000) ha definido que la diversificación productiva es una estrategia para minimizar el riesgo y estabilizar los rendimientos, usando bajos niveles de insumos externos y con un limitado impacto ambiental. Adicionalmente, Stupino, Iermanó, Gargoloff y Bonicatto, (2004) establecen que los sistemas diversos se constituyen como una estrategia para alcanzar la soberanía alimentaria de las familias agricultoras; concibiéndose también como un seguro para enfrentar el cambio ambiental o las necesidades sociales y económicas cambiantes. 
Estos sistemas diversos se caracterizan por un alto intercambio de conocimiento sobre el ambiente y sistemas de cultivo, a partir de la propia experiencia o del diálogo de saberes con otras personas (agricultores, investigadores, extensionistas). Estos "conocimientos son únicos y propios de cada comunidad ya que se modifican por procesos adaptativos y son transmitidos generalmente en forma oral y en la acción compartida" (Bonicatto, Marasas, Pochettino y Sarandón, 2014).

Lo anterior, se considera como indicadores de la necesidad de sostener y fomentar la autoproducción de semillas en los sistemas de la agricultura familiar (Cababié, Bonicatto y Abbona, 2015).

Aún, cuando se reconoce la importancia de la diversidad de semillas a nivel productivo, ambiental y cultural, la agrobiodiversidad se ha pérdido paulatinamente a causa, principalmente, de la expansión del modelo de agricultura de Revolución verde. La Organización de las Naciones Unidas para la Alimentación y la Agricultura (FAO, 2010) calcula que el 75\% de la agrobiodiversidad se perdió entre los años 1900 y 2000. Miles de variedades de semillas nativas y criollas se han perdido y, con ellas, su conocimiento y cultura. La diversidad de las especies vegetales se ve amenazada por la erosión genética, es decir, la pérdida de genes individuales o combinaciones de genes, como los que se encuentran en las variedades nativas adaptadas a nivel local. Lo anterior, como consecuencia de la sustitución de variedades locales por variedades modernas, la degradación medioambiental, la urbanización y el desbroce de nuevas tierras a través de la deforestación y los incendios de matorrales (FAO, 2011).

Muchos campesinos se han resistido a adoptar las semillas denominadas "mejoradas" y han mantenido sus sistemas tradicionales de producción de semillas nativas y criollas, las cuales producen, intercambian y venden a través de mercados locales; que las políticas públicas reconocen en muchos lugares como el mercado o sistema "informal" de semillas. Basado en lo anterior, invitamos a denominarlo el sistema local de semillas, como lo han descrito académicos y ONG a nivel mundial, el cual, ante todo, propende por la óptima calidad de las semillas que en él circulan.

Cuando se habla de calidad de las semillas, desde las organizaciones campesinas articuladas a la RSLC, se habla de aspectos que van más allá de una calidad física y agronómica. Se habla entonces de una calidad genética desde la diversidad, la no homogeneidad, de la variabilidad genética, que permite, por un lado, tener especies que fenotípicamente son similares o estables, pero que permiten tener una gran capacidad de adaptabilidad a diferentes condiciones climáticas, edáficas y manejos 
tecnológicos. Por otro lado, la calidad se aplica a la ancestralidad de las semillas, al manejo cultural y a las prácticas y conocimientos asociados a las semillas.

La evaluación de la calidad de las semillas es determinada por entes gubernamentales y la normativa que expiden en dicha materia, en la que se disponen los parámetros reconocidos de calidad. Como ya se ha mencionado, para el caso de Colombia, estas normativas son las emitidas por el ICA como autoridad competente. Sin embargo, las familias agricultoras han creado, conservado y multiplicado un gran número de variedades para el uso y consumo propio. Ellos mismos garantizan la calidad y, en la actualidad, trabajan arduamente a través de las Redes de Semillas en el establecimiento y funcionamiento de un Sistema Participativo de Garantía para asegurar la calidad de semillas criollas y nativas, asimismo, buscan proyectarse e incidir con este instrumento en la normativa y políticas públicas en Colombia.

Estas experiencias en las que familias campesinas y étnicas se agrupan en pro de la conservación y uso de la agrobiodiversidad y del conocimiento asociado a ella, se han consolidado en otras partes del mundo. Entre las experiencias significativas y que han sido referente para este trabajo en Colombia, se encuentra el caso en Brasil con Semillas de la Pasión (Sementes da Paixao) y Bionatur (Aguirre, 2006), el de Nicaragua con la Red de Bancos Comunitarios de Semillas (Rivas-Platero et al., 2013), el de Ecuador con la Red de Guardianes de Semillas de Ecuador originada en el año 2002 (Red de Guardianes de Semillas, 2018) y, finalmente, el caso de la Red Semillas de Libertad que une a guardianes y productores de semillas de 10 países de las Américas.

\section{Conclusiones}

El funcionamiento de las redes y ccs exhalta el trabajo de custodios y guardianes de semillas en las comunidades, quienes son indispensables para la existencia de los dos mecanismos. Tantos las redes como las ces son espacios vitales para la recuperación, protección, uso, conservación y multiplicación de semillas criollas y nativas y sus conocimientos asociados.

Aunque se han construido parámetros de calidad para las semillas nativas y criollas, es un reto la medición de los elementos que componen dichos parámetros de calidad de las semillas, el registro y sistematización de la información en cada red y CCS. En este sentido, el SPG para calidad de semillas criollas y nativas es un instrumento novedoso visto a la luz de diferentes procesos organizativos y que ayuda a salvaguarda la agrobiodiversidad en el mundo. Este instrumento requiere de un alto compromiso y cualificación de los custodios y de las redes de semillas frente 
a los criterios de garantía de la calidad. Para ello, será muy importante fortalecer técnica y organizativamente las redes, así como mantener el trabajo articulado con otros movimientos sociales a nivel nacional e internacional.

Es necesario que el Estado colombiano formule e implemente una política pública a partir de estrategias orientadas a la protección, recuperación, uso, conservación y multiplicación de semillas criollas y nativas, pero que esta política se materialice en apoyo a las comunidades para el desarrollo de actividades de inventariado, caracterización y diagnóstico y aval de la calidad de estas.

\section{Agradecimientos}

Agradecemos a los custodios y guardianes de semillas que integran todas las redes de semillas del país. A las organizaciones de apoyo como SWISSAID, RECAB y las organizaciones articuladas, igualmente, al MAELA por su perseverancia y constancia ante las dificultades técnicas, organizativas, climáticas y de orden social, que impiden un trabajo más rápido en resultados. Asimismo, por su comprensión de los problemas del territorio y del cosntante animó que infundan a los custodios y el empeño en el rigor técnico y científico, que posibilitará en el futuro cercano tener semillas de alta y estable calidad con criterios escogidos por las mismas comunidades.

\section{Referencias}

Aguilar-Gómez, T., y García-Hoyos, A. (2018). Sistematización de dos Procesos de Sistemas Participativos de Garantia (SPG) que adelanta la Red de Semillas Libres de Colombia (RSLC). Bogotá: Fundación SwissaID y Asociación Red Colombiana de Agricultura Biológica.

Aguirre, R. (2006). Red Bionatur de semillas: una herramienta estratégica del MST. Recuperado de https://www.grain.org/article/entries/3789-red-bionatur-desemillas-una-herramienta-estrategica-del-mst

Almekinders, C. J., Louwaars, N., y de Bruijn, G. (1994). Local seed systems and their importance for an improved seed supply in developing countries. Euphytica, 78(3), 207-216. Doi: https://doi.org/10.1007/BF00027519

Altieri, M. (2000). Biodiversidad multifuncional en la agricultura tradicional latinoamericana. LEISA. Revista de Agroecología, 15(3-4). Recuperado de http:// leisa-al.org/web/index.php/volumen-15-numero-4-3/2397-biodiversidadmultifuncional-en-la-agricultura-tradicional-latinoamericana 
Badstue, L. (2007). Adquisición de semillas: el papel que juega la confianza. LEISA. Revista de Agroecología, 23(2), 14-17. Recuperado de http://www.leisa-al.org/ web/images/stories/revistapdf/vol23n2.pdf

Binimelis, R. (2004). La pretendida coexistencia con la agricultura transgénica en España. Revista Ecología Politica, 28: 59-60. Recuperado de https://www. ecologiapolitica.info/novaweb2/wp-content/uploads/2017/06/028_Binimelis_2005.pdf

Bonicatto, M., Marasas, M., Pochettino, M., y Sarandón, S. (2014). La semilla en la conservación de los gustos y la historia. LEISA. Revista de Agroecología, 30(4). Recuperado de http://www.leisa-al.org/web/index.php/volumen-30-numero-4/1078-la-semilla-en-la-conservacion-de-los-gustos-y-la-historia

Cababié, J., Bonicatto, M., y Abbona, E. A. (2015). Semillas y saberes de los agricultores familiares. ¿Cuál es el rol de las ferias de intercambio en su reproducción y conservación? Revista de la Facultad de Agronomía, 114(3), 122-128. Recuperado de http://sedici.unlp.edu.ar/handle/10915/48679

Ceccon, E. (2008). La revolución verde tragedia en dos actos. Ciencias, 1(91), 21-29. Recuperado de https://www.redalyc.org/pdf/644/64411463004.pdf

Chacón, X., y García, M. (2016). Guía metodológica. Redes de custodios y guardianes de semillas y casas comunitarias de semillas nativas y criollas. Bogotá: Fundación SWISSAID y Corporación Biocomercio Sostenible. Recuperado de http:// semillas.org.co/apc-aa-files/5d99b14191c59782eab3da 99d8f95126/guiaredes-de-semillas-2017.pdf

Organización de las Naciones Unidas para la Alimentación y la Agricultura - FAO. (2010). Biodiversidad agricola: utilizarla para que no se pierda. Recuperado de http://www.fao.org/news/story/es/item/46805/icode/

Organización de las Naciones Unidas para la Alimentación y la Agricultura - FAO. (2011). La FAO se moviliza para detener la pérdida de recursos genéticos. Nuevo impulso a la diversidad vegetal mundial. Recuperado de http://www.fao.org/ news/story/es/item/116092/icode/

García, M. (2012). Zonas y territorios libres de transgénicos. Guía metodológica para declarar zonas y territorios libres de transgénicos. Bogotá: Fundación SWISSAID. Recuperado de https://www.swissaid.org.co/sites/default/files/ TLT\%20 Gu\%C3\%ADa\%20metodol\%C3\%B3gica.pdf

Grupo Semillas. (2016). Guia metodológica. Diagnóstico, recuperación, conservación y difusión de semillas criollas. Bogotá: ARFo editores e impresores Ltda. Recuperado de http://semillas.org.co/es/publicaciones/gu-3 
Gutiérrez-Escobar, L. (2015). Soberanía alimentaria. La Red de Semillas Libres de Colombia. Contextos, 4(13), 11-24. Recuperado de http://www.academia.edu/ 15260227/Soberani_a_alimentaria._La_Red_de_Semillas_Libres_de_Colombia

Hermann, M., Amaya, K., Latournerie, L., y Castiñeiras, L. (eds.). (2009). ¿Cómo conservan los agricultores sus semillas en el tropico húmedo de Cuba, México y Perú? Experiencias de un proyecto de investigación en sistemas locales de semillas de chile, frijoles y maiz. Roma: Bioversity International. Recuperado de https://www.bioversityinternational.org/fileadmin/_migrated/uploads/tx_ news/_Cómo_conservan_los_agricultores_sus_semillas_en_el_trópico_húmedo_de_Cuba_México_y_Perú_Experiencias_de_un_proyecto_de_investigación_en_sistemas_informales_de_semillas_de_chile_frijoles_y_ ma\%C3\%ADz_1355.pdf

Instituto Colombiano Agropecuario (ICA). (2015). Resolución 3168. Por medio del cual se reglamenta y controla la producción, importación y exportación de semillas producto del mejoramiento genético para la comercialización y siembra en el pais, asi como el registro de las unidades de evaluación agronómica y/o unidades de investigación en fitomejoramiento y se dictan otras disposiciones. Recuperado de https://www.ica.gov.co/ getattachment/4e8c3698-8fcb-4e42-80e7a6c7acde9bf8/2015R3168.aspx

May, C. (2008). PGS Guidelines. How participatory guarantee systems can develop and function. Germany: International Federation of Organic Agriculture Movements-IfOAM. Recuperado de https://www.ifoam.bio/sites/default/ files /page/files/pgs_guidelines_en_web.pdf

Mercado de semillas mueve más de \$200000 millones en Colombia. (2018). Revista Dinero. Recuperado de https://www.dinero.com/edicion-impresa/pais /articulo/ asi-es-el-mercado-de-semillas-en-colombia/258614

Ministerio de Agricultura y Desarrollo Rural. (2017). Resolución 464. Por la cual se adoptan los lineamientos estratégicos de politica pública para la Agricultura Campesina, Familiary Comunitaria y se dictan otras disposiciones. Recuperado de https://www.minagricultura.gov.co/Normatividad/Resolucion es/Resolución\%20No\%20000464\%20de\%202017.pdf

Movimiento Agroecológico América Latina y El Caribe (maela). (2018). Declaración politica MAELA Colombia. Riosucio, Caldas, mayo 18, 19 y 20 de 2018. Agenda Agroecológica y Agriculturas Alternativas Colombia. Recuperado de 
http://semillasdeidentidad.blogspot.com/2018/05/agenda-agroecologicay-agriculturas.html

Red de Guardianes de Semillas. (2018). La Red de Guardianes de Semillas conecta a familias que protegen la agrobiodiversidad y promueven sistemas regenerativos de vida en Ecuador. Recuperado de http:// redsemillas.org/conocenos-yparticipa/quienes-somos/

Red de Semillas Libres de Colombia y Grupo Semillas. (2015). Las semillas patrimonio de los pueblos, en manos de los agricultores. Acciones sociales para enfrentar el colonialismo corporativo de las semillas en Colombia. Bogotá: ARFO Editores e Impresores Ltda. Recuperado de http://semillas.org.co/apc-aa-files/5d99b14 191c59782eab3da99d8f95126/cartilla-semillas-patrimonio-de-los-pueblosbaja.pdf

Rivas-Platero, G., Rodríguez, A., Padilla, D., Hernández, L., y Suchini, J. (2013). Bancos comunitarios de semillas criollas: una opción para la conservación de la agrobiodiversidad. Turrialba, Costa Rica: Centro Agronómico Tropical de Investigación y Enseñanza (CATIE). Recuperado de https://www.catie.ac.cr /guatemala/ attachments/article/17/bancos-comunitarios-de-semillas-criollas.pdf

Ruíz, M. (2009). El análisis de tetrazolio en el control de calidad de semillas. Caso de estudio: cebadilla chaqueña. (Publicación Técnica No. 77). Recuperado de https:// inta.gob.ar/sites/default/files/script-tmp-el_anlisis_de_tetrazolio_en_el_control_de_calidad_de_.pdf

Stupino, S., Iermanó, M. J., Gargoloff, N. A., y Bonicatto, M. (2014). La biodiversidad en los agroecosistemas. En S. J. Sarandón y C. C. Flores (eds.), Agroecología. Bases teóricas para el diseño y manejo de agroecosistemas sustentables (pp. 131-158). Buenos Aires: Editorial de la Universidad de La Plata. Recuperado de http:// sedici.unlp.edu.ar/handle/10915/37280

Shiva, V. (2016). The violence of the green revolution. Third world agriculture, ecology and politics. Kentucky: University Press of Kentucky.

Terramocha, E. (2012). Los sistemas participativos de garantía. Herramientas de definición de estrategias agroecológicas. Agroecología, 6, 89-96. Recuperado de https://digitum.um.es/xmlui/bitstream/10201/29885/1/Los\%20sistemas\% 20participativos\%20de\%20garant\%C3\%ADa.\%20Herramientas\%20de\%20 definici\%C3\%B3n\%20de\%20estrategias\%20agroecol\%C3\%B3gicas.pdf 


\title{
Capítulo 5
}

\section{Importancia de la agrobiodiversidad y agregación de valor a productos agroecológicos en la asociación} APACRA en Cajamarca, Tolima

\author{
Importance of agrobiodiversity and value added to agroecological \\ products in the APACRA association in Cajamarca, Tolima
}

\author{
Astrid Ximena Cortés Lozano* \\ Álvaro Acevedo Osorio** \\ Cielo Esperanza Báez Mojica***
}

\section{Cómo citar}

\begin{abstract}
APA
Cortés, A. Acevedo, Á. y Báez, C. (2019). Importancia de la agrobiodiversidad y agregación de valor a productos agroecológicos en la asociación APACRA en Cajamarca, Tolima. En Á. Acevedo-Osorio y N., Jiménez-Reinales (comps.). La agroecología. Experiencias comunitarias para la Agricultura Familiar en Colombia. (pp. 113-135). Bogotá: Corporación Universitaria Minuto de Dios-UnIMINUTO, Editorial Universidad del Rosario.
\end{abstract}

\section{Chicago}

Cortés-Lozano, Astrid, Acevedo Osorio, Álvaro y Báez, Cielo Esperanza. "Importancia de la agrobiodiversidad y agregación de valor a productos agroecológicos en la asociación APACRA

* Gerencia de Desarrollo Rural. Corporación Universitaria Minuto de Dios-uniminuto. astrid.cortes@uniminuto.edu

** Programa de Ingeniería Agroecológica, Facultad de Ingeniería. Corporación Universitaria Minuto de Dios-uniminuto. alacevedo@uniminuto.edu

*** Asociación de Productores Agroecológicos de la Cuenca del Río Anime, apacra. cieloesperanzab@yahoo.com.mx 
en Cajamarca, Tolima". En La agroecología. Experiencias comunitarias para la Agricultura Familiar en Colombia, comps. Álvaro Acevedo-Osorio y Nathaly Jiménez-Reinales. Bogotá: Corporación Universitaria Minuto de Dios-UNIMINUTO, Editorial Universidad del Rosario, 2019.

\section{MLA}

Cortés Lozano, Astrid. Acevedo Osorio, Álvaro y Báez, Cielo Esperanza. "Importancia de la agrobiodiversidad y agregación de valor a productos agroecológicos en la asociación APACRA en Cajamarca, Tolima". En La agroecología. Experiencias comunitarias para la Agricultura Familiar en Colombia. En Á. Acevedo-Osorio y N., Jiménez-Reinales (comps.) Bogotá: Corporación Universitaria Minuto de Dios-UNIMINUTO, Editorial Universidad del Rosario, 2019, pp. 113-135.

\section{Resumen}

Los agricultores familiares enfrentan el reto de subsistir económicamente compitiendo en mercados que, en general, no les permiten participar en condiciones justas; por lo cual, habitualmente reciben bajos ingresos por sus productos y, además, tienen desventajas al momento de la negociación. La biodiversidad es un concepto actual para la sociedad en general, que no parece ser entendido, pues no son reconocidos ni valorados los servicios que presta y que están asociados a la supervivencia humana. Con el aprovechamiento de la agrobiodiversidad, los agricultores de la Asociación de Productores Agroecológicos de la Cuenca del Río Anaime (APACRA) no sólo han constituido una estrategia para suplir sus necesidades productivas y comerciales, sino que han establecido relaciones socioeconómicas dinámicas, que les ha permitido ejercer acciones en torno a la conservación de ecosistemas, a garantizar su seguridad alimentaria y a aportar al desarrollo local sustentable. El capítulo tiene como propósito reflejar cómo a través de la agregación de valor y la innovación en algunos productos, basados en la agrobiodiversidad local en Cajamarca (Tolima), los agricultores familiares reconocen, aprovechan y estiman los recursos regionales, al mismo tiempo, que contrarrestan los efectos de la agricultura industrializada y las relaciones inequitativas y desequilibradas de los mercados.

Palabras clave: adaptabilidad campesina, agregación de valor, agrobiodiversidad, emprendimiento agroecológico, innovaciones agroecológicas.

\section{Abstract}

Family farmers face the challenge of surviving economically by competing in markets that, in general, do not allow them to participate in fair conditions; therefore, they usually receive low income for their products and have a disadvantage at the time of negotiation. Although biodiversity is a current concept for society in general, it does not seem to understand the exact magnitude that this entails, since the services it provides that are associated with human survival are not recognized or valued. With the use of agrobiodiversity, the farmers of the Association of Agroecological Producers of the Anaime River Basin (APACRA) have not 
only constituted a strategy to meet their productive and commercial needs, but have also established dynamic socio-economic relations, which has allowed them to to take actions around the conservation of ecosystems, to guarantee their food security and to contribute to sustainable local development. The purpose of the chapter is to reflect how, through the aggregation of value and innovation in some products, based on local agrobiodiversity in Cajamarca (Tolima), family farmers recognize, take advantage of and estimate regional resources, at the same time, that counteract the effects of industrialized agriculture and inequitable and unbalanced market relations.

Keywords: peasant adaptability, agrobiodiversity, value aggregation, agroecological entrepreneurship, agro-ecological innovations.

\section{Introducción}

Los estudios sobre agricultura familiar enfatizan que su papel es relevante para el desarrollo rural sostenible de las comunidades, asimismo, para la seguridad y soberanía alimentaria, la promoción de estilos de vida saludables, la protección de los recursos naturales y, especialmente, de la biodiversidad (Toader y Roman, 2015). No obstante, al cumplir con estas funciones importantes para la sociedad, los agricultores familiares enfrentan el reto de subsistir económicamente vinculándose con mercados que, en general, no les permiten participar en condiciones justas; por lo cual, generalmente reciben bajos ingresos por sus productos y tienen poca de capacidad de negociación. Para compensar estas dificultades del mercado, los agricultores recurren a diversas estrategias de emprendimiento, entre las cuales, está el uso de la agrobiodiversidad local para diversificar su producción y descentralizar sus fuentes de ingresos.

En este sentido, es pertinente decir que por agrobiodiversidad se concibe al conjunto diverso de organismos vivos que cumplen un papel relevante en la agricultura y la alimentación, en un sentido amplio; también se incluye dentro de esta definición, al conocimiento asociado a su manejo (Jackson, Pascual y Hodgkin, 2007). La agrobiodiversidad de un territorio constituye su principal capital social y ecológico, porque es la base sobre la cual se configuran sus sistemas locales de producción, esto permite crear sistemas altamente diversificados, en el que los recursos genéticos son también abundantes y diversos. En su tratado sobre la memoria biocultural, Toledo y Barrera-Bassols (2008) explican como la diversidad genética tiene un carácter humano (cultural), puesto que son las comunidades de agricultores las que a partir de un refinado conocimiento ecológico de las condiciones locales, como el clima, la topografía, el suelo, los ciclos naturales, las interacciones entre organismos, entre 
otros, han creado un sinnúmero de razas y variedades que constituyen la agrobiodiversidad de cada territorio. Por esta razón, Toledo y Barrera-Bassols consideran que:

El producto final ha sido, tras 10000 años de diversificación agrícola y pecuaria, de cientos y miles de diseños genéticos originales, que a su vez son la consecuencia de creaciones de innumerables culturas locales a lo largo del espacio y del tiempo. (2008, p. 39).

No obstante, la importancia de este concepto, por la obsesión por la productividad, ha generado una gran incapacidad de la agricultura moderna por reconocer la importancia de un sinnúmero de agroecosistemas y formas de producción que garantizan la conservación de bienes culturales y genéticos, que caracterizan la agrobiodiversidad del mundo rural (Niederle, 2015).

Aunque la biodiversidad es un concepto conocido y actual para la sociedad, en general, esta no parece entender la magnitud exacta que conlleva el no ser reconocidos, ni valorados los servicios que ella presta y que están asociados a la supervivencia humana. El reto es, entonces, abordar la combinación de funciones ecológicas y sociales de la agrobiodiversidad, valorar su contribución a la sociedad y evaluar opciones para su uso sostenible y conservación en los territorios agroproductivos (Jackson et al., 2007).

Por su parte, la agroecología es considerada como la alternativa científica y práctica, más promisoria, para enfrentar la pérdida de la agrobiodiversidad. Es entendida como base ideológica de muchos movimientos de agricultores familiares alrededor del mundo. La agroecología demuestra como es posible practicar una agricultura con bajos insumos externos, que aprovecha, de manera eficaz, la agrobiodiversidad de los territorios y generar no sólo alimentos sanos en dietas variadas, sino procesos de conservación in situ de la biodiversidad, y así, contribuye a la estabilidad ecológica de los sistemas de cultivo. Un estudio de Perry (2008 como se citó en Rojas, 2010), sobre 286 proyectos de base agroecológica en 57 países, mostró principios claves de la práctica agroecológica basados en: a) la integración de procesos biológicos y ecológicos; b) el uso reducido de recursos no renovables; c) el empleo productivo de los conocimientos y destrezas de los campesinos; y d) el uso productivo de las capacidades colectivas de la gente para la solución de problemas comunes.

Frente a la necesidad de generar alternativas productivas y de transformación que agreguen valor, así como de encontrar alternativas a las desventajas competitivas en los mercados, la Asociación de Productores Agroecológicos de la Cuenca 
del Río Anaime (APACRA) en Cajamarca, Tolima, ha desarrollado, durante más de 20 años, una experiencia basada en la innovación local para agregar valor a alimentos locales y creación de nichos de mercado para sus productos, mejorando con ello los procesos productivos agroecológicos y los ingresos de los agricultores. Este capítulo analiza la manera cómo los agricultores generaron las innovaciones a partir de su agrobiodiversidad local y lograron concretar estrategias propias de mercado, respondiendo alas siguientes preguntas:

¿Cómo ha sido el proceso de aprovechamiento de la agrobiodiversidad local en la cuenca del río Anaime, Tolima, para la producción y transformación con base agroecológica?

- ¿Qué innovaciones agroecológicas se han generado?

- ¿Cuál ha sido la contribución de estas innovaciones productivas en el fortalecimiento de la asociación APACRA?

- ¿Qué factores han permitido el fortalecimiento de estas innovaciones para hacerlas sostenibles?

\section{Resultados}

\subsection{Los orígenes de la agroecología en APACRA}

La Asociación de Productores Agroecológicos de la Cuenca del Río Anaime se encuentra ubicada en el corregimiento de Anaime, del municipio de Cajamarca, en el departamento del Tolima. Este municipio es conocido como una despensa agrícola de Colombia, por la alta cantidad de productos de la canasta básica de los colombianos que se cosechan en este lugar. Sobresalen los cultivos de fríjol (Phaseolus vulgaris), arracacha (Arracacia xanthorrhiza), arveja (Pisum sativum), zanahoria (Daucus carota), entre otros productos (Alcaldía de Cajamarca, 2018).

La asociación está compuesta por 14 familias campesinas distribuidas en la cuenca del río, en especial, por mujeres que han adoptado la agroecología como un estilo de vida para producir, consumir y comercializar alimentos sanos, e igualmente, garantizar la seguridad y soberanía alimentaria; asimismo, para proporcionarle valor agregado a los productos agroalimentarios locales y así mejorar, con ellos, su economía familiar.

En los orígenes de la asociación, se destaca la presencia de diversos programas de desarrollo local en la cuenca del río Anaime, estos fueron motivados por la problemática del territorio, especialmente por la contaminación de aguas superficiales 
y subterráneas en la cuenca, la presencia de suelos erosionados y degradados, así, como la fragmentación del paisaje y la pérdida de biodiversidad como resultado de la promoción de la Revolución Verde, especialmente, con monocultivos de fríjol (Phaseolus vulgaris), arveja (Pisum sativum) y arracacha (Arracaciaxanthorrhiza).

Desde 1998, las familias organizadas en APACRA trabajan por el mejoramiento de las condiciones de vida. Pero fue a partir de la ejecución de un proyecto de formación en sistemas productivos agroecológicos, promovido por la fundación “Semillas de Agua” y el Programa Nacional de Transferencia Agropecuaria (PRONATTA), que APACRA surgió de manera formal en el año de 2002.

Los proyectos productivos de base agroecológica iniciaron, especialmente, con procesos de formación en los que aprendieron prácticas como la elaboración de compostaje, métodos para la conservación de suelos, cultivo de huertas orgánicas, instalación de filtros de agua, entre otros, que fueron aplicados por los productores, a partir de cada una de sus posibilidades y limitaciones.

La agroecología en APACRA es concebida bajo una serie de principios socioambientales y sociopolíticos, establecidos por la asociación en su trayectoria como agricultores y, también, como activistas ambientales y sociales. Algunos de los principios son los siguientes:

\section{1) El cuidado del suelo y su manejo como un organismo vivo.}

Bajo esta comprensión, el suelo, como entidad viva con "fuerza vital", requiere del cuidado y la protección constante que, como agricultores, le han venido dando a través de diversas estrategias, por ejemplo, como: el reciclaje de nutrientes y prácticas asociadas, el uso de abonos orgánicos y de coberturas vegetales

2) Todos los seres de la naturaleza cumplen una función.

Este principio ha llevado a los socios de APACRA al acercamiento con diferentes plantas para conocer sus usos y beneficios, no sólo para la alimentación, sino para las diversas formas de aprovechamiento que surgen de las familias y los demás seres del ecosistema. Así, por ejemplo, reconocen que existen plantas que producen sustancias con funciones como la de repelencia, antifúngicas o alelopáticas que atraen o alejan insectos. De igual forma, evidencian las interacciones benéficas que se dan entre plantas y microorganismos, mediante el reconocimiento de estructuras vegetales radiculares como los nódulos, que albergan microorganismos, los cuáles a su vez, llevan a cabo relaciones simbióticas en la solubilización y fijación 
de nutrientes, indispensables para el crecimiento vegetal. Igualmente, los asociados han sabido identificar de manera general, la amplia variedad de insectos, su morfología y sus funciones dentro del ecosistema, asimismo, reconocen y comprenden que, como seres vivos, las plantas y microorganismos, les gustan los colores, olores y sabores, y aplican diferentes estrategias para asegurar su permanencia.

3) Los procesos de competencia entre las plantas se dan, fundamentalmente, por la luz antes que por nutrientes.

En ese sentido, los asociados realizan las labores culturales de sus cultivos y permiten que las plantas, de interés económico, tengan los niveles adecuados de luz solar mediante el manejo de estratos y comprenden que las medidas como el uso de herbicidas y prácticas convencionales, como el deshierbe completo y el volteo del suelo, generan efectos adversos sobre su biología y representan riesgos para sus cultivos.

4) Proteger los árboles en su hábitat.

Respecto a este principio, los productores han implementado cultivos dentro de los bosques cuidando las diferentes especies que allí crecen, al tiempo que mantienen una producción estable. Asimismo, dentro de cultivos como el café han comenzado a sembrar plantas nativas como la palma de cera (Ceroxylon quindiuense), una especie catalogada susceptible de extinción. Con estas acciones, reafirman su conciencia ambiental y su racionalidad ecológica (Toledo, 1993) que crea, transforma y protege los ecosistemas para mejorar la calidad de vida de las familias y de la sociedad. Otra práctica importante, en producción agroecológica, para los agricultores de APACRA es la rotación de cultivos que permite la recuperación de los suelos y conservación de su potencial productivo; igualmente, la siembra en terrazas como método de conservación del suelo ayuda a controlar la erosión, mejorar la infiltración, evitar la escorrentía y mantener estable la fertilidad al suelo; del mismo modo, está la práctica del cuidado de las semillas propias, mediante intercambio y conservación en bancos vivos y de depósito, porque constituye la fuente de soberanía alimentaria.

5) Defensa del territorio.

La dimensión sociopolítica de la agroecología en APACRA se expresa en el principio de defensa de su territorio, manisfestadodo en la gestión política que han llevado a cabo frente al megaproyecto de explotación minera de oro en el municipio. APACRA constituye una de las organizaciones que reivindica 
su proyecto de vida integral y se ha involucrado en esta lucha política, no sólo fortaleciendo y diversificando su economía desde la agroecología, sino, convirtiéndose en parte activa de diversas acciones de movilización, en defensa de su territorio.

\subsection{Aprovechamiento de la agrobiodiversidad en procesos agroindustriales}

Desde su conformación, APACRA ha trabajado en procesos de innovación para la transformación de productos de la agrobiodiversidad local de su territorio, de igual forma, para el posicionamiento de sus productos en mercados diferenciados, incluidos sus propios puntos de venta, todo fundamentado en procesos de investigación autónoma y de formación, impulsados por diversas instituciones que promovieron el fortalecimiento del sector rural y la racionalidad ambiental. De esta manera, APACRA ha llevado a cabo procesos de revalorización del potencial agroecológico local, a partir de la restauración de los procesos ecológicos de los agroecosistemas y la revalorización de las formas tradicionales de producción.

La preocupación permanente de los socios de APACRA, con respecto a la salud de sus familias y los beneficios de alimentarse con productos orgánicos, siempre ha existido y fue a partir de análisis colectivos que surgieron las ideas para tener una dieta variada, equilibrada, sana y libre de toda sustancia tóxica que pudiera generar consecuencias negativas en el bienestar humano. Llevadas a la práctica, estas reflexiones permitieron identificar recursos de la región con potencial nutricional y benéfico para la salud.

Los recursos de agrobiodiversidad local varían entre especies propias de los Andes y otras, no nativas, que han sido adaptadas y aprovechadas de diferentes maneras, a lo largo de los territorios campesinos de nuestro país (tabla 1). A partir de esta agrobiodiversidad local, los socios de APACRA analizaron las posibilidades de aprovechamiento de estas especies subvaloradas por el mercado, subutilizadas y marginadas, así como otras especies exóticas con potencial para la salud y nutrición. 
Tabla 1. Recursos de agrobiodiversidad local con potencial nutricional de la cuenca del río Anaime.

\begin{tabular}{|c|c|c|c|}
\hline $\begin{array}{c}\text { Especie de la } \\
\text { agrobiodiversidad local }\end{array}$ & $\begin{array}{l}\text { Familia } \\
\text { botánica }\end{array}$ & $\begin{array}{l}\text { Nombre } \\
\text { científico }\end{array}$ & Potencial productivo y usos frecuentes \\
\hline Chachafruto & Fabaceae & Erythrina edulis & $\begin{array}{l}\text { El chachafruto es una especie leguminosa } \\
\text { latinoaméricana que produce sus frutos en } \\
\text { vainicas y su importancia radica en la presencia } \\
\text { de aminoácidos esenciales, que le confieren una } \\
\text { excelente calidad nutricional (Pérez, 1984). } \\
\text { Es un árbol leguminoso que se comporta muy } \\
\text { bien desde los } 1200 \text { a los } 2100 \mathrm{~m} \text { s. n. m., } \\
\text { actúa como mejorador de suelos, ya que en su } \\
\text { relación simbiótica con bacterias rizosféricas, } \\
\text { convierte el nitrógeno atmosférico en } \\
\text { moléculas asimilables para las plantas. } \\
\text { El chachafruto es, en Cajamarca, un producto } \\
\text { subutilizado, ya que solo en algunas viviendas } \\
\text { rurales se utiliza para la alimentación de } \\
\text { especies menores como cerdos y pollos. } \\
\text { En las cocinas cajamarcunas, se prepara } \\
\text { esporádicamente cocinado o sudado. }\end{array}$ \\
\hline Papayuela & Caricaceae & $\begin{array}{l}\text { Carica } \\
\text { candamarcensis }\end{array}$ & $\begin{array}{l}\text { Es un fruto alargado que, dependiendo del } \\
\text { grado de madurez, varía del color amarillo } \\
\text { al verde; puede llegar a medir los } 20 \mathrm{~cm} \text { de } \\
\text { largo y } 6 \mathrm{~cm} \text { de ancho. Tiene beneficios a } \\
\text { nivel respiratorios, ya que este fruto tiene } \\
\text { potentes cualidades pectorales lo que ayuda a } \\
\text { descongestionar las vías respiratorias (Bhusan, } \\
\text { Gautam, Chander y Sharma, 2015). } \\
\text { Esta planta arbustiva que crece entre los } 1800 \text { y } \\
\text { los } 2800 \mathrm{~m} \text { s. n. m. en Cajamarca, es reconocida } \\
\text { por su potencial en la preparación de dulce, } \\
\text { generalmente, es preparado por las mujeres } \\
\text { para fechas especiales. }\end{array}$ \\
\hline Ruibarbo & Polygonaceae & $\begin{array}{l}\text { Rheum } \\
\text { rhabarbarum }\end{array}$ & $\begin{array}{l}\text { Es una planta vascular que se cultiva como } \\
\text { verdura. Sus hojas concentran ácido oxálico, lo } \\
\text { que les confiere toxicidad y, por lo cual, solo es } \\
\text { consumible el tallo. Cada porción de ruibarbo } \\
\text { provee un } 45 \% \text { del valor diario de vitamina K, } \\
\text { la cual apoya el crecimiento de huesos sanos } \\
\text { y puede limitar el daño neuronal del cerebro } \\
\text { (Libert, 1993). } \\
\text { Aunque este arbusto es poco conocido en } \\
\text { la región, APACRA utiliza su tallo para la } \\
\text { preparación de confites y jugos. También es } \\
\text { utilizado en medicina natural para el control de } \\
\text { infecciones hepáticas. }\end{array}$ \\
\hline
\end{tabular}




\begin{tabular}{|c|c|c|c|}
\hline $\begin{array}{c}\text { Especie de la } \\
\text { agrobiodiversidad local }\end{array}$ & $\begin{array}{l}\text { Familia } \\
\text { botánica }\end{array}$ & $\begin{array}{l}\text { Nombre } \\
\text { científico }\end{array}$ & Potencial productivo y usos frecuentes \\
\hline Plátano Guineo & Musaceae & Musa $A A A$ & $\begin{array}{l}\text { El plátano guineo es una planta herbácea de } \\
\text { gran tamaño que crece bien a una temperatura } \\
\text { de } 18 \text { a } 22^{\circ} \mathrm{C} \text { y entre una altura de } 1800 \mathrm{a} \\
2100 \mathrm{~m} \text { s. n. m. Su parte consumible es el } \\
\text { fruto proveniente de las espigas. Por su alto } \\
\text { contenido en potasio y bajo en sal, es un buen } \\
\text { alimento para proteger el sistema digestivo y } \\
\text { contrarrestar la hipertensión (Parra, Cayón y } \\
\text { Polanía, 2009). } \\
\text { En el municipio de Cajamarca existen } \\
\text { abundantes plantaciones en la parte media } \\
\text { y baja de la cuenca del rio Anaime y, en la } \\
\text { parte baja de la cuenca del rio Bermellón. Su } \\
\text { fruto es comercializado generalmente por la } \\
\text { Cooperativa de Agricultores de Cajamarca y } \\
\text { Anaime, quien la distribuye a almacenes de } \\
\text { cadena o por medio de intermediarios, que } \\
\text { la comercializan en las ciudades de Ibagué, } \\
\text { Armenia, Cali y Bogotá. }\end{array}$ \\
\hline Gulupa & Passifloraceae & $\begin{array}{l}\text { Passiflora } \\
\text { pinnatistipula }\end{array}$ & $\begin{array}{l}\text { Es una baya amazónica que puede medir } \\
\text { entre } 4 \text { y } 8 \mathrm{~cm} \text { de diámetro. Se le atribuyen } \\
\text { propiedades antioxidantes y cardiovasculares, } \\
\text { puesto que evita la obstrucción de las arterias. } \\
\text { Es usada por la población en general para la } \\
\text { elaboración de jugos, APACRA la utiliza para la } \\
\text { elaboración de yogur. }\end{array}$ \\
\hline Arracacha & Apiaceae & $\begin{array}{l}\text { Arracacia } \\
\text { xanthorrhiza }\end{array}$ & $\begin{array}{l}\text { Es una planta bianual originaria de los Andes, } \\
\text { cuya raíz es la parte comestible. Se cultiva en } \\
\text { suelos livianos en temperaturas que oscilan } \\
\text { entre los } 15 \text { y } 21^{\circ} \mathrm{C} \text {. En varios lugares es usada } \\
\text { como tópico para algunas dolencias de la piel } \\
\text { (Muñoz, Alvarado y Almanza, 2015). } \\
\text { En el municipio de Cajamarca, la arracacha } \\
\text { representa un porcentaje importante de la } \\
\text { economía del municipio. Se siembra como } \\
\text { monocultivo y de manera convencional. } \\
\text { Es comercializada principalmente por } \\
\text { intermediarios, quienes la distribuyen en la } \\
\text { central de abastos de Bogotá, Cali y el Eje } \\
\text { Cafetero. }\end{array}$ \\
\hline
\end{tabular}




\begin{tabular}{|c|c|c|c|}
\hline $\begin{array}{c}\text { Especie de la } \\
\text { agrobiodiversidad local }\end{array}$ & $\begin{array}{l}\text { Familia } \\
\text { botánica }\end{array}$ & $\begin{array}{l}\text { Nombre } \\
\text { científico }\end{array}$ & Potencial productivo y usos frecuentes \\
\hline Níspero & Rosaceae & $\begin{array}{l}\text { Eriobotrya } \\
\text { japónica }\end{array}$ & $\begin{array}{l}\text { Es un árbol frutal que no supera los } 6 \text { metros de } \\
\text { altura, y crece entre } 1200 \text { a } 2000 \mathrm{~m} \text { s. n. m. } \\
\text { Entre sus propiedades nutricionales, se } \\
\text { caracteriza por ser un excelente diurético y } \\
\text { por poseer una buena presencia de carotenos, } \\
\text { flavonoides y ácido ursólico lo convierten en } \\
\text { un fruto hepato-protector (Delucchi y Keller, } \\
2010 \text { ) } \\
\text { El níspero sirve de alimentación para aves y } \\
\text { mamíferos. Los campesinos de la zona utilizan } \\
\text { sus tallos como fuente de energía (leña) y, en } \\
\text { algunos casos, en sombrío para el café }\end{array}$ \\
\hline $\begin{array}{l}\text { Cidra, "papa de pobre”, } \\
\text { Guatila }\end{array}$ & Cucurbitaceae & Sechium edule & $\begin{array}{l}\text { Es una planta voluble que crece muy bien } \\
\text { entre los } 1000 \text { y } 2200 \mathrm{~m} \text { s. n. m. Se caracteriza } \\
\text { por crecer rápidamente, trepar árboles y ser } \\
\text { resistente a insectos y a enfermedades (Barrera, } \\
\text { 1996). } \\
\text { En la región se utiliza principalmente en la } \\
\text { alimentación de animales. En la alimentación } \\
\text { humana es usada para preparar los fríjoles o } \\
\text { como acompañamiento de otros alimentos. Es } \\
\text { útil como cobertura de suelos, principalmente } \\
\text { en nacimientos de agua y como potencializador } \\
\text { de materia orgánica y control de arvenses. }\end{array}$ \\
\hline
\end{tabular}

Fuente: elaboración propia.

\subsection{Diversidad productiva e innovación social}

El aprovechamiento de los recursos propios de la agrobiodiversidad en Anaime inició a partir de la experimentación propia de algunas familias asociadas, en las cocinas de sus propias casas. Un proceso paciente, de ensayo y error, inherente a estos primeros ejercicios, estos permitieron ganar aprendizaje y mayor capacidad creativa. De esta manera, iniciaron la elaboración de preparaciones con base en harina y lácteos, probando sabores no comunes, sumando fracasos y enseñanzas hasta llegar a construir recetas propias, para mejorarlas e incluirlas en un catálogo único de productos de su agrobiodiversidad, con valor agregado (tabla 2).

La diversificación productiva inicia con el aprovechamiento de materias primas obtenidas localmente, que se subvaloraban y desperdiciaban por la falta de conocimiento sobre su valor nutricional. Así, productos como las galletas y las tortas elaboradas a partir del chachafruto (Erythrina edulis), comenzaron a fabricarse 
en las cocinas de las asociadas, usando equipos domésticos. En la línea de lácteos, también se producen quesos como insumo para la panadería y venta.

Tabla 2. Productos procesados en APACRA que emplean recursos de la agrobiodiversidad local no convencional.

\begin{tabular}{|c|c|c|}
\hline $\begin{array}{l}\text { Línea de productos } \\
\text { procesados }\end{array}$ & Producto elaborado & Materias primas empleadas \\
\hline \multirow{3}{*}{ Lácteos } & $\begin{array}{l}\text { Queso } \\
\text { (fabricado por algunos socios y } \\
\text { comercializado en uno de los puntos de } \\
\text { venta). }\end{array}$ & Leche, cuajo y sal. \\
\hline & $\begin{array}{l}\text { Yogur de papayuela, café, arracacha, } \\
\text { níspero, gulupa, zanahoria y cidra. }\end{array}$ & $\begin{array}{l}\text { Leche, azúcar, cepa microbiana, producto } \\
\text { específico (papayuela, café, arracacha, } \\
\text { níspero, gulupa, zanahoria o cidra). }\end{array}$ \\
\hline & Manjar de arequipe y de arracacha. & Leche, azúcar y arracacha. \\
\hline \multirow{4}{*}{ Panadería } & $\begin{array}{l}\text { Galletas de chachafruto, arracacha y } \\
\text { zanahoria }\end{array}$ & $\begin{array}{l}\text { Harina de trigo, chachafruto, mantequilla, } \\
\text { huevos, sal y azúcar. }\end{array}$ \\
\hline & Bizcochos & $\begin{array}{l}\text { Harina de maíz, chachafruto, mantequilla, } \\
\text { huevos, sal y azúcar. }\end{array}$ \\
\hline & Mogollas & $\begin{array}{l}\text { Harina de trigo integral, chachafruto, } \\
\text { mantequilla, huevos, sal, levadura y azúcar. }\end{array}$ \\
\hline & $\begin{array}{l}\text { Tortas de zanahoria, arracacha, cidra, } \\
\text { guineo y ahuyama. }\end{array}$ & $\begin{array}{l}\text { Harina de trigo, (zanahoria, ahuyama, } \\
\text { arracacha o guineo), mantequilla, huevos } \\
\text { y azúcar. }\end{array}$ \\
\hline Dulces & Dulces de ruibarbo & Ruibarbo y azúcar. \\
\hline Café & Café de bosque & Café tostado y molido. \\
\hline \multirow{2}{*}{ Fritos (snacks) } & Guineo frito & Guineo, aceite para freír y sal. \\
\hline & Arracachas fritas & Arracachas, aceite para freír y sal. \\
\hline
\end{tabular}

Fuente: elaboración propia.

Estos ensayos iniciales, se fueron concretando como productos a la venta en el mercado, cuya demanda creciente hizo necesario aumentar la producción de materias primas en las fincas de los asociados. Al tiempo que se diversificó la producción en las fincas, se fortalecieron las capacidades de los agricultores en ciertas líneas de producción especialmente en café, lácteos y panadería.

En cuanto a la relación con los consumidores, el proceso que comenzó en las fincas de los asociados, enmarcado en el autoconsumo, fue tomando fuerza a partir de la apertura de un primer punto de venta de productos frescos y procesados, en la plaza principal del municipio de Cajamarca en el 2001; el cual surgió como una opción para que las mujeres asociadas, tuvieran la oportunidad de generar ingresos 
propios. Este ejercicio generó la idea de que producir para vender, valía la pena y podía ser significativo para la organización y los consumidores.

Las estrategias de organización para poder atender a una demanda creciente de productos se centraron en que, cada miembro de la asociación asumiera la especialización en algunos cultivos y la transformación de determinados productos. Estas responsabilidades se acordaron teniendo en cuenta variables como el clima, el suelo y la facilidad para trabajar de acuerdo con la conformación familiar. En adición a esto, se ha establecido un cronograma de siembras escalonadas, lo cual ha permitido no sólo cumplir con la producción para los puntos de venta, sino garantizar la seguridad alimentaria de la comunidad.

Para el caso específico del café (Coffea arabica), se siembra la variedad Colombia que se adaptada a los $1500 \mathrm{~m}$ s. n. m y a libre exposición. Los agricultores de APACRA consideran una innovación producirlo a $2220 \mathrm{~m} \mathrm{s.n.m.,} \mathrm{donde} \mathrm{sin}$ obtener la producción de 15 cargas por héctarea, las plantas se desarrollaron bajo sombra sin manejo de arvenses, y se obtiene un café dulce de muy buena calidad.

Al igual que las actividades o prácticas tradicionales, las innovaciones en APACRA han sido participativas y, es así como, las acciones individuales de sus miembros han sido trasmitidas y adoptadas por otros miembros de la comunidad. En este sentido, se puede decir que la transición hacia la sustentabilidad que ha venido estableciendo APACRA, a partir de sus prácticas de producción y sus procesos de transformación de alimentos, constituyen un espacio de protección para la configuración y desarrollo de sus innovaciones, tal como lo plantean Schot et al., (1994) y Kemp et al., (1998) (como se citó en Smith y Raven, 2012).

\subsection{Procesos de autogestión}

Para el surgimiento y desarrollo de estas innovaciones productivas basadas en el aprovechamiento de la agrobiodiversidad regional, APACRA ha tenido que enfrentar dificultades que han exigido de sus socios desarrollar una dinámica de autogestión. Para la financiación de los procesos productivos, por ejemplo, recurrieron a la creación de un Fondo Rotatorio, que facilitara créditos de baja cuantía a los asociados que emprendían procesos de transformación de sus productos, así como, para financiar las actividades propias de la organización. La comercialización se inició con un esfuerzo de la asociación por acopiar y llevar sus productos al mercado local en Cajamarca. Inicialmente, se compuso de productos frescos perecederos, posteriormente, fueron se incursionó en los productos procesados que, hoy constituyen la base de sus procesos de mercadeo. 
Los procesos de transformación obligaron a su vez al mejoramiento de sus instalaciones de poscosecha. Para esto, mediante un proyecto financiado por la Gobernación del Tolima, se mejoraron las condiciones de las cocinas en términos de higiene y eficiencia productiva, sumado al propósito de los miembros de APACRA de solicitar el registro de producción al Instituto Nacional de Vigilancia de Medicamentos y Alimentos (INVIMA). Este evaluó como inapropiadas las condiciones de las cocinas para los procesos de transformación que se estaban adelantando.

Esta situación constituyó un momento difícil para la asociación, que se vio obligada a cambiar su forma de entender la producción doméstica, de tipo familiar, para dar cumplimiento a los estándares del mercado. Las dificultades radicaron en el momento de establecer una estrategia logística, no sólo por la falta de una infraestructura apropiada y de procesos estandarizados, sino por la alteración de las actividades cotidianas, familiares y productivas de los agricultores asociados.

Posteriormente, hacia el año del 2013, con un proyecto avalado por el Departamento de Protección Social (DPS) y el programa de “Oportunidades rurales”, los socios de APACRA pudieron conseguir una instalación exclusiva y debidamente dotada para la transformación de sus productos. Esta reforma, alteró muchos otros aspectos del funcionamiento de la organización, pues obligó a cambiar la producción en finca y la trasformación en las cocinas de las mismas familias, por el traslado de las materias primas al centro de transformación y, que allí, se encargará a una sola persona de hacer el procesamiento, esto significó el incremento en los costos de producción.

Tanto la experiencia de financiar los procesos de producción y transformación de las materias primas, como la generación de estrategias de mercado y el cumplir con la normativa para procesamiento de productos, hizo que los asociados de APACRA otorgarán prioridad a los aspectos necesarios para consolidar una estrategia productiva y de mercadeo, a mayor escala. Sin intervención institucional externa permanente, APACRA logró, a partir de sus procesos internos de autogestión, consolidar su innovación productiva y convertirla en la posibilidad económica para fortalecer su propuesta organizativa.

\subsection{Viabilidad económica de los procesos de transformación}

En el año del 2012 APACRA estableció un nuevo punto de venta en la Universidad del Tolima, ubicada en el municipio de Ibagué. Este punto de venta, dirigido a la población estudiantil de la universidad, permitió a APACRA iniciar una campaña por el consumo saludable en esta comunidad académica, generando conciencia sobre el 
valor de los recursos regionales de la agrobiodiversidad y su potencial para una alimentación saludable.

Posteriormente, en el año del 2016, otro punto de venta fue establecido en Ibagué, en un sector comercial de la ciudad. Así, nuevos retos comenzaron a ser enfrentados por APACRA, en tanto los puntos de venta de Cajamarca y la Universidad del Tolima tenían subsidios de arrendamiento y mantenimiento, mientras que este nuevo lugar obligó al pago de arriendo para su funcionamiento. En los planes de consolidación de la propuesta productiva y comercial de APACRA, se contempla establecer otros dos puntos de venta de productos agroecológicos, uno más en la Universidad de Ibagué y otro en la ciuda de Armenia, Quindío.

La gráfica 1 muestra los resultados del ejercicio de producción y venta de productos de APACRA entre el año de 2010 y 2017 utilizando circuitos cortos de comercialización. Se observa un incremento significativo en las ventas a partir del año del 2012, con la apertura del punto de venta en la Universidad del Tolima. Desde esta fecha, los productos han adquirido un importante posicionamiento, en especial, las galletas de chachafruto, las tortas de zanahoria, fritos de guineo, arequipe de arracacha y yogur. El crecimiento de ventas de yogur se evidencia en que han pasado de 720 litros en el 2010, a 2200 litros en el 2012, lo que representa un aumento del $305 \%$. De los demás productos, se puede evidenciar un pequeño aumento en este mismo año, a excepción de los bizcochos de maíz con queso.

Figura 1. Comportamiento de la producción de seis productos durante 7 años.

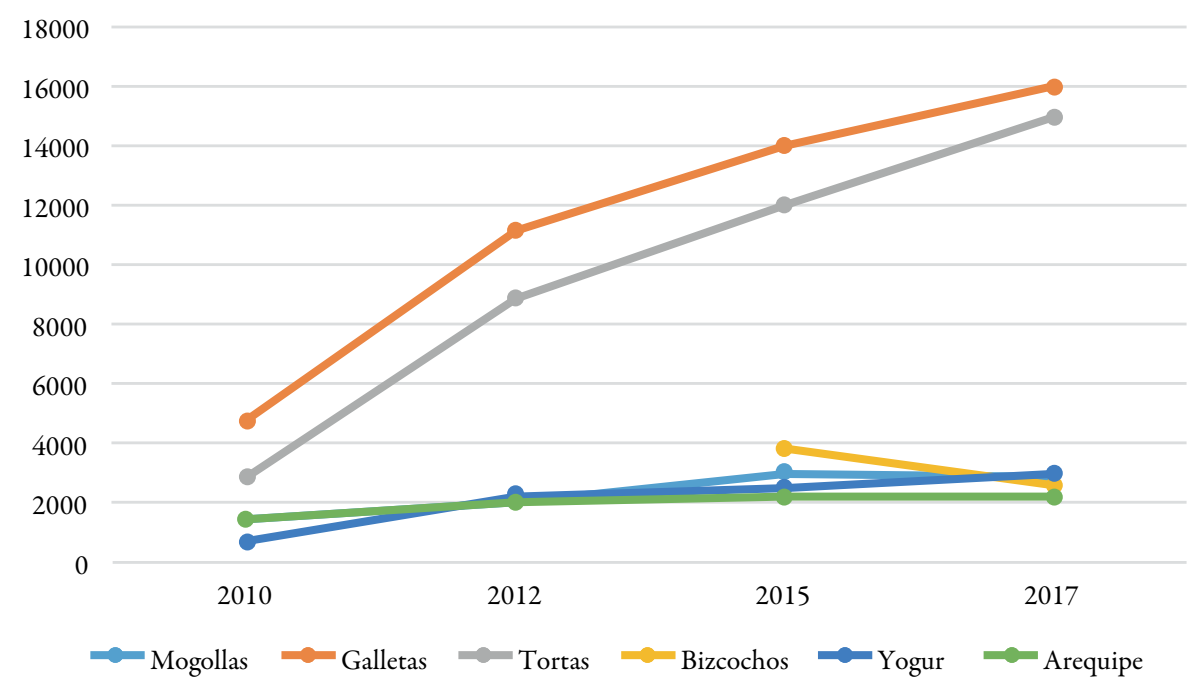

Fuente: elaboración propia. 
$\mathrm{Al}$ revisar el porcentaje de rentabilidad por cada producto (figura 2), se observa que disminuye levemente, lo cual es atribuible al fenómeno inflacionario y, por lo tanto, al aumento de los costos de producción y a los precios que la asociación ha decidido mantener constantes durante 7 años. El anterior análisis, no tiene en cuenta los costos de comercialización, toda vez que, no han sido acuciosamente obtenidos en la contabilidad de la asociación. Sin embargo, la rentabilidad promedio del total de la producción, evidencia que ha aumentado y se ha mantenido por encima del $36.4 \%$, lo cual demuestra una forma justa de distribución de las ganancias.

La rentabilidad de los productos ha sido analizada permanentemente, lo cual ha permitido tomar decisiones respecto a la continuidad de los productos en el mercado y fortalecer su condición financiera.

Figura 2. Porcentaje de rentabilidad por producto durante 7 años.

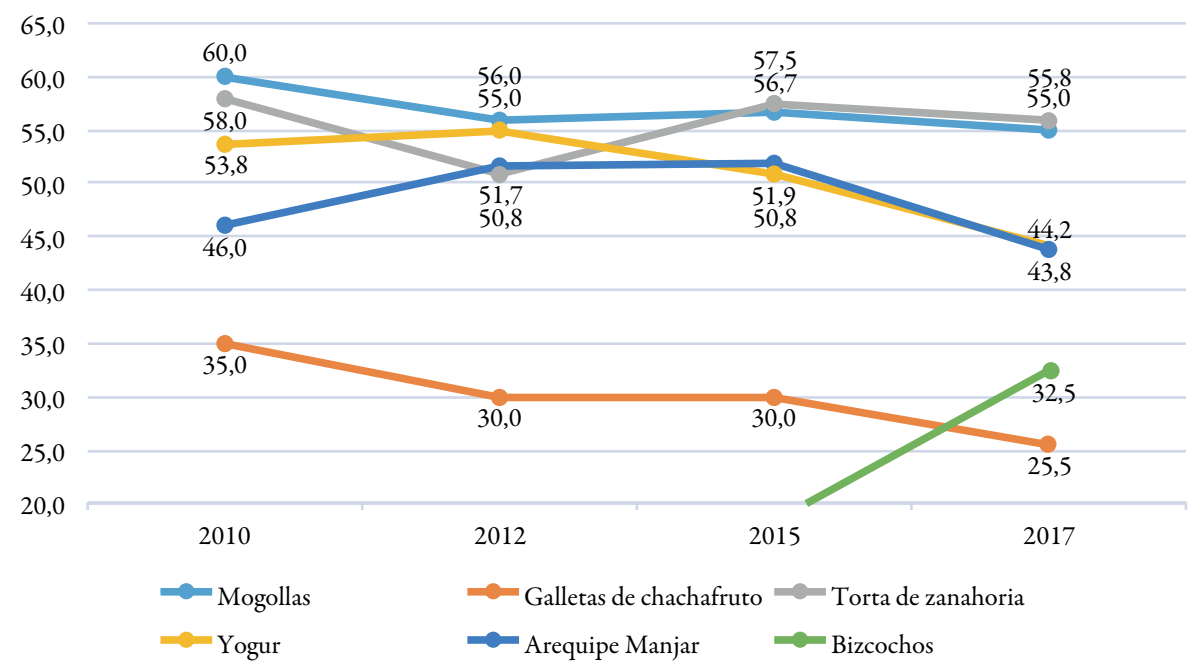

Fuente: elaboración propia.

Este aspecto ha estado fundamentado en el liderazgo que ha ejercido, especialmente, una de sus asociadas, que, al tener formación específica en el área de la administración, elabora cada año el balance comercial y analiza con los agricultores la manera de estandarizar los productos, ajustar los procesos y costos para hacerlos rentables. De manera que, se reconoce el éxito de esta propuesta de aprovechamiento de la agrobiodiversidad se sustenta no sólo en la motivación y ánimo de los asociados a APACRA, sino en su ingenio y creatividad para generar nuevos productos para el 
mercado, el alto grado de autogestión para lograr apoyos externos y la formación financiera de un líder que los impulsó.

\section{Discusión}

El término innovación puede entenderse en dos sentidos; uno abstracto, referente a pensamientos o métodos y, el otro, referente a algo tangible y real (Yang, 2009). Las innovaciones campesinas manifestadas, a partir de sus actividades tradicionales, reflejan su capacidad de actuar frente a diferentes procesos de transición social. Estas modificaciones en cuanto recursos, actividades y propósitos productivos han permitido garantizar una vida sostenible de manera paulatina, pues al re-agrupary readministar sus recursos, también ejercen una movilización de su propio capital social.

En la actualidad, hay estudios sobre innovación campesina que se concentran en los mecanismos de innovación técnica agrícola (Yang, 2009; Han, 2010) y otros que, se concentran en el contexto de proyectos participativos de desarrollo técnico y social (Lu, Wei y Sun, 2003). Sin embargo, el punto común en las investigaciones es que todos reconocen a los campesinos como sujetos protagonistas de las innovaciones y propiciadores de su trasferencia tecnológica en la práctica (Lu et al., 2003).

Con los procesos de innovación desarrollados por APACRA descritos en este capítulo, la organización ha logrado conjugar los esfuerzos de cada miembro de la asociación a partir de su experiencia productiva y su conocimiento. El proceso de innovación se hizo posible por la articulación de esfuerzos en dos ámbitos, el familiar y comunitario (figura 6). En el primero, los núcleos familiares de socios de APACRA generan las condiciones para transformar su entorno en relaciones de co-producción de base agroecológica con sus ecosistemas, aprovechando los recursos de agrobiodiversidad para la producción de materias primas y alimentos; también es el espacio de comunicación, gestión del conocimiento, relaciones de cooperación entre los miembros de la familia. Por su parte, en el ámbito comunitario u organizativo, mediante procesos de organización, participación y gestión de conocimiento, se da la posibilidad de articulación al mercado. Esta experiencia de uso de la agrobiodiversidad y agregación de valor ha promovido la implementación de sistemas productivos locales sustentables, el empoderamiento local, el fortalecimiento de la seguridad alimentaria, el cuidado de los bosques, la organización social y la reapropiación del conocimiento.

Al igual que lo ha logrado APACRA varios proyectos de base agroecológica, desarrollados por comunidades tradicionales en Colombia y a lo largo de toda América Latina, han demostrado el valor intrínseco de la agrobiodiversidad y el conocimiento 
asociado a ella. En Brasil, se han encontraron en los recursos de la agrobiodiversidad local los elementos necesarios para estructurar sistemas innovadores de producción y transformación, como los descritos para el caso de APACRA. Estos proyectos muestran cómo se generan alternativas viables para la reproducción social de las familias agricultoras, anteriormente en una situación de vulnerabilidad socio-económica. Algunas de estas iniciativas, incluyen el trabajo de 85 familias en la región central del Paraná en el cultivo y procesamiento de plantas aromáticas y medicinales. Igualmente, esta la experiencia de 500 familias, en asentamientos de reforma rural, que siembran, producen y se benefician de la hierba mate, generando una marca propia para su producto que, de manera simbólica, remite al movimiento de lucha por la reforma agraria. Finalmente, se reseña la experiencia de comunidades campesinas ubicadas entre Paraná y Sao Paulo que desarrollan sistemas innovadores de manejo agroforestal de la Mata atlántica, uno de los biomas más devastados por la agricultura del sur del Brasil (Niederle, 2015).

En el ámbito colombiano es importante destacar experiencias como la de la Asociación Red Agroecológica Campesina (ARAC), conformada por agricultores familiares de los municipios de La Pradera y Subachoque en Cundinamarca, quienes al igual que APACRA han llevado un proceso de transición hacia la sustentabilidad (Acevedo y Angarita, 2013). Del mismo modo, la empresa comunitaria Ríos Unidos (Proyecto Pacífico Sur, 2011), quienes han trabajado en la transformación de las plantas silvestres locales para la generación de productos fitoterapéuticos autóctonos de la región del Pacífico. También, la granja agroecológica familiar "Pura vida" ( Agencia de Noticias un, 2016), una iniciativa en la que el proceso de transición se llevó a cabo en 10 años y hoy tienen alrededor de 100 variedades con más de 200 especies de alimentos en 1 h de tierra y quienes, a su vez, participan en la Red de mercados agroecológicos campesinos del Valle del Cauca. Estos últimos han realizado un trabajo de promoción del diálogo de saberes entre actores rurales y urbanos, también han promovido la agrobiodiversidad y funcionan desde hace 10 años sin financiación (Tapias, 2018).

\section{Conclusiones}

El proceso agroecológico con de más de 20 años de la asociación APACRA, se ha desarrollado en fases que incluyen la capacitación, la transformación productiva de las fincas de los asociados, el desarrollo de innovaciones en transformación y la consolidación de estrategias de mercado. Este proceso ha tenido a la organización social como su fundamento y la agrobiodiversidad como el recurso impulsor de los cambios. 
Figura 3. Componentes de la innovación en APACRA.

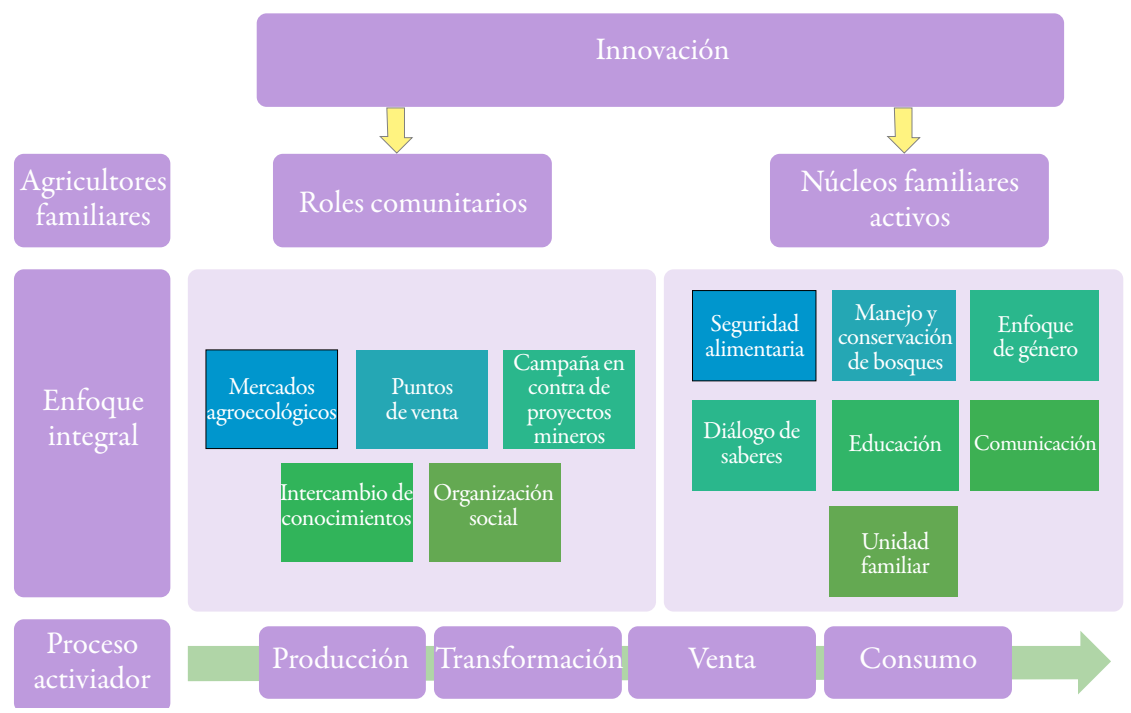

Fuente: elaboración propia.

La pertinencia de la agroecología, como base de los procesos de formación que promueven la transición hacia la agricultura sustentable, resalta el papel central del conocimiento local y del diálogo de saberes que facilita la construcción de conocimientos e innovaciones que, en el caso concreto de la experiencia descrita, han permitido crear productos con identidad específica y nuevos nichos de mercado.

El aprovechamiento de la agrobiodiversidad junto a la motivación de los asociados, su ingenio y creatividad para generar nuevos productos y el alto grado de autogestión y liderazgo, han sido esenciales para permanecer unidos y consolidar su trabajo y su proceso organizativo.

Es importante que la asociación se vea enriquecida por la participación y trabajo activo de nuevas generaciones y nuevos liderazgos, que permitan no solo mantener el nivel de producción y comercialización, sino que, fortalezcan las estrategias existentes y promueva nuevas formas de hacer aún más visible su producción, la asociación, sus valores y conocimientos.

\section{Agradecimientos}

A las familias agricultoras de la Asociación de productores de la cuenca del Río Anaime, Cajamarca, Tolima. A María Antonia Mojica (qepd), María Antonia Báez, Cielo Báez Mojica, Nohora Yolanda Rojas, Carmen Neila Urueña, Eufracina 
Monroy, Alirio Durán, Ever Cáceres, Iván Cortés, Alfonso Arias, Maria Inés Pinzón, Olga Perdomo, Fausto Cajamarca y María Torres.

\section{Referencias}

Acevedo, A., y Angarita, A. (2013). Metodología para la evaluación de sustentabilidada partir de indicadores locales para el diseño y desarrollo de programas agroecológicos, MESILPA. Bogotá: UNIMINUTO.

Alcaldía Municipal de Cajamarca. (2018). Recuperado de http://www.cajamarcatolima.gov.co/

Agencia de Noticias UN. (2016). De la agroecología si se puede vivir. Recuperado de http://agenciadenoticias.unal.edu.co/detalle/article/de-la-agroecologia-sise-puede-vivir.html

Barrera, N. (1996). La cidra papa, chayote o guatila. Sechium edule (Jacq.) Swartz. Una especie del mundo que debemos rescatar para Colombia. Recuperado de http://bibliotecadigital.agronet.gov.co/bitstream/11348/4077/1/Informaci\% C3\%B3n\%20general\%20de\%20cultivo\%20de\%20la\%20cidra\%2C\%20 guayote\%20o\%20guatila.pdf

Bhusan, B., Gautam, S., Chander, R., y Sharma, A. (2015). Characterization of nutritional, organoleptic and functional properties of intermediate moisture shelf stable ready-to-eat Carica papaya cubes. Food Bioscience 10(1), 69-79. doi: https://doi.org/10.1016/j.fbio.2015.02.001

Delucchi, G., y Keller, H. (2010). La naturalización del níspero, Eriobotrya japonica (Rosaceae, maloideae), en la Argentina. Bonplandia, 19(1), 71-77. Recuperado de http://ibone.unne.edu.ar/objetos/up/documentos/bonplandia / public/19_1/71_77.pdf

Han, L. (2010). Study on mechanism of agricultural technology innovation in which farmers are assumed as the main body (master's thesis, Shadong Agricultural University, Shandong, China).

Jackson, L. E., Pascual, U., y Hodgkin, T. (2007). Utilizing and conserving agrobiodiversity in agricultural landascapes. Agriculture ecosystems and environment, 121, 196-210. doi: http://dx.doi.org/10.1016/j.agee.2006.12.017

Libert, B. O. (1993). Chapter 53 - Rhubarb: Rheum spp. En G. Kalloo y B. O. Bergh (eds.), Genetic improvement of vegetable crops (pp. 771-775). doi: https://doi. org/10.1016/B978-0-08-040826-2.50057-6 
Lu, M., Wei, X., y Sun, C. (2003). On peasants' role in the process of practical technique innovation: Case study of water saving rice engineering in Shuangyang District. Social Science Edition, 4, 20-26.

Muñoz, A., Alvarado, A., y Almanza, P. (2015). Caracterización preliminar del cultivo de arracacha Arracacia xanthorrhiza Bancroft en el departamento de Boyacá. Revista de Ciencias Agricolas, 32(1),3-11. doi: http://dx.doi.org/10.22267/rcia.153201.20

Niederle, P. A. (2015). A agrobiodiversidade como recurso estratégico nos novos mercados agroalimentares. En J. Santilli, P. Goulart y R. Barbieri (eds.), Agrobiodiversidade (pp. 51-80). Brasilia: ABA, EMBRAPA.

Parra, O., Cayón, D., y Polanía, J. (2009). Descripción morfoagronómica de materiales de plátano (Musa AAB, ABB) y banano (Musa AAA) cultivados en San Andrés Isla. Acta Agronómica, 58(4), 292-298. Recuperado de http://www.redalyc. org/articulo.oa?id=169916220009

Pérez, G. (1984). Isolation and characterization of a lectin from the seeds of Erythrina Edulis. Phytochemistry, 23(6), 1229-1232. doi: https://doi.org/10.1016/ S0031-9422(00)80431-8

Proyecto Pacífico Sur. (2011). Informe proyecto de desarrollo rural, sanidad de base a través del uso de recursos locales en el fortalecimiento de la empresa comunitaria - Mujeres Rurales de Guapi "Rios Unidos". Guapi - Cauca. [Entrada de blog]. Recuperado de http://proyectopacificosur.blogspot.com

Rojas, A. (2010). Policultivos de la mente. Enseñanzas del campesinado y de la agroecología para la educación en la sustentabilidad. En T. León-Sicard y M. Altieri (eds.).Vertientes del pensamiento agroecológico. Fundamentos y aplicaciones (pp. 175-195). Bogotá: SOCLA y Universidad Nacional de Colombia.

Smith, A., y Raven, R. (2012). What is protective space? Reconsidering niches in transitions to sustainability. Research Policy, 41, 1025-1036. doi:10.10 16/j. respol.2011.12.012

Tapias, D. (2018). Así funciona la Red de Mercados Agroecológicos Campesinos del Valle del Cauca. Siembra el Provenir. Apuesta por un mundo mejor. Recuperado de http://comunicacionpuj.javerianacali.edu.co/buga/index.php /2018/05/22/asi-funciona-la-red-de-mercados-agroecologicos-campesinosdel-valle-del-cauca/\#more-200

Toader, M., y Roman, G.V. (2015). Family Farming. Examples for rural communities development. Agriculture and Agricultural Sciencia Prcoedia, 6, 89-94. doi: https://doi.org/10.1016/j.aaspro.2015.08.043 
Toledo, V. M. (1993). La racionalidad ecológica de la producción campesina. En E. Sevilla y M. González (eds.), Ecología, campesinado e historia (pp. 197-218). España: Lapiqueta.

Toledo, V. M., y Barrera-Bassols, N. (2008). La memoria biocultural. La importancia ecológica de las sabidurías tradicionales. Barcelona: Icaria Editorial. Recuperado de http://era-mx.org/biblio/Toledo-_y_Barrera_2008.pdf

Yang, P. (2009) Commercialization of grassroots innovations: Challenges and solutions (master's thesis). Tianjin, China: Tianjin University of Finance and Ecomics. 


\title{
Capítulo 6
}

\section{Sistemas agroecológicos de producción de gallinas criollas orientados a la sustentabilidad de la agricultura familiar campesina}

\author{
Agroecological systems for production of creole hens oriented \\ towards the sustainability of peasant family agriculture
}

\author{
Arlex Angarita Leiton* \\ Fernando Castrillón Zapata**
}

\section{Cómo citar}

\begin{abstract}
APA
Angarita, A. y Castrillón, F. (2019). Sistemas agroecológicos de producción de gallinas criollas orientados a la sustentabilidad de la agricultura familiar campesina. En Á. Acevedo-Osorio y N., Jiménez-Reinales (comps.). La agroecología. Experiencias comunitarias para la Agricultura Familiar en Colombia. (pp. 137-160). Bogotá: Corporación Universitaria Minuto de Dios-UnIMINUTO, Editorial Universidad del Rosario.
\end{abstract}

\section{Chicago}

Angarita Leiton, Arlex y Castrillón Zapata, Fernando. "Sistemas agroecológicos de producción de gallinas criollas orientados a la sustentabilidad de la agricultura familiar campesina". En La agroecología. Experiencias comunitarias para la Agricultura Familiar en Colombia, comps. Álvaro Acevedo-Osorio y Nathaly Jiménez-Reinales. Bogotá: Corporación Universitaria Minuto de Dios-uniminuto, Editorial Universidad del Rosario, 2019.

* Corporación Universitaria Minuto de Dios-uniminuto. aangarita@uniminuto.edu

** Corporación Grupo Semillas. fernando@semillas.org.co 


\section{MLA}

Angarita Leiton, Arlex y Castrillón Zapata, Fernando. "Sistemas agroecológicos de producción de gallinas criollas orientados a la sustentabilidad de la agricultura familiar campesina". En La agroecología. Experiencias comunitarias para la Agricultura Familiar en Colombia. En Á. Acevedo-Osorio y N., Jiménez-Reinales (comps.) Bogotá: Corporación Universitaria Minuto de Dios-uniminuto, Editorial Universidad del Rosario, 2019, pp. 137-160.

\section{Resumen}

Los sistemas tradicionales de producción animal representan para las familias y comunidades campesinas una fuente importante de alimentos e ingresos, a la vez que, mejoran el establecimiento de relaciones con el medio sociocultural y natural. Sin embargo, son poco estudiados, por lo que el presente texto ofrece algunos elementos para iniciar dicho proceso. La experiencia desarrollada por un grupo de familias campesinas e indígenas en el municipio de Natagaima, Tolima, permitió importantes aprendizajes y aportes a los estudios de agricultura familiar y al desarrollo local, a partir del mejoramiento de los sistemas tradicionales de producción de gallinas criollas desde un enfoque agroecológico en una zona de bosque muy seco Tropical (bms-T); donde se hace uso y aprovechamiento de la biodiversidad local, el conocimiento tradicional asociado, la adaptación al cambio climático y la autogestión financiera. La investigación, soportada desde la perspectiva de los enfoques de sistemas, Investigación-Acción Participativa y de tipo colaborativa, fue desarrollada por el grupo de familias con la ayuda y la concertación de apoyos tecnológicos y metodológicos puntuales de profesionales de la agroecología e investigadores locales sobre gallinas criollas. Los resultados permiten identificar elementos de tipo metodológico y tecnológico orientados, principalmente, a la optimización de la alimentación y manejo de los animales. Se resaltan logros importantes en el diseño, establecimiento y manejo de sistemas agroecológicos de gallinas criollas, fundamentados en la aplicación del conocimiento tradicional de las comunidades, que combinado con el saber técnico-científico moderno y con una baja inversión financiera, permiten a las familias campesinas asegurar la disponibilidad permanente de alimentos para el autoconsumo y para el mercado. Además, de mejorar el flujo de ingresos, generar resiliencia en los agroecosistemas y recuperar la autónomía en el manejo de sus sistemas productivos, como un ejercicio que rescata y realza el papel de las mujeres.

Palabras clave: agricultura familiar, autonomía, avicultura sustentable, desarrollo local, investigación campesina.

\section{Abstract}

Traditional animal production systems represent an important source of food and income for rural families and communities, while at the same time improving relations with the sociocultural and natural environment. There are few studies about it, so the present study offers some elements to start in this process. The experience developed by a group of peasant and indigenous families in the municipality of Natagaima, Tolima, allowed important learnings and contributions 
to the studies of family farming and local development, from the improvement of the traditional systems of production of Creole chickens from an agroecological approach in a very dry tropical forest area (bms-T); where use and benefit of local biodiversity, associated traditional knowledge, adaptation to climate change and financial self-management are made. The research, supported from the perspective of systems approaches, participatory-action research and collaborative, was developed by the group of families with the help and coordination of specific technological and methodological support from agroecology professionals and local researchers on Creole chickens. The results allow to identify elements of methodological and technological type, mainly, to the optimization of the feeding and handling of the animals. Important achievements are highlighted in the design, establishment and management of agroecological systems of Creole chickens, based on the application of traditional knowledge of the communities, which combined with modern technical-scientific knowledge and low financial investment, allow rural families ensure the permanent availability of food for self-consumption and for the market. In addition, to improve the flow of income, generate resilience in agroecosystems and recover the autonomy in the management of their productive systems, as an exercise that rescues and enhances the role of women.

Keywords: family farming, autonomy, sustainable poultry farming, local development, peasant research.

\section{Introducción}

Los sistemas tradicionales de producción animal representan para las familias y comunidades campesinas una fuente importante de alimentos y de ingresos (Tovar, Narváez y Agudelo, 2015). También permite evidenciar los aportes de las mujeres desde el análisis de género y entender las relaciones que establecen las familias con el entorno (Soler, 2010). Distintos estudios en Colombia han revelado la importancia que tienen los sistemas de producción pecuarios para la seguridad alimentaria y económica de las familias campesinas (Corrales, 2003; Farah y Pérez, 2004).

En la producción pecuaria, los sistemas tradicionales familiares de producción avícola son los más representativos como alternativa económica y alimentaria para las familias rurales marginadas; quienes, pese a estar ubicadas generalmente en medios ambientales frágiles, aportan el 70\% de los huevos y de la carne que se produce en países con déficits económicos y alimentarios (FAO, 2002).

Las gallinas criollas (Gallus domesticus) constituyen la especie más representativa y común en los sistemas tradicionales de producción campesina de Latinoamérica (Soler, 2010); y forman parte integral del sistema productivo familiar, de la economía local, la identidad cultural rural y la agrobiodiversidad. Sin embargo, 
los desarrollos tecnológicos han sido pocos y el sistema no ha sido especializado, probablemente, por ser parte de los sistemas productivos tradicionales que, al estar bajo la racionalidad de la economía campesina, busca disminuir riegos y asegurar su permanencia en el tiempo (Landini, 2011). Para este manejo, se recurre al conocimiento tradicional mejorado durante siglos por las familias campesinas, que lo heredan a las nuevas generaciones.

En contraste, la industria avícola comercial, con desarrollos tecnológicos más fuertes, presenta problemáticas cada vez mayores, mientras que la avicultura tradicional se mantiene estable aportando alimentos de buena calidad para las familias rurales (Valencia, 2011).

La disciplina agroecológica reconoce y valora el patrimonio natural, así como también, las tradiciones locales y culturales sobre las cuales se desarrollan los sistemas de producción campesinos (Galvis, 2015), que incorpora innovaciones tecnológicas sustentables que los potencian (Martínez, 2004).

Bajo este marco y a partir de sistemas tradicionales de producción de gallinas criollas, se desarrolla un amplio campo de prácticas agroecológicas en un proceso metodológico de investigación-acción participativa y colaborativa en la finca La Primavera, comunidad de Tamirco en Natagaima,Tolima. La finca es centro piloto de investigación de un grupo de trabajo comunitario compuesto por comunidades indígenas y mestizas (campesinos), donde se experimenta y luego se comparten los hallazgos del proceso. También, se comparten saberes con productores de las comunidades de Palma Alta y Pocharco.

La comunidad habita una zona de vida de bosque muy seco Tropical (bms-T) con régimen climático bimodal y sequías muy pronunciadas. Se localiza en una zona que es prolongación del desierto de la Tatacoa, situación que hace muy difícil el desarrollo de sistemas agropecuarios de producción.

Con el establecimiento de los cultivos agroindustriales de algodón, maíz y sorgo entre los años 1980 y 1990, los bosques fueron arrasados para dar lugar a los monocultivos. Los suelos fueron degradados con la mecanización excesiva y la aplicación elevada de fertilizantes y herbicidas, y en consecuencia, se agotaron las reservas de agua, se incrementó la temperatura y se aceleró la pérdida de buena parte de nutrientes y materia orgánica de los suelos.

A la erosión de los suelos, la pérdida de agua en fuentes superficiales y en el ambiente, se sumó la pérdida de la biodiversidad in situ, la agrobiodiversidad local y el conocimiento tradicional asociado. Las semillas nativas y criollas fueron desplazadas 
Figura 1. Sistema tradicional de manejo de gallinas criollas en el sur del Tolima.

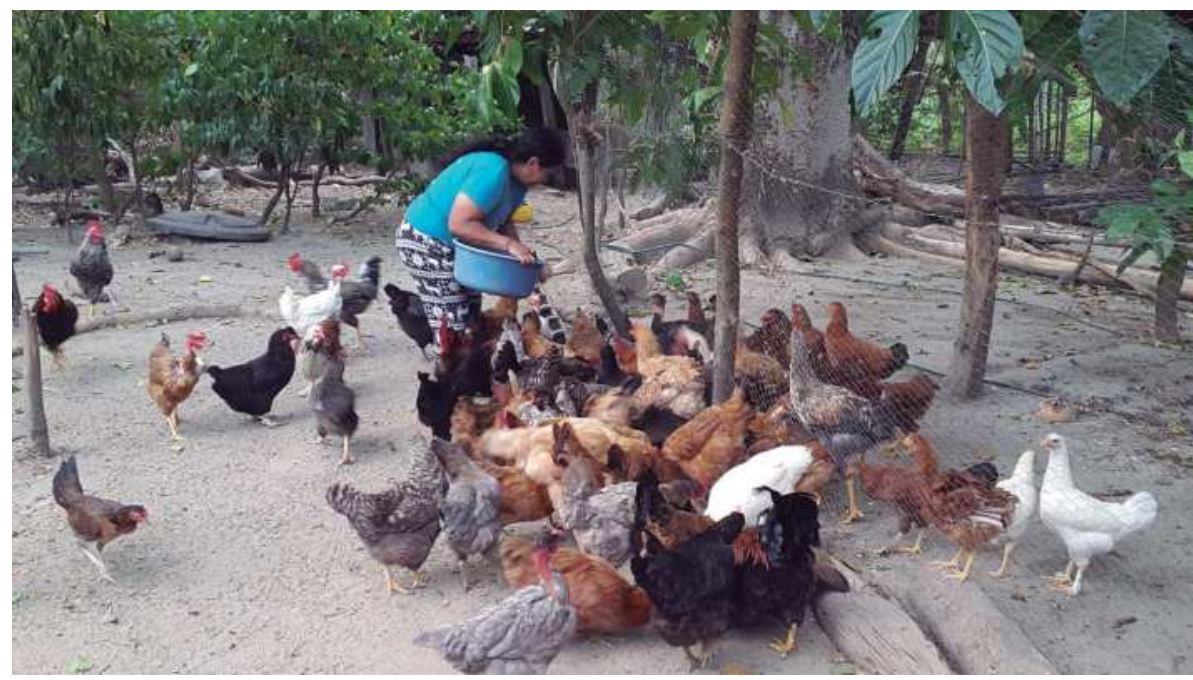

Fuente: Angarita (2018).

por la introducción de semillas foráneas, fertilizantes de síntesis química y agrotóxicos; así mismo las razas criollas de animales, fueron desplazadas por razas mejoradas y el uso de tecnologáis de altos insumos basadas en concentrados y medicina veterinaria. Con el tiempo, esto ha generado una alta dependencia externa y un grave deterioro de los sistemas productivos y alimentarios con los que contaba ancestralmente el territorio. Al fracaso del modelo de monocultivo, siguió la ganadería extensiva de tipo vacuno agravando el problema de la desertificación y la crisis socioambiental.

No obstante, muchas familias campesinas e indígenas de la zona generan alternativas ante estas difíciles condiciones, haciendo un uso eficiente de los limitados recursos para mantener sus sistemas productivos en los periodos de sequía. Se destaca el sistema tradicional de producción pijao que integra árboles leguminosos, frutales, pancogeres, medicinales y animales domésticos, especialmente, las gallinas criollas destinadas al autoconsumo y el mercado local. La estrategia central de este sistema tradicional es asegurar la conservación de la humedad en el suelo por periodos prolongados. Resulta frecuente escuchar entre los habitantes locales, el concepto de "enfriar el clima", ya que es la forma como los productores tradicionalmente generan condiciones microclimáticas para asegurar que especies como el maíz y las gallinas cumplan sus ciclos reproductivos. 


\section{Resultados y discusión}

Los resultados del proceso de investigación están enmarcados en un modelo comunitario de gestión del conocimiento de desarrollo agropecuario local, desde una perspectiva que involucra estrategias ambientales, sociales y económicas. De acuerdo con los planteamientos de Báez, Hernández, Perdomo, Garcés y Carrasco (2018), este modelo busca soluciones a problemas concretos que mejoran los ecosistemas y la calidad de vida bajo un marco de sostenibilidad.

El modelo comunitario de gestión del conocimiento es de naturaleza compleja. Tiene que ver con múltiples decisiones que han demostrado eficiencia y efectividad creciente, y pueden ser tenidos en cuenta, incluso, para formular políticas de desarrollo local. Las familias toman decisiones de tipo ambiental y económico de manera rápida, apoyadas en la observación y las pruebas permanentes que derivan en la selección de animales, el descarte de animales improductivos, el uso de alimentos locales, el balanceo de dietas y el destino de la producción. Es muy importante destacar que las prácticas desarrolladas permiten adaptar los agroecosistemas al cambio climático, cosa que los productores reconocen.

\subsection{Identificación de las razas de gallinas criollas presentes en la región}

El desarrollo del trabajo inició con la identificación fenotípica de las razas o biotipos de gallinas criollas presentes en la comunidad y el territorio. Para esta caracterización se realizaron descripciones, pesajes periódicos y observaciones del comportamiento productivo y reproductivo de cada una de las razas durante 8 meses. Se complementó la información con indagaciones a los sabedores de la comunidad y la región. Los sistemas de clasificación y diferenciación de las razas criollas constituyen un saber acumulado de generación en generación y existe un consenso para la denominación y descripción de las razas, que coincide con la descripción de los biotipos identificados por Rivas, Escudero, Cueva y Luzuriaga (2016).

En la tabla 1 se presenta el inventario y descripción de las razas identificadas en Tamirco, Pocharco y Palma Alta. 
Tabla 1. Inventario y descripción de las razas de gallinas criollas presentes en el territorio.

\begin{tabular}{|c|c|c|}
\hline No. & Nombre de la raza & Descripción de las principales características \\
\hline 1 & Negras & $\begin{array}{l}\text { Su plumaje es de color negro, son buenas ponedoras y es una de las razas que } \\
\text { más predomina en los patios o lotes de gallinas. }\end{array}$ \\
\hline 2 & Coloradas & $\begin{array}{l}\text { Su plumaje es de color rojizo, son buenas ponedoras y son las que más } \\
\text { predominan en los patios. }\end{array}$ \\
\hline 3 & Blancas & $\begin{array}{l}\text { Su plumaje es de color blanco, son buenas ponedoras. Poco abundantes en el } \\
\text { territorio, son susceptibles a enfermedades. }\end{array}$ \\
\hline 4 & Cenizas & $\begin{array}{l}\text { Su plumaje es de color gris y en algunos casos rojizo claro, son excelentes } \\
\text { ponedoras y sacadoras, es una de las razas predominantes en las } \\
\text { comunidades. }\end{array}$ \\
\hline 5 & Saraviadas & $\begin{array}{l}\text { Su plumaje es de color negro y blanco en forma de líneas. También las hay de } \\
\text { color amarillo y blanco. Son buenas ponedoras y sacadoras. Son comunes en } \\
\text { el territorio. }\end{array}$ \\
\hline 6 & Copetonas & $\begin{array}{l}\text { Aunque el color del plumaje puede variar, la característica que la identifica es } \\
\text { el copete de plumas que poseen en la cabeza. Son comunes en el territorio. }\end{array}$ \\
\hline 7 & Cariocas & $\begin{array}{l}\text { El color del plumaje puede ser variado, la característica distintiva es poseer el } \\
\text { cuello desnudo con una especie de penacho al frente que asemeja un moño o } \\
\text { corbatín. Son abundantes en el territorio. }\end{array}$ \\
\hline 8 & Enzamarradas & $\begin{array}{l}\text { De plumaje de color variado, la característica distintiva es poseer las patas y } \\
\text { dedos cubiertas por abundantes plumas. }\end{array}$ \\
\hline 9 & Papujas & $\begin{array}{l}\text { De colores variados, la característica distintiva corresponde a que posee el } \\
\text { cuello amplio en forma de papada y pómulos abultados. }\end{array}$ \\
\hline 10 & Cincodedos & $\begin{array}{l}\text { El color del plumaje puede ser variado, la característica particularmente } \\
\text { distintiva es que posee dos dedos más en cada pata. Escasa en el territorio. }\end{array}$ \\
\hline 11 & Pintas & $\begin{array}{l}\text { Su color de plumaje es una combinación de puntos o manchas negras, } \\
\text { blancas y en algunos casos también rojas. Son comunes en la zona o } \\
\text { territorio. }\end{array}$ \\
\hline 12 & Cresta de rosa & $\begin{array}{l}\text { El color del plumaje puede variar, la característica distintiva particular } \\
\text { corresponde a la forma de la cresta que es ancha y de la cual sobresalen una } \\
\text { serie de puntas o protuberancias. }\end{array}$ \\
\hline 13 & Huevoazul & $\begin{array}{l}\text { El color del plumaje puede ser variado, la característica que identifica a esta } \\
\text { raza es el color verde-azul de la cáscara del huevo. }\end{array}$ \\
\hline 14 & Carinegras & $\begin{array}{l}\text { El plumaje, generalmente, es de color negro, y la característica } \\
\text { particularmente distintiva es el color oscuro-negro de la piel y la carne. Muy } \\
\text { escasas en el territorio. }\end{array}$ \\
\hline 15 & Culimbas & $\begin{array}{l}\text { El color del plumaje puede variar, la característica distintiva particular } \\
\text { corresponde a que no poseen el hueso pigóstilo del que se deriva el musculo } \\
\text { que origina la cola, por lo tanto, no tiene cola. }\end{array}$ \\
\hline 16 & Charuzas & $\begin{array}{l}\text { El color del plumaje puede variar, la característica distintiva de esta raza } \\
\text { corresponde a la forma invertida de las plumas. }\end{array}$ \\
\hline 17 & Paturras & $\begin{array}{l}\text { Aunque el color pude ser variado, esta raza posee los tarsos (huesos de las } \\
\text { patas) muy cortos }\end{array}$ \\
\hline
\end{tabular}

Fuente: elaboración propia con información de los sabedores locales. 


\subsection{Consolidación de un sistema productivo de gallina criolla, bajo enfoque agroecológico}

\section{a. Características iniciales del predio y la familia}

Las condiciones iniciales de la familia y del predio en el cual se desarrolla la experiencia son las siguientes:

La familia está conformada por una pareja, con 2 hijos ausentes. Deriva su sustento a partir de los ingresos obtenidos por el arriendo de una parte de la finca (potreros) y lo complementan con la producción de yuca, plátano cachaco y maíz, también con la venta de mano obra (jornaleo). Estos elementos característicos identificados son congruentes con los hallados por Acevedo (2016), respecto a la multifuncionalidad de los sistemas tradicionales familiares del sur del Tolima.

En los últimos 15 años, la familia ha ensayado varias alternativas productivas, pero debido a las difíciles condiciones del clima, estas han fracasado. Por esta razón, optaron por arrendar el predio para el pastoreo de ganado y quedarse solo con un lote pequeño, el más sombreado, donde cultivan las especies para el sustento familiar.

El predio de 3 hectáreas presenta, inicialmente, las siguientes características:

- El 80\% del área del predio está arrendado y dedicado al pastoreo de ganado bovino. Existen tres potreros. El área de terreno restante (20\%) esta destinada a la producción de maíz, yuca y plátano y poseían su vivienda.

- Las gramíneas dominantes en los potreros son pasto colosuana (Bothriochloa pertusa) y pasto india (Panicum maximum). También hay árboles de iguá (Pithecellobium guachapele), el matarratón (Gliricidia sepium), guácimo (Guazuma ulmifolia), pelá (Vachellia farnesiana) y samán (Samanea saman) que son sembrados en los cercos, borde de los lotes y linderos del predio y se usan estratégicamente en época de sequía como forraje.

- Son suelos arcillosos, con bajo contenido de orgánica y compactados.

- El predio cuenta con un aljibe (pozo profundo) del cual se extrae el agua para uso doméstico y suministro a los animales. En época de sequía, no hay agua disponible y tampoco se tiene almacenamiento y reciclaje de agua.

- Se cuenta con un lote permanente de gallinas criollas que oscila entre los 20 y 30 animales. Estas están en diferentes etapas de desarrollo y producción. Son manejadas por la mujer y el alimento es principalmente maíz (se compra semanalmente una arroba). También son suplementadas con 
desperdicios de comida, productos del lote y, ocasionalmente, por el maíz que se logra producir cuando las condiciones climáticas lo permiten.

\section{b. Planificación predial enfocada a la producción de alimento para las gallinas}

La familia ha establecido un proceso autónomo de concepción, organización y estructuración del predio que, si bien no está representado gráficamente, usa con acierto esquemas mentales que les funcionan. La planificación productiva está orientada a la provisión del alimento para las gallinas, que de acuerdo con Machado et al., (2015), demuestra la amplia capacidad que tienen estos productores para planificar, administrar e innovar en el mejoramiento productivo de sus unidades agropecuarias. Las características centrales de la planificación encontrada son:

- El sistema es organizado de acuerdo con la disponibilidad de recursos disponibles.

- Se privilegian especies y conocimientos autóctonos, incorporando gradualmente saberes científicos externos que sean funcionales y hagan más eficiente el sistema. Se incorporan innovaciones tecnológicas, si son compatibles con el enfoque agroecológico.

- La organización y complejidad del sistema productivo varía de acuerdo con la disponibilidad del terreno familiar y de mano de obra.

- Se prioriza la recuperación y conservación del suelo para mejorar y mantener su capacidad productiva en el largo plazo.

- Prevalece el uso, recuperación, mejoramiento y conservación de semillas tradicionales.

- Se hace uso de regulación microclimática en áreas pequeñas usando técnicas como barreras y estratos de árboles que generen confort térmico, a través de un sistema de enfriamiento del clima.

- Se diversifica y optimiza la producción de alimentos, principalmente para las gallinas y el consumo familiar.

El sistema de producción de alimentos y manejo de las gallinas criollas incluye la finca, los recursos, los conocimientos, la mano de obra, pero también, las interrelaciones con áreas vecinas, que conforman el sistema productivo como tal. Lo anterior, implica los siguientes elementos y relaciones: 
- Se hace el diseño y la planificación de lotes para establecer los cultivos con los cuales se elabora el alimento para las gallinas. Allí se realizan las actividades de siembra, preparación de suelos, fertilización, manejo del cultivo, y control de plagas enfermedades, entre otras.

- Igualmente, se hace la siembra sistemática de plantas proveedoras del alimento. Se siembran plantas para producir carbohidratos (cereales, tallos, tubérculos, raíces, plátanos, etc.); plantas proveedoras de proteínas como leguminosas; plantas que aportn vitaminas y carbohidratos como las frutas (guayabas, totumos, mangos, anones, cítricos, ahuyamas y ajíes) y plantas ricas en vitaminas como follajes frescos y algunas hortalizas. Es una estrategia determinante para el balanceo de las dietas.

- La planificación, diseño y manejo de lotes de pastoreo o picoteo que incluyen arreglos para asegurar la sombra adecuada, provisión de forrajes y su cosecha para el almacenamiento y la conservación.

- La planificación de cultivos transitorios como productos que puedan ser almacenados en seco como el sorgo, los maíces y los frijoles; para la conservación en ensilajes como las yucas, los plátanos, las ahuyamas y forrajes; para la conservación por deshidratación como es el caso de los pastos y forrajes.

- El cultivo de las plantas medicinales y aromáticas que son empleadas para prevenir y tratar enfermedades en los animales.

- La incorporación de nuevas especies con potencial de utilización para la elaboración de alimentos concentrados.

- El desarrollo de cultivos para el abastecimiento familiar y para el mercado.

- La adecuación de infraestructura apropiada para el manejo de las gallinas: corrales de pastoreo y rotación, nidales, comederos, bebederos y dormitorios; al igual que, la adecuación y mantenimiento de la infraestructura para la elaboración del alimento como molinos, deshidratadores, ensilajes, etc.

- El diseño y adecuación de sistemas para la cosecha, captación y el aprovisionamiento de agua para el uso doméstico, para los animales y el riego de los cultivos en los periodos de sequía. 


\section{c. Valoración de la cantidad y calidad del alimento recibido por las gallinas en el predio}

La pregunta que motivo la indagación para conocer el requerimiento diario de las gallinas en estas condiciones fue ¿cuántos gramos en promedio y de qué calidad, necesita diariamente una gallina criolla, para desarrollar plenamente su potencial productivo y reproductivo?

Para caracterizar el suministro de alimentos con los requerimientos nutricionales que necesitan las gallinas criollas, se colectó y pesó el alimento que cotidianamente se les suministra y se calculó los aportes de nutrientes, a partir del método del tanteo. Se encontró que la principal fuente de alimento es el maíz, seguido de desperdicios de cocina y, ocasionalmente, subproductos de cosecha.

La cantidad promedio de maíz suministrado por animal al día es menor a $50 \mathrm{~g} /$ día. Este suministro es muy bajo frente a la dosis recomendada de $100 \mathrm{~g} /$ día para asegurar una buena producción de huevos y carne en los sistemas de libre pastoreo.

Se identificó como limitante asociada a la producción, la concepción que tienen los productores acerca de que las gallinas criollas se deben alimentar principalmente con maíz. Este producto es escaso, costoso y está priorizado para la alimentación humana. En el año 2011, los investigadores Mora-Delgado, Calderón y Gómez ya habían encontrado la relación existente entre la precariedad en la alimentación de gallinas y su desempeño productivo, a partir del manejo que los productores de la zona norte del Tolima hacen de sus animales.

$\mathrm{Al}$ realizar el balanceo de la ración convencional suministrada diariamente a las gallinas criollas, que se basada principalmente de maíz, se identificó que el fundamental aporte de este producto corresponde a carbohidratos (más del 90\%), mientras que el proteico corresponde a menos del 10\%, cuando este debe ser del $20 \%$ del alimento.

Esta situación fue también reportada por Mora-Delgado et al. (2011), respecto a la deficitaria alimentación suministrada, en el lugar de su estudio, a los animales; en el que, además, se encontró que para los otros grupos de nutrientes tampoco se hacía algún suministro específico. Sin embargo, se concluyó con los productores locales, que, al estar los animales a libre pastoreo, podrían estar obteniendo estos nutrientes en las colectas realizadas en campo abierto.

Para conocer la cantidad y calidad de alimento, se realizó un ensayo con varios lotes de animales confinados en diferentes fases de desarrollo y se calculó el rango de consumo diario de alimento (gramos por animal), tanto para alimento fresco 
(mezcla con la humedad de los productos frescos), como para alimento deshidratado (mezcla a partir de materias secas) como se muestra en la tabla 2. El cálculo se hizo a través del pesaje inicial de los alimentos, el suministro gradual a voluntad y el pesaje final de alimento no consumido. El ejercicio se realizó durante un periodo de siete meses, haciendo seguimiento a un lote de animales durante su proceso de desarrollo, hasta que estos alcanzaron la madures reproductiva.

Al determinar el consumo de alimento animal/día bajo condiciones de confinamiento, se puede hacer la proyección de la cantidad de alimento a producir en el sistema y, también, a el número de animales que se pueden mantener, tanto en desarrollo como en producción.

De este modo se logró estimar que, para alimentar un lote de 300 animales en diferentes fases de desarrollo o producción, bajo confinamiento, el suministro de alimento debe ser de $5590 \mathrm{~kg} /$ año de alimento fresco o $3058 \mathrm{~kg} /$ año de alimento deshidratado.

Tabla 2. Consumo de alimento diario en gallinas según fase desarrollo, en base fresca y deshidratado.

\begin{tabular}{lcc}
\hline \multicolumn{1}{c}{ Fase de desarrollo o producción } & $\begin{array}{c}\text { Consumo diario de } \\
\text { alimento en fresco }\end{array}$ & $\begin{array}{c}\text { Consumo diario de } \\
\text { alimento deshidratado }\end{array}$ \\
\hline Hembras adultas & $300400 \mathrm{~g}$ & $150200 \mathrm{~g}$ \\
\hline Pollos en fase de madurez reproductiva $(5-7$ meses de edad $)$ & $200-300 \mathrm{~g}$ & $100-150 \mathrm{~g}$ \\
\hline Pollos en fase de levante $(3-5$ meses de edad) & $150-200 \mathrm{~g}$ & $80-120 \mathrm{~g}$ \\
\hline Pollos volantones $(2-3$ meses de edad $)$ & $50-150 \mathrm{~g}$ & $50-80 \mathrm{~g}$ \\
\hline Pollitos fase cría $(0-2$ de meses de edad) & No se suministra & $10-50 \mathrm{~g}$ \\
\hline
\end{tabular}

Fuente: elaboración propia.

Al realizar el balanceo de la ración suministrada diariamente a las gallinas, basada principalmente en maíz, se identificó que, el principal aporte que se estaba haciendo correspondía a carbohidratos (más del 90\%), mientras que las fuentes proteicas suministradas estaban por debajo del $10 \%$ cuando estas, como se dijo anteriormente, deben corresponder al 20\% del alimento. Esta situación confirma los planteamientos de Mora-Delgado et al. (2011), respecto a la deficitaria alimentación que los campesinos suministran a los animales. Para los otros grupos de nutrientes, tampoco se hacía algún suministro específico; sin embargo, al estar los animales a libre pastoreo, los podían estar obteniendo en el campo, pero no se podía determinar con exactitud si los estabanadquiriendo . 


\section{d. Identificación y caracterización de especies forrajeras disponibles en el territorio con potencial para alimentación de las gallinas criollas}

Una vez conocidos los requerimientos nutricionales de las gallinas criollas y el tipo de fuentes posibles, se procedió a la identificación e inventario de las fuentes disponibles en el predio. Esto se desarrolló mediante un ejercicio de observación participante entre sabedores locales y los investigadores. Se identificó e inventarió todos los productos de la finca que las gallinas consumen (tabla 3 ).

Tabla 3. Inventario de fuentes alternativas de alimentos identificados en la finca La Primavera y su disponibilidad.

\begin{tabular}{lll}
\hline \multicolumn{1}{c}{$\begin{array}{c}\text { Grupo de } \\
\text { nutrientes }\end{array}$} & \multicolumn{1}{c}{ Fuentes identificadas } & \multicolumn{1}{c}{ Disponibilidad } \\
\hline Proteínas & $\begin{array}{l}\text { Insectos, gusanos, lombrices y otros } \\
\text { animales que las gallinas cazan en los lotes } \\
\text { de pastoreo. } \\
\end{array}$ & $\begin{array}{l}\text { Irregular. Según capacidad de búsqueda de la } \\
\text { gallina y según época del año. } \\
\text { Ocasional. Es poco abundante } \\
\text { Abundante. Especialmente en épocas de }\end{array}$ \\
& $\begin{array}{l}\text { Follaje de leguminosas (samán, iguá, } \\
\text { matarratón, leucaena). }\end{array}$ & lluvias. \\
\hline Carbohidratos & Granos de maíz. & Ocasional. Poco abundante. \\
& Plátano cachaco. & $\begin{array}{l}\text { Abundante y ocasionalmente. } \\
\text { Abundante y ocasionalmente. } \\
\text { Yuca. }\end{array}$ \\
& Algunos pastos de pastoreo y de corte. & Abundantes y ocasionalmente. \\
\hline Vitaminas & Frutas: mango, anón, limón, guácimo. & Abundantes, ocasionalmente \\
\hline Minerales & Tierra, arenas, ceniza. & Abundantes y permanentes \\
\hline Agua & Aljibe, lluvias & Permanente \\
\hline
\end{tabular}

Fuente: elaboración propia con información de sabedores locales.

Con la realización del inventario de los productos que las gallinas consumen diariamente, se comprendió que al estar libres (pastoreo) y contar con amplias áreas de vegetación, ellas puedan conseguir distintos tipos de alimentos balanceados, se mantienen en buen estado físico y generar niveles adecuados de producción.

También, se realizó un inventario de las potenciales fuentes de alimentos en la finca, en la comunidad y en la región que podrían ser aprovechadas, como se muestra en la tabla 4. No obstante, se debe tener en cuenta que, aunque existe una elevada diversidad de fuentes alternativas, la mayoría de estas y su disponibilidad es estacional, es decir, está disponible en la temporada de lluvias y se agotan en período 
de sequía. Razón por la cual, se necesita desarrollar alternativas para aprovechar las fuentes o materias primas producidas en épocas de lluvia y asegurar su disponibilidad de manera permanente.

Entre las alternativas identificadas para la conservación de las materias primas están las prácticas de ensilaje y de deshidratación, las cuales fueron aprendidas, evaluadas por los productores y adaptadas a las condiciones propias de cada sistema productivo.

Tabla 4. Identificación de potencialidades alternativas de alimentos para las gallinas criollas presentes en la comunidad de Tamirco y el territorio Pijao del sur de Natagaima.

\begin{tabular}{|c|c|c|}
\hline $\begin{array}{l}\text { Fuentes de } \\
\text { nutrientes }\end{array}$ & Potencialidades & $\begin{array}{c}\text { Alternativas para asegurar la disponibilidad } \\
\text { permanente }\end{array}$ \\
\hline \multirow[t]{3}{*}{$\begin{array}{l}\text { Fuentes de } \\
\text { proteína }\end{array}$} & $\begin{array}{l}\text { Existen áreas suficientes para que los animales } \\
\text { busquen parte de su alimento, especialmente } \\
\text { insectos, pequeños vertebrados y moluscos } \\
\text { que abundan, si hay vegetación. }\end{array}$ & $\begin{array}{l}\text { Manejo de encierros amplios (potreros), bajo } \\
\text { sistemas de rotación. } \\
\text { Es necesario adecuar corrales para proteger } \\
\text { los animales y evitar su perdida por } \\
\text { depredadores. }\end{array}$ \\
\hline & $\begin{array}{l}\text { Se cuenta con una gran diversidad de } \\
\text { leguminosas silvestres de las cuales se puede } \\
\text { aprovechar su follaje, frutos y semillas. }\end{array}$ & $\begin{array}{l}\text { Deben ser incorporadas al sistema productivo } \\
\text { para disponer de ellas permanentemente. }\end{array}$ \\
\hline & $\begin{array}{l}\text { Se cuenta también con variedades criollas } \\
\text { y nativas de frijoles que son cultivadas } \\
\text { semestralmente. }\end{array}$ & $\begin{array}{l}\text { Se podrían cultivar en el predio o adquirirlas } \\
\text { con otros productores. Al usarlas se estimula } \\
\text { su cultivo. }\end{array}$ \\
\hline \multirow[t]{3}{*}{$\begin{array}{l}\text { Fuentes de } \\
\text { carbohidratos }\end{array}$} & $\begin{array}{l}\text { Tienen variedades de maíz criollo que son } \\
\text { cultivadas semestralmente. }\end{array}$ & $\begin{array}{l}\text { Se puede incrementar su cultivo en el predio } \\
\text { o adquirirla en la localidad. Al usarlas, se } \\
\text { estimula su cultivo. }\end{array}$ \\
\hline & $\begin{array}{l}\text { En algunas comunidades se dispone de } \\
\text { abundante plátano, especialmente cachaco. }\end{array}$ & $\begin{array}{l}\text { Se puede incrementar su cultivo en el predio o } \\
\text { adquirirla en la localidad. }\end{array}$ \\
\hline & $\begin{array}{l}\text { En algunas comunidades se dispone de } \\
\text { abundante yuca. }\end{array}$ & $\begin{array}{l}\text { Se puede incrementar su cultivo en el predio o } \\
\text { adquirirla en la localidad. }\end{array}$ \\
\hline $\begin{array}{l}\text { Fuentes de } \\
\text { vitaminas }\end{array}$ & $\begin{array}{l}\text { Hay una amplia disponibilidad de frutas } \\
\text { como limones, naranjas, mangos, papayas, } \\
\text { anones, guayabas, entre otras. También se } \\
\text { cuenta con algunas especies forrajeras que se } \\
\text { pueden aprovechar mejor. }\end{array}$ & $\begin{array}{l}\text { Se puede incorporar algunas especies a } \\
\text { las parcelas o poteros donde los animales } \\
\text { picotean. También es posible adquirirlas en } \\
\text { la localidad. }\end{array}$ \\
\hline $\begin{array}{l}\text { Fuentes de } \\
\text { minerales }\end{array}$ & $\begin{array}{l}\text { Se dispone de áreas para pastoreo. Hay } \\
\text { diversidad de arenas y rocas. Se dispone de } \\
\text { ceniza y carbón de manera permanente. }\end{array}$ & $\begin{array}{l}\text { Si los animales están en pastoreo pueden } \\
\text { obtener la mayoría. Es necesaria la compra de } \\
\text { algunas fuentes en el mercado externo. }\end{array}$ \\
\hline Agua & Se dispone de aljibe (pozo profundo) & $\begin{array}{l}\text { Se hace necesario un sistema de distribución } \\
\text { para asegurar que permanezca fresca. } \\
\text { Desarrollar prácticas de cosecha de agua. }\end{array}$ \\
\hline
\end{tabular}

Fuente: elaboración propia. 
En este proceso, se identificaron los siguientes logros:

- Formulación de dietas balanceadas. Usando las materias primas locales identificadas, se logró desarrollar formulaciones de raciones mediante el método del tanteo, para satisfacer los requerimientos nutricionales de las gallinas, especialmente de proteína que es el factor limitante en la alimentación balanceada en las unidades de producción tradicionales. Se logró conseguir una dieta estándar con un porcentaje del 19.7\% de proteína, como se constató mediante análisis bromatológico.

- Estandarización en la producción y conservación de materias primas para la elaboración del alimento. Esto garantiza la disponibilidad y calidad de materias primas para estandarizar las formulaciones de raciones necesarias, para la producción de las gallinas criollas durante todo el año. El método propio, que se puede mejorar, es el de la planificación de siembras y almacenamiento de producciones excedentes logrados en épocas de lluvias.

- Estandarización en la elaboración del alimento. Asegurando rangos básicos de aportes nutricionales en las dietas, con adiciones de insumos externos no costosos y en cantidades adecuadas (melaza y algunas sustancias minerales), se determinan las formulaciones adecuadas para la elaboración del alimento mediante el método del tanteo.

- Formación del "pellet" o grano de alimento. Al optimizar la fase de mezclado de materias primas, adicionando melaza y realizando el prensado por medio un molino y, posteriormente, el deshidratado en marquesina, se logró homogenizar la mezcla y preparar gránulos. Esto asegura el consumo pleno de la mezcla y la no selección de las materias primas de mayor palatabilidad por parte del animal, aumentando la eficiencia del alimento.

\subsection{Generalidades del sistema de manejo de las gallinas criollas}

El manejo de las gallinas criollas bajo enfoque agroecológico implica un diseño predial que oriente la producción diversificada de alimentos y la adecuación de instalaciones y potreros para el pastoreo y búsqueda (picoteo). En la figura 2 se ilustra el tipo de corrales para la cría y levante de los animales.

Para el manejo de los lotes de gallinas y gallos productores y reproductores, se cuenta con 3 potreros (figura 3), de $3500 \mathrm{~m}^{2}$ cada uno aproximadamente, los cuales son manejados como sistemas avipastoriles, adaptados a los principios del huerto tradicional Pijao. Las densidades de carga son de $10 \mathrm{~m}^{2}$ por ave (300 gallinas en pastoreo). 
Figura 3. Esquema general de las instalaciones para el manejo de las gallinas en la fase de levante y cría.

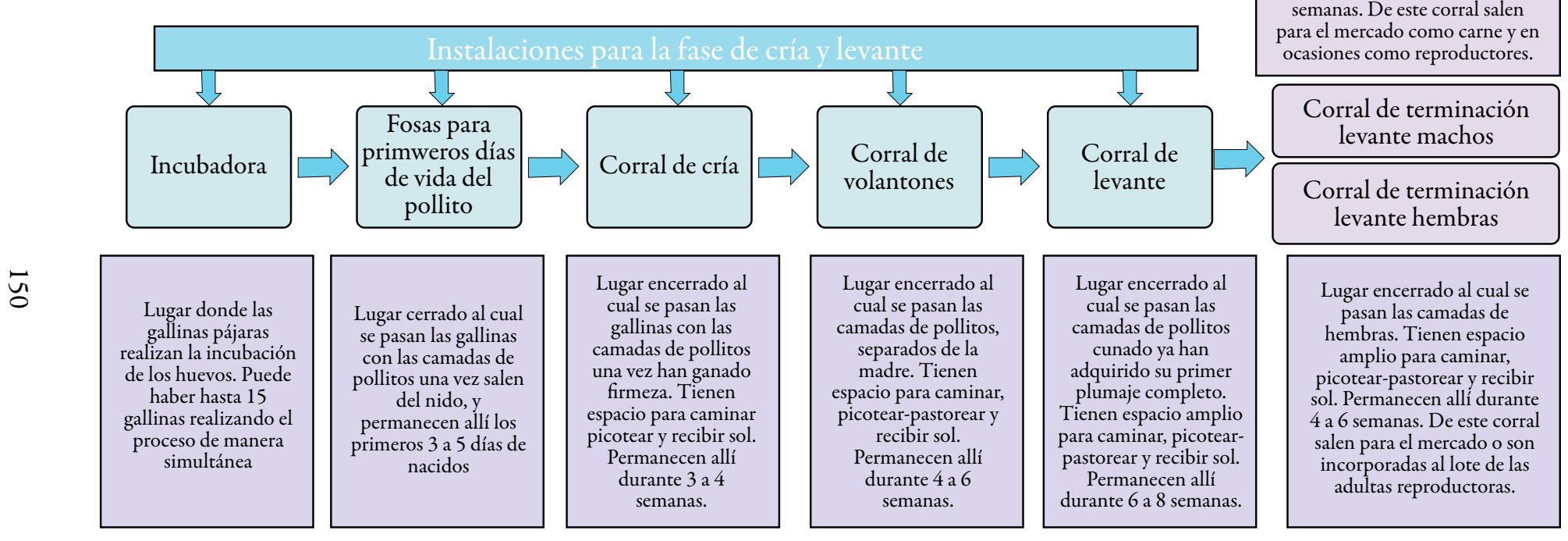

Lugar encerrado al cual se pasan las camadas de machos. Tienen espacio amplio para caminar. Permanecen allí durante 4 a 6 semanas. De este corral salen ara el mercado como carne y e

\begin{tabular}{|c|c|c|c|c|}
\hline 5 & 3 & 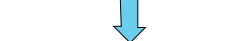 & 3 & 3 \\
\hline Incubadora & $\mid \begin{array}{c}\text { Fosas para } \\
\text { primweros días } \\
\text { de vida del } \\
\text { pollito }\end{array}$ & Corral de cría & $\begin{array}{c}\text { Corral de } \\
\text { volantones }\end{array}$ & $\begin{array}{l}\text { Corral de } \\
\text { levante }\end{array}$ \\
\hline $\begin{array}{l}\text { Lugar donde las } \\
\text { gallinas pájaras } \\
\text { alizan la incubación } \\
\text { e los huevos. Puede } \\
\text { haber hasta } 15 \\
\text { allinas realizando el } \\
\text { proceso de manera } \\
\text { simultánea }\end{array}$ & $\begin{array}{c}\text { Lugar cerrado al cual } \\
\text { se pasan las gallinas } \\
\text { con las camadas de } \\
\text { pollitos una vez salen } \\
\text { del nido, y } \\
\text { permanecen allí los } \\
\text { primeros } 3 \text { a } 5 \text { días de } \\
\text { nacidos }\end{array}$ & $\begin{array}{l}\text { Lugar encerrado al } \\
\text { cual se pasan las } \\
\text { gallinas con las } \\
\text { camadas de pollitos } \\
\text { una vez han ganado } \\
\text { firmeza. Tienen } \\
\text { espacio para caminar } \\
\text { picotear y recibir sol. } \\
\text { Permanecen allí } \\
\text { durante } 3 \text { a } 4 \\
\text { semanas. }\end{array}$ & $\begin{array}{c}\text { Lugar encerrado al } \\
\text { cual se pasan las } \\
\text { camadas de pollitos, } \\
\text { separados de la } \\
\text { madre. Tienen } \\
\text { espacio para caminar, } \\
\text { picotear-pastorear y } \\
\text { recibir sol. } \\
\text { Permanecen allí } \\
\text { durante } 4 \text { a } 6 \\
\text { semanas. }\end{array}$ & $\begin{array}{l}\text { Lugar encerrado al } \\
\text { cual se pasan las } \\
\text { camadas de pollitos } \\
\text { cunado ya han } \\
\text { adquirido su primer } \\
\text { plumaje completo. } \\
\text { Tienen espacio amplio } \\
\text { para caminar, picotear- } \\
\text { pastorear y recibir sol. } \\
\text { Permanecen allí } \\
\text { durante } 6 \text { a } 8 \text { semanas. }\end{array}$ \\
\hline
\end{tabular}

Fuente: elaboración propia. 
Figura 4. Sistema de rotación de potreros.

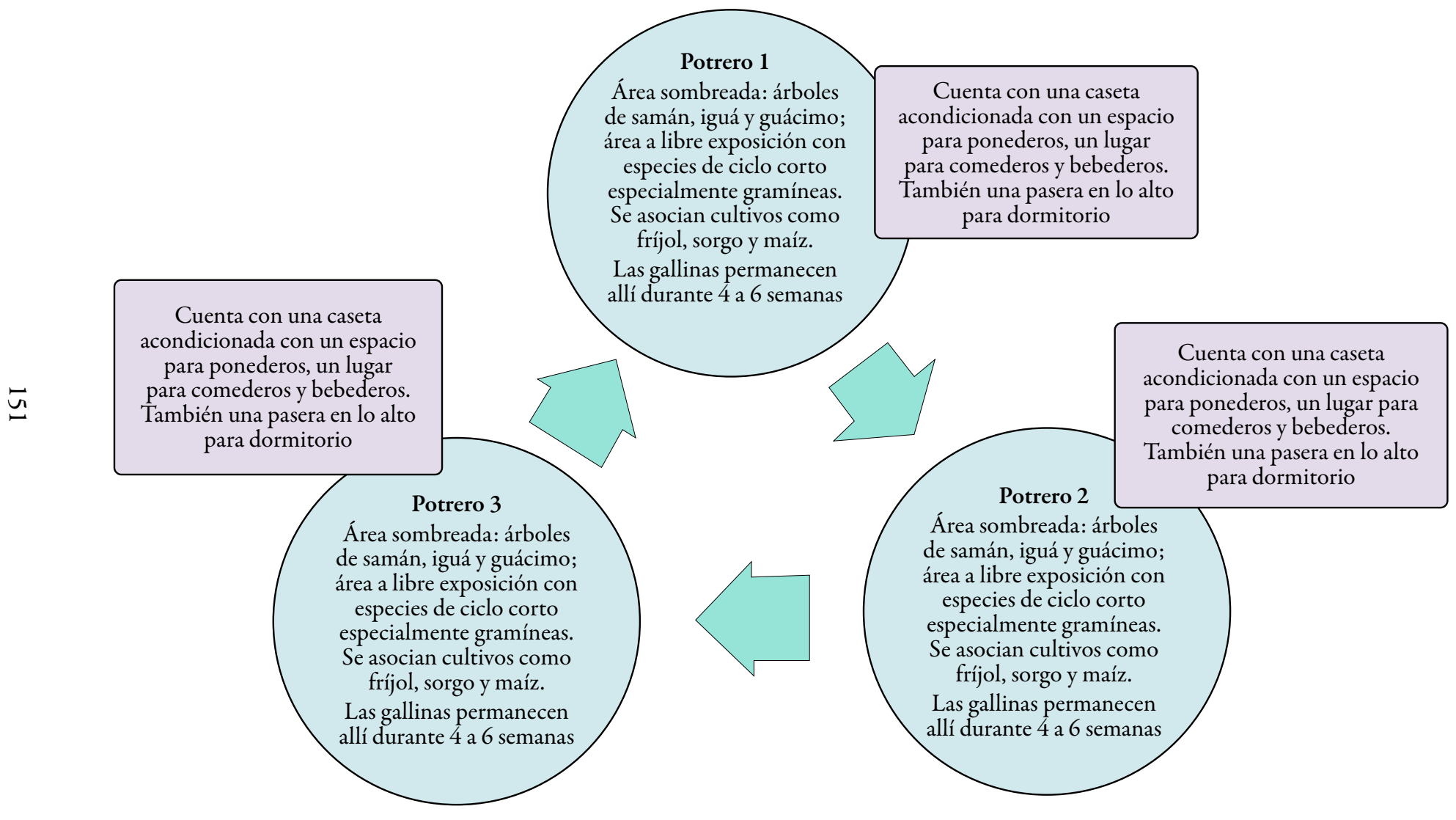

Fuente: elaboración propia. 
Adicional a los corrales, anteriormente descritos, se cuenta con espacios y equipos que se han ido incorporando según los ingresos del proyecto. Se cuenta con un espacio cubierto, aireado y amplio donde se realizan las mezclas. Está dotado con un molino de martillo para el molido y triturado de materias primas, un molino para la peletización, una balanza, una gramera, canecas y utensilios básicos para el proceso de elaboración de alimentos balanceados.

Adicionalmente, hay dos marquesinas para realizar el deshidratado de materias primas y del alimento peletizado.

A partir del diálogo de saberes, se logró establecer el calendario para el desarrollo productivo y reproductivo de las gallinas criollas, con el fin de facilitar la planeación al tener en cuenta los periodos de lluvias y de sequias; factor ambiental determinante en la eficiencia productiva y reproductiva de las gallinas criollas (tabla 5).

Tabla 5. Calendario productivo y reproductivo para gallinas criollas

\begin{tabular}{|c|c|c|}
\hline Periodo & Principales actividades desarrolladas & Observaciones \\
\hline Diciembre y enero & $\begin{array}{l}\text { Incubación de huevos. } \\
\text { Producción de huevos. }\end{array}$ & $\begin{array}{l}\text { La pérdida de huevos es mínima, atribuible } \\
\text { a que no hay tormentas. }\end{array}$ \\
\hline Febrero y marzo & $\begin{array}{l}\text { Cría de pollitos. } \\
\text { Producción de huevos. }\end{array}$ & Las gallinas aumentan la postura. \\
\hline Abril y mayo & $\begin{array}{l}\text { Levante de pollitos. } \\
\text { Producción de huevos. }\end{array}$ & $\begin{array}{l}\text { Como incrementan las lluvias y tormentas } \\
\text { no se incuban huevos, pues las pérdidas } \\
\text { son altas tanto de huevos como de pollitos } \\
\text { por la humedad y el frío. }\end{array}$ \\
\hline Junio y julio & $\begin{array}{l}\text { Incubación de huevos. } \\
\text { Producción de huevos. } \\
\text { Levante y ceba. }\end{array}$ & $\begin{array}{l}\text { Como no hay tormentas, la pérdida de } \\
\text { huevos es mínima. }\end{array}$ \\
\hline Agosto y septiembre & $\begin{array}{l}\text { Cría de pollitos } \\
\text { Producción de huevos. } \\
\text { Levante y ceba. }\end{array}$ & Las gallinas aumentan la postura \\
\hline $\begin{array}{l}\text { Octubre y } \\
\text { noviembre }\end{array}$ & $\begin{array}{l}\text { Levante de pollitos. } \\
\text { Producción de huevos. Levante y ceba. }\end{array}$ & $\begin{array}{l}\text { Como incrementan las lluvias y tormentas } \\
\text { no se incuban huevos, pues las pérdidas } \\
\text { son altas tanto de huevos como de pollitos } \\
\text { por la humedad y el frio. }\end{array}$ \\
\hline
\end{tabular}

Fuente: elaboración propia con información de sabedores locales.

\subsection{Rentabilidad del sistema productivo de gallinas manejadas bajo enfoque agroecológico}

Para conocer la rentabilidad del sistema se realizó un ejercicio de costos e ingresos a partir de la recuperación de información relacionada con el sistema de los últimos 4 años. Los resultados se presentan en la tabla 6. 
Tabla 6. Indicadores asociados a rentabilidad del sistema productivo de gallinas en un año.

\begin{tabular}{|c|c|c|}
\hline Indicador & Desempeño & Observaciones \\
\hline$\%$ de postura en lote de gallinas & $60-80 \%$ & Para gallinas criollas es un excelente porcentaje de postura. \\
\hline $\begin{array}{l}\text { Ingresos efectivos por venta de } \\
\text { huevos y animales }\end{array}$ & $\$ 35000000$ & $\begin{array}{l}\text { Comprende la venta anual de } 800 \text { a } 1200 \text { pollas o gallinas } \\
\text { como pie de cría, más la venta semanal de huevos. }\end{array}$ \\
\hline $\begin{array}{l}\text { Ingresos valorados por carne y } \\
\text { huevos }\end{array}$ & $\$ 3380000$ & $\begin{array}{l}\text { Comprende el valor asignado a los animales y huevos } \\
\text { consumidos por la familia. }\end{array}$ \\
\hline Ingresos valorados por gallinaza & $\$ 250000$ & $\begin{array}{l}\text { Corresponde al valor estimado de la producción de } \\
\text { gallinaza. }\end{array}$ \\
\hline $\begin{array}{l}\text { Egresos efectivos por insumos } \\
\text { y equipos }\end{array}$ & $\$ 5500000$ & $\begin{array}{l}\text { Son los gastos en minerales como roca fosfórica, cal, azufre } \\
\text { y sal. También melaza, harina de arroz y salvado de maíz, } \\
\text { empaques y combustible. }\end{array}$ \\
\hline $\begin{array}{l}\text { Egresos valorados insumos } \\
\text { propios y mano de obra }\end{array}$ & $\$ 16630000$ & $\begin{array}{l}\text { El valor del alimento suministrado anualmente a los } \\
\text { animales, que es producido en la misma finca. También el } \\
\text { valor de la mano de obra invertida en el sostenimiento de } \\
\text { los animales. }\end{array}$ \\
\hline Balance económico anual & $\$ 16500000$ & $\begin{array}{l}\text { Corresponde a valor derivado de restarle al valor total de los } \\
\text { ingresos el valor total de los gastos. }\end{array}$ \\
\hline Relación Beneficio/Costo & 1.74 & $\begin{array}{l}\text { Corresponde a la relación de pesos obtenidos por cada peso } \\
\text { invertido en la unidad productiva }\end{array}$ \\
\hline
\end{tabular}

Fuente: elaboración propia con información de sabedores locales.

La conformación del sistema de producción agroecológico de gallinas criollas ha permitido que, desde el año 2013, la familia reduzca la dependencia económica del alquiler del terreno y aumente los ingresos a partir de la cría y venta de gallinas y de huevos. Mora-Delgado et al. (2010) habían identificado que el componente pecuario representaba más del $38 \%$ del ingreso bruto en predios familiares del norte del Tolima. Resaltaron que, si se efectuaban mejoras en la diversidad, oferta y calidad nutricional de la alimentación suministrada a los animales, estos sistemas productivos mejorarían significativamente sus rendimientos productivos. De acuerdo con Lampkin et al. (2015), el aumento en la producción evidencia los beneficios de la implementación de sistemas agroecológicos de producción, en familias con espacios y recursos limitados. Adicionalmente, los productores señalan como "importantes ganancias" el enriquecimiento de los suelos con materia orgánica y contar con mejor clima.

\section{Conclusiones}

La producción de gallinas criollas constituye una alternativa productiva de fácil manejo y que reporta beneficios en tiempos cortos a las familias rurales del sur 
del Tolima y a sus agroecosistemas. Está integrada a los sistemas tradicionales de producción familiar campesinos, que son autónomos, sustentables y que influye sensiblemente en la autonomía alimentaria y el sustento de los hogares rurales, cuyo manejo involucra, fácilmente, a todos los integrantes de la familia, y sobre las cuales, se tejen relaciones comunitarias, principalmente entre las mujeres.

El proceso desarrollado por el grupo de productores y, en especial, por la familia de la finca La Primavera permite evidenciar que existe eficiencia del sistema productivo, basado en la gallina criolla con enfoque agroecológico. Se encontró que hay mejoras en la eficiencia productiva y en la generación de ingresos, lo que a su vez genera bienestar de la familia y la comunidad. En lo ambiental, se halló que este tipo de sistemas productivos aportan a la reducción de la temperatura, a la conservación de la humedad en el agroecosistema, además, que permite el aumento del contenido de materia orgánica en el suelo y la ampliación de la diversidad genética cultivada, en la medida que se amplía la población, y la genética de las gallinas criollas. Igualmente, se hace un uso de la biodiversidad in situ y se incorporan semillas criollas y nativas, como fríjoles, frutales, hortalizas, etc., que son necesarias para mejorar la alimentación de las aves. Este sistema de producción es replicable y tiene un efecto positivo y demostrativo en las comunidades vecinas de la vereda y del municipio.

Este sistema constituye una alternativa de trabajo colaborativo que aporta al uso sustentable de la agrobiodiversidad, asimismo, a la adopción de tecnologías aplicadas para mejorar el rendimiento y la calidad de la producción de carne y huevo destinados a mercados de tipo local y regional. Al caracterizarse por los ciclos cortos y la baja dependencia de recursos externos, permiten incorporar alternativas tecnológicas para su mejoramiento, las cuales son propuestas, adaptadas y desarrolladas con facilidad, por las mismas familias y comunidades.

La experiencia desarrollada en el predio La Primavera y en la vereda Tamirco de Natagaima, demuestra que la producción, cría y manejo de la gallina criolla es un aporte muy valioso de las mujeres rurales y, a su vez, les brinda condiciones favorables, en la medida que, aseguran ingresos económicos autónomos y reconoce, desde la evidencia, la importancia de los saberes aplicados y transmitidos por sus madres y abuelas. Además, generó un impacto positivo en las áreas manejadas por ellas, en la distribución equitativa de ingresos en la familia y en la generación de redes de apoyo y de investigación, como el que desarrolla este grupo comunitario que participó en esta investigación.

Un gran aprendizaje proporcionado por los productores locales, a partir del diseño y manejo de agroecosistemas para la producción de gallinas bajo enfoque agroecológico, 
es la adaptabilidad al cambio climático. La siembra "poliestratificada”, el establecimiento de barreras vivas con leguminosas y forrajes, el uso de semillas criollas tolerantes a la sequía y las razas criollas de gallinas adaptadas a esas difíciles condiciones son un aporte muy valioso para el diseño de agroecosistemas resilientes y adaptativos en el sur del Tolima, y en otras zonas secas y muy secas de Colombia.

Las zonas secas tropicales ofrecen una importante y variada oferta de alternativas (vegetales y animales) de buena calidad nutricional para alimentar las gallinas criollas. Sin embargo, su disponibilidad está restringida debido a los marcados períodos de sequias, por lo que se debe hacer una planificación y diseño de estos sistemas de producción agroecológicos, involucrando el saber tradicional de las comunidades y la innovación del conocimiento técnico, basado en aprovechamiento de excedentes. Este es un campo de investigación colaborativa que debe profundizarse.

\section{Referencias}

Acevedo, A. (2016). La multifuncionalidad de los sistemas tradicionales de producción de agricultores en el sur del Tolima. En A. Acevedo y J. Martínez (comps.) La agricultura familiar en Colombia. Estudios de caso desde la multifuncionalidad y sus aportes a la paz (pp.187-209). Bogotá: Ediciones Ediciones Universidad Cooperativa de Colombia, Corporación Universitaria Minuto de Dios y Agrosolidaria. Doi: http://dx.doi.org/10.16925/9789587 600476

Báez, A., Hernández, C. A., Perdomo, J. M., Garcés, R., y Carrasco, M. (2018). Modelo de gestión del conocimiento para el desarrollo agropecuario local. Revista Estudios Sociales. 28(51), 1-26. doi: http://dx.doi.org/ 10.24836/ es.v28i51.517

Corrales, E. (2003). El papel de los animales domésticos en la seguridad alimentaria rural. Conferencia electrónica, Sistemas pecuarios diversificados para el alivio de la pobreza rural en América Latina Facultad de Estudios Ambientales y Rurales, Universidad Javeriana. Recuperado de https://es.scribd.com/ document/45470812/Animales-domesticos-y-SA-Rural

Farah, M. A., y Pérez, E. (2004). Mujeres rurales y nueva ruralidad en Colombia. Revista Cuadernos de Desarrollo Rural. (51), 137-160. Recuperado de https://revistas. javeriana.edu.co/index.php/desarrolloRural/article/view/1275

Galvis, A. (2015). Agroecology key concepts, principles and practices. Oakland, CA.: Third World Network y socla Recuperado de: https://foodfirst.org/agroecology -key-concepts-principles-and-practices/ 
Landini, F. (2011). Racionalidad económica campesina. Revista Mundo Agrario, 12(23). Recuperado de https://www.mundoagrario.unlp.edu.ar/article/down load/v12n23a14/195?inline=1

Lampkin, N. H., Pearce, B. D., Leake, A. R., Creissen, H., Gerrard, C. L., Girling, R., Lloyd, S., Padel, S., Smith, J., Smith, L. G. Vieweger, A., y Wolfe, M. S. (2015). The role of agroecology in sustainable intensification. Report for the Land Use Policy Group. Escocia: Organic Research Centre, Elm Farm y Game y Wildlife Conservation Trust. Recuperado de http://publications.naturalengland.org. uk / publication/6746975937495040

Machado, H., Miranda, T., Bover, K., Oropesa, K., Suset, A., y Lezcano, J. C. (2015). La planificación en la finca campesina, una herramienta para el desarrollo de la agricultura sostenible. Revista Pastos y Forrajes, 38(3), 195-201. Recuperado de http://www.redalyc.org/articulo.oa?id=269141594006

Martínez, R. (2004). Fundamentos culturales, sociales y económicos de la agroecología. Revista de Ciencias Sociales, vol. I-II(103-104), 93-102. Recuperado de http:// www.redalyc.org/articulo.oa?id=15310407

Mora-Delgado J., Calderón, J.C., y Gómez, S. M. (2011). El componente pecuario en fincas campesinas de la ecorregión cafetera del departamento del Tolima (Colombia). Revista Luna Azul, (32), 16-31. Recuperado de http://www.redalyc. org/articulo.oa? id=321727234003

Organización de las Naciones Unidas para la Alimentación y la Agricultura - FAO, (2002). Avicultura Familiar. Revista Enfoques, 203(sp1). Recuperado de http:// www.fao.org/ag/esp/revista/0203sp1.htm

Rivas, G., Escudero, G., Cueva, F., y Luzuriaga, A. (2016). Características morfométricas de las gallinas criollas de comunidades rurales del sur del Ecuador. Revista de investigaciones veterinarias del Perú, RIVEP, 27(2), 218-224. Recuperado de http://www.redalyc.org/articulo.oa?id=371845996002

Soler, D. M. (2010). Importancia de los sistemas avicolas campesinos (pollo de engorde y gallina ponedora) dentro de la unidad productiva y su aporte a la seguridad alimentaria: estudio de caso vereda La Pradera, municipio de Duitama, Boyacá (tesis de maestría). Recuperado de https://repository. javeriana.edu.co/bitstream/handle/10554/852/eam70.pdf;jsessionid=3B5C1FF7E665DB1947 9BC77478145BAA ? sequence $=1$

Tovar-Paredes, J. L., Narváez-Solarte, W., y Agudelo-Giraldo, L. (2015). Tipificación de la gallina criolla en los agroecosistemas campesinos de producción en la zona 
de influencia de la selva e Florencia (Caldas). Revista Luna Azul, (41), 57-72. Recuperado de http://www.redalyc.org/articulo.oa?id=321739268004 Valencia, N. F. (2011). La gallina criolla colombiana. Palmira: Universidad Nacional de Colombia. Recuperado de http://bdigital.unal.edu.co/46222/ 



\title{
Capítulo 7
}

\section{Construyendo desde la base una opción de vida: experiencia de la Red de Mercados Agroecológicos Campesinos del Valle del Cauca-REDMAC}

Building a life option from bottom-up: experience of the Network of Agroecological Farmers Markets of Valle del Cauca-REDMAC

\author{
Diego Iván Ángel Sánchez* \\ Carlos Arturo Aristizábal Rodríguez ${ }^{* *}$
}

Red de Mercados Agroecológicos Campesinos del Valle del Cauca, REDMAC ${ }^{* * *}$

\section{Cómo citar}

\begin{abstract}
APA
Ángel, D., Aristizábal, C., y REDMAC. (2019). Construyendo desde la base una opción de vida: experiencia de la red de mercados Agroecológicos Campesinos del Valle del Cauca-REDMAC. En Á. Acevedo-Osorio y N., Jiménez-Reinales (comps.). La agroecología. Experiencias comunitarias para la Agricultura Familiar en Colombia. (pp. 161-181). Bogotá: Corporación Universitaria Minuto de Dios-UNIMINUTO, Editorial Universidad del Rosario.
\end{abstract}

\section{Chicago}

Ángel Sánchez, Diego Iván, Aristizábal Rodríguez, Carlos Arturo y REDMAC. "Construyendo desde la base una opción de vida: experiencia de la red de mercados Agroecológicos Campesinos del Valle del Cauca-REDMAc". En La agroecología. Experiencias comunitarias para la Agricultura Familiar en Colombia, comps. Álvaro Acevedo-Osorio y Nathaly Jiménez-

\footnotetext{
* Universidad Nacional de Colombia, Sede Palmira. dangels@unal.edu.co

** Universidad Nacional de Colombia, Sede Palmira. caaristizabalro@unal.edu.co

*** redmercadosagroecologicos@gmail.com
} 
Reinales. Bogotá: Corporación Universitaria Minuto de Dios-UnIMINUTO, Editorial Universidad del Rosario, 2019.

\section{MLA}

Ángel Sánchez, Diego Iván, Aristizábal Rodríguez, Carlos Arturo y REDMAC. "Construyendo desde la base una opción de vida: experiencia de la red de mercados Agroecológicos Campesinos del Valle del Cauca-REDMAc". En La agroecología. Experiencias comunitarias para la Agricultura Familiar en Colombia. En Á. Acevedo-Osorio y N., Jiménez-Reinales (comps.) Bogotá: Corporación Universitaria Minuto de Dios-UNIMINUTO, Editorial Universidad del Rosario, 2019, pp. 161-181.

\section{Resumen}

Este capítulo presenta los procesos y aprendizajes que ocurrieron en las dinámicas sociales, económicas, políticas y culturales que surgieron durante la conformación y consolidación de la Red de Mercados Agroecológicos Campesinos del Valle del Cauca (REDMAC) y su Sistema Participativo de Garantías (SPG). Se aplicó para esto la metodología de sistematización de experiencias, e incluyó, la revisión de diferentes documentos y la realización de entrevistas en profundidad con miembros fundadores de la Red. Como aspectos importantes de este proceso, se encontró que la REDMAC es fruto autónomo de voluntades de campesinos que, desde su entendimiento de la agroecología como opción de vida, han logrado una estrecha relación con los amigos consumidores, lo cual ha contribuido a sostener los mercados a pesar de las numerosas dificultades presentes, principalmente, con la institucionalidad oficial. Otro aspecto que hay que destacar es su independencia política frente a diferentes actores e instituciones, alcanzado gracias al establecimiento de relaciones horizontales para la cooperación con ellos. Todo lo anterior, ha permitido consolidar una propuesta de desarrollo rural con base agroecológica, la cual es referente nacional e internacional y tiene como fin contribuir a que sus asociados avancen hacia el buen vivir, pero también, aporten positivamente a las condiciones ambientales y sociales de su entorno local y regional.

Palabras clave: agricultura familiar, agroecología, asociatividad, circuitos cortos de comercialización, mercados agroecológicos campesinos.

\section{Abstract}

This chapter presents the processes and learnings that occurred in the social, economic, political and cultural dynamics that emerged during the conformation and consolidation of the Network of Agroecological Farmers Market of Valle del Cauca (REDMAC) and its Participatory Guarantee System (PGS). The methodology for systematizing experiences was applied to this, and included the review of different documents and conducting in-depth interviews with founding members of the Network. As important aspects of this process, it was found that REDMAC is an autonomous fruit of wills of farmers who, from their understanding of agroecology as an option of life, have achieved a close relationship with consumer friends, which 
has helped sustain markets despite the numerous difficulties present, mainly, with the official institutionality. Another aspect that must be highlighted is the political independence in front of different actors and institutions, achieved thanks to the establishment of horizontal relations for cooperation with them. All of the above has made it possible to consolidate a rural development proposal based on agroecology, which is a national and international reference and aims to help its members move towards good living, but also contribute positively to the environmental and social conditions of its local and regional environment.

Keywords: family farming, agroecology, associativity, short marketing circuits, agroecological farmers markets.

\section{Introducción}

En Colombia, la Agricultura Familiar Campesina (AFC) aporta a la mesa de las familias colombianas alrededor del $42 \%$ de los alimentos que allí se consumen. Las familias que se dedican a esta actividad involucran en la producción agropecuaria a los miembros de la familia, en algunos casos a la comunidad (Ministerio de Agricultura y Desarrollo Rural, 2017) y en varias regiones del país lo hacen en pequeñas extensiones de tierra. La AFC es la principal generadora de empleo en el campo, a pesar de que aún las comunidades campesinas no han sido reconocidas como sujetos con derechos diferenciales por el estado colombiano. Por otro lado, la Agricultura Familiar Agroecológica Campesina (AFAC) propende por la seguridad y soberanía alimentaria por medio de la producción de alimentos en armonía con el medio ambiente, sin depender de insumos de la industria petroquímica, con el fin de conservar la biodiversidad y respetar el conocimiento tradicional y ancestral de las comunidades rurales. Por ello, la AFAC es la responsable de la mitigación del cambio climático a través del cuidado de los bienes naturales -agua, suelo, aire-, así como de la diversidad genética y cultural, mediante la custodia de semillas criollas y nativas; asimismo, busca la conservación del acervo de conocimiento tradicional y ancestral.

En el departamento del Valle del Cauca, la AFAC se desarrolla principalmente en la zona de ladera, debido a que la agricultura industrial, dedicada a la producción de caña de azúcar, ha desplazado paulatinamente a la pequeña producción a sitios con menor calidad de suelo y, por ende, de menor valor en el mercado de tierras. En este sentido, quienes en la región se han dedicado a la AFAC, han sido apoyados por algunas instituciones que, a su vez, han impulsado la creación de mercados campesinos para la comercialización de los alimentos producidos en las fincas agroecológicas; con el propósito de buscar y brindar acceso al alimento sano en las cabeceras municipales. Como resultado de diferentes esfuerzos, surgió la Red de Mercados 
Agroecológicos Campesinos del Valle del Cauca (REDMAC), una entidad de segundo nivel que agrupa a doce mercados campesinos agroecológicos que, al mismo tiempo, representan a más de 300 familias agrupadas, en casi 60 asociaciones y grupos de origen campesino, indígena y afrodescendiente.

La experiencia de la REDMAC es un caso de aplicación de la agroecología como ciencia, práctica y movimiento social. Sus principios deben orientar lo que hoy se conoce como Sistemas Alimentarios Sostenibles (SAS), que son una alternativa al imperante sistema alimentario industrial o globalizado. El cual tiene su fundamento en la agricultura convencional y en el monopolio de grandes transnacionales (Hatt et al., 2016). En este sentido y para complementar este enfoque, es interesante analizar el caso de la REDMAC a la luz de los principios socioeconómicos ligados a la agroecología, recopilados por Dummont, Vanloqueren, Stassart y Baret (2016, p. 28), quienes manifiestan que dichos principios son los siguientes: la igualdad ambiental, la independencia financiera, el acceso e independencia de los mercados, la sostenibilidad y adaptabilidad, la diversidad y el diálogo de saberes, la equidad social, la asociación entre productores y consumidores, la proximidad geográfica, el desarrollo rural y preservación del tejido social, la organización comunitaria, la distribución limitada de utilidades, el gobierno democrático y la implementación conjunta de varios principios en la práctica cotidiana.

El trabajo comprendido en este capítulo es un ejercicio de sistematización de experiencias que pretende ayudar a la comprensión de las dinámicas sociales, económicas, políticas y culturales acaecidas durante el proceso de conformación de la REDMAC y de la consolidación de su Sistema Participativo de Garantías (SPG); además de visibilizar las experiencias y aprendizajes extraídos de dichos procesos. Lo anterior, se logró a través de la revisión de algunas publicaciones y documentos de la red, además de una serie de entrevistas, no estructuradas, con algunos miembros de la junta directiva de la entidad y líderes de algunos de los mercados.

\section{Resultados}

\subsection{Un poco de historia}

A finales de los años 1980 y 1990, se dio en el departamento del Valle del Cauca un auge de la producción agrícola con características agroecológicas. Los campesinos, de diferentes municipios, producían alimentos para el autoconsumo y, ocasionalmente, generaban excedentes para el intercambio local; sin embargo, no se sembraba pensando en el mercado urbano. Este proceso fue seguido y acompañado permanentemente por 
organizaciones como el Instituto Mayor Campesino (IMCA) y, esporádicamente, por entes gubernamentales que fueron impulsados por las directrices originadas después de la Cumbre de “Río-92", en el año 1992. Esta conferencia buscaba el fomento y el apoyo a las agriculturas alternativas, entre ellas, la orgánica con bases agroecológicas.

Al llegar el año 2000, se planteó la inquietud por la disponibilidad de alimentos ecológicos para los habitantes de las ciudades, sumada a la necesidad de vender los excedentes producidos por los agricultores. Al mismo tiempo, la Corporación Autónoma Regional del Valle del Cauca (CVC) comienza a acompañar los procesos comunitarios de producción orgánica y a conformar mercados campesinos para la venta de los productos, en el casco urbano de los municipios. Es así que, aparecen dos sectores diferenciados: por un lado, el de la agroindustria orgánica empresarial y, pro el otro, el integrado por las organizaciones de productores de base ya existentes, con apoyo institucional, a causa del boom ecológico. Estas organizaciones eran apoyadas por grupos de profesionales pertenecientes a la corriente de pensamiento ecológico. En el departamento del Valle del Cauca, estaba liderada por el maestro Guillermo Castaño Arcila, los profesores Hernando Patiño Duque y Mario Mejía de la Universidad Nacional de Colombia, Sede Palmira, y por la cvc que gestionaba espacios físicos y aportaba materiales, como carpas y canastillas para los mercados.

A partir del año 2007, se inicia el diagnóstico de los mercados existentes y la formulación de planes estratégicos para su fortalecimiento. Lo que conllevó a que, en el año 2009, la cvc financiara el Primer Encuentro de Mercados Verdes. Allí, hicieron presencia los siete mercados que funcionaban en los municipios de Cali, Palmira, Cartago, Sevilla, Tuluá, Roldanillo y Buga. En este encuentro, se identificaron complementariedades entre los mercados, es decir, las debilidades de unos eran las fortalezas de otros. Esto se vio como una oportunidad para mejorar su articulación y trabajo conjunto. Como resultado, se acordó crear una organización que uniera los diferentes mercados y, es así que, nació la Red de Mercados Agroecológicos Campesinos del Valle del Cauca (REDMAC). Como producto de las discusiones se elaboró una declaración y se propusó hacer otro encuentro en el año siguiente. Es así que, en 2010 se celebró el segundo encuentro con asistencia de delegados de los 12 mercados existentes para ese momento. Estos representaban a alrededor de 60 organizaciones de base, distribuidas entre asociaciones de productores, grupos de mujeres, escuelas campesinas agroecológicas y familias comprometidas con la agroecología. 


\subsection{Organización y articulación, base para el desarrollo y fortalecimiento de la REDMAC.}

En la práctica, la estructura de la Red es horizontal y no existen jerarquías para su funcionamiento, esta propende a llevar a la acción los fundamentos sociales de la agroecología y acorde con un dinamismo participativo y solidario. Su estructura formal está conformada por la asamblea general, la cual está integrada por dos delegados de cada mercado; un fiscal; seguidos por la junta directiva, de la que forman parte el representante legal y presidente, el vicepresidente, la tesorera, la secretaria y el vocal. Finalmente, en el primer nivel, se encuentran los comités de trabajo del SPG. El siguiente es el organigrama de la REDMAC (figura 1).

Cada mes y de manera ininterrumpida desde sus inicios, se celebra una reunión de la junta directiva, ampliada con la participación de dos representantes por cada mercado, elegidos de manera autónoma. Las actuaciones de la Red están regidas por sus estatutos y las decisiones se toman por consenso, construyendo posibilidades de democracia participativa. Esta dinámica, le ha permitido a la organización estar enterada, de forma permanente, de lo que sucede en cada mercado y así poder solucionar las diferentes situaciones que se presentan. Igualmente, se ha constituido en un espacio de diálogo y formación permanente en temas de ecología, salud, incidencia política

Figura 1. Organigrama REDMAC.

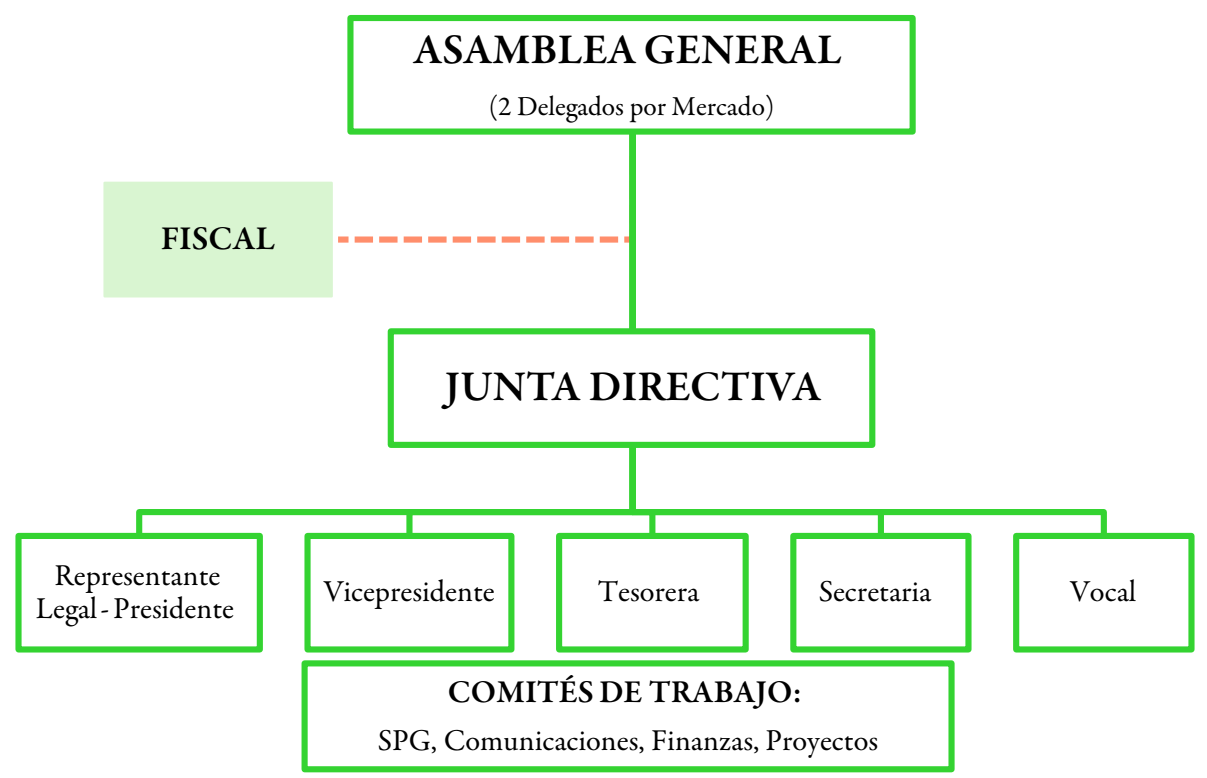

Fuente: elaboración propia. 
y otros relacionados con la producción y los mercados agroecológicos. Lo anterior, a través de su interacción con otras instituciones, organizaciones, redes o desde los propios miembros de la Red. También en algunos casos, la Red ha gestionado y delegado a algunas organizaciones de base la ejecución de proyectos, propiciando con esto un acercamiento entre ella y las familias, aspecto que, ha contribuido a fortalecer su vínculo y pertenencia entre estas, lo cual es necesario seguir desarrollando.

En la actualidad la Red está compuesta por alrededor de 60 organizaciones de diferente índole, pertenecientes a 23 municipios de los departamentos del Valle del Cauca y Cauca (IfOAm, 2013), que hacen presencia en mercados campesinos ubicados en los municipios de Andalucía, Buga, Cali, Dagua, Guacarí, Palmira, Restrepo, Roldanillo, Sevilla y Tuluá.

Actualmente, la REDMAC está compuesta por aproximadamente 300 familias campesinas, indígenas y afrocolombianas, que mediante su labor hacen un importante aporte a la agroecología en sus diferentes dimensiones (figura 2); Asimismo, generan relaciones con sus pares, los consumidores y con el ambiente, lo que da como resultado el fortalecimiento de la soberanía alimentaria, la conservación de la agrobiodiversidad y la mitigación del cambio climático; todo por medio del manejo sostenible de los bienes naturales.

Figura 2. Aporte de las familias desde la agroecología.

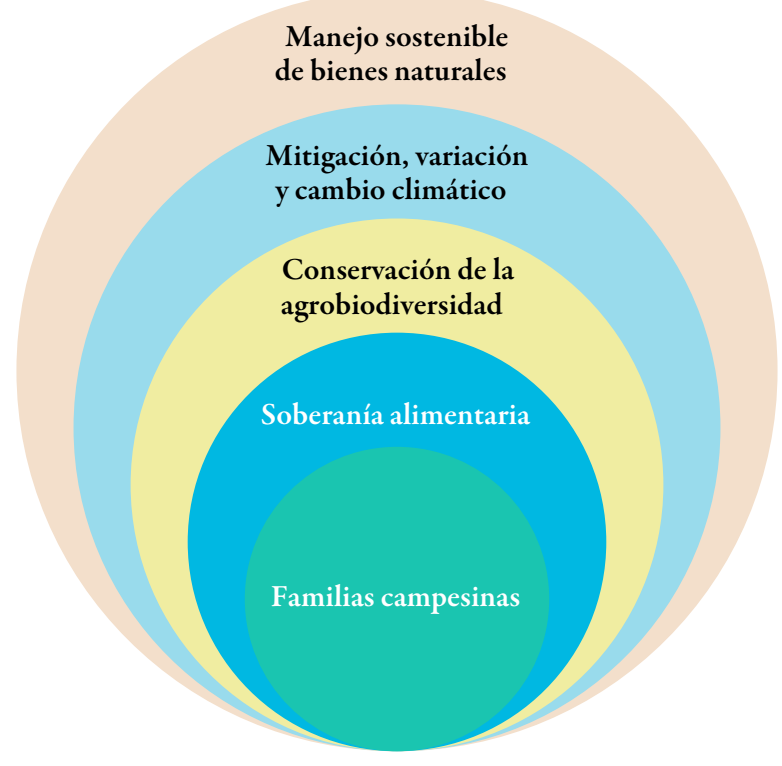

Fuente: elaboración propia. 


\subsection{Acercando "los alimentos de vida" al consumidor: ¿cómo funcionan los mercados?}

Los mercados que integran la Red son conocidos como mercados tipo feria, los cuales, desde los principios agroecológicos, buscan establecer circuitos cortos de comercialización, mediante un consumo que involucre la proximidad física y comercial, en otras palabras, un consumo en la que se logre una relación directa entre el productor y el consumidor; igualmente, la Red tiende a la fijación de precios justos para ambas partes y un menor gasto energético, esto último, se debe a que se recorren menores distancias desde las fincas hasta los sitios del mercado (figura 3).

Figura 3. Aplicación de los principios agroecológicos en la REDMAC.

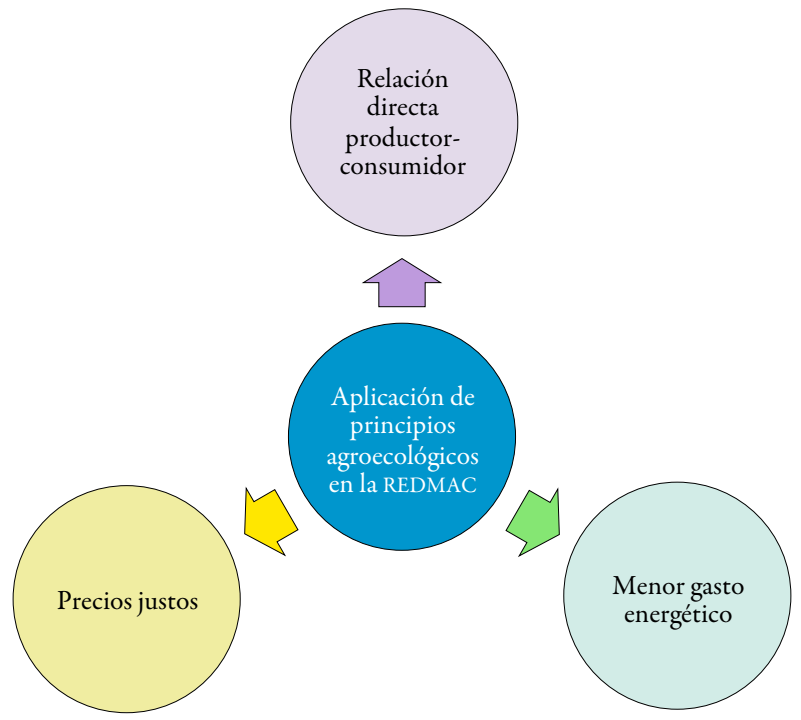

Fuente: elaboración propia.

La mayoría de los mercados funcionan con frecuencia semanal, en espacios localizados dentro del casco urbano de los municipios o corregimientos, como lo son las plazas de mercado o parques. De otra parte, al tener autonomía en su conformación y funcionamiento, cada mercado tiene características particulares de organización (tabla 1); no obstante, cada uno presenta como base los principios de equidad y solidaridad, lo que ha permitido el desarrollo de tres tipos en particular de estos espacios. 
Tabla 1. Tipos de mercados que agrupa la REDMAC.

\begin{tabular}{|c|c|c|c|}
\hline Tipo & Características & Nombre & Ubicación \\
\hline \multirow{8}{*}{$\begin{array}{l}\text { Operados y } \\
\text { regidos por } \\
\text { organizaciones } \\
\text { formalmente } \\
\text { constituidas. }\end{array}$} & \multirow{8}{*}{$\begin{array}{l}\text { La organización coordina } \\
\text { las actividades del } \\
\text { mercado, composición de } \\
\text { la oferta de productos y } \\
\text { funcionamiento interno } \\
\text { (precios, organización del } \\
\text { espacio físico, aseo, entre } \\
\text { otros) }\end{array}$} & ASOPROORGÁNICOS & Cali (Valle) \\
\hline & & Semilla Sevilla & Sevilla (Valle) \\
\hline & & Renacer Campesino & Santa Rosa de Tapias, Guacarí (Valle) \\
\hline & & ASOPECAM & La Marina, Tuluá (Valle) \\
\hline & & MERCADAGRO & Dagua (Valle) \\
\hline & & MERCOVIDA & Restrepo (Valle) \\
\hline & & MERCAPAZ & La Habana, Buga (Valle) \\
\hline & & APROMERCAR & Roldanillo (Valle) \\
\hline \multirow{2}{*}{$\begin{array}{l}\text { Anexo a } \\
\text { mercados } \\
\text { campesinos } \\
\text { de productos } \\
\text { convencionales. }\end{array}$} & \multirow{2}{*}{$\begin{array}{l}\text { Los productores de } \\
\text { manera individual o } \\
\text { representando alguna } \\
\text { organización se ubican en } \\
\text { mercados campesinos ya } \\
\text { establecidos en algunos } \\
\text { municipios. }\end{array}$} & MERCACENTRO & Tuluá (Valle) \\
\hline & & MERCOBUGA & Buga (Valle) \\
\hline $\begin{array}{l}\text { Acuerdo } \\
\text { informal de } \\
\text { voluntades entre } \\
\text { organizaciones } \\
\text { formalmente } \\
\text { constituídas. }\end{array}$ & $\begin{array}{l}\text { Asociaciones que } \\
\text { provienen de diferentes } \\
\text { pisos térmicos de una } \\
\text { región para conformar } \\
\text { una oferta diversa de } \\
\text { productos. }\end{array}$ & $\begin{array}{l}\text { Mercado } \\
\text { Agroecológico } \\
\text { Campesino del } \\
\text { Centro del Valle }\end{array}$ & Tuluá (Valle) \\
\hline
\end{tabular}

Fuente: elaboración propia.

Debido a su importante aporte a la soberanía alimentaria regional, los mercados han tenido que enfrentar amenazas a su funcionamiento y permanencia, la mayoría asociadas a la relación de los mercados con los entes gubernamentales. Frente a ello, gracias al capital social generado y al establecimiento de relaciones interinstitucionales, se han podido sortear estos desafíos (Figura 4). 
Figura 4. Amenazas y respuestas de la REDMAC a fenómenos del entorno.

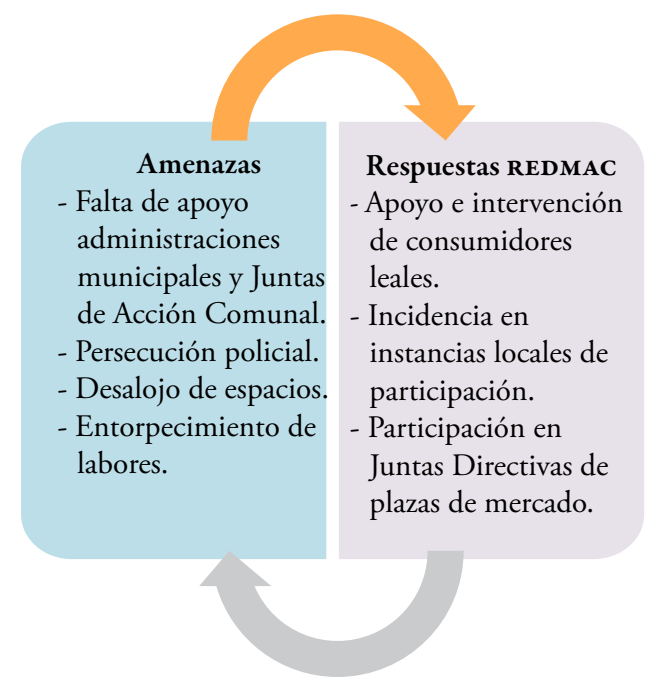

Fuente: elaboración propia.

\subsection{Del consumidor al amigo consumidor: solidaridad, confianza y reciprocidad}

Por la permanencia y constancia en los mercados, los productores y los consumidores se conocen desde hace varios años y su relación es muy estrecha, lo que facilita el diálogo y propicia lazos de confianza, cercanía, amistad y familiaridad. Esto ha llevado a que la Red hable de amigos o hermanos consumidores, permitiéndoles tener manifestaciones de solidaridad y reciprocidad como, por ejemplo, hacer algunas ventas o parte de ellas a crédito; asimismo, se presentan casos en el que algunos consumidores prestan su dinero a los productores para el apoyo a algunos proyectos productivos. Estas son algunas de las estrategias y resultados obtenidos en cuanto a la promoción, fidelización de clientes y fijación de precios, ideas implementadas por los mercados de la Red; las cuales, a pesar de haber surgido en mercados específicos, se han ido replicando en otros, como prueba del aprendizaje colectivo en sus procesos (figura 5). 
Figura 5. Estrategias de mercadeo implementadas por la REDMAC.
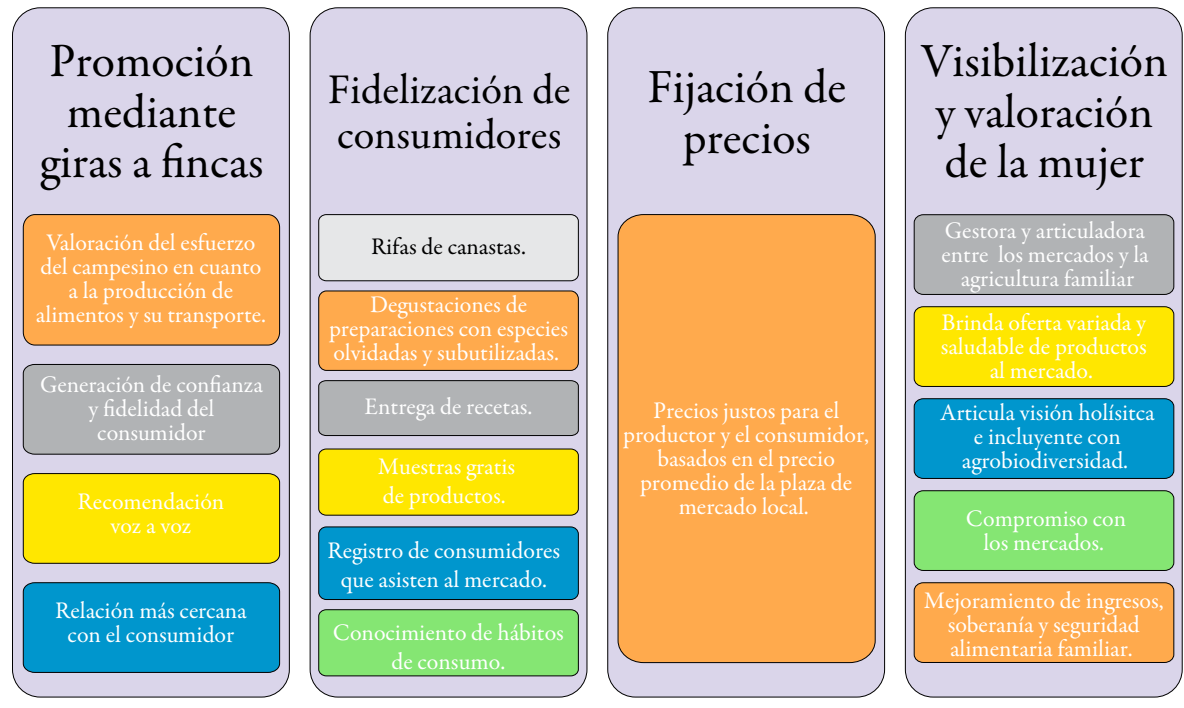

Fuente: elaboración propia.

\subsection{Interacción y articulación: ampliando la red interna y externamente}

Teniendo como base el empoderamiento de sus diferentes miembros e instancias, la Red ha logrado consolidar su autonomía. Esta, ha propiciado el establecimiento de relaciones horizontales en su interior y en el exterior. En este sentido, la interacción con otras organizaciones ha sido objetivo de la Red, desde sus inicios, y se ha podido desarrollar gracias a su liderazgo regional, nacional e internacional, consolidado por los miembros de la Red, y por actores externos que han apadrinado el proceso.

A nivel regional, se destaca el estrecho vínculo establecido con el Instituto Mayor Campesino (IMCA), el cual ha contribuido en la formulación y ejecución de diferentes proyectos, algunos de ellos en asocio con entidades como el Centro de Educación y Tecnología para el Desarrollo del Sur (CETSUR) de Chile y la Agencia de Cooperación Suiza (swissaID). La CVC ha acompañado a la Red desde su constitución y ha aportado recursos para la realización de proyectos. Igualmente, el Servicio Nacional de Aprendizaje (SENA) ha brindado capacitación en diferentes temas. A la par, el Grupo de Investigación en Agroecología de la Universidad Nacional de Colombia, Sede Palmira, a través de la realización de proyectos de extensión e investigación, ha contribuido al fortalecimiento y a lageneración de argumentos que fundamenten la importancia del aporte, con su pensar y quehacer, que hace la Red a la humanidad, al ambiente y al planeta. 
En espacios nacionales, la organización participa en la Red Nacional de Agricultura Familiar (RENAF), que busca unificar esfuerzos en los espacios centrales de incidencia política. Esta labor se ha complementado, en lo regional, con la Coordinadora Regional de Organizaciones Agroecológicas y de Comercio Justo (CROAC), mediante la interlocución con entes gubernamentales.

A nivel internacional, el apoyo de la Federación Internacional de Movimientos de Agricultura Orgánica (IFOAM, por sus siglas en inglés) y el Movimiento Agroecológico de América Latina y el Caribe (MAELA) han permitido su participación en eventos y publicaciones que la han visibilizado esta Red. Estas entidades, también le han brindado información para el mejoramiento del SPG, consolidación de los mercados locales, soberanía alimentaria y producción agroecológica. En otras latitudes, la Organización Francia América Latina (FAL) recoge aportes económicos que han permitido la realización de algunos eventos y proyectos, además de solventar ciertos gastos de funcionamiento.

\subsection{Cosechando lo sembrado: logros y aprendizajes}

Son muchos los resultados y aprendizajes alcanzados en el proceso vivido por la REDMAC. Por su diversidad, pueden agruparse en temas afines, como: los relativos a familias campesinas y organizaciones de base, seguridad alimentaria de las familias y diálogo de saberes (figura 6). Se ha construido tejido social alrededor de las diferentes organizaciones familiares y de base, a través de la integración de estas en los diferentes mercados. Además, mediante la resignificación del papel del campesino en la sociedad se han podido construir historias y sentidos compartidos, esto ayuda muchoa elevar el autoestima de las personas. Las familias campesinas han salvaguardado el patrimonio biocultural a través de la conservación de semillas y de tradiciones alimentarias, lo que deriva en una toma de conciencia sobre la autonomía, seguridad y soberanía alimentaria para todos. Lo anterior, se combina con el diálogo de saberes establecido entre campesinos, organizaciones de base, la Red y diferentes instituciones relacionadas, que han contribuido a replicar y adquirir nuevas experiencias y conocimientos, formular e implementar su SPG y, además, en poder apoyar al fortalecimiento y la conformación de otras redes. Todo ello ha redundado en mejorar las condiciones de vida para las familias involucradas en los mercados de la Red, no sólo desde aspectos materiales, sino también emocionales y espirituales. 
Figura 6. Logros y aprendizajes de la REDMAC.

\title{
Familias campesinas y organizaciones de base:
}

\author{
Mejoramiento del autoestima, identidad y sentido de pertenecia para las familias, \\ reconocimiento de su papel en la sociedad. \\ Consolidación de relaciones.
}

\section{Seguridad y soberanía alimentaria de las familias:}

Recuperación, multiplicación y uso de semillas criollas y nativas.

Intercambio de productos, provision de alimentos diversos, sanos y nutritivos.

\section{Diálogo de saberes:}

Implementación de SPG.

Replicabilidad de experiencias.

Apoyo en la creación de otras redes de productores.

Fuente: elaboración propia.

\subsection{El Sistema Participativo de Garantías (SPG): acuerdos para construir una opción de vida}

El sPG fue, para la REDMAC, un principio y un fin dentro de su desarrollo. Principio del proceso en el tiempo de su conformación y como base fundamental para el reconocimiento de las familias campesinas que practicaban la agricultura ecológica, y se acercaban a la superación de ese gran cuello de botella de la producción agropecuaria campesina: la comercialización. Y un fin, porque se volvió el reto a alcanzar, el fruto de un trabajo conjunto, que superando diferencias y potenciando coincidencias, permitiría concretar su "carta de navegación" mediante la consolidación de "acuerdos de vida" comunes y éticos, que les permitieran visibilizarse, fortalecerse y consolidarse.

Entonces el SPG, además de instrumento de certificación de confianza que contribuiría al acercamiento y solidaridad del amigo consumidor, se constituyó en elemento unificador de aquellos que estaban dispersos, les permitiría reconocerse, facilitando el diálogo de saberes entre los individuos y, posteriormente, su empoderamiento como Red. 
El SPG menciona las prácticas permitidas, prohibidas, restringidas y los diferentes criterios por evaluar en las visitas de verificación, además de un formulario de fácil interpretación y diligenciamiento para el productor (figura 8). En conclusión, el SPG de la REDMAC vela por el cumplimiento de criterios, como la producción amigable y en armonía con el ambiente, la nutrición y nutracéutica de las personas mediante la producción de alimentos sanos e inocuos, la preservación de la salud y bienestar animal; además, cuida de generar condiciones de justicia y equidad al interior de las familias productoras, sus colaboradores y demás grupos de interés.

Figura 7. Proceso de implementación del SPG.

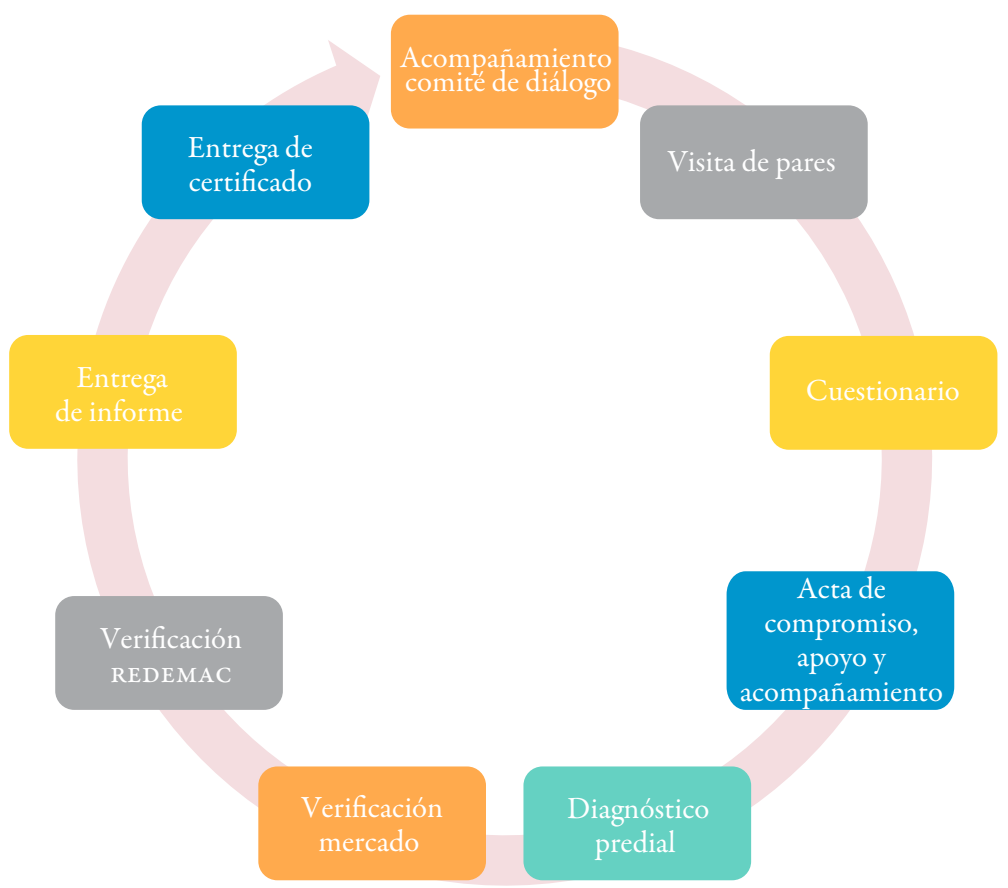

Fuente: adaptado de IFOAM (2013).

La implementación del SPG se centra, inicialmente, en el deseo formal y voluntario de la familia de ingresar en el sistema, a través de una carta enviada a la Red. Con ello, el mismo productor realiza el diagnóstico predial, apoyado por un formato que debe diligenciar. Posteriormente, el comité de diálogo del mercado al que pertenece programa una visita al predio, en donde se aplica una lista de chequeo sobre aspectos permitidos, restringidos y prohibidos. Producto de la visita, 
el comité elabora un informe y emite un primer concepto, el cual considerará si cumple con el acuerdo de vida y si se le puede otrogar la certificación de confianza. Este documento es enviado a la Red, la cual tiene dos opciones: si está de acuerdo con los documentos presentados, expide el certificado de confianza, que es el mismo “respaldo de confianza”; por el contrario, si no está de acuerdo, debe programar una visita de su comité de diálogo, para finalmente tomar la decisión (IFOAM, 2013).

El sPG en la Red ha sido el fundamento de su articulación con las organizaciones de base y, a su vez, con el productor. Esto debido a que el sistema certifica al campesino y su familia en su respectiva finca, propiciando una interacción directa, por ello, también, se ha constituido en un espacio de fortalecimiento de la producción agroecológica, elevando en los campesinos su sentido de pertenencia y empoderamiento.

\subsection{Navegando contra la corriente: políticas gubernamentales $v s$. agricultura familiar agroecológica}

La experiencia de persistencia y resistencia compartida tiene como características principales el esfuerzo propio y la voluntad de seguir adelante, siendo conscientemente de las adversidades, “contra viento y marea”. Lo cual se hace cada vez más difícil en el marco de las políticas gubernamentales, estas tienden a ser más lesivas con la agricultura familiar, en el que, a nivel estatal, el campesino no es sujeto de derechos y en esa situación, la agricultura familiar ecológica es casi invisibilizada. Como ejemplo de lo anterior, la más reciente amenaza a estos procesos se da en el interés de normalizar los SPG. Esto determina que se corra el riesgo de que las organizaciones de base y, en este caso, la Red pierdan el control sobre la ideología, la filosofía y la aplicación del SPG. Lo que puede derivar en condiciones desfavorables de producción y comercialización para la familia campesina, igualmente, en un posible incremento de los precios y disminución de la calidad de los productos para el consumidor.

\section{Discusión}

Son conocidas las diferentes barreras que impone el llamado Sistema Agroalimentario Industrial a la Agricultura Familiar Campesina en Colombia, para su acceso a los mercados. Estas van desde la alta concentración de la propiedad (Álvarez, Saiz, Herrera, Castillo y Díaz, 2012), la cual condiciona y restringe la productividad de la tierra; el acceso deficiente a información sobre los mercados (Santacoloma, 2011); hasta la presentación de una cantidad desmedida de intermediarios comerciales 
con alto poder de mercado (Fernández, Hernández, Ibáñez y Jaramillo, 2009), quienes manipulan los precios y se apropian de gran parte del margen de comercialización, presente en el precio de venta al consumidor final (Peñalosa-Otero y Díaz-Mateus, 2011), y además, concentran grandes volúmenes de venta destinada a los supermercados, entre otras dificultades. En consecuencia, estas condiciones hacen que se reduzca el precio de venta para la familia campesina y se aumente el mismo para el consumidor final.

En contraste y como un ejemplo de comercialización de circuito corto, los mercados integrados por la REDMAC buscan el contacto directo con el consumidor, eliminando o reduciendo, hasta el nivel necesario la presencia de intermediarios; por lo que se paga un precio justo al productor, esto redunda en ingresos más estables y justos para las familias campesinas y, a la vez, en la disponibilidad de alimentos sanos a un precio asequible al consumidor. La comercialización de circuito corto no solo reduce o elimina el número de transacciones para que un producto llegue al consumidor final, también hace lo propio con la distancia física que separa a los actores de un canal de distribución, lo que reduce la huella de carbono que deja el transporte de los productos (López-García, 2011; Craviotti y Soleno-Wilches, 2015).

En medio de las dificultades sociales y culturales que prevalecen en este contexto, las cuales representan un freno a la asociatividad, tales como: la desconfianza, el individualismo y la falta de visión colectiva, sumadas a una baja capacidad de liderazgo y de visión empresarial (Fernández et al, 2009, Cáceres-Gómez, Pardo-Enciso y TorresCárdenas, 2012). La REDMAC ha podido consolidar un proceso asociativo mediante una forma de organización horizontal, que ha servido para lograr la permanencia de los mercados en el tiempo y en el espacio. Esto se ha logrado, en gran parte, gracias a la constancia y al espíritu inclusivo de las mujeres que integran los mercados que sirven de plataforma a la Red, que han hecho que estos persistan y resistan los embates del tiempo y del contexto. En este sentido, la posibilidad de vender una diversidad de productos en pequeñas cantidades ha permitido a la mujer reforzar su deteriorada autoestima , afectada por una tradición machista; es por esto que el trabajo en la Red le ha devuelto la confianza en sí misma y, a través de la cooperación y las interacciones con sus pares en el mercado, le ha permitido generar confianza en el otro (RuedaGalvis y Muñoz-Rojas, 2011).

Por lo anterior, puede afirmarse que los mercados y la Red han podido acumular un capital social bastante apreciable, el cual desde la concepción de Bordieu (1983), se centra en los réditos que logran las personas gracias a la participación en grupos y a la conformación de relaciones sociales. Lo dicho, puede enmarcarse, según la 
definición de la Comisión Económica para América Latina y el Caribe (CEPAL), en lo que se conoce como capital social individual, que "consta del crédito que ha acumulado la persona en la forma de reciprocidad difusa que se puede reclamar en momentos de necesidad, a otras personas a las cuales les ha ofrecido servicios o favores en el pasado" (CEPAL, 2001, p. 3). Además, puede decirse que gracias a las interacciones resultantes de la actividad en los mercados, también se ha generado un capital social comunitario, definido por la CEPAL (2001), como "aquel tipo de capital que se expresa en instituciones complejas con contenido y gestión." (p. 3). Lo cual puede verse en los logros y las diferentes estructuras organizacionales que presentan los mercados y la REDMAC.

Del capital social acumulado por la REDMAC, hay que destacar su capacidad de acción colectiva, que en concepto de Flores y Rello (2001), reside en la habilidad que tiene el colectivo de tomar decisiones y actuar en conjunto para perseguir metas definidas, en común. Esto, según los mismos autores, se desprende de componentes de su arquitectura social como la confianza y las redes entre otros, dadas las sinergias que se obtienen gracias a la capacidad de la acción colectiva.

\section{Conclusiones}

La autonomía e independencia de la REDMAC expresada en su desarrollo y consolidación (proceso organizativo, SPG), además de ser clave para garantizar una evolución consistente, ha sido un baluarte indispensable para su permanencia. Dichas cualidades, han sido complementadas con la constancia de sus miembros, que se demuestra a través del compromiso y cumplimiento con las actividades estipuladas como red, entre ellas, las reuniones mensuales de la asamblea, que se han venido celebrando de manera ininterrumpida desde su fundación.

Si bien es importante contar con apoyo institucional para conformar iniciativas como las de la REDMAC, se debe destacar que estas deben contar con el arraigo y compromiso de personas, familias y organizaciones de base que las sustenten, para generar un verdadero capital social que las haga viables. Este capital social está fundamentado en aspectos como la confianza, la solidaridad, el espíritu colectivo, las historias compartidas y reside, principalmente, en las mujeres, quienes han aportado su tenacidad y resistencia.

La cercanía que se logra entre consumidor y productor mediante el encuentro que permiten los mercados, neutraliza la desconexión que hace el sistema agroalimentario industrial, la cual es un artificio para poder obtener mayores márgenes 
de ganancia para los intermediarios y el sistema, en general. Por lo tanto, esta experiencia de circuitos cortos de comercialización afianza la relación campo-ciudad y viabiliza económicamente la actividad agropecuaria agroecológica a pequeña escala, que contribuye, también, a garantizar alimento sano al consumidor urbano.

\section{Agradecimientos}

Sinceros agradecimientos a quienes aportaron su tiempo y dedicación para dar información importante sobre la REDMAC o bien para ayudar a entender esta experiencia, desde los principios filosóficos de la agroecología; igualmente, a aquellos que leyeron los borradores de este capítulo y realizaron los ajustes correspondientes. Especialmente, a María Fernanda Palacios, María Clara Rivera, Gustavo Suárez Rendón, Alfredo Añazco, José Carrillo y Rafael Hoyos. Se extiende este agradecimiento al Grupo de Investigación en Agroecología de la Universidad Nacional de Colombia, Sede Palmira, en general y en particular a los Profesores Marina Sánchez de Prager, Gabriel de la Cruz Aparicio y al estudiante Edison Alexander Muyuy Ojeda.

\section{Referencias}

Álvarez, Y., Saiz, J., Herrera, A., Castillo, D., y Díaz, R. (2012). Relación entre la estructura agraria y la cadena productiva láctea. Gestión y Sociedad, 5(1), 17-132.

Bourdieu, P. (1986). Forms of capital. En J. C. Richards (ed.), Handbook of theory and research for the sociology of education (pp. 241-258). New York: Greenwood Press.

Cáceres-Gómez, L., Pardo-Enciso, C., y Torres-Cárdenas, A. (2012). La asociatividad en la dinámica productiva del municipio de El Yopal, Casanare. Gestión y Sociedad, 5(2), 37-50.

Comisión Económica para América Latina y el Caribe-CEPAL. (septiembre, 2001). Conferencia regional sobre el capital social y pobreza. (Documento informativo $\mathrm{N}^{\circ}$ 1). Santiago: CEPAL. Recuperado de https://repositorio.cepal.org /bitstream/handle/11362/33039/S2001514_es.pdf ?sequence $=1$ \&isAllowed=y

Craviotti, C., y Soleno-Wilches, R. (2015). Circuitos cortos de comercialización agroalimentaria: un acercamiento desde la agricultura familiar diversificada en Argentina. Mundo Agrario, 16(33). Recuperado de http://www.Mundo agrario.unlp.edu.ar/article/view/MAv16n33a01

Dumont, A., Vanloqueren, G., Stassart, P., y Baret, P. (2016). Clarifying the socioeconomic dimensions of agroecology: between principles and practices. Agroeco- 
logy and Sustainable Food Systems, 40(1), 24-47. Recuperado de http://www. philagri.net/wp-content/uploads/2015/12/Article-Dumont-2016.pdf

Fernández, M., Hernández, C., Ibáñez, A. M., y Jaramillo, C. (2009). Dinámicas departamentales de pobreza en Colombia 1993-2005. (Documento de Trabajo $\mathrm{N}^{\circ} 33$ ). Santiago: Programa Dinámicas Territoriales Rurales-Rimisp. Recuperado de http://www.ceppia.com.co/Documentos-tematicos/ECONO MIA/ Dinamicas-Departamentales-de-Pobreza.pdf

Flores, M., y Rello, F. (2001). Instituciones rurales, capital social y organizaciones de pequeños productores en México y Centroamérica. México: Plaza y Valdés.

Hatt, S., Artru, S., Brédart, D., Lassois, L., Francis, F., Haubruge, É., Garré, S., Stassart, P., Dufrêne, M., Monty, A., y Boeraeve, F. (2016). Towards sustainable food systems: the concept of agroecology and how it questions current research practices. A review. Biotechnologie, Agronomie, Sociéte et Environnement, 20(S1), 215-224. Recuperado de https://orbi.uliege.be/ handle/2268/197503

International Federation of Organic Agriculture Movements. (2013). Sistemas Participativos de Garantía: estudios de caso en América Latina. Alemania. Recuperado de https://www.ifoam.bio/sites/default/files/page/files/ la_case_ studies_color_print_fc_0.pdf

La Vía Campesina. (2018). UNITED NATIONS: Third Committee approves the UN Declaration on the Rights of Peasants and Other People Working in Rural Areas. Recuperado de https://viacampesina.org/en/united-nations-third-committeeapproves-the-un-declaration-on-the-rights-of-peasants-and-other-peopleworking-in-rural-areas/

López-García, D. (2011). Canales cortos de comercialización como elemento dinamizador de las agriculturas ecológicas urbana y periurbana. I Congreso Estatal de Agricultura Ecológica Urbana y Periurbana, Universidad Miguel Hernández, Ayuntamiento Elche y SEAE, Valencia, España. Recuperado de http://media. utp.edu.co/centro-gestion-ambiental/archivos/documentos-relacionados-conagroecologia-seguridad-y-soberania-alimentaria/canales cortosdecomercializacioncomoelementodinamizadordeagriculturasecologicas.pdf

Ministerio de Agricultura y Desarrollo Rural. (2017). Resolución 464. Por la cual se adoptan los lineamientos estratégicos de politica pública para la Agricultura Campesina, Familiary Comunitaria y se dictan otras disposiciones. Recuperado de https://www.minagricultura.gov.co/Normatividad/Resolucion es/Resolución\%20No\%20000464\%20de\%202017.pdf 
Peñalosa-Otero, M., y Díaz-Mateus, R. (2011). Un camino al desarrollo territorial: la especialización en la producción de cebolla de rama (Allium fistulosum) en el municipio de Aquitania (Boyacá, Colombia). Gestión y Sociedad, 4(2), 57-66.

Rueda-Galvis, M., y Muñoz-Rojas, J. (2011). Asociatividad, capital social y redes de innovación en la economía rural. Gestión y Sociedad, 4(1), 27-41.

Santacoloma, L. E. (2011). Análisis comparado de las condiciones de producción de dos asociaciones de productores de fruta del Occidente de Colombia para su participación en proyectos de comercio justo. Revista de Investigación Agrariay Ambiental, 2(2),77-87. Recuperado de https://academia.unad. edu.co/images/ investigacion/hemeroteca/RIAA/RIAA_vol2_N2_2011/analisis\%20comparado\%20de\%20las\%20condiciones\%20de\%20produccion\%20de\%20dos.pdf 


\title{
Capítulo 8
}

\section{Fondos autogestionados para la transición agroecológica: el caso de ASPROINCA, Riosucio, Caldas}

\author{
Self-managed funds for agro-ecological transition: the case of
} ASPRoInca, Riosucio, Caldas

\author{
Álvaro Acevedo Osorio* \\ Julia Katharina Waeger** \\ Willington Ortiz Orozco***
}

\section{Cómo citar}

\begin{abstract}
APA
Acevedo, Á. Waeger, J., y Ortiz, W. (2019). Fondos autogestionados para la transición agroecológica: el caso de ASPRONICA, Riosucio, Caldas. En Á. Acevedo-Osorio y N., JiménezReinales (comps.). La agroecología. Experiencias comunitarias para la Agricultura Familiar en Colombia. (pp. 183-205). Bogotá: Corporación Universitaria Minuto de Dios-UNIMINUTO, Editorial Universidad del Rosario.
\end{abstract}

\section{Chicago}

Acevedo Osorio, Á. Waeger, Julia y Ortiz, Willington. "Fondos autogestionados para la transición agroecológica: el caso de ASPRONICA, Riosucio, Caldas”. En La agroecología. Experiencias comunitarias para la Agricultura Familiar en Colombia, comps. Álvaro Acevedo-Osorio

* Facultad de Ciencias Agrarias. Universidad Nacional de Colombia. aacevedoo@unal.edu.co

** Instituto de Manejo y Tecnología de Recursos en los Trópicos y Subtrópicos. Universidad de Ciencias Aplicadas, TH Köln, Colonia, Alemania. julia.waeger@gmail.com

*** Instituto Wuppertal para el Clima el Medio Ambiente y la Energía. Universidad Leuphana de Lüneburg - Alemania.willington.ortiz@wupperinst.org 
y Nathaly Jiménez-Reinales. Bogotá: Corporación Universitaria Minuto de Dios-UNIMINUTO, Editorial Universidad del Rosario, 2019.

\section{MLA}

Acevedo Osorio, Á. Waeger, Julia y Ortiz, Willington. "Fondos autogestionados para la transición agroecológica: el caso de ASPRONICA, Riosucio, Caldas”. En La agroecología. Experiencias comunitarias para la Agricultura Familiar en Colombia. En Á. Acevedo-Osorio y N., Jiménez-Reinales (comps.) Bogotá: Corporación Universitaria Minuto de Dios-UNIMINUTO, Editorial Universidad del Rosario, 2019, pp. 183-205.

\section{Resumen}

El acceso a servicios financieros adecuados a las condiciones de los agricultores familiares constituye una de las principales barreras que limita su dinámica productiva y económica. Por más de 20 años, la organización ASPROINCA, en el occidente de Caldas, ha promovido un fondo autogestionado como alternativa financiera y social para apoyar los procesos de transición agroecológica en las fincas, el mejoramiento ambiental y el bienestar de sus asociados. Vinculado a un sistemático proceso de planificación de las fincas, priorización de actividades productivas y acompañamiento técnico de promotores rurales, el Fondo Rotatorio (FR) presta servicios financieros altamente flexibles tanto en montos como en plazos, adaptándose a las necesidades específicas de cada una de las 300 familias que conforman la asociación. Con 12 líneas de crédito organizadas en las áreas productiva, ambiental y de bienestar social, y con altos niveles de retorno, el FR se ha logrado mantener estable, prestando servicios financieros integrales a las familias. Esta experiencia demuestra cómo los fondos autogestionados constituyen una respuesta efectiva a las necesidades financieras que implican los procesos de transición agroecológicos en la agricultura familiar.

Palabras clave: economía solidaria, finanzas solidarias, fondo rotatorio, transición agroecológica.

\section{Abstract}

Access to financial services appropriate to the conditions of family farmers is one of the main barriers that limit their productive and economic dynamics. For more than 20 years, the organization ASPROINCA, in the west of Caldas, has promoted a self-managed fund as a financial and social alternative to support the processes of agroecological transition in the farms, the environmental improvement and the welfare of its associates. Linked to a systematic process of planning of the farms, prioritization of productive activities and technical support of rural promoters, the Rotating Fund (RF) provides highly flexible financial services in both amounts and installments, adapting to the specific needs of each of the 300 families that make up the association. With 12 credit lines organized in the productive, environmental and social welfare areas, and with high levels of return, the RF has been able to maintain stable, providing integral financial services to families. This experience demonstrates how self-managed 
funds are an effective response to the financial needs involved in agroecological transition processes in family farming.

Keywords: solidarity economy, solidarity finance, rotating fund, agro-ecological transition.

\section{Introducción}

En la discusión sobre el Desarrollo Rural, el acceso a recursos monetarios siempre ha jugado un papel central. Independiente del paradigma agrícola promovido y de la época, los servicios financieros adecuados a los pequeños productores muestran, principalmente, su ausenciahasta el día hoy (Van der Ploeg, 2010). La Corporación Financiera Internacional, por ejemplo, critica a la mayoría de los estudios sobre el acceso a las finanzas para pequeños productores, por que su enfoque se centra en aquellos que están dentro de cadenas de valor; sin embargo, estos solo representan un $7 \%$ del grupo destinatario total (IFC, 2014). Por lo tanto, la gran mayoría, especialmente productores con menos orientación comercial, no participan en el así llamado "sistema regulado" de la banca comercial y, en consecuencia, para configurar sistemas financieros inclusivos, los proveedores deberían tener en cuenta no solo las necesidades financieras de los pequeños productores, sino también, sus ciclos y prácticas económicas (Olaniyi, 2017). Frente al hecho de que $70 \%$ de los alimentos a nivel global son producidos por pequeños productores y que, por otro lado, pero en consonancia con lo anterior, el acceso a los servicios financieros están proyectados a ser parteesencial de ello (FAO, 2014). Por esta razón, se plantea la cuestión urgente de buscar soluciones adecuadas para los pequeños productores frente a este tema(Olaniyi, 2017). Además del acceso, el diseño del crédito es otra característica central. Muchos servicios convencionales que tiene que ver con la producción agrícola están vinculados a determinadas prácticas y normas, como las semillas certificadas, los fertilizantes, entre otros. De esa manera, el crédito otorgado crea una dependencia enorme frente a la producción y el manejo que el productor haga de este, más aún, cuando las expectativas de cosecha no se cumplen y el pago se dificulta. Van der Ploeg (2010) describe este círculo vicioso de la siguiente forma: “Este es, en pocas palabras, uno de los dramas del desarrollo rural: el crédito llevó a las personas a tener problemas, sin embargo, es lo que necesitan para resolver esos problemas, aunque ya no pueden obtenerlo." (p. 6).

La necesidad de recursos económicos también está presente en la implementación de los principios de reconversión agroecológica. En agriculturas familiares el proceso transformativo hacia la agroecología implica, en la mayoría de los 
casos, procesos de cambios y ajustes significativos en la organización de las fincas. Estos cambios están generalmente ligados a costos monetarios, por ejemplo, para la compra de insumos y materiales, la inversión en equipos e infraestructura o la adquisición de servicios técnicos.

Ahora bien, en Colombia y en el hemisferio sur en general, han existido una gran variedad de iniciativas de carácter local y comunitario como respuesta a las necesidades financieras de pobladores y comunidades rurales (Bouman, 1995). Algunos de estos formatos clásicos se conoce con el nombre microcréditos, "bancos sin paredes", uniones de créditos, grupos de ahorro, redes sociales, fondos rotatorios $\mathrm{y}$ fondos autogestionados, entre otroscalificativos.

En el caso Colombiano, hay una larga trayectoria de experiencias de fondos autogestionados que se dirigen a campesinos, indígenas, desplazados y afrocolombianos, en general, además, de otros grupos vulnerables, con el fin de diversificar la oferta de servicios financieros (Solarte, 2010). Villarraga (2008) define estos servicios financieros de la siguiente manera:

Los fondos autogestionados se enmarcan en una alternativa económica, financiera y social, mediante la cual una población organizada del sector urbano y rural moviliza recursos propios y/o de terceros para prestarlos entre ellos. Son rotatorios en la medida que los recursos de los créditos recuperados se vuelven a prestar. (p. 10).

El objetivo central del presente capítulo es avanzar en la comprensión sobre cómo estas prácticas organizativas de financiación pueden contribuir a superar aquellas barreras financieras en la transición agroecológica de las agriculturas familiares. Para este fín, se presenta la experiencia de la Asociación de Productores Indígenas y Campesinos de Riosucio (ASPROINCA), localizada en el occidente de Caldas, que está relacionada con el desarrollo y la operación de un fondo autogestionado y, se analiza estaexperiencia a lo largo de las siguientes preguntas clave: a) ¿cómo aporta el fondo a la realización efectiva de la transición agroecológica de las familias agricultoras? y b) ¿cómo contribuye el fondo al fortalecimiento económico, social, medioambiental y cultural de las familias?

El capítulo se estructura de la siguiente forma: Inicialmente, se describe, en forma concisa, la propuesta general de ASPROINCA y el rol que el fondo autogestionado tiene en ella. En seguida, se enfoca en las líneas de crédito con las cuales el Fondo Rotatorio aporta al fortalecimiento de las condiciones de vida de sus 
asociados (y en general de su región de influencia). Posteriormente, se discute el caso descrito en dos momentos: uno, en cuanto a las dos preguntas específicas que guían el estudio; y dos, en comparación a hallazgos y conclusiones de literatura sobre fondos autogestionados en contextos rurales de Colombia y América Latina. Finalmente, se extraen algunas conclusiones del estudio.

\section{Resultados}

\subsection{El Fondo Rotatorio en la historia y la propuesta de ASPROINCA}

La Asociación de Productores Indígenas y Campesinos de Riosucio es una asociación de carácter agroambiental, que integra familias de pequeños productores indígenas y campesinos de los municipios de Riosucio y Supía, el corregimiento de San Bartolomé de Pácora, departamento de Caldas; además de familias del municipio de Quinchía en Risaralda, dedicadas a la agricultura de tipo familiar. Fue constituida en 1992, con el objetivo de:

Desarrollar programas y proyectos que contribuyan a mejorar las condiciones socio-ambientales, productivas y económicas de las comunidades indígenas y campesinas promoviendo y apoyando la defensa de los derechos y la permanencia en sus tierras y territorios en condiciones de vida dignas. (ASPROINCA, 2012).

En la actualidad, está conformada por alrededor de 300 familias, que poseen un área de tierra en promedio de $1.8 \mathrm{~h}$. También, se integran a la asociación algunos grupos asociativos de producción (especialmente, resguardos indígenas), grupos organizados de mujeres y comités ambientales.

Un fondo autogestionado de la organización ASPROINCA fue conformado en 1994 con el nombre de Fondo Rotatorio (FR), cuyo objetivo fue "apalancar financieramente a los pequeños agricultores y agricultoras, para el mejoramiento productivo-ambiental de sus fincas y de los procesos de transformación de su producción” (ASPROINCA, 2015). El capital semilla para su establecimiento sumaba Col\$2000000 y fué aportado a la organización para este fin como parte del proyecto "Mujer y Agroecología” por la agencia SWISSAID. No obstante, esta cantidad de dinero no fue suficiente para lograr su objetivo, por lo tanto, para fortalecer el FR, la Junta Administradora de la asociación decidió capitalizarlo desde sus inicios, a partir de donaciones percibidas por otros proyectos de cooperación. La estrategia consistió en que parte de las donaciones percibidas por entidades cooperantes, se 
entregaban a los socios a modo de préstamo, dando facilidades para su pago. De esta manera, se logró aumentar rápidamente el capital y la cantidad de socios que podían beneficiarse.

Desde el punto de vista técnico, el FR para ASPROINCA representa una herramienta para facilitar la transición de las fincas de sus asociados hacia sistemas agroecológicos de producción. Más que un fondo económico para hacer créditos, el FR hace parte de un proceso integral que incluye el diagnóstico, planificación, priorización, implementación de proyectos, seguimiento y mejoramiento continuo en los procesos de producción en las fincas. Ser un socio de ASPROINCA, significa involucrarse en el desarrollo de este proceso permanente que inicia con la capacitación de la familia, la visita a fincas de asociados antiguos de los que se aprenden aspectos de la producción agroecológica, así como el compromiso de ser parte de la organización y apropiar los principios de la asociación. Solo después, la familia puede acceder a un crédito que permita comenzar la transformación de la finca a partir de un plan de trabajo diseñado con el promotor.

En efecto, el proceso de las fincas se garantiza a través de la articulación del funcionamiento del FR con el programa de "promotoría" de la asociación que consiste en la formación y mantenimiento de un grupo de promotores rurales para el acompañamiento a las familias de los asociados. Los promotores son agricultores y socios de la organización, estos han tenido capacitación y experiencia suficiente para liderar los procesos de acompañamiento de sus compañeros de la organización, bajo un enfoque agroecológico. Más que asistencia técnica, en el sentido convencional del término, el papel de los promotores es considerado como un acompañamiento integral "entre iguales", enfocado al proceso de transformación de las fincas. De esta manera, la interrelación de estos componentes determina el éxito de la propuesta de trabajo de la organización.

El FR cuenta actualmente con doce líneas de crédito diseñadas para atender tanto aspectos de tipo productivo, como también aspectos ambientales y de bienestar individual y familiar (tabla 1). Las líneas han sido creadas en la medida que, las circunstancias lo hicieron necesario, asimismo, han primado criterios de flexibilidad tanto en los montos de cada línea como en los plazos de pago. Lo que se ha tenido muy claro, en la definición de las líneas, han sido algunos criterios que deben cumplirse para que las solicitudes de crédito sean aceptadas por la Junta Administradora, entre ellas: el estudio previo de la viabilidad técnica y financiera de las actividades financiables de cada línea, así como su aporte al mejoramiento productivo, ambiental y social de las familias agricultoras. 
Tabla 1. Líneas de crédito definidas por ASPROINCA para su Fondo Rotatorio.

\begin{tabular}{|c|c|c|c|}
\hline Línea & Actividades que financia & Monto límite* & Criterios \\
\hline \multirow{2}{*}{$\begin{array}{l}\text { Especies } \\
\text { menores }\end{array}$} & Cerdos & $\begin{array}{l}\$ 80000 \text { por cría y } 1 / 2 \\
\text { bulto de levante. }\end{array}$ & \multirow{2}{*}{$\begin{array}{l}\text { Tener asegurada la } \\
\text { alimentación (forrajes). } \\
\text { Condiciones para manejo. } \\
\text { Instalaciones. }\end{array}$} \\
\hline & Pollos y aves ponedoras & $\begin{array}{l}\text { Valor de } 10 \text { crías y } 1 / 2 \\
\text { bulto de levante. }\end{array}$ & \\
\hline $\begin{array}{l}\text { Ganadería } \\
\text { sostenible }\end{array}$ & $\begin{array}{l}\text { Vacas de cría } \\
\text { Terneros } \\
\text { Adecuación de potreros } \\
\text { para Sistemas Silvopastoriles } \\
\text { Infraestructura ganadera: } \\
\text { mejoramiento de establos, } \\
\text { Picapasto. }\end{array}$ & $\begin{array}{l}\$ 2500000 \text { por vaca } \\
\$ 1500000 \text { por ternero } \\
\text { No hay tope económico } \\
\text { para lo demás }\end{array}$ & $\begin{array}{l}\text { La persona o familia debe } \\
\text { tener los forrajes y las } \\
\text { condiciones de espacio para } \\
\text { criar la vaca. }\end{array}$ \\
\hline $\begin{array}{l}\text { Ampliación de } \\
\text { área de finca }\end{array}$ & Para lotes nuevos. & $\$ 2500000$ & $\begin{array}{l}\text { Una familia que busca ampliar } \\
\text { su producción. Debe tener un } \\
\text { diseño de la parcela que va a } \\
\text { establecer. }\end{array}$ \\
\hline $\begin{array}{l}\text { Mejoramiento } \\
\text { de vivienda }\end{array}$ & $\begin{array}{l}\text { Para situaciones prioritarias } \\
\text { para la vivienda de la familia } \\
\text { como techos o pisos. }\end{array}$ & No definido & $\begin{array}{l}\text { La familia debe estar al día en } \\
\text { todos los pagos. }\end{array}$ \\
\hline $\begin{array}{l}\text { Establecimiento } \\
\text { y mejoramiento } \\
\text { de cultivos }\end{array}$ & $\begin{array}{l}\text { Siembra de café, caña, } \\
\text { plátano, tomate, otros. } \\
\text { Incluye compra de semillas } \\
\text { o plántulas, ahoyado, } \\
\text { siembra. } \\
\text { Sostenimiento de cultivos }\end{array}$ & No definido & $\begin{array}{l}\text { Debe tener un diseño del } \\
\text { cultivo. Acompañar con } \\
\text { aplicación de prácticas de } \\
\text { conservación de suelos, asocio } \\
\text { con cultivos de pancoger. }\end{array}$ \\
\hline Biodigestor & $\begin{array}{l}\text { Incluye el plástico y } \\
\text { accesorios. }\end{array}$ & No definido & $\begin{array}{l}\text { Disponer de materia } \\
\text { prima para alimentarlo, } \\
\text { especialmente estiércoles de } \\
\text { animales. }\end{array}$ \\
\hline Acuicultura & $\begin{array}{l}\text { Alevinos, construcción y } \\
\text { adecuación de estanques. }\end{array}$ & No definido & $\begin{array}{l}\text { Disponer de suficiente agua y } \\
\text { producción parcial de forrajes. }\end{array}$ \\
\hline $\begin{array}{l}\text { Manejo de } \\
\text { aguas lluvias }\end{array}$ & $\begin{array}{l}\text { Incluye la tubería, canales, } \\
\text { tanques tipo Zamorano. }\end{array}$ & No definido & \\
\hline Estufa eficiente & $\begin{array}{l}\text { Materiales, mano de obra } \\
\text { del constructor. }\end{array}$ & No definido & \\
\hline $\begin{array}{l}\text { Manejo y } \\
\text { tratamiento de } \\
\text { aguas residuales }\end{array}$ & $\begin{array}{l}\text { Sistemas sépticos } \\
\text { unifamiliares y } \\
\text { comunitarios, canales } \\
\text { canaletas con plantas } \\
\text { acuáticas para manejo de } \\
\text { aguas residuales }\end{array}$ & No definido & \\
\hline
\end{tabular}




\begin{tabular}{|c|c|c|c|}
\hline Línea & Actividades que financia & Monto límite* & Criterios \\
\hline Microempresa & $\begin{array}{l}\text { Iniciativas de } \\
\text { emprendimientos no } \\
\text { agropecuarios. }\end{array}$ & No definido & \\
\hline $\begin{array}{l}\text { Mejoramiento } \\
\text { de } \\
\text { infraestructura } \\
\text { productiva }\end{array}$ & $\begin{array}{l}\text { Procesamiento de caña, café, } \\
\text { maquinaria, adecuación de } \\
\text { instalaciones, construcción } \\
\text { de porquerizas, galpones. } \\
\text { Adquisición de mulares. }\end{array}$ & No definido & $\begin{array}{l}\text { Hace parte de un plan con la } \\
\text { familia en que se estudia las } \\
\text { posibilidades que ella tiene de } \\
\text { cofinanciación, uso de recursos } \\
\text { propios. }\end{array}$ \\
\hline
\end{tabular}

Nota: ${ }^{*}$ En pesos colombianos. Fuente: elaboración propia.

Las líneas de crédito del FR buscan un beneficio integral a la familia rural y parten de financiar actividades productivas que mejoren la base económica de la familia, también que, permita la reproductividad del sistema de finca. No obstante, para ASPROINCA es fundamental el objetivo de la preservación ambiental y promueve acciones que, no siempre, son fácilmente financiables por los productores, puesto que se tratan de inversiones no recuperables en dinero; lo que lleva a la necesidad de apoyar también algunas de estas estrategias ambientales con posibilidades más flexibles de retorno, que aquellas que implican inversión y generación de ingresos directos. Finalmente, la organización pretende generar bienestar a las familias y comunidades, ofreciendo la oportunidad de que amplíen sus áreas de cultivo, accedan a tierra o mejoren sus viviendas; igualmente, con plazos y modalidades de retorno flexibles que se ajusten a las posibilidades de las familias.

\subsection{Condiciones legales y administrativas de funcionamiento}

Las decisiones sobre las líneas de crédito, montos de los créditos y funcionamiento en general, son tomadas por la Junta Administradora, conformada por miembros de la asociación, son agricultores que temporalmente asumen la responsabilidad de dirigirla y que representan cada una de las zonas geográficas donde hace presencia la organización. ASPROINCA no cuenta con un equipo de colaboradores externos o un equipo técnico que se hagan cargo del FR, son sus propios asociados quienes lo gestionan y administran.

Las condiciones de manejo administrativo, por parte de la Junta Administradora y el equipo de promotores, genera alto grado de confianza en los asociados. 
Los informes periódicos analizados en las reuniones mensuales de la junta, las reuniones zonales en las que se comparte información y los talleres de formación sobre principios de la economía solidaria permiten la generación de un nivel de confianza suficiente para que los asociados sientan que son parte de una organización, en la que el manejo responsable y cuidadoso de los recursos comunes, constituyen un acto de solidaridad compartida.

El manejo operativo y registro de información ha pasado por varias etapas, desde el registro manual en libretas y el recaudo en efectivo en la sede de la asociación, hasta el manejo sistematizado y la bancarización total que, caracteriza en la actualidad el manejo administrativo del FR. Para alcanzar el propósito de un manejo cada vez más transparente y organizado de la información, fue necesario que se generarán competencias en los mismos asociados, lo que llevó a que una de las socias, más activas en el manejo del $\mathrm{FR}$, se formará profesionalmente en contaduría. Actualmente, es quien administra el FR.

La situación financiera del FR, en los últimos nueve años, muestra un valor total más o menos constante a través del tiempo; sin embargo, se evidencia una tendencia hacia el aumento en el depósito en banco y disminución del valor que circula en préstamos (figura 1). En 2009, el 90\% del FR estaba en créditos; al finalizar el 2017, este valor alcanzó solo el 35\%. Esta situación puede responder a que, hasta el 2015, no había un límite para la cantidad de créditos que un asociado podía tener, llegando a presentar casos en que una familia podía tener unos 8 a 10 créditos. Una decisión de la junta fue la de limitar dicha cantidad a un máximo de 3 créditos. Adicionalmente, la tendencia de disminución se puede explicar a un proceso avanzado de transformación de las fincas de los asociados, esto se traduce en que se disminuye su dependencia al crédito o que acceden a otras fuentes de financiación, especialmente, la banca comercial que ofrece créditos sin mayores condiciones de inicio y con más libertad para su ejecución; aunque son créditos costosos y exigen altas condiciones de garantía para el pago. 
Figura 1. Tendencias financieras del Fondo Rotatorio de ASPRoInCA, período 2009-2017 (COL\$).

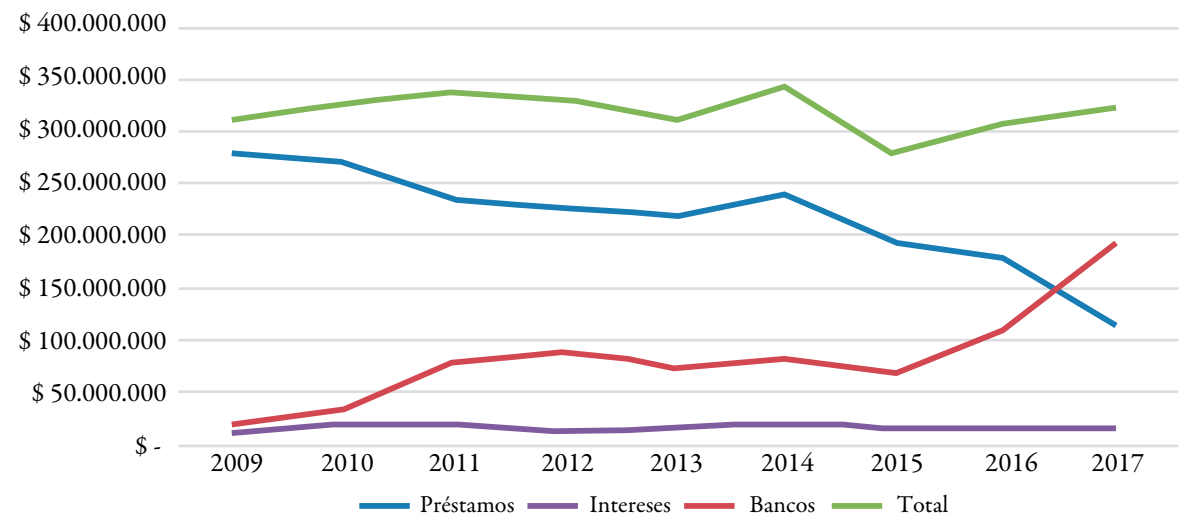

Fuente: elaboración propia con información de la asociación.

Esta tendencia al decrecimiento puede verse también reflejada en el registro de los créditos en los últimos 3 años (tabla 2), con una reducción en unos 150 créditos en total, al tiempo que se conserva el valor de créditos nuevos cercano al $20 \%$; es decir, una mayor cantidad de familias saldan sus deudas con el FR y la reglamentación actual o limita el acceso a nuevos créditos o son créditos para los cuales las familias no requerirían nuevos empréstitos, siendo, en tal caso, conveniente una revisión de las líneas de crédito actuales.

Tabla 2. Distribución de créditos entre 2015 y 2017del FR de ASPROINCA.

\begin{tabular}{ccccc}
\hline Año & No. créditos año & No. créditos nuevos & No. créditos antiguos & No. créditos Nuevos \\
\hline 2015 & 703 & 154 & 549 & $21.9 \%$ \\
\hline 2016 & 609 & 138 & 471 & $22.7 \%$ \\
\hline 2017 & 551 & 99 & 452 & $18.0 \%$ \\
\hline
\end{tabular}

Fuente: elaboración propia con información de la asociación.

La base del manejo del FR es la confianza en los asociados respecto al cumplimiento de los acuerdos de pago. La flexibilidad con la cual se definen los montos del crédito y la forma de pago, hacen que sea el propio agricultor el que proponga el crédito que mejor se adapte a sus condiciones, lo que facilita su posterior pago. De esta manera, se logra un alto nivel de retorno del capital, por medio del préstamo. No obstante, para garantizar la devolución de fondos prestados y el mantenimiento del valor total del FR sin descapitalizarlo, ASPROINCA ha definido una norma 
general de firma de un documento legal que le permita un cobro jurídico en caso extremo. En casos de demora en los pagos acordados, el grupo de promotores hace acompañamiento para definir nuevas estrategias y la junta acuerda nuevas formas y plazos de pago. Solo en muy pocos casos ( 2 en los últimos 5 años) se ha tenido que recurrir a medios legales de cobro.

\subsection{Transición agroecológica}

Las líneas de crédito del FR, dirigidas a la transición agroecológica de las fincas, incluyen la compra de crías, el establecimiento de cultivos y el mejoramiento de instalaciones y equipos (figura 2). En un promedio de los 3 últimos años, de 450 créditos vigentes por año para 6 de las 12 líneas, la tendencia muestra el decrecimiento del número de créditos en 5 de estas y un crecimiento en créditos para infraestructura.

Figura 2. Número total de créditos por año para las líneas de producción, en el período 2015-2017. 250

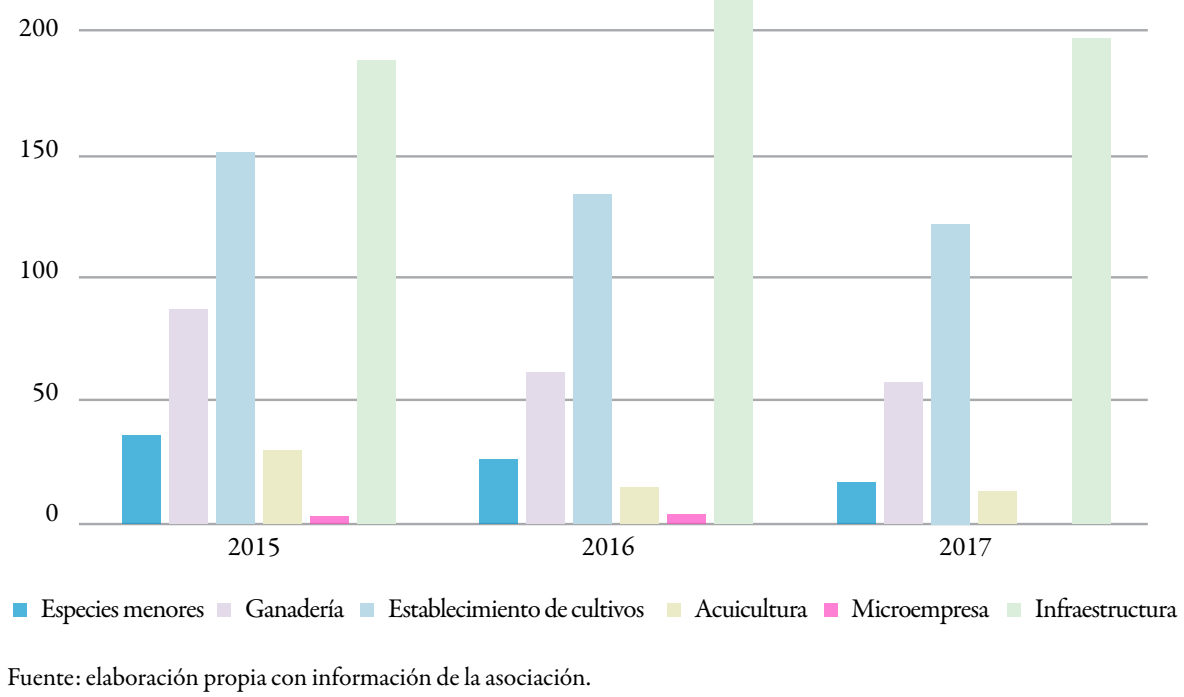


Entre los criterios agroecológicos apalancados por ASPROINCA con estos créditos, se incluye:

Integración vertical del proceso productivo. La aceptación del crédito implica un trabajo previo en la finca. Si se trata de producción pecuaria, la familia debe garantizar la producción suficiente de forrajes de alto valor proteico, aprovechando los recursos que el trópico proporciona. Si se trata de un cultivo, se debe garantizar la producción parcial de abonos orgánicos y la ejecución de prácticas de conservación de suelos. En cualquier caso, se trata de integrar distintos eslabones en la cadena productiva, de modo que, se logren sistemas de máxima utilización de los recursos disponibles. Aprovechamiento de espacios reducidos. La cría de especies menores permite el aprovechamiento de espacios reducidos, ejercer menor presión sobre los suelos de ladera y optimizar la producción y uso de la mano de obra familiar. El área reducida de terreno se aprovecha óptimamente, asociando cultivos en distintos estratos, es decir, el aprovechamiento del espacio horizontal y vertical dentro de la parcela.

Ganadería sostenible. Esto incluye la cría de razas multiprósito con genética mixta, adaptada a las condiciones agroclimáticas de la zona; el establecimiento de sistemas silvopastoriles y bancos de forrajes que provean recursos locales para su alimentación; la estabulación o semiestabulación del ganado bovino, reduciendo el riesgo de generar erosión por su alto peso. El aprovechamiento de excretas para la producción de abonos orgánicos o biogás, a partir del biodigestor, esto constituye otro de los beneficios adicionales de este importante renglón productivo.

Cultivos asociados. Integrar especies comerciales como el café y la caña de azúcar, con especies para el autoconsumo familiar, que garantiza niveles adecuados de autoconsumo. El asocio de cultivos regula la presencia de plagas y enfermedades y permite relaciones de complementariedad, intensificando servicios ambientales como la polinización, regulación hídrica o reciclaje de nutrientes del suelo.

La aceptación de cualquier crédito, de tipo productivo, lleva consigo la condición de que el proyecto aprobado tiene involucrados principios de conservación, a partir del cumplimiento de los criterios agroecológicos expuestos. Otro requisito adicional del crédito es que el agricultor se comprometa con la realización de una 
práctica de tipo conservacionista que haga parte del plan de transición en la finca, esto incluye acciones de reciclaje o descontaminación de aguas, arborización, reciclaje de residuos sólidos, instalación de cercas vivas, prácticas de conservación de suelos, obras de bioingeniería para la retención de suelos de ladera, entre otras.

\subsection{Bienestar social: familia, mujer y comunidad}

Tres líneas de crédito están enfocadas al mejoramiento de las condiciones de bienestar de la familia y, en el período 2015 a 2017, se registraron en promedio 104 créditos por año (figura 3). El crédito para “ampliación de área” permite que familias con menor cantidad de tierra o sin tierra, puedan acceder o incrementarla adquiriendo un lote colindante con su predio o en otro sector cercano. La importancia de esta línea radica en la oportunidad que genera para el trabajo familiar, dada la baja capacidad de tenencia actual de las familias de ASPROINCA. En efecto, el promedio de $1.8 \mathrm{~h}$ está muy por debajo de la unidad agrícola familiar, para la región occidente el departamento de Caldas, el cual es de 5 a 10 h. para actividad agrícola y de 10 a 20 h para actividad ganadera ${ }^{1}$.

Figura 3. Número total de créditos vigentes por año para la línea de bienestar social, en el período 2015-2017.

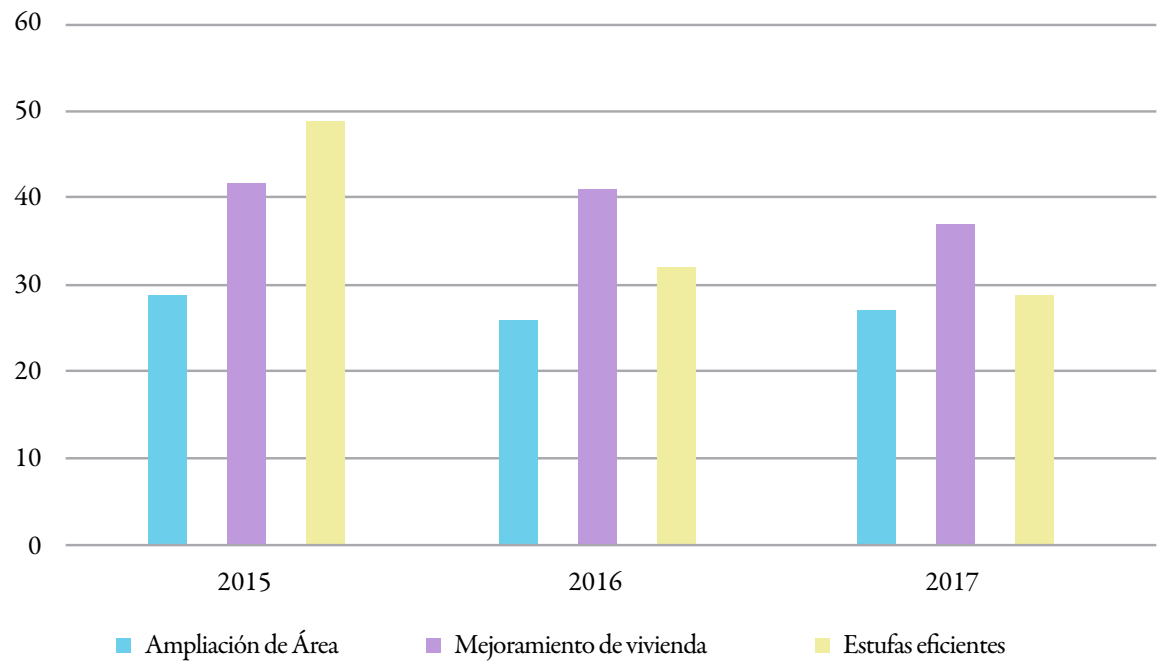

Fuente: elaboración propia.

\footnotetext{
${ }^{1}$ La resolución 041 de 1996 reglamenta las extensiones de las Unidades Agrícolas Familiares en la llamada región del Antiguo Caldas.
} 
Las dos líneas de crédito adicionales son tomadas de manera preferencial por las mujeres. El "Mejoramiento de vivienda" incluye el apoyo a acciones prioritarias para mejorar el bienestar del núcleo familiar, como la adecuación de pisos o de techos. De otra parte, la línea "Estufas eficientes" permite la reconstrucción de estufas con modelos técnicos y materiales que hacen más eficiente la combustión de leña en la cocción de alimentos y genera menor cantidad de humo dentro de las cocinas, lo que beneficia de manera directa la salud de las mujeres (madres e hijas) que, en general, son responsables por la alimentación de su familia. Esta línea podría entenderse como una acción más para el mejoramiento de vivienda, pero también y, sobre todo, como una línea que aporta a la conservación de recursos forestales, ya que, tradicionalmente, la leña de especies silvestres constituye el principal combustible empleado en las cocinas de las regiones campesinas del país. La tendencia de esta línea de crédito, en el tiempo, es que disminuya su demanda, dado que buena parte de las familias ya cuentan con estufas mejoradas bajo esta estrategia.

Aunque la mayor cantidad de créditos están centrados en las familias, ha sido interés de ASPROINCA, promover también créditos comunitarios. En la década de 1990 y comienzos del año 2000, se promovieron créditos colectivos para la instalación de tiendas comunitarias, pero, posteriormente, los créditos se concentraron en las familias, con casos marginales de iniciativas comunitarias. Los créditos asociativos actuales se registran especialmente en resguardos indígenas, cuya gestión comunitaria de la tierra favorece también la inversión grupal. Créditos actuales de tipo asociativo incluyen, especialmente, la instalación de 4 trapiches comunitarios y un crédito para ganadería en 4 grupos asociativos de ASPROINCA, de esta manera, se contribuye al fortalecimiento de las redes comunitarias.

\subsection{Acciones de cuidado ambiental}

Acorde al planteamiento del objetivo misional de ASPROINCA, existen al menos 3 líneas del FR que tienen como propósito central, el mejoramiento de las condiciones agroambientales de las familias asociadas (figura 4). Estas líneas nacieron de manera simultánea con el surgimiento del FR, lo que resalta la importancia que ha dado ASPROINCA a los temas ambientales. 
Figura 4. Número total de créditos vigentes por año destinado a la línea ambiental, en el período 2015-2017.

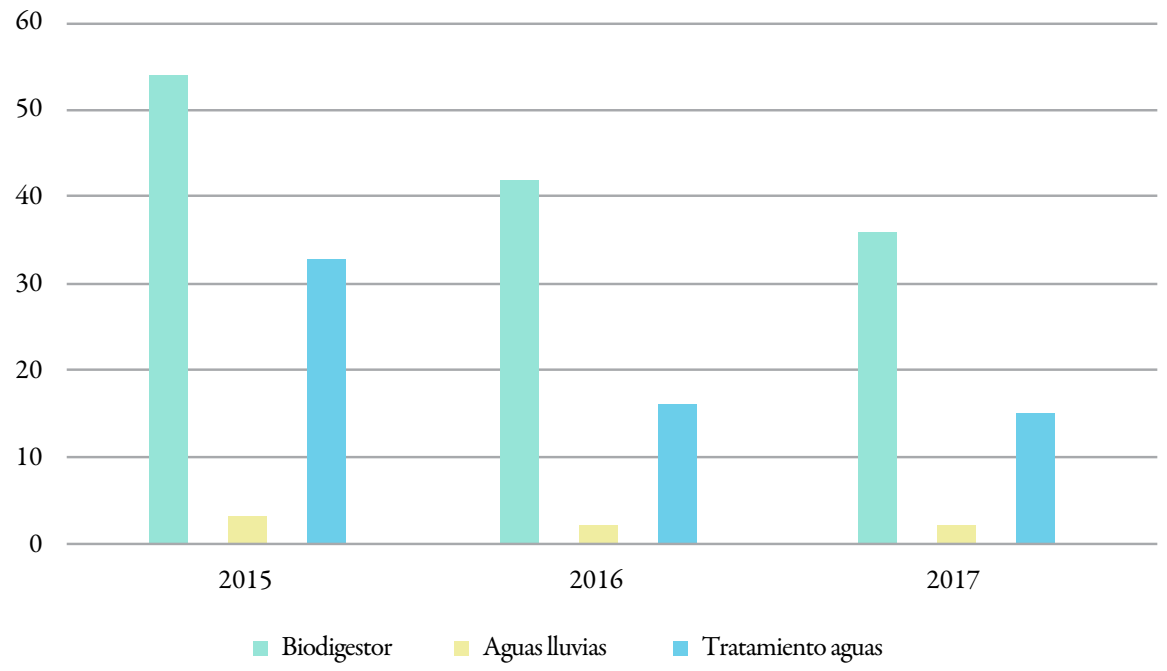

Fuente: elaboración propia con información de la asociación.

En los último tres años (2015 a 2017), se contabilizan en promedio 68 créditos por año en temas ambientales, en las líneas de biodigestores, aguas lluvias y tratamiento de aguas. No obstante, al ser estas las líneas centrales, que atañen a la preocupación ambiental, toda propuesta productiva apoyada financieramente por ASPROINCA, tiene implícitos objetivos y acciones ambientales en su implementación. De esta forma, aspectos como la biodiversidad funcional, la protección de fuentes de agua, la arborización de los sistemas productivos, la agrobiodiversidad, las energías renovables, el manejo de residuos sólidos, etc., hacen parte de una propuesta integral de protección y conservación ambiental, auspiciada por ASPROINCA a través del FR.

La instalación de biodigestores para producción de biogás de uso doméstico y de efluentes útiles, como biofertilizantes líquidos (bioles), constituye una de las estrategias productivas y ambientales por excelencia de la organización; no sólo por el manejo ambientalmente seguro de excretas animales usadas como materia prima, sino por la reducción del uso de leña para estufas. Esta tecnología ha sido fortalecida 
y compartida con otras organizaciones aliadas de la Red $\mathrm{BioCol}^{2}$, a la cual pertenece ASPROINCA, dedicada a la difusión de tecnologías para generar energía renovable, a partir de la biomasa producida en las fincas. Otras acciones ambientales apoyadas por el FR incluyen la cosecha de agua lluvia y su almacenamiento para riego y la descontaminación de aguas residuales que, en muchas ocasiones, se reintegran al proceso productivo de la finca.

\section{Discusión}

El caso del FR de ASPROINCA ilustra de manera clara cómo los fondos autogestionados pueden ser una respuesta efectiva a las necesidades financieras que implican los procesos de transición agroecológica en la agricultura familiar. Esta eficacia está claramente relacionada tanto con el diseño particular de las líneas de crédito, como con el grado de integración del fondo en la propuesta general de la organización. En cuanto al diseño, los resultados presentados muestran que las líneas de crédito establecidas, por la asociación, cubren un rango amplio de acciones. Esta variedad de líneas permite una planeación flexible del proceso de transformación; esta se expresada tanto en la posibilidad de amoldar las perspectivas de bienestar contenidas, en los planes prediales a las características y aspiraciones de cada familia productora; como también en la posibilidad de una implementación gradual de cambios y ajustes. Además, las líneas de crédito están alineadas con criterios agroecológicos claros, como son: la integración vertical del proceso productivo, el aprovechamiento de espacios reducidos, la aplicación de cultivos asociados y las prácticas de ganadería sostenible.

Por otro lado, la integración del fondo en la propuesta de ASPROINCA se evidencia tanto en cuestiones administrativas y procedimentales, como en la misión central de la asociación. Los procesos de estudio, decisión y seguimiento de los créditos están directamente involucrados con otros procesos de operación no financieros de la asociación. Así, por ejemplo, el acceso a los créditos está supeditado a que estos estén dirigidos a la implementación de componentes para un diagnóstico predial. A su vez, el diagnóstico y plan predial son el resultado de un proceso de capacitación de la familia y de la construcción de su propuesta individual de bienestar, con

\footnotetext{
${ }^{2}$ La Red Nacional de Energías de la Biomasa está conformada por diversas organizaciones del país con el objetivo de promover el uso de tecnologías de la biomasa como una herramienta importante de los sistemas de producción, facilitar el intercambio de experiencias y conocimientos, además, promover el desarrollo de la investigación en el área de energías renovables y su relación con la agricultura bajo principios de sustentabilidad y solidaridad. www.redbiocol.org; http://www.wisions.net/pages/redbiocol
} 
el acompañamiento de los promotores de la asociación. Aún más, el conocimiento mutuo que se desarrolla, a través de este acompañamiento, es fundamental tanto en la decisión como en el seguimiento continuo de los créditos. Ya lo señalaba Villarraga (2008), en su estudio sobre fondos autogestionados, al señalar que, a través de sus promotores, no sólo se presta asesoría de tipo técnico, sino que, al mismo tiempo, se hace seguimiento al crédito realizado. Asimismo, las decisiones sobre créditos (y sobre el fondo en general) hacen parte de las labores de la junta directiva, la cual a su vez tiene a su cargo asegurar la operación de la asociación, que está en manos de los promotores. Así pues, la integración del fondo en la propuesta de la asociación se mantiene a través de la interacción de tres tipos de roles: las familias productoras, los/ las promotores y la junta directiva. Una particularidad interesante aquí, es que todos estos roles son asumidos por asociados y asociadas, es decir, son interacciones en las cuales existe un denominador común, son hechos por productores y productoras rurales.

Ahora bien, en el diseño de las líneas de crédito, se evidencia la misión de la asociación al aportar al fortalecimiento integral del bienestar socio-ambiental de las familias. Así, por ejemplo, algunas líneas de crédito van más allá de un horizonte agroecológico y apuntan, más directamente, a cuestiones de bienestar social o ambiental. Otro ejemplo, es que resaltan el apoyo a inversiones tendientes a proteger las micro-cuencas de agua (un tema que la asociación ha abordado en profundidad desde el ejercicio de planeación regional) o el apoyo a inversiones para el fortalecimiento productivo de carácter comunitario.

De esta forma, el FR de ASPROINCA ofrece clara ilustración de algunas de las características más prominentes que han sido identificadas por estudios sobre fondos autogestionados en Colombia y en América Latina. Vale la pena resaltar, el alto nivel de especificidad de los créditos, la integración a procesos organizativos más amplios, el carácter de complementariedad de los fondos y el impulso inicial a través del capital semilla. Los fondos autogestionados, en contextos rurales, surgen por lo general como respuesta a la falta de servicios financieros apropiados para las condiciones y proyectos de vida de la población rural (Alves de Souza y Sátiro, 2010; Villarraga, 2008). Así pues, una característica central de estos fondos es el alto nivel de adaptación a las particularidades específicas de sus miembros o de la comunidad a la que se dirigen. Esto se refleja, por un lado, en los propósitos cubiertos por los créditos, como lo ilustran las líneas de crédito del fondo de ASPROINCA, las cuales permiten adaptar cada plan de transición agroecológica a las condiciones y visiones de bienestar de cada familia en particular. Por otro lado, la especificidad de los fondos también se refleja en las condiciones referentes a la alocación (y en 
particular) a los pagos de los créditos, en el que "las condiciones de los créditos se establecen de acuerdo con las características y ciclos productivos de las actividades que financian, con lo cual tienen una racionalidad económica poco aplicada por la banca comercial" (Villarraga, 2008, p. 12).

El carácter "autogestionado" de estos fondos implica que estos deben encontrarse incluidos en una estructura que los gestiona. Sin embargo, es característico de estos fondos que la misión de la organización, que los gestiona, no es la de proveer servicios financieros a sus miembros. Por el contrario, la mayoría de los casos de fondos autogestionados rurales emergen de procesos organizativos, donde la comunidad implicada ha formado conciencia sobre su realidad y ha decidido construir alternativas propias de bienestar. Así pues, fondos autogestionados se pueden encontrar en diferentes tipos de organizaciones de carácter comunitario como “juntas de acción comunal, juntas de vecinos, asociaciones de productores y de mujeres, organizaciones indígenas y tiendas comunitarias, entre otras" (Villarraga, 2008, p. 11). Ahora bien, este marco organizativo está directamente relacionado con el carácter complementario que asumen los fondos. Pues, enmarcados en procesos de construcción de alternativas de bienestar para la vida rural, la provisión de servicios financieros (es decir, la función específica de los fondos) no son un fin en sí mismos, sino un medio hacia la realización de esas alternativas. Aquí de nuevo, el fondo rotatorio de ASPROINCA ofrece una clara ilustración, pues el FR se articula a la propuesta de la Asociación como una herramienta (entre otras) para realizar su misión central de mejorar las condiciones socioambientales productivas y económicas de sus asociados.

Algunas experiencias sobre fondos autogestionarios en América Latina resaltan a la ONG Caatinga (Alves de Souza y Sátiro, 2010), que en 1987 inicia una experiencia en financiación en créditos rotativos para combatir la sequía en la región semiárida del nordeste brasileño, promoviendo la cría de especies menores y cultivos resistentes a la sequía. Esta experiencia fue apoyada financieramente por OXFAM, la ONG realizó los primeros créditos en dinero efectivo, permitiendo su devolución nuevamente en efectivo o en productos cosechados. El fondo se conoce hoy como "Crédito Agroecológico y Solidario" y es gestionado por 39 asociaciones de productores agroecológicos. Esta experiencia refuerza la idea de que los fondos autogestionados requieren un apoyo económico inicial, que en ambos casos (ASPROINCA y Caatinga) proviene de la cooperación internacional, pero solo como un apoyo inicial para permitir, lo que Van der Ploeg (2010) llama, una 
base autónoma de recursos económicos. Cuando las asociaciones que los gestionan asumen compromisos de alta responsabilidad para su manejo, los fondos autogestionados pueden no sólo crecer, sino ampliar la capacidad para brindar nuevos servicios financieros solidarios a sus integrantes, aumentando las líneas de crédito para actividades productivas o incursionando en otras dimensiones de la vida rural como la educación, la vivienda, la salud y la recreación.

Finalmente, vale la pena resaltar el engranaje que ha logrado ASPROINCA entre su Fondo Rotatorio y su programa de Promotoría. El impacto del trabajo de la asociación a nivel tanto de predios individuales, como de paisaje ha sido validado por diferentes estudios (Solarte-Sánchez, Zapata-Arango y Gómez, 2014; Corrales, 2010; Forero-Álvarez y Furio, 2010). Ahora bien, el análisis presentado sugiere que esa combinación y ese engranaje entre el fondo y la promotoría, podría ser una clave central para la efectividad y la robustez de la propuesta de ASPROINCA. Mientras, el primero es un fondo autogestionado de recursos financieros, el segundo podría ser entendido como un fondo autogestionado de conocimiento y capacidades de asistencia técnica. El trabajo de transformación de las fincas hacia una producción más sostenible y justa hacia los productores, aplica diversas estrategias de manera articulada, no aislada. El diagnóstico determina el plan de trabajo, el fondo facilita recursos para la financiación de aquellos aspectos más onerosos para el agricultor, los promotores formados se encargan de acompañar la ejecución de los planes hacia la transformación de las fincas. De esta manera la interrelación de estos componentes representa un factor determinante para el éxito de la propuesta de trabajo de la Organización. Nuevamente, puesto en los términos de Van der Ploeg (2010), la combinación de estos dos componentes genera y mantiene de forma sólida una base autónoma de recursos (financieros, humanos, conocimientos) que, a su vez, fortalece la autonomía del proceso organizativo de la asociación. Visto desde esta perspectiva, y considerando el potencial transformador evidenciado en la propuesta de ASPROINCA ( $y$ en tantos otros casos ilustrados en este libro), vale la pena preguntarse: ¿cómo se puede fomentar la difusión profusa de este tipo de experiencias? y ¿cómo promover dinámicas para la reproducción y el fortalecimiento de las bases autónomas de los recursos en zonas rurales?

\section{Conclusiones}

La falta de servicios financieros flexibles, que se adecúen a los requerimientos específicos de los agricultores familiares, constituye una de las limitantes más comunes para fortalecer su actividad productiva y económica. La economía solidaria ofrece 
alternativas reales que involucran a los actores locales en la generación de soluciones, a partir de los principios de solidaridad y cooperación. El caso del fondo autogestionado, por familias de la asociación ASPROINCA, se configura como una experiencia relevante de generación autónoma de soluciones financieras para promover la transición agroecológica, además, de generar bienestar socio-ambiental de sus asociados.

El FR constituye una herramienta importante en el desarrollo de la propuesta de la organización, ya que sirve a los propósitos de transformación productiva de las fincas, mejoramiento ambiental del entorno y social de las familias. Está fuertemente relacionado al proceso participativo de planificación de la transición agroecológica de las fincas y de la actividad de promotoría rural, constituyéndose en parte esencial de esta triada que conforma la base del fortalecimiento organizacional de ASPROINCA.

Como servicio financiero alternativo inmerso en la estructura de la organización, el FR constituye una pieza clave para el cumplimiento de su propósito misional. Junto a su capital humano y de conocimientos, se conforma una base de recursos que permiten a ASPROINCA discurrir de manera autónoma, ejerciendo gobernanza propia sobre sus procesos de mejoramiento productivo agroecológico, conservación ambiental y bienestar de sus asociados.

\section{Agradecimientos}

Especial agradecimiento a los miembros de la Junta Administradora de ASPROINCA, particularmente, a su presidente el señor Eulises Trejos y al Grupo de Promotores por su entusiasmo al compartir su rica experiencia del Fondo Rotativo; igualmente, a Ubeimar Tapasco, Élida Gañán, Guillermo Gañán, Claudia Largo, Verónica Calvo, Viviana Hernández. Por último, nuestra admiración por la tenacidad de su trabajo.

\section{Referencias}

Alves de Souza, B., y Sátiro, G. H. (2010). Crédito agroecológico y solidario en apoyo a la transición agroecológica. LEISA. Revista de Agroecología, 26(2), 10-13. Recuperado de http://www.leisa-al.org/web/images/stories/revistapdf / vol26n2.pdf

ASPRoInCA. (2012). Asociación de Productores Indígenas y Campesinos de Riosucio, ASPROINCA. En ¿Quiénes somos? Documento Institucional. No publicado. 
ASPRoInCA. (2015). Fondo Rotatorio de la Asociación de Productores Indígenas y Campesinos AsproincA. Documento Institucional. No publicado.

Bouman, F. J. A. (1995). Rotating and accumulating savings and credit associations: A development perspective. World Development, 23(3), 371-384. doi: https:// doi.org/10.1016/0305-750X(94)00141-K

Corrales, E. (2010). Viabilidad cultural y ambiental de sistemas de producción rurales. El caso de Asproinca en Riosucio-Supía, Colombia. En J. Ramírez y J. C. Tulet (coords.), Recomposición territorial de la agricultura campesina en América Latina (pp. 39-58). México D.F.: Editores Plaza y Valdés.

Forero-Álvarez, J., y Furio, V. (2010). Colombian family farmers' adaptations to new conditions in the world coffee market. Latin American Perspectives, 37(2), 93-110.

Corporación Financiera Internacional - IFC. (2014). Acceso a las finanzas para pequeños productores agropecuarios. Lecciones de las experiencias de instituciones microfinancieras en América Latina. Washington: IFC.

Olaniyi, E. (2017). Back to the land. The impact of financial inclusion on agriculture in Nigeria. Iranian Economic Review, 21(4), 885-903. doi: https://dx.doi. org/10.22059/ier.2017.64086

Organización de las Naciones Unidas para la Alimentación y la Agricultura-FAO. (2014). Hacia una agricultura familiar más fuerte. Voces en el Año Internacional de la Agricultura Familiar. Roma: FAO. Recuperado de http://www.fao. org/3/a-i4171s.pdf

Solarte, M. R. (2010). Los fondos autogestionarios de microcrédito, como aporte al desarrollo local (tesis de maestría). Recuperado de https://repository.javeriana. edu.co/bitstream/handle/10554/851/eam69.pdf ?sequence=1\&isAllowed=y

Solarte-Sánchez, A. J., Zapata-Arango Y. C., y Gómez A. M. (2014). Mosaicos de conservación para preservar la biodiversidad. LEISA. Revista de agroecología, 30(3), 11-14. Recuperado de http://www.leisa-al.org/web/images/stories/ revistapdf/vol30n3.pdf

Villarraga, J. (2008). Fondos autogestionados rurales de ahorro y crédito: experiencias y lecciones para el fortalecimiento de las microfinanzas rurales en Colombia. Bogotá: Fundación Ford y Corporación Consorcio para el Desarrollo Comunitario. Recuperado de http://www.iedmicrofinanzas.com /portal/prueba/assets/ estudio.pdf 
Van der Ploeg, J. D. (2010). Sobre el crédito a los agricultores de pequeña escala y la necesidad de una base autónoma de recursos. LEISA. Revista de Agroecología, 26(2), 6-9. Recuperado de http://www.leisa-al.org/web /images/stories/ revistapdf/vol26n2.pdf 


\title{
Capítulo 9
}

\section{Formación agroecológica en la experiencia de las "escuelas agroambientales" del Comité de Integración del Macizo Colombiano (CIMA)}

\author{
Agroecological training in the "agro-environmental schools" of \\ the Colombian Macizo Integration Committee (CIMA)
}

\author{
Gustavo Adolfo Alegría Fernández* \\ William Bernardo Macias Orozco **
}

\section{Cómo citar}

\begin{abstract}
APA
Alegría, G., y Macias, W. (2019). Formación agroecológica en la experiencia de las "escuelas agroambientales" del Comité de Integración de Macizo Colombiano (CIMA). En Á. AcevedoOsorio y N., Jiménez-Reinales (comps.). La Aagroecología. Experiencias comunitarias para la Agricultura Familiar en Colombia. (pp. 207-230). Bogotá: Corporación Universitaria Minuto de Dios-UnIMINUTO, Editorial Universidad del Rosario.
\end{abstract}

\section{Chicago}

Alegría Fernández, Gustavo Adolfo y Macias, William. "Formación agroecológica en la experiencia de las "escuelas agroambientales" del Comité de Integración de Macizo Colombiano (CIMA)". En La agroecología. Experiencias comunitarias para la Agricultura Familiar en Colombia, comps. Álvaro Acevedo-Osorio y Nathaly Jiménez-Reinales. Bogotá: Corporación Universitaria Minuto de Dios-UNIMINUTO, Editorial Universidad del Rosario, 2019.

* Universidad del Cauca - Unicauca. gustavoalegria@unicauca.edu.co

** Corporación Universitaria Comfacauca - Unicomfacauca. williammacias.o@gmail.com 


\section{MLA}

Alegría Fernández, Gustavo Adolfo y Macias, William. "Formación agroecológica en la experiencia de las "escuelas agroambientales" del Comité de Integración de Macizo Colombiano (CIMA)". En La agroecología. Experiencias comunitarias para la Agricultura Familiar en Colombia. En Á. Acevedo-Osorio y N., Jiménez-Reinales (comps.) Bogotá: Corporación Universitaria Minuto de Dios-uniminuto, Editorial Universidad del Rosario, 2019, pp. 207-230.

\section{Resumen}

La educación rural en Colombia es débil para incentivar el sentimiendo de arraigo por su territorio entre los jóvenes. Por esta incapacidad del modelo de educación, esta no les permitirles estructurar sus proyectos de vida alrededor de la ruralidad, aquella que les caracteriza; por ende, va aumentado la migración de sus territorios. Las inciativas campesinas en Agroecología desarrollan experiencias de formación en escuelas de campo con agricultores, basadas en el intercambio y construcción de conocimientos en el territorio, un ejemplo de ello, se desarrolla al sur occidente de Colombia, con las experiencias agroecológicas de las Escuelas Agroambientales, impulsadas por el Comité de Integración del Macizo Colombiano (CIMA), que propone una formación de arraigo y defensa territorial. En la actualidad, continúan organizadas como el nombre de Fincas de Referencia Agroambiental Maciceñas (FRAM). Para que estas prácticas agroambientales y su conocimiento no se pierdan, necesario sistematizar estas experiencias, desde un acercamiento crítico que permita dilucidar los aprendizajes y epistemologías emergentes, asimismo, los saberes y medios de adaptación que han tenido las comunidades en la apropiación de sus territorios. Esta propuesta se fundamenta en la perspectiva integral de la agroecología, en tanto que, es un paradigma con una visión integral, en el que las variables socio-ambientales son importantes, además, procura entender la política y la economía y su interrelación con los sistemas agroecológicos, pero desde el nivel concreto de la finca campesina. En el resultado del proceso de sistematización de las experiencias, se refleja que muchas de las escuelas del Macizo siguen vigentes, trabajando a partir de principios agroecológicos y reivindicando el saber campesino y de la agricultura familiar. Las escuelas han permitido a las organizaciones sociales generar estrategias de identidad, arraigo y defensa del territorio.

Palabras clave: agroecología, campesinado, escuela de agroecología, escuelas de campo, hoja de coca, sistematización de experiencias.

\section{Abstract}

Rural education in Colombia has a lack when it comes to strengthening the sense of belonging to young people in their territory. Because of this inability of the education model, this does not allow them to structure their life projects around rurality, that which characterizes them; therefore, the migration of their territories is increased. Initiative farmers in Agroecology develop training experiences in field schools with farmers, based on the exchange and construction of knowledge in the territory, an example of this is developed in the south west of Colombia, with the agroecological experiences of the Agro-environmental Schools, impelled by the Committee 
of Integration of the Colombian Massif (CIMA), which proposes a formation of rooting and territorial defense. At present, they are still organized as the name of Farms of Reference Agroambiental Maciceñas (FRAM). So that these agro-environmental practices and their knowledge are not lost, it is necessary to systematize these experiences, from a critical approach that allows elucidating emerging learning and epistemologies, as well as the knowledge and means of adaptation that communities have had in the appropriation of their territories. This proposal is based on the integral perspective of agroecology, as it is a paradigm with an integral vision, in which socio-environmental variables are important, in addition, it seeks to understand politics and economics and their interrelation with agroecological systems, but from the concrete level of the peasant farm. In the result of the process of systematization of experiences, it is reflected that many of the schools of the Massif are still in force, working from agro-ecological principles and claiming peasant knowledge and family farming. The schools have allowed social organizations to generate strategies of identity, roots and defense of the territory.

Keywords: agroecology, peasantry, agroecology school, field schools, coca leaf, systematization of experiences.

\section{Introducción}

El Macizo es un lugar único de la geografía colombiana donde nacen los ríos Magdalena, Patía, Putumayo, Caquetá, Cauca y un sinfín de afluentes de menor grado, por esta razón, es conocido como la estrella fluvial del macizo.Igualmente, concentra, en sus montañas y páramos, una riqueza social para defender la vida y el territorio, ejemplo de ello, es el Comité de Integración Social del Macizo Colombiano (CIMA), integrado por organizaciones campesinas de quince municipios de Cauca y Nariño. En 1999 logró hacer escuchar su voz al gobierno nacional al depositar en un manifiesto las demandas de las poblaciones indígenas y campesinas del Cauca.

Desde entonces, indios ruanudos, campesinos y afrosdescendientes de los diferentes pueblos hermanos del Macizo colombiano, al igual que sus ríos, recorren la palabra en búsqueda de la paz, la soberanía alimentaria, la defensa del territorio y los derechos humanos. Este documento nace en el marco de estas luchas, las Escuelas Agroambientales del Cima germinan como una estrategia para generar un espacio de intercambio de saberes y experiencias, además, se concibe como una alternativa a la carencia de educación rural pertinente (Freire, 1973), y a una asistencia técnica contextualizada a las unidades productivas de los pequeños campesinos, basada en un manejo armónico con la naturaleza. En Colombia, de 100 estudiantes que se matriculan a primero de primaria en las zonas rurales, solo 35 terminan este ciclo, y un poco menos de la mitad (16 estudiantes) logran realizar estudios de secundaria; de éstos, 8 completan el noveno grado y solo 7 culminan el ciclo completo 
de educación básica (Perfetti, 2003, p. 183), con estos datos podemos pensar en las pocas o nulas posibilidades que tienen en la formación universitaria. Para la década de 1980, venían creciendo las iniciativas de Escuelas de Campo en el país, especialmente, con ayuda internacional muchas escuelas en nuestro territorios se consolidaban.

De esta semilla sembrada en muchas regiones, en el decenio de 1990 el CimA inicia sus movilizaciones y ve la necesidad de constituir sus escuelas de formación política para fomentar la educación en este ámbito y les permitierá fortalecer la defensa y arraigo de su territorio; por esta razón, luego del consenso con sus comunidades y recibir apoyo económico internacional, por falta del gobierno local y estatal, en el 2000 se pone en marcha la propuesta de las Escuelas Agroambientales del Cima, este proyecto les permitiría influir no solo en trabajo y apoyo técnico a la diversidad de cultivos, sino también incidir política y organizativamente en sus comunidades.

El proceso de sistematización que generó este capítulo, se estructuró bajo una pregunta orientadora: ¡ cómo se configuran y cuáles son las epistemologías, saberes, aprendizajes y prácticas campesinas que desde las escuelas agroambientales pueden servir de referentes para futuros programas en Agricultura Familiar? El propósito de esta investigación es sistematizar la experiencia de las escuelas agroambientales promovidas por el CIMA, resaltando los conocimientos, saberes, aprendizajes y prácticas campesinas. Para resolver el anterior interrogante, metodológicamente, se utiliza un enfoque cualitativo que esta fundamentado en las entrevistas realizadas a las personas que estuvieron al frente de las escuelas y, se recurre a la sistematización de experiencias planteada por Jara (1994), con el propósito de hacer un acercamiento crítico a la experiencia de las escuelas que permita dilucidar la configuración historica, los aprendizajes, las dificultades y el desarrollo de las apuestas agroambientales agenciadas. Muchas de las escuelas agroambientales se constituyeron en cada uno de los municipios que tiene incidencia la organización del CIMA, su dinámica fue fortalecida por los agricultores, denominados en estas escuelas como "agro sembradores y agro sembradoras", grupo de personas vecinas, que en su vereda compartían lo aprendido por medio de la dinámica de cascada. Esta permite difundir muchos de los saberes agroecológicos, propuestos en los currículos, que sustentaban el componente pedagógico de las escuelas y, cuya construcción fue motivado por el consenso y la participación, por que, desde sus orígenes, el propósito de esos currículos era el posicionamientos de las ocho apuestas como principios organizativos del CIMA. 
Las escuelas agroambientales han permitido fortalecer la identidad campesina, como apuesta política en la lucha del reconocimiento del campesino como sujeto de derecho, asimismo, reivindicar el saber campesino como contraste a la contaminación de las apuestas homogeneizadoras de producción, reflejadas enla Revolución Verde que, más allá de aumentar los indicadores de productividad ha dejado una alta dependencia a insumos externos y sistemas productivos insostenibles por el pequeño productor. La defensa y arraigo del territorio, como principio de enseñanza de las escuelas agroambientales, han permitido también la reivindicación del uso ancestral de la hoja de coca. Ejemplo de eso, es la escuela El Arraigo en el corregimeinto de Lerma perteneciente al municipio de Bolívar (Cauca), una experiencia en la cual se hace mención mediante un reconocimiento a sus saberes y enseñanzas acumuladas, en la lucha por desmitificar el uso de la hoja de coca como cultivo ilícito y darle la importancia en la alimentación, así como, en el ámbito medicinal, cultural y espiritual, este último, como hoja sagrada.

Los dos conceptos teóricos que guían este trabajo son: la agroecología y las escuelas campesinas, asimismo, se plantea adoptar una visión, no reducida de lo agrícola y lo campesino, para tratar dimensiones relativas a lo familiar, económico y la soberanía alimentaria, lo que permite una visión integral.

\subsection{Agroecología}

La agroecología resalta el papel de la matriz sociocultural que dota de identidad y saberes al agricultor, igualmente, de red o redes de relaciones y de prácticas políticas (Sevilla, 2006). La recurrencia a la agroecología, en tanto movimiento social (Sevilla, 2006), sustenta por ende el quehacer de las organizaciones estudiadas, más allá de lo técnico productivo, para abarcar el modo de vida campesino y su resistencia al modelo agrícola convencional, la globalización y el neoliberalismo (Martinez, 2004).

Como se verá en el transcurso del capítulo las escuelas agroambientales de la organización estudiada se apoyan en el discurso del reconocimiento a la diversidad cultural y la diversidad biologica. Este acto se traduce en la siembra de lo que es propio de la localidad según los climas, suelos y con base en la tradición agrícola (campesina, indígena, afro). Además, este reconocimiento de la biodiversidad implica que se opte por el policultivo, asi como, por el cuidado de los rastrojos y bosques considerados como escenarios de existencia de la comunidad y son parte integral del territorio por sus funciones ecosistémicas. Por consiguiente, se entiende por prácticas y saberes agroecológicos o agroambientales las que estén marcadas 
bajo la concepción integral y política del cuidado y la sustentabilidad (Altieri y Toledo, 2011). No se trata sólo de prácticas y saberes técnicos, sino, ante todo, de la construcción de un sentido de movimiento social, frente una realidad inmediata en las escuelas agroambientales.

\subsection{Escuelas campesinas}

El enfoque conocido como Escuelas de Campo de Agricultura (ECA) fue desarrollado en los años de la década de 1980, para capacitar a los agricultores en el cultivo de arroz en el manejo integrado de plagas (IPM), el eje de enseñanza aprendizajedescubrir basado en la educación de adultos ha trascendido a otros cultivos y a la crianza de animales. Estas escuelas de campo son vistas como puntos de entrada para el fortalecimiento y empoderamiento de la comunidad. Sobre su origen Acevedo (2011) señala que:

Las ECA nacieron en Asia en los años 80, impulsadas por la FAO para promover la incorporación rápida de innovaciones tecnológicas en cultivos de arroz; posteriormente en América Latina las impulsa el Centro Internacional de la Papa, CIP, para cumplir el mismo propósito en cultivos de papa en Perú; desde allí se extiende a otros países de América Latina con diversas modificaciones en su concepción y desarrollo como puede verificarse en las experiencias detectadas en Colombia en este breve estudio. (p. 13).

En Colombia, se vienen fortaleciendo desde hace muchos años experiencias de escuelas de campo, entre ellas, tenemos: la Escuela Territorial y Agroecológica Manuel Quintín Lame, Tolima, su pedagogía se basa en la educación popular y trasciende lo técnico y evoca la construcción y defensa del territorio (Grupo Semillas, 2015).

La Escuela de cultura campesina para la defensa del territorio, el agua y las semillas criollas del Catatumbo que promueve el reconocimiento del territorio, la cultura, los medios de vida y los recursos genéticos locales, así como, la defensa de los valores y elementos que dan soporte a la ruralidad campesina (Castrillón y Fawcett, 2017).

La Escuela Itinerante Afronortecaucana es una propuesta de articulación y de formación con varias características, además de su énfasis investigativo, integra el enfoque diferencial, generacional y de género. El objetivo central está en for- 
mar dirigentes-representantes de organizaciones afrocolombianas en temáticas ambientales, territoriales, sociales y económicas; buscando con ello, el desarrollo de propuestas alternativas para mejorar la calidad de vida de las comunidades afrodescendientes, por último, al igual que las otras iniciativas, la se centra prioridad en la defensa del territorio (Grupo Semillas, 2017).

Finalmente, está la escuela Surcos Comunitarios. Se trata de una experiencia pionera en el país sobre la educación agroecológica y la implementación de la metodología campesino a campesino. En términos de las experiencias citadas, las escuelas agroambientales del CIMA se asemejan a la experiencia de Surcos Comunitarios tanto en la concepción de escuela, como en los ejes de trabajo. Que involucran lo social, lo identitario, la historia local, los saberes tradicionales, lo político, lo organizativo, lo económico solidario y la soberanía alimentaria, además de lo agroecológico como apuesta politica.

Se reconoce en estas escuelas, un valioso espacio para el rescate de los saberes y conocimientos locales y la articulación de las organizaciones sociales, de la academia y de las ONG. Las escuelas campesinas realizan un importante ejercicio político, en la medida que, da fuerza a las propuestas de defensa del territorio, la identidad cultural y la promoción de la autonomía económica.

\section{Resultados}

\subsection{El CIMA y sus apuestas políticas, organizativas y productivas}

En cuanto al desarrollo de las escuelas agroambientales, son las comunidades las que definen quienes asisten a las escuelas en calidad de agrosembradores para después transmitir a los escolares ${ }^{1}$ en sus localidades los saberes aprehendidos. En este sentido, es un espacio de consolidación de liderazgos legítimos y de construcción de tejido social agroambiental; lo cual, se puede observar en que algunos de los participantes, posteriormente, se convierten en líderes o coordinadores del proceso agroambiental. Las escuelas, de acuerdo con esto, además de ser espacios de educación popular agroecológica, son un espacio de formación política en las cuales los participantes construyen y aprenden lo relacionado con las ocho apuestas educativas: en lo Político, lo organizativo, lo familiar, lo forestal, lo agrícola, lo pecuario, lo agroindustrial y lo comercial, igualmente, lo relacionado con el plan de

\footnotetext{
${ }^{1}$ Los y las estudiantes de las escuelas en el macizo colombiano.
} 
vida y la identidad cimeña fundada en el modo de vida campesino (Plan de Vida, Agua y Dignidad Campesina) y en el autorreconocimiento del territorio maciceño.

Las escuelas impulsan prácticas y saberes que toman distancia de las prácticas tradicionales agrícolas programadas por la Revolución Verdey, en general, las promocionadas en el marco de la política agraria nacional, en tanto que, se considera que estas generan efectos negativos en los ecosistemas y cultivos. Por ende, esto conduce a que las escuelas se desarrollen con base en un currículo propio (currículos agroambientales), con enfoque agroecológico, de economía campesina y relacionadas con el ámbito político organizativo; este curriculo se materializa en cuatro cartillas que contienen y desarrollan didácticamente las ocho apuestas, estos cuadernillos son un desarrollo propio de la organización. Por lo anterior, la escuela tiene cuatro momentos que pueden llamarse ciclos formativos y en cada ciclo se trabajan dos apuestas de las ocho. Quienes asisten a las escuelas se denominan agrosembradores, estos se capacitan, aprenden, y replican las capacitaciones con los escolares.

Según Ernei Ruiz, líder de la escuela agroambiental El Arraigo-Lerma:

Para la formación de las escuelas agroambientales, la organización del CiMA bajaba la información a la base y la misma base debe escoger a sus agrosembradores y cada agrosembrador escoge donde va a ser la finca FRAM articulada con la escuela agroambiental y escoge su grupo de familiares, ya después de haber definido, llevaba la información del Centro Integrado de Servicios (CIS), en estos centros se capacita en prácticas agroecológicas, que luego trabaja con las familias de la comunidad que había escogido. (Fragmento de la Entrevista con Ernei Ruiz, líder de la escuela agroambiental El Arraigo-Lerma durante 1996-2015).

Cada escuela desarrolla un proyecto productivo definido en función de las características agrícolas y dinámicas sociales locales, teniendo en cuenta todas las apuestas o algunas de ellas según el caso.

Si bien es cierto que tenían que tener en cuenta todas las apuestas, algunos escogen algo más característico del grupo que se tenía de la zona o del clima, nos referimos a que entonces existía algo mínimo en lo que se apoyaba, como especies menores: gallinas, conejos, o en la recuperación de saberes, recuperación de sabores de acuerdo a la dinámica del grupo y de la zona. (Fragmento de la entrevista con Ernei Ruiz). 
El agrosembrador coordinador de la escuela tiene el compromiso de replicar lo aprendido en las Fincas de Referencia Agroambiental Maciceñas (FRAM), a partir de formas de trabajo colectivo (mano intercambiada, mingas) y de la formación de otras escuelas. Por ende, los agrosembradores son multiplicadores de lo aprendido a partir de formas de trabajo colectivo y metodologías propias. Las escuelas orientan su quehacer desde las metodologías propias centradas en el campesino como sujeto activo, en la reivindicación del saber campesino y en las epistemologías locales, por esta razón

Como se trata de reivindicar y legitimar el saber campesino tiene una metodología propia que se denomina campesino a campesino, entre otras metodologías, como dejando huella, aprender haciendo, la bioaula que son propuestas originadas desde el cima y que han ido trascendiendo a propuestas más regionales y a otras organizaciones. (Fragmento de la entrevista con Alex Fernández, coordinador del área agroambiental de Fundecima, durante el período de 2002 a 2015).

Estas metodologías tienen la impronta de las dinámicas del CIMA, al mismo tiempo que, se basan en los referentes obtenidos por la observación de otras escuelas campesinas y del movimiento agroecológico. La principal forma método es la metodología extensión campesino a campesino: basada en las recuperación de los saberes agrícolas propios y, que tiene como referente, los desarrollos conceptuales realizados por MAELA. Entre las premisas metodológicas se encuentran que:

es el campesino quien por naturaleza investiga y ensaya permanentemente en su parcela. Es un voluntario que usa y prueba las tecnologías y, una vez que se obtienen resultados concretos, decide si difunde al resto de sus vecinos. Pone en práctica desde la cotidianidad y transforma su parcela en Finca de Referencia Agroambiental del Macizo y se compromete a multiplicar saberes con la Escuela Veredal. (En Ajustes al informe técnico final, 2005).

A las mencionadas metodologías, se puede sumar el método participativo de Investigación Acción Participativa(IAP), la construcción de mapas sueño, aprender haciendo, estos métodos derivados de las visitas de experiencias a los Surcos comunitarios y de las experiencias propias en el Macizo colombiano. En síntesis, las metodologías propias se basan en el reconocimiento, autorreconocimiento y, 
permiten el fortalecimiento de aprendizajes colectivos y su puesta en práctica de sistemas agroecológicos en las FRAM.

\subsection{Origen de las escuelas Agroambientales}

La experiencia de las escuelas agroambientales impulsadas por el CIMA se desarrolló en dos fases entre los años 2002 a 2006 en diferentes zonas del Macizo colombiano, además, en el sur y centro del departamento del Cauca. Estas escuelas son el espacio donde se desarrollan los contenidos de formación y es el espacio práctico que sirven de ejemplo en el territorio. Los principios de la escuela son: la autonomía, la vocería, la identidad, la movilización, el respeto, el compromiso, la integración, la solidaridad; asimismo, estos buscan fortalecer las 'apuestas' de enfoque de desarrollo del sistema agroambiental del plan de Vida, Agua y Dignidad Campesina, partiendo del modelo multiescalar desde la familia, la finca, la microcuenca y los Centros Integrales de Servicios (CIS) ${ }^{2}$ hasta llegar al nivel regional, al cima se le ha permitido el fortalecimiento organizativo y de autonomía en el territorio.

Las escuelas agroambientales se constituyeron como una experiencia de educación no formal y se desarrollaron con base en el marco de proyecto "Encadenamientos productivos agroambientales para economías campesinas, indígenas y afrodescendientes del macizo“ con el apoyo de la oficina de la FAO de Holanda y Laboratorios de Paz. En sus inicios se configuró como una escuela itinerante, el currículo contenia y desarrollaba didácticamente las ocho apuestas, las cuales son un desarrollo propio de la organización; además, contó con el apoyo de técnicos del Servicio Nacional de Aprendizaje (SENA), quienes orientaron en el proceso de formación técnica de las escuelas del macizo. Las escuelas buscaban la réplica de lo aprendido en las FRAM y estaban encaminadas a articular las otras iniciativas lideradas en el territorio, como las ferias Agroambientales, los encuentros de las Tienda Regional del Macizo Colombiano, las dinámicas económicas de la Cooperativa Multiactiva del

\footnotetext{
${ }^{2}$ Los Centros Integrales de Servicios (cIs) consistieron en espacios geográficos delimitados en función de los climas, en los cuales se establecía una oficina cuyo objeto era recopilar información de la producción generada en la zona por las FRAM y las escuelas agroambientales, con el fin de articular los productores y permitir el desarrollo de agroindustria rural y comercialización de productos. Funcionaron entre el año 2001 a 2006 y siguen siendo un referente dentro del discurso agroambiental del cima. Está estrategia de articulación de los productores, en el marco del Proyecto encadenamientos de economías campesinas, tenía por función apoyar las escuelas agroambientales y a las fincas de referencia agroambiental.
} 
Macizo (Confiar) ${ }^{3}$. Entre otros acumulados y estrategias del cima, las escuelas buscan metodologías proclives al empoderamiento comunitario y con las cuales se trabaja: la extensión rural, la visita de experiencias, la planeación estratégica situacional, los mapas sueño, aprender haciendo, entre otros métodos.

\subsection{Estructura y organización de la escuela Agroambiental}

El desarrollo de las escuelas agroambientales no es posible de entender sin las experiencias previas del CIMA, que constituyeron un acumulado organizativo, político y de acciones colectivas en la defensa del territorio, las movilizaciones, las escuelas de gobierno y el proceso de construcción de los pilares que cimentan las escuelas: el eje agroambiental, cultural y educativo. La expresión "sembradores culturales y ambientales" o "agro sembradores" usada para nombrar a los participantes en las escuelas, pone de relieve la importancia de tales referentes; puesto que, se trata de un proceso histórico de construcción social, que parte de los antecedentes. Lo anterior, también sucede en la metáfora "recoger las semillas y criarlas" usada por los líderes del cima para referirse a esta dimensión histórica del proceso agroambiental, se descifra la figura de la "semilla" por relación de las experiencias previas en el fortalecimiento organizativo y territorial, cuyo papel fue empoderar a las comunidades y la organización.

Las escuelas son el espacio para que la gente, los pueblos conversen entre ellos, las asambleas del Cima tienen el mismo propósito, que la gente converse entre ellos y empecemos a mirar cómo las personas resuelve los problemas. Sabiendo que el Estado nunca nos iba a cumplir. Se decidió que existieran las escuelas [...]. Las escuelas nacen de la escuela de gobierno, de hacer la escuela pilar se da entre el 2000-2002, lideradas por los sembradores culturales y agroambientales. (Fragmento de la entrevista con el coordinador del área agroambiental de Fundecima, entre los años 1996-2002).

Las escuelas agroambientales también deben entenderse como el ejercicio hincado en la reivindicación de epistemologías y prácticas locales; el saber campesino

\footnotetext{
${ }^{3}$ Confiar es una organización gremial creada por las escuelas agroambientales y organizaciones gremiales, el equipo de mercados, directivos de Funde-Cima y Fundesuma, y las asistentes cis. Esta, busca el fortalecimiento e integración de las FRAM, las asociaciones de productores y las experiencias de economía campesina impulsadas por el cIMA. Además, con este propósito se conforma el fondo rotativo FIAR (Fondo de Inversión Agroambiental Regional) y los centros de acopio.
} 
se constituye en mina de prácticas agroambientales. Estas prácticas se entienden en el discurso agroambiental del CIMA, como ambientalmente sustentables y opuestas al modelo y prácticas agrícolas prevalentes con sus efectos destructivos sobre la naturaleza (Naredo, 2010). Aquí el empoderamiento se relaciona con un autorreconocimiento y valoración de los saberes y prácticas campesinos.

En perspectiva, las escuelas agroambientales se constituyen como los espacios sociales para "retroalimentar, aprender y enseñar" las epistemes locales; la forma de alimentarlas es a través del principio de dialogicidad, reconocimiento y diálogo entre saberes propios y técnicos; de este modo, las escuelas agroambientales se establecen con el carácter de una acción de educación popular y ecológica. El currículo de las escuelas agroambientales está constituido por cuatro cartillas de manejo agroambiental de las fincas, en el que se desarrollan las ocho apuestas elaboradas con base en el saber agroecológico, técnico y campesino, en cada una de las cartillas se despliegan dos apuestas. Estas se formulan de una manera integral, pues como se observa involucran no sólo lo agrícola y ecológico, sino también aspectos relacionados con lo familiar, la comunidad, lo político y lo económico; que, a su vez, comprende la comercialización, transformación y la economía solidaria.

\subsection{Atributos como apuestas y currículos de las escuelas agroambientales}

En el marco de las escuelas se plantea el desarrollo de las ocho apuestas llamadas “apuestas agroambientales", en las cuales la construcción participativa con las comunidades validan los “currículos agroambientales", estos como componentes pedagógicos de las escuelas. A la configuración propia de las Escuelas agroambientales del Cima se suma la observación y aprendizaje de otras experiencias de escuelas agroecológicas en el país, y a nivel internacional "conocíamos Surcos Comunitarios, conocimos los referentes de otra gente que venía haciendo lo mismo y decidimos construir una escuela regional" (Fragemnto de la entrevista coordinador del área agroambiental de Fundecima 2012-2015). Entre los referentes observados, se encuentran Surcos Comunitarios, Cisca (Comité de Integración Social del Catatumbo), AGRUCO y MAELA (Movimiento Agroecológico Latinoamericano y del Caribe). Cabe mencionar que en Colombia, el desarrollo de escuelas campesinas de agroecología se viene dando desde la década de 1990. 
Las ocho apuestas del CimA que sustentan el trabajo de las escuelas y su propósito de posicionarlas en el territorio se presentan de manera resumida a continuación:

1. Apuesta al desarrollo social y ambiental (lo político-organizativo y la compensación): $\operatorname{Pan}^{4}$ Gobernar, Pan Encadenar.

2. Apuesta al desarrollo familiar y comunitario (lo humano): Pan in-formar y Pan vivir dignamente.

3. Apuesta al desarrollo acuícola (las aguas y los servicios ambientales): Pan recoger, Pan llevar, Pan vivir.

4. Apuesta al desarrollo forestal y rastrojero (la biomasa). Pan Conservar, Pan Reforestar.

5. Apuesta al desarrollo agrícola (las plantas): Pan Coger, Pan Multiplicar.

6. Apuesta al desarrollo pecuario (los animales): Pan Comer. Pan Abonar.

7. Apuesta al desarrollo de la agroindustria rural (los transformados): Pan Transformar, Pan Guardar.

8. Apuesta al desarrollo comercialización y trueque (los negocios solidarios). Pan Comer-cializar, Pan Truequear.

En términos de un marco conceptual de referencia, el currículo posee una orientación agroecológica que responde a la búsqueda de soluciones a problemáticas identificadas. Tal marco conceptual, se formula teniendo como principio: el saber agrícola campesino, que está mediado por cada una de sus prácticas y manejos en la finca; las epistemologías locales; las escuelas agroecológicas en que se inscriben los profesionales agrícolas, que brindan el acompañamiento directo en la construcción de estos y la influencia de las perspectivas conceptuales y metodológicas de las organizaciones y movimientos agroecológicos, a nivel nacional e internacional. Según lo relata Yimi Rodríguez quien lideró y participó en la elaboración de los currículos:

teníamos que posicionar otros términos, pero hablando de producción orgánica, limpia. Hemos tomado de la escuela agroecológica, de la permacultura, de la bioenergética, de la producción orgánica, y, pero tal vez, el que más incidencia ha tenido en la construcción participativa de los currículos de la escuela ha sido el enfoque agroecológico. (Fragmento de la entrevista con el coordinador del área agroambiental de Fundecima 1996-2012).

\footnotetext{
${ }^{4}$ Es una metáfora de referencia al alimento en el lenguaje maciceño.
} 
En términos temáticos, las cartillas trascienden de lo ambiental y agroambiental para tratar dimensiones familiares; de lo económico, pero en términos de la economía campesina solidaria; asimismo, del producir para comer y vender, la soberanía alimentaria, lo que constituye un ejercicio integral que aporta con elementos detonantes de la agricultura familiar. Por consiguiente, el saber agrícola campesino se fortalece "no sólo la parte puntual de una asistencia técnica, sino una asistencia técnica integral”. La concepción agroecológica sustenta, por ende, el quehacer de las escuelas pues más allá de lo técnico productivo, se abarca el modo de vida campesino y su resistencia al modelo agrícola convencional.

\subsection{La escuela agroambiental El Arraigo}

Un ejemplo, que permanece en el territorio y trasciende el tiempo, es la Escuela Agroambiental El Arraigo liderada por Erney Ruiz. El Arraigo es producto de la tradición de la organización del CiMA, que puede rastrearse desde los años 1980 con la formación del cima como tal. También es producto de la recuperación de saberes, sabores y semillas ancestrales alrededor de la hoja de coca y las plantas medicinales. En el año 1991, se da un encuentro de mambeadores y de esta nace una iniciativa de trabajar con niños las semillas, artesanías y el rescate de la cultura de la hoja de coca, por esta razón, se conforma el grupo Coca y Tejido, desde esta época hasta el 2006 trabaja, pero solo hasta este último año se empiezan a llamarse Escuela El Arraigo. Para contextualizar esta época, existe un escenario de criminalización de la planta de coca, como cultivo de uso ilícito, asimismo, el conflicto armado se desplega sobre el territorio; sin embargo, pese a todas las vicisitudes, las escuelas agroambientales caminan paralelo a estos acontecimientos de desarraigo, pobreza y desplazamiento de los territorios. Al tener este escenario, los pobladores comenzaron a cuestionarse el por qué no empezar a crear y desarrollar proyectos económicos alrededor de la transformación de la hoja de coca, para el fortalecimiento de la economía y la identidad campesina y arrebatarle su uso ilícito de las dinámicas delicuenciales.

La escuela agroambiental avanza, entonces, en esa lucha por reivindicar el uso lícito de la coca, con ejemplo como su uso en la alimentación, con la incorporación de harina de coca en galletas, tortas, pan; así como, en bebidas como el refresco endulzado con panela; igualmente, el uso de las hojas y semillas en lo medicinal, la hoja seca para té. Por otro lado, en lo cultural reivindicar la actividad de mambear la hoja; y en lo espiritual, su reconocimiento como planta sagrada, en contra de la campaña que, por esos tiempos, se difundió en el país titulada "la mata que mata". 
Esta escuela de El Arraigo ha desarrollado las ocho apuestas agroambientales desde sus inicios. En lo político-organizativo, la incidencia en la formación y capacitación a la comunidad en el empoderamiento y defensa del territorio. En lo familiar, el rescate de la familia como unidad organizativa y centro de cualquier propuesta asociativa. En lo forestal, la recuperación del rastrojo como espacio de diversidad biológica para las fincas. En lo agrícola, el rescate de las prácticas y saberes ancestrales en el manejo de los suelos y el rescate de las semillas propias. En lo pecuario, la inclusión del componente animal en las unidades productivas y sistemas productivos como estrategias en el cierre de flujo de materia y energía de los agroecosistemas de la finca, haciéndolas más sustentables y resilentes al cambio climático. En lo agroindustrial, la generación y retención de valor de los productos producidos en la finca como es el de la hoja de coca; y en lo comercial, aportar a los circuitos cortos y la dinamización de los flujos económicos locales, como principio de fortalecimientos de la economía campesina. Las siguientes figuras describen este trabajo realizado en los últimos años, entre el período de 2010 a 2017; de años anteriores, aunque se hizo mucho trabajo comunitario desde el posicionamiento de la escuela, no se tiene registros de la dinámica e incidencia de la escuela en el territorio.

Como se observa en la figura 1 con relación en la apuesta familiar organizativa, se tienen una participación de 1200 escolares quienes se han formado en diversas prácticas agroecológicas, además, de 30 grupos de réplica, mismo número de agrosembradores y familias que han participado en los procesos formativos.

Figura 1. Formación apuestas familiares y organizativo de la escuela El Arraigo 2010-2017.

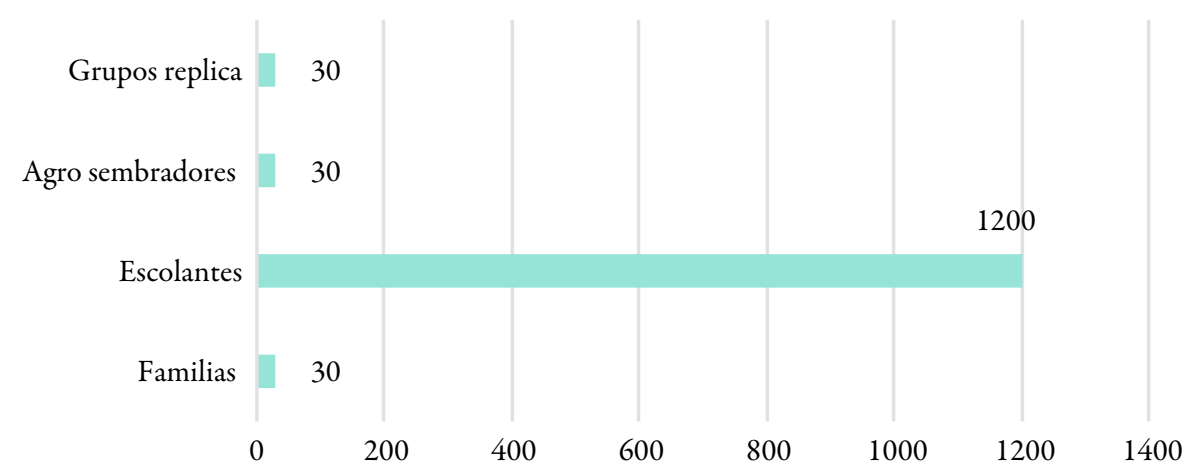

Fuente: elaboración propia a partir de la entrevista realizada al líder de la Escuela Agroambiental El Arraigo. 
En cuanto a la apuesta pecuaria y agrícola, se tienen un (1) centro de crianza, 10 custodios de semillas, 5 intercambios de semillas, entre otros logros, que pueden observar en la figura 2.

Figura 2. Desarrollo de los procesos apuesta pecuaria y agricola escuela El Arraigo 2010-2017.

Fincas de referencia agroambiental Intercambios de semillas Huertas caseras Especies y variedades 0

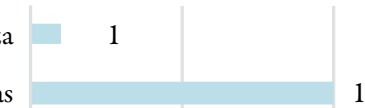

10

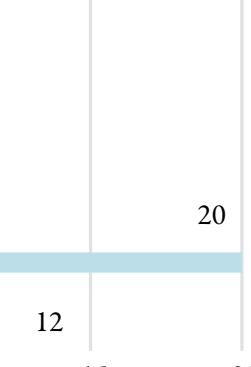

15
20

Fuente: elaboración propia a partir de la entrevista realizada al líder de la Escuela Agroambiental El Arraigo.

Se resalta de la figura 3 la apuesta relativa a bosques y agua, se han hecho 12 mingas de reforestación, donde se conserva el rastrojo, se recuperan especies nativas y bosques en las fincas.

Figura 3. Protección de bosques y aguas en la Escuela El Arraigo 2010-2017.

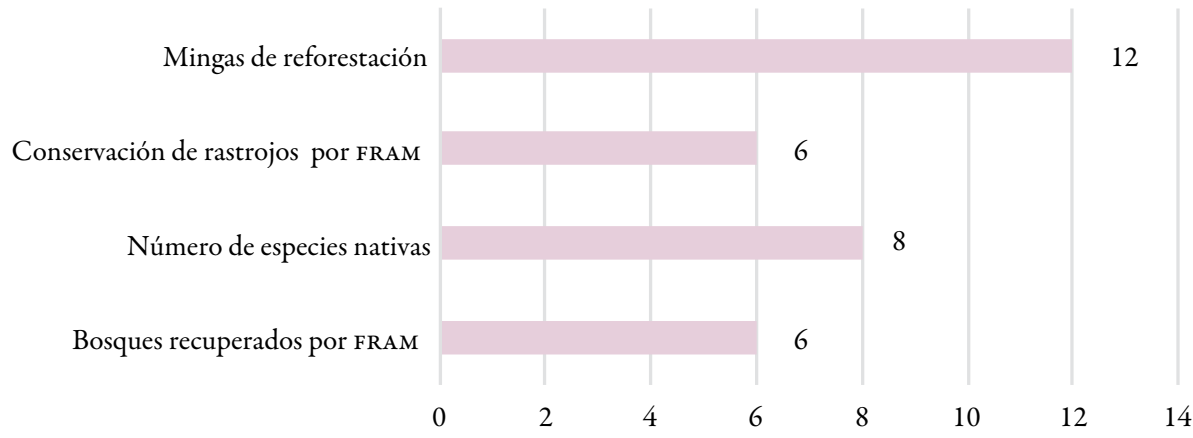

Fuente: elaboración propia a partir de la entrevista realizada al líder de la Escuela Agroambiental El Arraigo.

Así mismo, en la figura 4, en la transformación y comercialización de productos campesinos, se muestra que entre los logros están 14 ferias agroambientales realizadas y 5 tiendas campesinas conformadas. 
Figura 4. Participación y comercialización de la escuela El Arraigo 2010-2017.

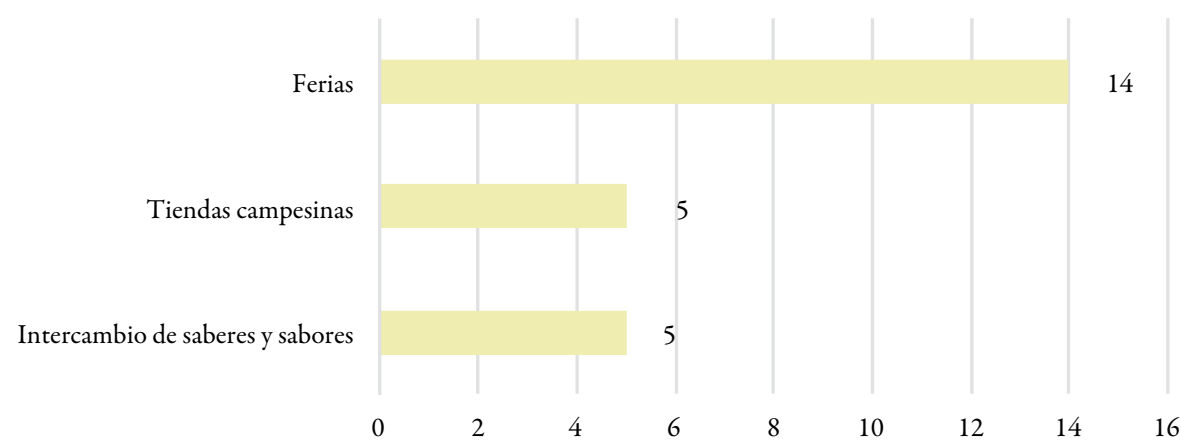

Fuente: elaboración propia a partir de la entrevista realizada al líder de la Escuela Agroambiental El Arraigo.

La organización ha visibilizado su trabajo a través de documentales transmitidos por el canal de televisión nacional Señal Colombia y en escenarios de eventos internacionales. El reconocimiento de esta experiencia se evidencia en la figura 5 que da cuenta de 35 visitas de diversas universidades, visitantes de 8 países acogidos, 6 procesos campesinos y una comisión de sustitución de cultivos de uso ilícitos de Estados Unidos entre los visitantes.

Figura 5. Reconocimiento Social Escuela El Arraigo 2010-2017.

Comisión de Sustitución de cultivos EE. UU.

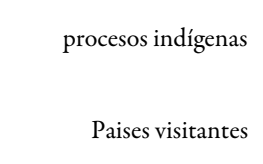

Visitas de universidades

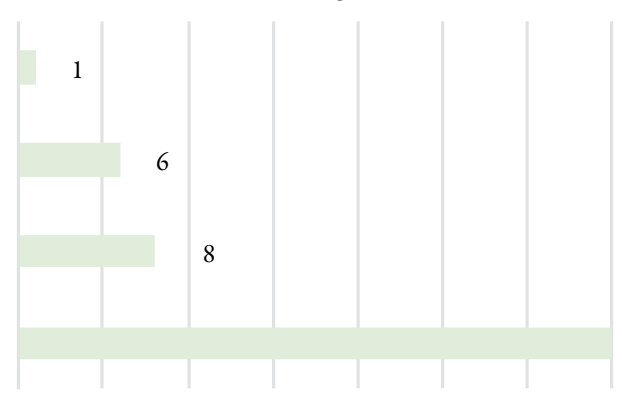

35

40

Fuente: elaboración propia a partir de la entrevista realizada al líder de la Escuela Agroambiental El Arraigo.

\section{Discusión}

En este sentido, el surgimiento de las escuelas agroambientales del cima coincide con el de escuelas agroambientales y campesinas, que tiene lugar en el país, desde la década de 1990, como lo señalan Mejía (2006) y Acevedo (2011). Estas escuelas campesinas agroambientales son experiencias de educación popular e informal, que reivindican los saberes agrícolas campesinos, indígenas y de afrosdescendientes; 
estas escuelas se proveen, principalmente, con apoyo de organizaciones no gubernamentales (ONG) y de cooperación internacional. Las escuelas agroambientales del Cima se inscriben en esta tendencia porque asumen como ejercicio la educación popular, al mismo tiempo que reivindican las epistemologías campesinas locales y, además, observan y toman como modelos otras escuelas agroecológicas que se desarrollan en el país.

Entre los acumulados derivados de las escuelas están el autorreconocimiento, la valoración de los saberes propios y la diversidad cultural del Macizo, la apropiación de la propuesta y proceso agroambiental, el fortalecimiento de aprendizajes y construcción del tejido social, el fortalecimiento de procesos organizativos, el conocimiento y el sentido identitario con el territorio, el desarrollo de planes de vida de los agrosembradores, el fortalecimiento de la soberanía alimentaria y el empoderamiento de líderes agroambientales. En sentido similar y con resultados análogos a los aquí expuestos, se encuentran las experiencias con fuerte enfoque agroecológico como la Escuela de cultura campesina para la defensa del territorio, el agua y las semillas criollas del Catatumbo, cuyas estrategias agroecológicas y ecológicas del campesinado de la zona de Campo Dos, Tibú, región del Catatumbo, Norte de Santander, evidencia cómo las comunidades inmersas en conflictos con el modelo de desarrollo inducido, el extractivismo y el propio estado colombiano logran generar procesos de resistencia y formación que persisten y se fortalecen. También, se ubican las experiencias de las Escuela de Formación Afronortecaucana y la Escuela Agroecológica y Territorial Manuel Quintín Lame las cuales representan un aporte a la construcción de paz, desde la región del sur occidente colombiano, reconocidas por las estrategias y las prácticas agroecológicas como perspectivas posibles. Estas iniciativas y estrategias dan cuenta de un escenario de fortalecimiento de la capacidad de agenciar el liderazgo de actores campesinos con discurso y prácticas agroecológicas para ganar terrenos con las comunidades, en estos propósitos las escuelas campesinas juegan un rol significativo y vital, aún y más representativo en contextos de violencia política y económica como el que sufre el campo caucano.

Las escuelas agroambientales, por tanto, constituyen una experiencia de educación rural con enfoque agroecológico de principio popular e informal, con base en epistemologías campesinas y saberes propios que orienta y lidera el intercambio de saberes, construcción de tejido social y fortalecimiento de prácticas a través de las FRAM. Asimismo, prima en las escuelas las metodologías populares (Fals, 1998), como las de campesino a campesino, investigación participativa, grupos de 
discusión y mapa parlante, estos métodos están centrados en el diálogo y reconocimiento del campesinado como portador de saberes, que han permitido no solo el empoderamiento y la apropiación del conocimiento y de saberes por parte de los campesino, sino, también que son capaces de generar respuestas y soluciones a problemáticas identificadas en el territorio.

Además, de ser una iniciativa campesina esta no cuenta con capacitadores $u$ orientadores, sino que, están lideradas por campesinos empoderados en el proceso de formación y que continúan desarrollando prácticas agroecológicas y se encuentran para intercambiar saberes entorno a problemáticas que los afectan. Las escuelas campesinas superan la noción de finca piloto, en tanto que, se constituyen en propuestas de defensa y arraigo territorial.

Por otra parte, en el discurso las escuelas agroambientales, en el CimA, se encuentran referencias al desarrollo maciceño sustentable, los encadenamientos de economías campesinas, indígenas y afros, al reconocimiento étnico y diversas formas de saber y hacer. Esto muestra cómo desde las concepciones agroecológicas y ecológicas se resignifican los discursos institucionales que promueven la agricultura convencional, desarrollo sostenible y el encadenamiento productivo, ejes fundamentales para una agricultura familiar fortalecida. Al igual que llo hacen la Escuela Territorial y Agroecológica Manuel Quintín Lame, en el Tolima, con su pedagogía que se basa en la educación popular que trasciende lo técnico y evoca la construcción y defensa del territorio, y La Escuela de cultura campesina para la defensa del territorio, el agua y las semillas criollas del Catatumbo, que promueve el reconocimiento del territorio, la cultura, los medios de vida y los recursos genéticos locales, así como, la defensa de los valores y elementos que dan soporte a la ruralidad campesina.

Se reconoce entonces en las escuelas campesinas un valioso espacio para el rescate de los saberes y conocimientos locales y la articulación de las organizaciones sociales, de la academia y las ONG. Las escuelas realizan un importante ejercicio político y de formación en la medida que da fuerza a las propuestas de defensa del territorio.

\section{Conclusiones}

Las escuelas campesinas mantienen, difunden y replican las apuestas agroambientales como propuesta política de las organizaciones sociales. Para el Cima una de las estrategias más significativa en el territorio fue la puesta en marcha de las escuelas agroambientales en el marco de la FRAM. Estas escuelas, en el territorio del macizo, 
permitieron evidenciar que hay otras formas de relacionarnos con la naturaleza y aprovechar la diversidad cultural y biológica de los territorios.

Las escuelas agroambientales lideran procesos de reivindicación del hacer campesino, su cultura y formas de producción, lo que se evidencia por medio de logros concretos como la recuperación de recetas, el trabajo familiar, la economía local y los saberes agros culturales. Lo anterior, favorece el fortalecimiento del campesino como sujeto de derecho, lo revindica y defiende el trabajo que se está liderando en Colombia, al ser reconocidos como sujetos politicos.

Estas iniciativas campesinas son fundamentales para fortalecer los elementos propios de la identidad campesina, en cuanto a la preservación de la riqueza agro cultural y la producción de alimento, teniendo como centro la familia, apuesta que fundamenta lo organizativo.

La escuela El Arraigo es una experiencia de gran valor para el CIMA, referencia obligada para el departamento de Cauca y que tuvo alcances internacionales. Esta refleja el trabajo local, el empoderamiento de líderes campesinos que resisten y persisten, en apuestas propias de reivindicación del ser campesino como sujeto de derecho y como poseedor de conocimiento y sabiduría necesaria para este mundo, que ha perdido su rumbo armónico en su relación con la naturaleza. Igualmente, es una exhortación del campesino sobre el uso de la hoja de coca que en su largo camino ha luchado por la reivindicación del uso tradicional, alimenticio y medicinal de esta planta.

El interés de conocer y visitar estas experiencias como escuelas campesinas es cada vez más marcado y necesario, frente a modelos de producción poco sustentables y, a largo plazo, insostenibles, que se presentan en los diversos territorios y no generan una solución a los campesinos, sino que, los somete a una dependencia sistemica de un paquete tecnologico o frente a un insumo externo, contario a esto la sistematizacion de las experiencias agroecologicos camposinas dan una esperanza concreta y contextualizadas a los territorios.

\section{Agradecimientos}

Agradecemos a los y las campesinas que lideran y mantienen las escuelas agroambientales en el macizo colombiano, como fincas de referencia agroambiental. A los gestores del Cima por conducir procesos de construcción de paz en los territorios. A Jimmy Rodriguez, Alex Fernandez, Olga Truque y Erney Ruiz por sus aportes a este capítulo. 


\section{Referencias}

Acevedo, A. (2011). Escuelas de agroecología en Colombia. La construcción e implementación del conocimiento agroecológico en manos campesinas. Trabajo presentado en el vi Encuentro Latinoamericano y del Caribe de Agricultura Ecológica, Cali. Recuperado de https://issuu.com/gestionde proyectos/docs/agrovida_y_sociedad_5

Altieri, M., y Toledo, V. (2011). La revolución agroecológica en América Latinarescatar la naturaleza, asegurar la soberanía alimentaria y empoderar a los campesinos. The Journal of Peasant Studies, 38(3), 587-612. Recuperado de https:// www.ucm.es/data/cont/media/www/pag-104576/3.\%20La\%20revoluci \%C3\%B3n\%20agroecol\%C3\%B3gica\%20en\%20Latinoam\%C3\%A9rica\%20 (M\%20iguel\%20Altieri\%20y\%20Victor\%20Toledo).pdf

Álvarez, S. (2009). Beyond NGO-ization? Reflections from Latin America. Development, 52(2), 175-184. Doi: https://doi.org/10.1057/dev.2009.23

Castrillón, F., y Fawcett, H. (coords.). (2017). Escuela de cultura campesina para la defensa del territorio, el agua y las semillas criollas del Catatumbo. Bogotá: Arfo Editores e Impresores S.A.s. Recuperado de http://www.semillas.org.co/es/ escuela-de-cultura-campesina-para-la-defensa-del-territorio-el-agua-y-lassemillas-criollas-del-catatumbo

Fals-Borda, O. (1998). Participación Popular: Retos del Futuro. Bogotá: ICFEs IEPRI - Colciencias.

Freire, P. (1973).¿Extensión o comunicación? La Conciencia en el medio rural. Mexico D.F.: Siglo XxI. Recuperado de https://grandeseducadores.files. wordpress. com/2015/07/extensic3b3n-o-comunicacic3b3n-la-conciencia-en-el-mediorural-1973.pdf

García-Frapolli, E., Toledo, V., y Martínez, J. (2007). Apropiación de la naturaleza por una comunidad Maya Yucateca: un análisis económico-ecológico. Revista Iberoamericana de Economia Ecológica, 7, 27-42. Recuperado de http:// www.academia.edu/14476251/Apropiaci\%C3\%B3n_de_la_naturaleza_por_ una_comunidad_Maya_yucateca_un_an\%C3\%A1lisis_econ\%C3\%B3micoecol\%C3\%B3gico

Grupo Semillas. (2015). Escuela Agroecológica y Territorial Manuel Quintín Lame. Investigación popular y transformación en la región del sur del Tolima. Bogotá: Arfo Editores e Impresores S.A.s. Recuperado de http://www.semillas. org.co/ es/escuelas-de-formacion/escuela-agroecol-2 
Grupo Semillas. (2017). Escuela Itinerante Afronortecaucana. Investigación popular para la transformación del territorio del norte del Cauca. Bogotá: Arfo Editores e Impresores S.A.s. Recuperado de http://www.semillas.org.co/es/escuelaitinerante-afronortecaucana-investigaci

Jara, O. (1994). Para sistematizar experiencias: una propuesta teórica y práctica. San José de Costa Rica: ALFORJA. Recuperado de http://www.fahce. unlp.edu.ar/ extension/Documentos\%20y\%20Ponencias/para-sistematizar-experienciasuna-propuesta-teorica-y-practica

Martínez, J. (2004). El ecologismo de los pobres, Conflictos ambientales y lenguajes de valoración. Barcelona: Editorial Icaria S.A.

Mejía, M. (2006). Agricultura y ganadería orgánicas a condiciones colombianas: retorno de los pobres al campo. Cali: Ediciones del autor.

Naredo, J. M. (2010). Raíces económicas del deterioro ecológico y social: más allá de los dogmas. $2^{\text {a }}$. ed. Madrid: Siglo XXI.

Perfetti, M. (2003). Estudio sobre la educación para la población rural en Colombia. Recuperadodehttp://www.red-ler.org/estudio_educacion_poblacion_rural_ colombia.pdf

Sevilla, E. (2006). De la sociología rural a la Agroecología. Barcelona: Editorial Icaria - Junta de Andalucía.

Toledo, V., y Barrera-Bassols, N. (2008). La memoria biocultural. La importancia ecológica de las sabidurias tradicionales. Barcelona: Icaria Editorial. Recuperado de http://era-mx.org/biblio/Toledo-_y_Barrera_2008.pdf

\section{Documentos anexos}

1. Documento de la Segunda Asamblea del Movimiento Social del Macizo colombiano

2. Documento Tierra y Territorio

3. Documento Hectárea Agroambiental: Un referente para la producción maciceña

4. Documento marco por Vida Digna en el Macizo colombiano y sur del Cauca

5. Entrevista a Líderes y liderezas campesinos Erney Ruiz, Alex Fernandez, Olga Truque, Cesar Willian Diaz.

6. Documento proyecto: encadenamientos productivos agroambientales 2002-2012

7. Plan de Vida, Agua y Dignidad. (Cima)

8. Plan de Desarrollo Educativo del Macizo Colombiano (CIMA)

9. Plan de Desarrollo Ambiental y Agropecuario del Macizo Colombiano y Sur del Cauca- PLADAMASUR. 
Capítulo 10

\title{
Gestión de la cadena de valor de café agroecológico en ciclo económico completo desde la economía social y solidaria en ASOPECAM - Tuluá, Valle del Cauca
}

Management of the agroecological coffee value chain in the complete economic cycle from the social and solidarity economy in ASOPECAM - Tuluá, Valle del Cauca

\author{
Álvaro Idárraga Quintero* \\ Gloria Inés Cárdenas Grajales**
}

\section{Cómo citar}

\begin{abstract}
APA
Idárraga, Á. y Cárdenas, G. (2019). Gestión de la cadena de valor de café agroecológico en ciclo económico completo desde la economía social y solidaria en ASOPECAM-Tuluá, Valle del Cauca. En Á. Acevedo-Osorio y N., Jiménez-Reinales (comps.). La agroecología. Experiencias comunitarias para la Agricultura Familiar en Colombia. (pp. 231-252). Bogotá: Corporación Universitaria Minuto de Dios-UNIMINUTO, Editorial Universidad del Rosario.
\end{abstract}

\section{Chicago}

Idárraga Quintero, Álvaro y Cárdenas Grajales, Gloria Inés. "Gestión de la cadena de valor de café agroecológico en ciclo económico completo desde la economía social y solidaria

* Red Comparte. alidarraga@yahoo.com

** Facultad Ciencias Administrativas y Desarrollo Rural. Corporación Universitaria Santa Rosa de Cabal - unisarc.gloria.cardenas@unisarc.edu.co 
en ASOPECAM-Tuluá, Valle del Cauca”. En La agroecología. Experiencias comunitarias para la Agricultura Familiar en Colombia, comps. Álvaro Acevedo-Osorio y Nathaly JiménezReinales. Bogotá: Corporación Universitaria Minuto de Dios-UnIMINUTO, Editorial Universidad del Rosario, 2019.

\section{MLA}

Idárraga Quintero, Álvaro y Cárdenas Grajales, Gloria Inés. "Gestión de la cadena de valor de café agroecológico en ciclo económico completo desde la economía social y solidaria en ASOPECAM-Tuluá, Valle del Cauca". En La agroecología. Experiencias comunitarias para la Agricultura Familiar en Colombia. En Á. Acevedo-Osorio y N., Jiménez-Reinales (comps.) Bogotá: Corporación Universitaria Minuto de Dios-UNIMINUTO, Editorial Universidad del Rosario, 2019, pp. 231-252.

\section{Resumen}

La Asociación de Pequeños Caficultores del corregimiento La Marina (ASOPECAM) es una organización que surge en 1993 con un grupo de familias campesinas que orientan su producción de café para negociar con este al comercio justo. Su trayectoria en la organización social y agroecológica es un referente a nivel nacional, porque basa su quehacer en reivindicaciones campesinas y comunitarias, a partir de procesos de organización, autonomía y toma de decisiones frente a sus sistemas productivos. El presente estudio tuvo como objetivo visibilizar los procesos que le han permitido a ASOPECAM consolidar su propuesta agroecológica, con base en la autosuficiencia alimentaria y la producción de café de alta calidad. Este se llevó a cabo utilizando una metodología de sistematización diseñada para documentar experiencias de agricultura campesina desde un análisis crítico, con el fin de obtener nuevos conocimientos que fortalezcan las iniciativas de otras organizaciones. El análisis se fundamentó en tres subsistemas: escalamiento de la experiencia agroecológica, economía social y solidaria en ciclo económico completo y modelo multiactor. Los resultados en el primer subsistema muestran los tres niveles de escalabilidad por los que ha pasado ASOPECAM: escalabilidad hacia dentro, escalabilidad hacia fuera y escalabilidad hacia lo alto; los cuales permitieron que la asociación de productores de café diera el paso a ser una organización social con autonomía en sus decisiones y en la gestión económica, bajo los principios de economía social y solidaria; en el subsistema dos, se identificaron las etapas del ciclo económico completo: producción, transformación, comercialización, financiación y reinversión social, lo mismo que las capacidades generadas para cada una de ellas, a partir de un modelo cíclico de organización social, basado en la relación directa con los consumidoress y los compradores del grano; en el subsistema tres, se identifica el modelo multiactor que ha apoyado la cadena de gestión de ASOPECAM y a los actores que han aportado a la ampliación de la escala agroecológica en economía social y solidaria. El estudio indica que, para la consolidación de ciclos económicos completos y el fortalecimiento de las cadenas de valor en agriculturas campesinas de base agroecológica, son necesarios elementos centrales que le dan sostenibilidad al proceso, como lo son 
la formación política, la autonomía en las decisiones, el seguimiento de los principios de la economía social y solidaria, la organización, la reinversión social y la calidad de los procesos.

Palabras claves: cadenas de valor, economia social y solidaria, escalabilidad, modelo multiactor.

\section{Abstract}

The Association of Small Farmers of La Marina municipality (ASOPECAM) is an organization that emerged in 1993 with a group of peasant families that guide their coffee production to negotiate fair trade with it. The trajectory of the association in social and agroecological organization is a reference at the national level, because the bases of the work on peasant and community demands, based on processes of organization, autonomy and decision-making in the face of the productive systems. The objective of this study was to make visible the processes that have allowed ASOPECAM to consolidate its agroecological proposal, based on food self-sufficiency and the production of high quality coffee. This was carried out using a systematization methodology designed to document experiences of peasant agriculture from a critical analysis, in order to obtain new knowledge that strengthens the initiatives of other organizations. The analysis was based on three subsystems: scaling of the agroecological experience, social and solidary economy in the complete economic cycle, and multi-actor model. The results in the first subsystem show the three levels of scalability that ASOPECAM has gone through: inward scalability, outward scalability and upward scalability; which allowed the association of coffee producers to take the step to be a social organization with autonomy in its decisions and economic management, under the principles of social and solidarity economy. In subsystem two, the stages of the complete economic cycle were identified: production, transformation, commercialization, financing and social reinvestment, as well as the capacities generated for each of them, based on a cyclical model of social organization, and on the direct relationship with consumers and grain buyers. In subsystem three, the multi-actor model that has supported the ASOPECAM management chain and the actors that have contributed to the extension of the agroecological scale in the social and solidarity economy is identified. The study indicates that, for the consolidation of complete economic cycles and the strengthening of value chains in agroecological-based peasant agriculture, central elements are necessary that give sustainability to the process, such as political training, autonomy in decisions, the monitoring of the principles of the social and solidarity economy, the organization, the social reinvestment and the quality of the processes.

Keywords: value chains, social and solidarity economy, scalability, multiactor model.

\section{Introducción}

En el marco de la agroecología y la economía campesina, la sistematización de experiencias y los relatos acerca de las mismas, sobre todo en organizaciones campesinas, se han centrado en su gran mayoría en mostrar las descripciones de los avances 
técnicos, políticos o sociales, dejando de lado los análisis económicos que permitan reconocer escenarios posibles de una economía mas acorde con los procesos agroecológicos; experiencias basadas en los principios de la economía solidaria y la construcción de cadenas de valor en Ciclo Económico Completo (CEC), desde la producción hasta la reinversión social.

Según Pérez, Etxezarreta y Guridi “la Economía Social reúne en su seno, principalmente, a tres entidades: cooperativas, mutualidades y asociaciones; consideradas tradicionalmente como el núcleo duro de la Economía Social” (2008, p. 1). También se refiere a entidades que "con funcionamiento y gestión democráticos e igualdad de derechos y deberes de los socios, practican un régimen especial de propiedad y distribución de las ganancias [...] para el crecimiento de la entidad y la mejora de los servicios a los socios y la sociedad" (Monzón, 2006 como se citó en Pérez et al, 2008, p. 3).

La relación entre economía solidaria y sostenibilidad ambiental se da en virtud de la diversidad de estudios que muestran la ruptura de la economía capitalista con los sistemas naturales y sus evidentes impactos: Con el reconocimiento de las fallas en el modelo económico y los problemas ambientales generados ha dado pie a la integración de la rama social y ambiental (Coraggio, 2002, como se citó en Figueroa y Castillo, 2013).

La economía y los sistemas financieros sociales representan dos de los doce campos de acción de la sustentabilidad y, se dan en las prácticas productivas y comerciales con base en la diversidad, la solidaridad, la equidad de los participantes y el consumo responsable, asimismo, en los mercados justos y orgánicos, al igual que, en la creación de cooperativas a escala local comunitaria, municipal o regional, en multiescalas y multiactores (Toledo y Ortiz-Espejel, 2014).

La sistematización realizada con ASOPECAM resalta los retos que las experiencias agroecológicas enfrentan en la búsqueda de escenarios económicos alternativos como la economía social y solidaria, donde se encuentran opciones viables para el fortalecimiento de la sostenibilidad, entendida esta última como:

el horizonte ético y conceptual, que va más allá de una estrategia de desarrollo. Es, sobre todo, una opción para aprender sobre la vida y el mundo. El principal objetivo del aprendizaje que queremos realizar debe ayudarnos a establecer relaciones armónicas entre los seres humanos y con la naturaleza, mientras realizamos nuestros sueños mas profundos y superamos los principales retos y desafíos del presente. Contribuir a la consolidación de alternativas de vida y desarrollo que 
superen las contradicciones escenciales ubicadas en la base de los desafíos y problemas estructurales de la región y el país nos exige buscar el mayor impacto y consistencia posible en los planes y proyectos, con resultados locales y regionales a corto, mediano y largo plazo. (Aguilar y Idárraga, 2017, p. 25).

El CEC en ASOPECAM visibiliza la autonomía y el control comunitario de un proceso que pasa de la producción agroecológica a la comercialización y, que se ha construído a partir de aprendizajes de carácter técnico, de gestión, de recursos físicos y financieros en un contexto de fuerte división del trabajo y de espacios públicos y privados (Red de Aprendizaje y Acción COMPARTE, 2017).

La economía social y solidaria, según Askunze (2013) “persigue construir relaciones de producción, distribución, consumo y financiación basadas en la justicia, cooperación, reciprocidad y la ayuda mutua" (p. 100) y contempla la equidad en todas las etapas del ciclo económico, desde la producción hasta la reinversión social, pasando por el consumo. Asimismo, ofrece:

algunos principios y nuevos enfoques alternativos frente al funcionamiento de la economía capitalista, propone iniciativas prácticas en todos los ámbitos del ciclo económico (financiación, producción, comercialización y consumo), colocando a las personas y, en general, a la sostenibilidad en el centro y como objetivo de su actividad. (p. 97).

Existen prácticas y herramientas de la Economía Social y Solidaria en todos los campos del ciclo económico de ASOPECAM, estas están basadas en criterios alternativos que alientan a la búsqueda de otras opciones para consumir, intercambiar, relacionarse y participar. Este ha sido el trasegar de la organización que, por años, ha tratado de escalar en las experiencias en un ejercico de aprendizaje y error, reduciendo cada vez más la curva de aprendizaje.

El presente estudio busca a través de un proceso de sistematización, documentar la experiencia de producción agroecológica con base en el ciclo económico completo y la economía social y solidaria, llevada a cabo por ASOPECAM entre los años 2001 a 2017, con el fin de realizar un análisis crítico de la misma y obtener conocimientos que sean útiles para el fortalecimiento de otras organizaciones de agricultura campesina, familiar y comunitaria.

Esta sistematización busca responder las siguientes preguntas: 
- ¿Se constituye Asopecam en un referente socio técnico de escalonamientos en economías alternativas y ciclo económico completo para la agricultura familiar, campesina y comunitaria en Colombia?

- ¿Cómo se expresan y experimentan en esta organización los procesos de escalabilidad basados en cadena de valor, en el marco de la economía social y solidaria como vías para alcanzar la sostenibilidad en todas las dimensiones de la agroecología?

- ¿Qué calidades y cualidades identifican a los diversos actores de economías alternativas basadas en la agroecología y, en el control y autonomía de las decisiones?

- ¿Qué implicaciones prácticas tiene para las economías campesinas, la búsqueda de alternativas económicas más sociales y solidarias en el que se puedan alcanzar niveles de control y autonomía para desarrollar el ciclo económico de un producto?

\section{Resultados}

ASOPECAM cuenta con una base social de 25 familias, son propietarios de la tierra con áreas entre $0.48 \mathrm{~h}$ y $13.4 \mathrm{~h}$ que, en total, suman $122 \mathrm{ha}$, en estos predios los campesinos y campesinas trabajan directamente. Según Idárraga y Sánchez el 0.9\% $(1.27 \mathrm{~h})$ del área total corresponde a monocultivo de caña y café, el $23 \%(3.16 \mathrm{~h})$ a pastos en monocultivo, el $46.6 \%(63.82 \mathrm{~h})$ a policultivos tradicionales en el que sobresalen los cafetales con sombrío y el $35.1 \%(47.97 \mathrm{~h})$ a potreros arborizados, que cumplen la función de producir forraje para los animales (2016, pp. 103-104).

La producción agroecológica en ASOPECAM tiene un fundamento importante en la autonomía alimentaria, se destacan tres categorías de producción: especies forestales, especies para la autosuficiencia alimentaria y especies productoras de semillas propias; todas ellas asociadas al agroecosistema cafetero. La asociación sustentan la estabilidad ecosistémica en la diversidad de especies no solo para uso productivo sino también silvestre (figura 1). El 85\% de las fincas adopta una relación de respeto y uso protector de la tierra que favorece la conservación natural y el flujo de biodiversidad sin detrimento del factor productivo.

La autosuficiencia alimentaria se fundamenta en el trabajo organizativo, lo que garantiza independencia, soberanía y uso de semillas criollas. Las fincas con mayor producción de alimentos son administradas por mujeres, algunas de ellas cabeza de hogar, quienes cultivan en promedio 11 especies de importancia para la alimentación y pertenecen al grupo de mujeres "Sembradoras de Vida“; participan del manejo del 
cultivo del café y su postcosecha, así como en los cultivos de hortalizas, pancoger y cuidado de especies menores; transforman productos para el autoconsumo y la venta, tales como: cacao (Theobroma cacao), cúrcuma (Curcuma longa), café (Coffea arabica), vino de naranja, champús, pomadas, mermeladas, miel, hortalizas, verduras, entre otros (Idárraga y Sánchez, 2016).

Figura 1. Categorías de productos obtenidas por las familias de ASOPECAM.

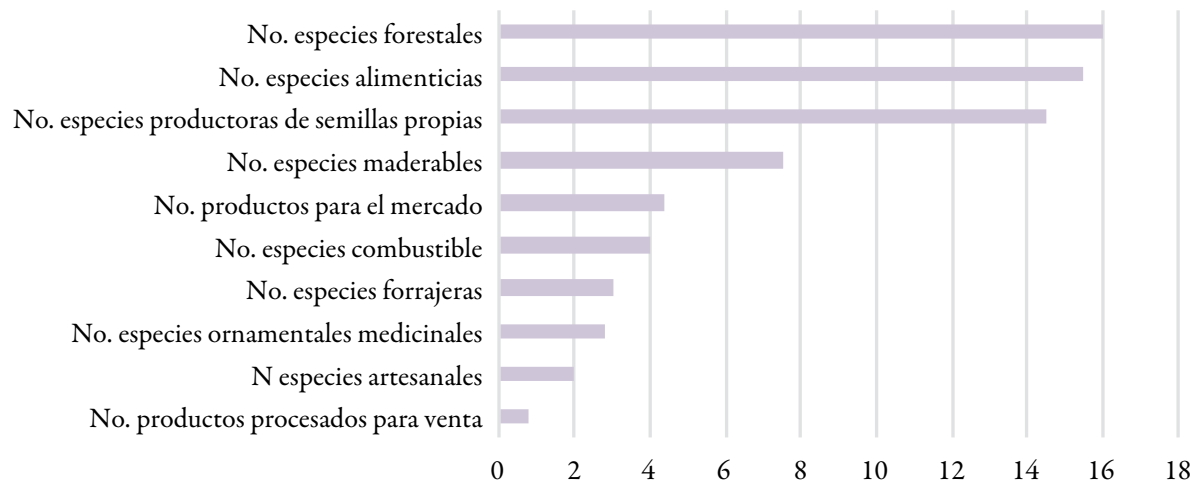

Fuente: tomada de Agricultura familiar ambientalmente sustentable y económicamente sostenible: estudio de caso de la asociación de pequeños productores de café (Asopecam), por Idárraga y Sánchez (2016).

En el año 2001, ASOPECAM asume la agroecología como una opción para mitigar el impacto negativo que la producción convencional de café había generado. Fue la primera decisión importante, con la cual se inicia una etapa de transición a nivel organizativo, técnico y comercial que condujó al fortalecimiento administrativo y técnico de los sistemas de finca y la puesta en marcha de las estrategias de comercialización de café.

Luego de explorar diversas alternativas de comercialización de café en verde (materia prima de exportación), en el año 2003, se construye una nueva opción para producir, comercializar y obtener excedentes con la iniciativa del comercio justo, FLO (Fairtrade Labelling Organizations International) ${ }^{1}$, lo que facilitó la estructuración de un Sistema Interno de Control. Estos fueron los primeros pasos de la comercialización de café orgánico que llevaron a la gestión de mercados especializados en

${ }^{1}$ Organización global que trabaja para asegurar un mejor trato para los agricultores y trabajadores. Fairtrade es un enfoque alternativo al comercio convencional y se basa en una asociación entre productores y consumidores, un producto con el sello Fairtride indica que ha cumplido los estándares de Comercio Justo. 
la expectativa de mejorar los precios en medio de la coyuntura de la crisis cafetera mundial de los años 1990 hasta el de hoy.

Con los retos del mercado del grano y los bajos precios de este, se vió la necesidad y urgencia de generar agregación de valor y avance hacia el Ciclo Económico Completo (CEC) del café; los cambios en este sentido fueron muy rápidos y se cometieron muchos errores. Este contexto, sumado a los retos por construir un proyecto alternativo basado en principios agroecológicos, fue encauzando la vinculación de manera natural y paulatina de los principios de la economía social y solidaria.

Al inicio, la asociación no contaba con un nivel de organización favorable para producir y vender café; los márgenes de precios de los cafés orgánicos empezaron a tener un decrecimiento, debido al aumento de su oferta a nivel mundial y, en especial, en países latinoamericanos. Razón por la cual, en el año 2008, la asociación realiza un análisis sobre la importancia de vincular a los jóvenes de la asociación a los procesos que se estaban adelantando, en relación con la transformación y comercialización de café, al mismo tiempo, se insistía en la importancia de tostar café con el fin de darle un valor agregado y vincular a los hijos de los asociados ${ }^{2}$. Hicieron los primeros ensayos y todo lo que sacaron, lo vendieron, ese primer café procesado tuvo como nombre de marca ASOPECAM, cuatro meses mas tarde, presentaron un proyecto al programa de Oportunidades Rurales del Ministerio de Agricultura y Desarrollo Rural, que fue encaminado al montaje de la planta de procesamiento, hoy el nombre de marca del café es Tinamú ${ }^{3}$.

Figura 2. Logotipo de asociación ASOPECAM.

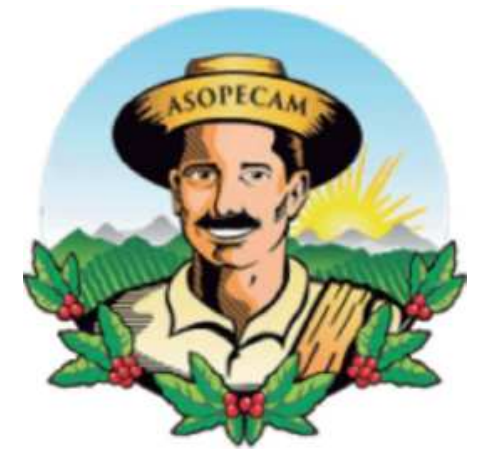

Fuente: ASOPECAM

\footnotetext{
${ }^{2}$ Euclides Narváez - asociado Asopecam.

${ }^{3}$ Tinamú es el nombre de un ave reconocida en la región donde se encuentran las fincas de las familias asociadas a ASOPECAM.
} 
Con el montaje de la planta, la asociación pasó de un ejercicio de producción y comercialización de café, a uno más complejo que involucró la transformación, la gestión de mercados y la generación de capacidades en las personas y en la organización, con el fin de acceder a mercados alternativos mas especializados.

Desde el año 2008 hasta la fecha, ASOPECAM ha pasado de produciry comercializar el 100\% de café pergamino seco orgánico, a transformar y comercializar el $40 \%$ como café tostado (molido y en grano), lo cual representa un avance importante en la cadena de valor y la construcción de CEC del café. La agregación de valor y la transparencia en la compra ha favorecido el precio de venta del café de los asociados, en aproximadamente un $30 \%$, por encima del precio del mercado convencional.

Figura 3. Tienda de café Garittea y empaque café Tinamú.
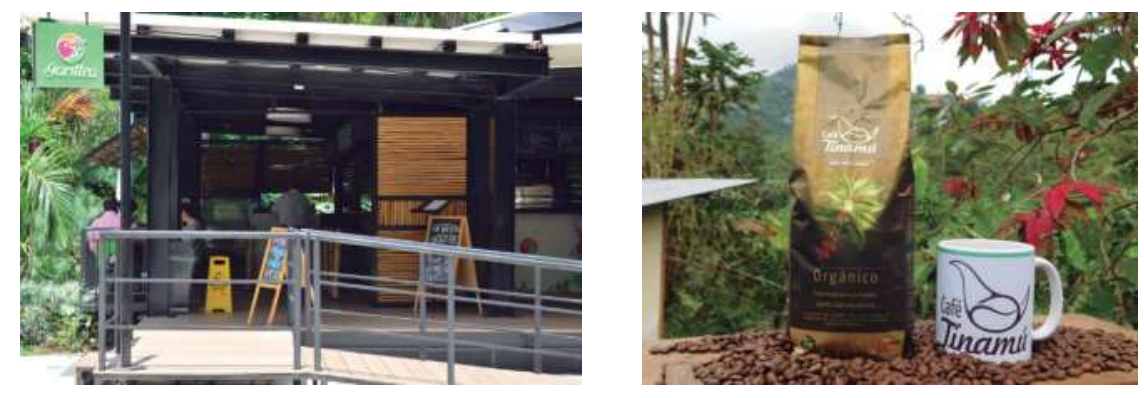

Fuente: archivo ASOPECAM.

Este sobreprecio, que hace parte de la reinversión social en CEC en economía social y solidaria, es complementado con otros servicios como asistencia técnica, programas sociales, fondos para compra de materia prima, mejoramiento de los sistemas productivos, diversificación de la producción, mejoramiento de vivienda e infraestructura en las fincas.

La comercialización de café con características diferenciadas, desde la organización social para la producción, se ha dado de manera directa, por medio de ventas al detal o exportaciones a países como Dinamarca, Alemania, Estados Unidos y Chile. Igulmente, se han realizado también acuerdos de compra y venta con otras organizaciones como Garittea, ACOC, Nuevo Futuro, Fair Trade; estas iniciativas, a diferentes escalas, se propician como parte de la gestión de mercados.

ASOPECAM participa desde hace 17 años en el mercado campesino agroecológico que hace parte de la Red de Mercados Agroecológicos del Valle del Cauca, en el cual han participado con iniciativas individuales y colectivas de transformación 
de productos, tales como: cacao, cúrcuma, vino de naranja, champús, pomadas, mermeladas, miel, entre otros.

Garittea, como empresa social y nueva iniciativa de comercialización, nace en el año 2017 y se ha constituido en un enorme reto para la gestión comercial de ASOPECAM. Desde allí, se están explorando alternativas de generación de ingresos que permitan una remuneración más justa del trabajo de las familias; lo cual ha supuesto avanzar en la cadena de valor, de tal manera que, se pueda construir un precio propio, superando la volatilidad y la especulación del mercado, dificultades surgidas por la crisis del café desde la década de 1990.

Nos referimos a [una empresa social] aquellas entidades organizadas en torno a bienes en propiedad común y formas de organización colectivas para la consecusión de objetivos comunes que se rigen por normatividades propias [...] es el caso de organizaciones orientadas a la producción, a la conservación y aprovechamiento de recursos naturales y la defensa de patrimonios colectivos. (Toledo y Ortiz-Espejel, 2014, p. 35).

La capacitación, participación y formación de los jóvenes de la asociación, en temas relacionados con el café y los sistemas finca, se constituyó en una de las acciones que se adelantan para lograr el relevo generacional, lo cual ha dado como resultado que, actualmente, nueve de estos jóvenes, hijos de asociados, estén vinculados laboralmente, gracias a la asociación, en funciones administrativas y de planta en tareas del procesamiento:: acopio, tostión, muestreo, catación y coordinación de planta. La asociación también promueve otras iniciativas en los jóvenes, relacionadas con la apicultura, la compra del café, el procesamiento, la promotoría en fincas, la gestión económica y administrativa.

Los hitos ${ }^{4}$ mas relevantes en la historia de ASOPECAM, que han contribuído a la escalabilidad de esta experiencia, han sido:

- La apuesta colectiva de los asociados por construir el proyecto de vida familiar y de organización comunitaria bajo los principios de la agroecología.

\footnotetext{
${ }^{4}$ Se consideran hitos, porque han sido acontecimientos puntuales y significativos que han marcado momentos de avance importante en el fortalecimiento de la autonomía y el control de las decisiones en los procesos agroecológicos y de economía social y solidaria en ASOPECAM; permiten verificar el progreso de la agroecología y la construcción de escenarios económicos alternativos, acordes con la agroecología.
} 
- El precisar el manejo político, administrativo, técnico y financiero de la institución en el gremio cafetero, en este caso de la Cooperativa de Caficultores del Centro del Valle del Cauca.

- La autonomía que toma la asociación, junto con otras organizaciones campesinas, frente a la representatividad que lideraba en ese momento la Coordinación Colombiana de Comercio Justo (CCJ), gestando la Iniciativa de Comercio Justo para Colombia, una instancia que hoy en día representa realmente los intereses de los pequeños productores.

- La participación en el Movimiento Agroecológico Latinoamericano (MAELA) a nivel Colombia y continental.

- La progresividad del cic, que comienza con la comercialización de café ecológico sin procesar, hasta contar con una marca propia, dotación de equipamiento para el procesamiento de café, generación de habilidades en los jóvenes para las acciones de tostión y catación, gestación de pequeños grupos organizativos de mujeres y jóvenes dentro de la organización y vinculación con los mercados de café a nivel nacional e internacional. Apuestas que han exigido el accionar de la organización, retos importantes a nivel de decisiones políticas y económicas que los han motivado a reforzar procesos de autonomía, pero también de calidad, organización, negociación y toma de decisiones.

- La conformación en el año 2017 de una empresa social en la que participan la Asociación de Caficutores Orgánicos de Colombia (ACoc-Café sano) y el Instituto Mayor Campesino (IMCA) con nombre Garittea, que busca la comercialización en tasa, de café de orígen campesino.

En la sistematización realizada con ASOPECAM, se encuentra cómo el tema económico ha sido difícil y complejo. Ellos insisten en la importancia de la formación política, ya que, de lo contrario, cualquier ejercicio económico convencional "puede desbaratar la propuesta agroecológica”. Javier Rivera, presidente de la asociación que "hay que trabajar mucho el tema de formación política, porque de lo contrario, las personas se van para una opción convencional, con el fin de recibir mejores rendimientos económicos". El caso de esta organización demuestra que los principios de la economía social y solidaria pueden ser la clave para armonizar políticamente, la agroecología con las relaciones económicas. 


\section{Discusión}

\subsection{Escalabilidad de la experiencia agroecológica}

Escalabilidad o escalamiento ${ }^{5}$ denota un proceso gradual que, en el caso de AsoPECAM, inicia en el control social de las decisiones, a partir de las cuales la agroecología empieza a ser la columna vertebral de la organización y, la economía impulsa la movilización hacia su gestión, sobre la base de principios de economía social y solidaria.

En ASOPECAM la escalabilidad tiene varias miradas: la primera, escalabilidad hacia adentro, en el sentido de cómo gradualmente se va profundizando en los principios de la agroecología desde los valores familiares y los procesos de reconversion de los sistemas finca; la segunda, escalabilidad hacia lo alto, representada por el paso de productores de café, sin control sobre su organización ni sobre la comercialización, es una organizacion autónoma en sus decisiones, lo que ha permitido el fortalecimiento de la agroecología y la gestión económica alternativa; y la tercera, escalabilidad hacia lo amplio, que representa el esfuerzo colectivo por ampliar el horizonte de la agroecología a través de la economía social y solidaria, con incidencia en políticas públicas y populares, explorando diversas rutas del ciclo económico.

En estas miradas de escalabilidad, el hilo tira hacia dos lados: de un lado, hacia la profundización de las relaciones de armonía con la naturaleza, el alimento y la producción del otro, hacia relaciones de la producción con el mercado, en escenarios de equidad por la remuneración justa del trabajo y la reciprocidad con todos los actores involucrados.

Casos de escalamiento en América Latina se evidencian en la experiencia del EDAC (Equipo de Desarrollo Agropecuario Cajamarca) en Perú y el CET (Centro de Educación y Tecnología) en Santiago de Chile, donde hay experiencias de agricultores campesinos en la generación de valor agregado a productos de la agricultura familiar y la gestión económica de los mismos.

Las estrategias de escalonamiento de estas dos experiencias han buscado "apoyar la transformación de productos en función de hacerlos más apropiados para un

\footnotetext{
${ }^{5}$ Escalamiento hace referencia a las condiciones necesarias y suficientes que debe tener un programa o un proyecto para pasar de un ámbito territorial menor, a otro de más amplia incidencia; por ejemplo, de lo local a lo subregional y de lo subregional a lo regional. Se aplica por analogía también al radio de influencia o incidencia de organizaciones y de las dimensiones de las regiones/territorios de referencia de un proyecto. Esta noción de escalamiento es una concretización del principio ético y moral de que "el bien entre más universal es mejor" (Aguilar y Idárraga, 2017, p. 26)
} 
mercado mayor y de cubrir los eslabones necesarios para lograr el acceso a ellos” (Ranaboldo y Vanegas, 2007, p. 41).

\subsection{Economía Social y Solidaria (ESS) en ciclo económico completo (CEC): principios, autonomía, capacidades}

En las decisiones y actuaciones económicas y políticas de ASOPECAM se expresan los principios de la economía social y solidaria, a partir de: una visión de empresa para el beneficio social, la calidad de vida y el desarrollo de las personas. Esta actividad económica está orientada a la producción de bienes y servicios beneficiosos, la generación de empleos dignos, el fomento a la autonomía en la gestión, la participación, la corresponsabilidad, las consideraciones de género, la promoción de la sostenibilidad medioambiental, el desarrollo de actividades empresariales sin ánimo de lucro y en los excedentes para la reinversión social (Askunse, 2013; Carta de principios de la Economía Social, 2002, como se citó en Pérez, et al., 2008).

La Ess ha estado presente en todo el ciclo del café: en la producción con la decisión de que sea un café orgánico y agroecológico con condiciones de tasa diferenciadas respecto de otros; en la transformación, mediante la adquisición y dotación de la planta de procesamiento y la generación de habilidades individuales y colectivas para profesionalizar el ciclo, por medio de la formación y empleo de jóvenes campesinos para el relevo generacional; en la comercialización, mediante el logro de una relación directa con los clientes en escenarios de comercio local, nacional e internacional en los cuales se ha resignificado la relación de cliente - consumidor desde las economías alternativas; en la reinversión social, decidiendo de manera consensuada, la destinación de los excedentes en la mejora de los procesos y la calidad de vida de los asociados.

En ASOPECAM siempre ha estado presente el ejercicio político, tanto a nivel interno como externo. A nivel interno, al asumir decisiones autónomas como la apuesta por la agroecología y haberse apartado de la institucionalidad cafetera para alcanzar el control del CEC del café; es así como, desde el proceso de autonomía fue brotando el aspecto de la comercialización. A nivel externo, con la participación, desde al año 2004, en el MAELA lo que ha sido fundamental para la incidencia en políticas públicas relacionadas con la agroecología a nivel local, nacional y continental.

Un elemento importante de continuidad y profundización de la autonomía fue la determinación colectiva de que la gestión económica no fuera subsidiada, 
encaminando las fuerzas y potencialidades de la asociación, a generar experiencias económico-productivas agroecológicas, desde una perspectiva de sostenibilidad.

Los primeros momentos de la producción, tanto de la autonomía alimentaria como del café se cofinanciaron con fondos concursables estatales y de ONG; posteriormente, al consolidarse la etapa de comercialización, se generando ingresos y, con ello, puntos de equilibrio, esto permitió reinvertir los excedentes con el fin de evitar aportes de terceros. Estos eventos condujeron a que, cada vez más, la iniciativa fuera autosostenible, a la par, se generaron estructuras organizativas de reinversión, finanzas, participación y gobernanza en las cadenas de valor (Red de Aprendizaje Comparte, 2017). En la actualdiad, ninguna de las etapas del CEC ha sido delegada, si bien han participado diferentes actores que han aportado recursos de diferentes fuentes, la asociación sigue teniendo bajo su control los procesos de la cadena de valor del café y la autonomía alimentaria.

\subsection{Reinversión social}

Un componente que amerita mayor profundización y análisis, en otros estudios, es el de la reinversión social de las utilidades, puesto que es en el contexto de la economía social y solidaria donde se verifica si todo el esfuerzo de la cadena de valor es compensado con la generación de mejores condiciones sociales, ambientales y políticas al interior de la organización; el cual, también puede ser medido en determinado momento, por el nivel de escala del proceso.

\subsection{Capacidades y calidad de procesos}

El camino del fortalecimiento de las capacidades para desarrollar relaciones efectivas en los procesos de negociación y comercialización, con participación en las decisiones comerciales y organizacionales, ha sido recorrido por la asociación desde la perspectiva de la agroecología, la autonomía alimentaria, la producción, la comercialización y la reinversión; siempre, sobre la base del compromiso social y ambiental, pero también, desde el criterio de que los productos y los procesos se desarrollen bajo estándares de calidad.

La generación de capacidades siempre ha estado presente en cada etapa de la cadena de valor; los asociados se han cuestionado sobre la forma cómo producen, cómo transforman, cómo se financian, cómo se relacionan y cómo reinvierten los excedentes, de tal manera que su participación no se circunscribe, única y exclusivamente a la producción y a la gestión de mercados. Puesto que, el "éxito" no se mide 
sola y simplemente por la utilidad y rentabilidad o por el mayor valor agregado, sino, por el logro de principios de reciprocidad, intercambio equitativo, flujo de bienes y servicios en los que, además, "circulan conocimientos que posibilitan la generación de códigos de inteligibilidad comunes“ (Toledo y Ortíz-Espejel, 2018, p. 35).

Para complejizar la cadena de valor del café, con fines de mejora económica gradual, ha sido sustancial mantener la cualidad agroecológica al igual que los estándares que llevan a la alta calidad final del café: lo primero genera autonomía y soberanía alimentaria; lo segundo, produce ingresos para mejorar las condiciones de vida de las familias y viabilizar procesos. Esta calidad también se deriva de lo que exige el mercado y el cliente, teniendo en cuenta que, el mercado de lo alternativo es limitado y por ello requiere un esfuerzo adicional. Un rasgo importante del "cliente" de los mercados alternativos es que se vincula a partir de la confianza, del sentido social y ambiental del proyecto, además de la calidad en los procesos.

Se constituye en una especie de asesor solidario, convirtiéndose en empresario social, que trasciende de la relación de negociación lineal de producto-precio, a una relación de cercanía que acompaña, no solo la etapa de logística del mercado, sino los procesos inmersos en la calidad; en este sentido, se resignifican los conceptos y las condiciones de cliente, consumidor y/o comprador.

En lo personal la gente empieza a valorar su autoestima... que ha sido agredida por el mismo sistema, cuando los productores muestran su producto se sienten orgullosos y la gente reconoce el trabajo y el valor que las personas tienen en el proceso... ellos se han dado cuenta que, a pesar de no haber tenido estudios académicos, ellos son muy buenos en el hacer; este valor agregado es incuantificable. (Javier Rivera, presidente ASOPECAM).

El proceso de control de la cadena de valor del café ha sido soportado, paulatinamente, en la generación de habilidades y capacidades en las personas para asumir, de manera idónea, cada una de las etapas del ciclo económico; es decir, desde la producción hasta la reinversión social de utilidades. La tabla 1 señala las capacidades individuales y colectivas que se han desarrollado en cada una de las etapas del cEc. 
Tabla 1. Ciclo económico completo en ASOPECAM. Capacidades individuales y colectivas.

\begin{tabular}{|c|c|}
\hline Etapa & Capacidades individuales y colectivas \\
\hline \multirow[t]{9}{*}{ Producción } & Sistema de control interno asumido por jóvenes de la organización. \\
\hline & Protocolos de calidad de café. \\
\hline & Batería técnica agroecológica para sistemas sostenibles de producción. \\
\hline & Mejoramiento de cultivos. \\
\hline & Inclusión de variedades de alta calidad de café. \\
\hline & Sistemas de planificación de familia-finca. \\
\hline & $\begin{array}{l}\text { Técnicas de clasificación, lavado, fermentado, secado y almacenamiento de café para la alta } \\
\text { calidad. }\end{array}$ \\
\hline & Conocimiento sobre normas de certificación ecológica. \\
\hline & Promotoría campesina agroecológica. \\
\hline \multirow[t]{7}{*}{ Transformación } & $\begin{array}{l}\text { Conocimiento y práctica de estándares de calidad física de café para la compra y } \\
\text { procesamiento. }\end{array}$ \\
\hline & Dotación y manejo de equipos de trilla, clasificación y tostión de café. \\
\hline & Tostión de café y protocolos de procesamiento. \\
\hline & Catación de café. \\
\hline & Barismo. \\
\hline & Estandares para empaque y almacenamiento. \\
\hline & Procesos de trazabilidad y control de riesgos. \\
\hline \multirow[t]{5}{*}{ Comercialización } & Desarrrollo de marcas propias y etiquetados. \\
\hline & Ofertas de calidades por demanda. \\
\hline & Gestión de mercados locales, nacionales e internacionales. \\
\hline & Normatividad y legislación para comercialización de café verde y tostado en grano y molido. \\
\hline & Adquisición de licencias de comercialización y exportación de café. \\
\hline \multirow{3}{*}{$\begin{array}{l}\text { Financiación y } \\
\text { reinversión social }\end{array}$} & Formulación y gestión de proyectos. \\
\hline & Consensos sobre inversiones. \\
\hline & Sistema de finanzas éticas (grupos de ahorro y crédito y fondos rotatorios). \\
\hline \multirow[t]{2}{*}{ Consumo } & Estrategiás para formación de consumidores de café orgánico y de alta calidad. \\
\hline & Base de datos de consumidores. \\
\hline
\end{tabular}

Fuente: elaboración propia.

Para la generación de capacidades, ASOPECAM ha construido un modelo de gestión cíclico desde el cual opera la autonomía alimentaria y el control del CEC en escenarios de economía social y solidaria (figura 4).

Las potencialidades desarrolladas por la asociación, en el control de la cadena de valor en CEC, han orientado sobre el tipo de capacidades qué se deben generar, quiénes las deben desarrollar y para qué desarrollarlas. La calidad de los procesos y productos del café pasa por la generación de capacidades de las personas y en la 
Figura 4. Modelo de gestión de ciclo económico completo en ASOPECAM.

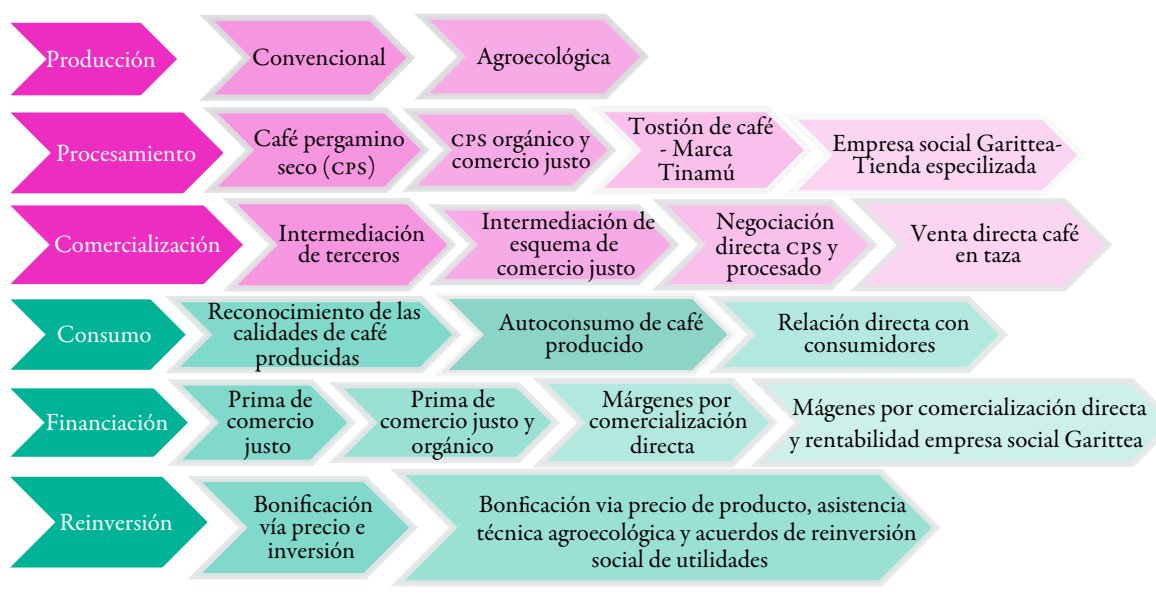

Fuente: elaboración propia con base en información información recibida de la organización.

organización, proceso que va creciendo en espiral en la medida que se va complejizando la gestión de la cadena de valor.

\subsection{Relaciones - Mercados}

Del análisis de la experiencia, se evidencia gran diversidad de formas de relación, tanto a nivel interno como externo. En ASOPECAM no existe una única forma de mercado y de relacionarse con el consumidor, prima un criterio esencial para diferenciarse de otras formas convencionales de mercado, y es la relación directa con el consumidor, a través de ferias, mercados campesinos, intercambio de semillas, acuerdos de compra-venta de café, tanto al detal como en exportaciones y alianzas, como empresa social, con otras organizaciones como ACOC, IMCA y ASOPECAM, con estás últimas, creando lo que hoy es Garittea.

Para desenvolverse en las relaciones comerciales, propias de los mercados alternativos ${ }^{6}$, se destacan tres elementos novedosos que dan cuenta de la importancia que tiene la asociación como referente en estos procesos: el primero, es el paso hacia

\footnotetext{
6 “ ¿Existen este tipo de empresas sociales?, ¿son tan alternativas como las describen?, ¿perduran en el tiempo tras crisis internas y externas? Ciertamente, son muchos los interrogantes que pueden surgir a la hora de plantear la creación y sostenimiento de estas empresas de carácter alternativo en un ambiente capitalista nada favorable para su promoción. Sin embargo, existen. Lo vienen haciendo desde hace décadas, con innumerables ejemplos de buenas prácticas y, a menudo también, con dificultades y fracasos. Pero es una corriente en crecimiento que, aun en tiempos de crisis, encuentra cada vez más personas, especialmente jóvenes, que quieren hacer empresa y ganarse la vida de otra manera a la convencional, o que piensan que colectivamente hay más posibilidades de generar empleo digno y
} 
la calidad de los procesos y productos que acompaña una cualidad agroecológica y campesina; el segundo, es el control de toda la cadena de valor desde la producción hasta la reinversión social, y el tercero; es el vínculo con empresas o empresarios sociales, comprometidos con la asesoría y los principios de la organización.

Una experiencia maestra en este tipo de organizaciones ha sido CAPELTIC, empresa social y solidaria, conformada por familias indígenas tseltales de Chiapas, México, que funciona bajo los principios de justicia social, defensa del territorio, propiedad social y eficiencia empresarial. Su actividad se fundamenta en la producción de café orgánico, asimismo, promueve sinergias entre productores, equipos de trabajo, comunidades universitarias y clientes. Además de la venta de café, lo que busca es ser una ventana intercultural que invite a nuevas formas de consumo y espacios de trabajo.

En el año 2010, CAPELTIC logró cerrar el ciclo económico entre la producción de café y la venta en taza para asegurar la construcción de un precio propio, posteriormente, esta organización ha dado orígen a otras empresas solidarias que hacen parte del mismo proceso: cooperativa de mujeres, grupo de cooperativas y empresas de economía social y solidaria, microfinanciera con el fin de prestar servicios financieros a las familias tseltales y apertura de tres tiendas en campus universitarios. (www.capeltic.com.co, julio de 2018, consultado 21 de julio 2018)

Otro caso similar, ha sido la Asociación Provincial de Cafetaleros Solidarios (APROCASI) en Cajamarca, Perú, que pasó de la producción convencional de café a aumentar la diversidad de sus fincas con fines de conservación ambiental y cafetales con sombrío; modificó toda su organización para la producción de café orgánico de alta calidad, con destino a mercados orgánicos ecoamigables, implementando un sistema de control interno y alianzas con el sector público para el desarrollo rural de la provincia.

El caso de APROCASI rescata el valor de las capacidades para aprender, como eje central de la transformación de las economías campesinas, y aunque, "la expansión de estas iniciativas de modernidad en la pequeña agricultura encuentra resistencias" (Torres, 2009, p. 25) son experiencias que reflejan las diferentes realidades agrarias de América del Sur.

satisfactorio, o que ante el cierre de empresas en las que trabajaban se plantean procesos de recuperación”. (Askunse, 2013, pp. 109). 


\subsection{Modelo multiactor: actores que han hecho parte de la consolidación del CEC}

La cadena de valor del café que gestiona ASOPECAM se desarrolla de manera integral y, en cada eslabón, hay una riqueza de aprendizajes y actores presentes. La ampliación de la escala de la agroecología, paralelo a la de economía social y solidaria, ha exigido el aporte de un número significativo de actores, que desde diferentes ámbitos e intereses, se han hecho presentes en distintos momentos e instancias claves del proceso.

Cada uno de ellos ha realizado aportes en cuanto a conocimientos, elementos de profesionalización, recursos para mejorar capacidades, alianzas y acuerdos, estas alternativas motivan la apuesta a ser sostenibles. Algunos de esos actores han sido: institucionalidad pública, organizaciones no gubernamentales, organizaciones sociales, empresa privada, cooperación internacional y universidades. En la tabla 2 se reseñan los actores y sus aportes.

Tabla 2. Actores que han contribuido a la cadena de valor del café en ASOPECAM.

\begin{tabular}{|c|c|c|}
\hline Tipo de actor & Actor & Aportes de los actores \\
\hline $\begin{array}{l}\text { Organizaciones no } \\
\text { gubernamentales }\end{array}$ & $\begin{array}{l}\text { IMCA, POCASUR (Chile), Red de Mercados } \\
\text { Agrecológicos del Valle del Cauca, Red } \\
\text { Comparte. }\end{array}$ & $\begin{array}{l}\text { Acompañamiento técnico, económico } \\
\text { y metodológico. Intercambio con } \\
\text { experiencias internacionales. }\end{array}$ \\
\hline Movimientos & $\begin{array}{l}\text { MAELA, Iniciativa de Comercio Justo, } \\
\text { Federación Campesina. }\end{array}$ & $\begin{array}{l}\text { Formación e incidencia política en espacios } \\
\text { nacionales y continentales. }\end{array}$ \\
\hline Academia & $\begin{array}{l}\text { Universidad Nacional de Colombia, sede } \\
\text { Medellín; Pontificia Universidad Javeriana, } \\
\text { sedes Cali y Bogotá; Universidad del Valle, } \\
\text { sede Tuluá. }\end{array}$ & $\begin{array}{l}\text { Investigación y estudios para la gestión } \\
\text { de mercados, aportes para la estructura } \\
\text { de acompañamiento técnico, pasantía de } \\
\text { estudiantes y voluntariado de jóvenes. }\end{array}$ \\
\hline Empresas & $\begin{array}{l}\text { Cooperativa Batsil Maya (México), } \\
\text { ECONEXos, FEDERACAFÉ, CAFEXCOop, } \\
\text { COSURCA, Exportaciones García y Aranda, } \\
\text { Café Mulatos, CAFICENTro, Coffee } \\
\text { Roasting, Tierra Verde, Café Miu, Equiri } \\
\text { La Equitativa. }\end{array}$ & $\begin{array}{l}\text { Acompañamiento en estántares de calidad, } \\
\text { comercialización, gestión y logística de } \\
\text { mercados. }\end{array}$ \\
\hline $\begin{array}{l}\text { Institucionalidad } \\
\text { pública }\end{array}$ & $\begin{array}{l}\text { Secretaría de Agricultura de Tuluá, cvc. } \\
\text { Minagricultura (proyecto Alianzas } \\
\text { Productivas y Oportunidades Rurales), } \\
\text { Acción Social de la Presidencia. }\end{array}$ & $\begin{array}{l}\text { Financiamiento de proyectos estratégicos } \\
\text { para mejora de la producción, el } \\
\text { procesamiento y gestión de marca. }\end{array}$ \\
\hline $\begin{array}{l}\text { Cooperación } \\
\text { internacional }\end{array}$ & $\begin{array}{l}\text { Fondo Internacional de Desarrollo } \\
\text { Agricola (FIDA) }\end{array}$ & Financiación \\
\hline $\begin{array}{l}\text { Organizaciones } \\
\text { sociales }\end{array}$ & $\begin{array}{l}\text { Asociación de Caficultores Orgánicos de } \\
\text { Colombia (ACOC - Café Sano) }\end{array}$ & $\begin{array}{l}\text { Aliado estratégico para comercialización y } \\
\text { gestión de la calidad. }\end{array}$ \\
\hline
\end{tabular}

Fuente: elaboración propia. 
La dinámica de relación multiactor en ASOPECAM está muy referenciada por las diferentes redes en las que directa o indirectamente participa, tales como: el MAELA, la Iniciativa de Comercio Justo y Símbolo de Pequeños Productores (SPP), la Red de aprendizaje y acción Comparte (a través del IMCA) y la Red de Mercados Agroecológicos del Valle del Cauca.

En los escenarios territoriales de gestión económico-productiva, de corte alternativo, es importante constatar que su consolidación, sostenible y escalable, solo es posible como resultado de procesos de construcción de alianzas y de la suma de compromisos y esfuerzos conjuntos.

El avance de condiciones sólidas de sostenibilidad en el CEC, basado en Ess, en este tipo de organizaciones, hace necesaria la implementación de alianzas e iniciativas comunes que fortalezcan la institucionalidad regional (pública y privada), profundizando en el manejo ético de los asuntos locales y brindando oportunidades de crecimiento humano y espiritual a todos los miembros (individuales y colectivos) de la institucionalidad regional. Estos mismos desafíos han sido inherentes a la gestión de ASOPECAM y se han ido solventado con la gradualidad que ha exigido cada momento del proceso. (Aguilar e Idárraga, 2017).

\section{Conclusiones}

- La experiencia de ASOPECAM se convierte en un referente importante de procesos agroecológicos ligados a la economía social y solidaria, no solo por la forma como gradualmente sus asociados han pasado de proveedores de materia prima (café excelso), a procesadores de café tostado, sino por los procesos de escalonamiento que le han permitido desenvolverse en el campo de las relaciones comerciales y los mercados alternativos de café. En esa transformación se han conjugado tres elementos: el paso hacia la calidad de los procesos y productos sin dejar de lado la agroecología y la economía campesina como sus fundamentos; el control de toda la cadena de valor desde la producción hasta la reinversión social y; el vínculo con empresas o empresarios sociales, comprometidos con la asesoría y los principios de la organización.

- En la experiencia de Asopecam se pueden inferir tres tipos de escalabilidad: hacia adentro, en el sentido de cómo gradualmente se va profundizando en los principios de la agroecología y desde los valores familiares y los procesos de reconversión de los sistemas finca; hacia lo alto, desde el tránsito de productores de café, sin control sobre su organización ni sobre 
la comercialización, a una organizacion autónoma en sus decisiones; hacia lo amplio, en el esfuerzo colectivo por ampliar el horizonte de la agroecología a través de la economía social y solidaria.

- En la consolidación de ciclos económicos completos y en el fortalecimiento de cadenas de valor en las agriculturas campesinas; se destacan tres elementos centrales para darle sostenibilidad a estos procesos: la formación política, el seguimiento decidido de los principios de la ESS acordes con la agroecología y la cualificación de los procesos.

- La resignificación de las economías campesinas en una lógica de Ess, armónica con la agroecología, implica dentro del factor multiactor, pasar de ser unos productores con autonomía de decisión frente a su proceso productivo y formas comercialización, a ser organizaciones sociales que construyan relaciones con otros actores, y al mismo tiempo, trascender del concepto lineal productor - producto - comprador, a una relación que acompaña los procesos. Se resignifican los conceptos y las condiciones de los actores y patrones, hacia los mercados alternativos.

\section{Agradecimientos}

Especialmente a los campesinos y campesinas de la Asociación de Pequeños Caficultores de La Marina (ASOPECAM), a Javier Rivera Laverde y Dayana Rivera Rivas por su apertura y disposición en poner al servicio de otros las experiencias, los aprendizajes del camino recorrido.

A Álvaro Acevedo por la confianza depositada en el espíritu que guía nuestros caminos de conocimiento de la agroecología y las economías campesinas.

\section{Referencias}

Aguilar, J. A., y Idárraga, A. (2017). Ruta metodológica para la construcción de alternativas económico-productivas de impacto local y regional. Cali: Pontificia Universidad Javeriana. Recuperado de http://desarrollo-alternativo.org/wp-content/ uploads/2018/04/MetodologiaDT.pdf

Askunze, C. (2013). Mas allá del capitalismo: alternativas desde la economía solidaria. (Documento Social 168). El Portal de la Economía Solidaria, 97-116. Recuperado de https://www.economiasolidaria.org/sites/default/files/reaslibra ry/ attachments/economia_solidaria_askunze.pdf

Figueroa, J., F., y Castillo, D. (2013). Conceptualizaciones ambientales en la economia: la búsqueda de una Economía Solidaria Ambiental. viII Conferencia Regional ACI 
Américas, Unimed Brasil, Sistema осв y Servicio Nacional de Aprendizagem do Cooperativismo, Sao Pablo, Brasil. Recuperado de https://www.aciamericas. coop/IMG/pdf/6._sostenibilidad_julian_figueroa.pdf

Idárraga, Á., y Sánchez, J. J. (2016). Agricultura familiar ambientalmente sustentable y económicamente sostenible: estudio de caso de la asociación de pequeños productores de café (Asopecam). En A. J. Acevedo-Osorio y J, MartínezCollazos (comps.), La agricultura familiar en Colombia. Estudios de caso desde la multifuncionalidad y su aporte a la paz (pp. 97-120). Bogotá: Ediciones Universidad Cooperativa de Colombia - Corporación Universitaria Minuto de Dios - Uniminuto, Agrosolidaria. doi: http://ediciones.ucc.edu.co/index. $\mathrm{php} / \mathrm{ucc} / \mathrm{catalog} / \mathrm{book} / 33$

Pérez, J.C., Etxezarreta, E., y Guridi, L. (marzo, 2008). ¿De qué hablamos cuando hablamos de Economía Social y Solidaria? Conceptos y nociones afines. ECO CRI. XI Jornada de Economía Crítica, Bilbao, España. Recuperado de http:// www.caritasburgos.es/documentos/documentacion/12-Econom\%C3\% Ada\%20social\%20y\%20solidaria.pdf

Ranaboldo, C., y Vanegas, C. (2007). Escalonando la agroecología: procesos y aprendizajes de cuatro experiencias en Chile, Cuba, Honduras y Perú. México D.F.: Plaza y Valdez Editores - Centro Internacional de Investigaciones para el Desarrollo (IDRC).

Red Comparte. (2017). Memorias experiencia de construcción de cadena de valor de ciclo económico completo. México, 2 al 7 de octubre de 2017; documento interno. Toledo, V. M., y Ortiz-Espejel, B. (2014). México, regiones que caminan hacia la sustentabilidad: Una geopolitica de las resistencias bioculturales. México D.F.: Universidad Iberoamericana Puebla. Recuperado de http://www.cidesca.org. $\mathrm{mx} /$ archivos/E2-2.pdf

Torres, F. (2009). Organización de pequeños agricultores gestiona su innovación. En: Iniciativas empresariales en el área rural. LEISA. Revista de Agroecología, 25(2), 22-25. Recuperado de http://www.leisa-al.org/web/images/stories/ revistapdf/vol25n2.pdf 


\title{
Epílogo
}

\author{
Álvaro Acevedo Osorio* \\ Jenny Paola Cruz Suárez** \\ Julia Katharina Waeger ${ }^{* * *}$
}

Las dos últimas décadas, en la historia de los programas de Desarrollo Rural, ha ganado mayor relevancia el interés por la integración de distintas disciplinas y formas de conocimiento, para impulsar así una mejor comprensión de los múltiples factores que constituyen la base de la sustentabilidad.

La Agroecología emerge como una ciencia y práctica para la sustentabilidad, integrando disciplinas y conocimientos. En este libro fueron presentadas nueve experiencias agroecológicas desarrolladas por agricultores familiares, construidas con pasión, entrega, compromiso, solidaridad y convicción de que las transformaciones se pueden generar localmente, desde el interior de las familias y sus organizaciones.

Estas experiencias, seleccionadas y analizadas a partir del enfoque de los "nichos sociotécnicos" han superado la etapa inicial de novedad y están impactando a comunidades rurales a escala regional. Han surgido desde los actores locales en respuesta a la inoperancia y negligencia de las políticas y programas del régimen dominante, para el cual el impacto ambiental o las condiciones de vida de las familias agricultoras, no están en el centro de interés de sus planes.

Los casos analizados permiten comprender con suficiencia cómo ocurren estos cambios, cuáles han sido los factores desencadenantes de las transformaciones

* Facultad de Ciencias Agrarias. Universidad Nacional de Colombia. aacevedoo@unal.edu.co

** Facultad de Ciencias. Universidad de Quebec, Montreal, Canadá. cruz.jenny_paola@courrier. uqam.ca

*** Instituto de Manejo y Tecnología de Recursos en los Trópicos y Subtrópicos. Universidad de Ciencias Aplicadas, TH Köln, Colonia, Alemania. julia.waeger@gmail.com 
generadas en cada caso y cómo la creatividad de los involucrados, su capacidad de adaptación, los procesos de capacitación y ciertos niveles de intervención facilitan las transiciones hacia la sustentabilidad. Se destacan en esta parte final, algunas consideraciones, a modo de conclusión, sobre las experiencias analizadas a la luz de los enfoques sugeridos.

\section{El potencial de la agroecología para fortalecer los procesos de transición hacia la sustentabilidad}

Por su origen conceptual interdisciplinario, transdisciplinario, participativo y orientado a la acción (Méndez, Bacon y Cohen, 2013), la agroecología se constituye en el mejor enfoque para promover la agricultura familiar hacia una agricultura más sustentable. Desde cualquiera de sus enfoques, como ciencia, enfoque técnico metodológico y movimiento social (Wezel et al., 2009), la agroecología puede contribuir al fortalecimiento de la agricultura familiar, ya que las experiencias de base agroecológica logran potenciar sistemáticamente su carácter multifuncional, al promover funciones productivas como, la diversificación productiva, la integración de componentes que cierran ciclos y generan encadenamientos complejos al interior del sistema creando insumos y productos de manera cíclica. Asimismo, coopera con el medio ambiente, por medio de funciones ambientales como incentivar la biodiversidad, proteger suelos y aguas, incrementar los ciclos biológicos y sinergias dentro del cultivo. Finalmente, promueve funciones sociales como la organización, participación, gestión del conocimiento, fortalecimiento de la red familiar y comunitaria e incidencia política.

La intensificación de las funciones ambientales y productivas está en la base de todas las experiencias analizadas. Desde las familias del altiplano boyacense que producen agroecológicamente para la seguridad y soberanía alimentaria, hasta la organización ASOPECAM que destina su café certificado al mercado internacional. Todas las experiencias comienzan por fortalecer la relación de co-producción con la naturaleza, a partir de reconocer y proteger el potencial de los ecosistemas que ocupan.

En efecto, la vía para concretar la transformación agrícola, es mediante procesos graduales de transición agroecológica, que comienzan con la aplicación de prácticas de restauración a nivel de finca, especialmente, rotaciones de cultivos, compostajes, cultivos asociados, entre otros, que mejoran la estabilidad, productividad y resiliencia del sistema productivo (Nicholls, Altieri y Vásquez, 2016) y disminuyen la dependencia de insumos externos. Esta transición avanza con el rediseño del agroecosistemas locales y regionales para que funcionen sobre procesos ecológi- 
cos (Gliessman, 2002). Los procesos avanzados de transición agroecológica involucran a las comunidades en la transformación productiva de territorios, el cambio en aspectos éticos y el fortalecimiento de procesos organizativos y sociopolíticos.

Esta gradualidad en la transición agroecológica está ampliamente evidenciada en los procesos vividos en estas nueve experiencias, que muestran como los procesos de transformación basados en el enfoque agroecológico, comienzan con acciones de ajuste tecnológico dentro de las fincas; pero este mejoramiento productivo obliga a transcender a aspectos de organización y comercialización a escalas cada vez más amplias, para hacer que este esfuerzo de mejoramiento productivo tenga las repercusiones sociales y financieras que están en las expectativas de los productores familiares.

La biodiversidad y agrobiodiversidad se constituyen en elementos recurrentes que facilitan la intensificación de las funciones de producción y, con esta, la mayor diversidad de productos para el autoconsumo y los mercados. Los recursos de agrobiodiversidad son centrales en experiencias como la Red de Semillas Libres, APACRA y las comunidades productoras de gallinas criollas en el sur del Tolima, ya que estos recursos genéticos constituyen su base productiva, por esta razón, se evidencia la dependencia esencial a estos por parte de algunos productores.

Simultáneamente, funciones sociales como la organización, también es característica a todas las experiencias descritas. Altos niveles de organización permiten que estas innovaciones agroecológicas sean ideadas, adaptadas, fortalecidas y protegidas, facilitando que alcancen grados de madurez y escalamiento pertinentes a sus procesos, ratificando con ello su consistencia para responder a las expectativas de las comunidades y la generación de bienestar. Otras funciones sociales que se han originado por la agroecología, incluyen los procesos de formación escolar en la experiencia del CIMA, la financiación autogestionada de ASPROINCA, el acceso a esquemas de comercio internacional justo en ASOPECAM o a circuitos cortos de comercialización directa entre productores y consumidores en REDMAC.

\section{Experiencias agroecológicas como nichos sociotécnicos.}

Utilizar el concepto de los nichos de innovación sociotécnica como eje transversal de análisis representa una valiosa oportunidad para entender y fortalecer la agricultura familiar. De un lado, permite identificar y visibilizar iniciativas, que durante largos periodos de tiempo, han venido desarrollando y consolidando los agricultores familiares y que les permiten mejorar sus sistemas a nivel técnico, al tiempo que cumplen funciones en múltiples dimensiones, como la ambiental, social y cultural, entre otras. Por otro lado, el enfoque permite captar la complejidad del contexto en el que operan 
las iniciativas, identificar los retos y dificultades a las que se ven enfrentados los agricultores familiares para ampliar su nicho y difundir sus innovaciones.

Como lo señalan Ortiz, Vilsmaier y Acevedo-Osorio (2018), las innovaciones nacen, casi siempre, en respuesta a las deficiencias estructurales de los regímenes dominantes, de manera que el uso de este marco conceptual permite, al considerar la agricultura familiar como un nicho de innovaciones agroecológicas prometedoras, visibilizar aspectos más profundos como la alineación del nicho con elementos externos, como el movimiento campesino que le brinda un marco ideológico de base a las alternativas. Igualmente, la conceptualización en función de los nichos sociotécnicos permite traer al centro de las discusiones, sobre la agricultura familiar, la necesidad de análisis más profundos acerca de las innovaciones técnicas y sociales y, la manera como pueden ser traducidas en el ámbito sociopolítico para que se lleve el mensaje a audiencias más amplias y se facilite la expansión del nicho y la difusión de las prácticas que lo alimentan.

Entre más innovaciones existan y sean soportadas a diferentes niveles, más presión se ejercerá sobre el régimen y, se abre así paso a una reconfiguración más profunda hacia la sustentabilidad.

\section{Agroecología para fortalecer la Agricultura Familiar}

Desde la campaña del año Internacional de la Agricultura Familiar en 2014, declarada por la ONU, tanto el término como los sistemas de producción de los agricultores familiares, a pequeña escala, aumentaron en el grado de reconocimiento nivel mundial. Esto permitió que no sólo se posicionará esta categoría socio-política, sino que se resaltará los diferentes atributos y expectativas vinculadas a la agricultura familiar que pueden contribuir al desarrollo sostenible y que deben estar en el corazón del discurso (Dufurnier, 2014; FAO, 2014; Toader y Roman, 2015). Aspectos como la contribución a la soberanía alimentaria y el clima global, el desarrollo económico, la generación de empleo e ingresos, el aumento de la productividad y biodiversidad, entre otros, (Graeub et al, 2015; Van der Ploeg, 2017) hacen parte del debate relacionado con la agricultura familiar y sus potencialidades transformadoras de la sociedad.

Este vínculo entre la agricultura familiar y el desarrollo sostenible está mediado esencialmente por propuestas agroecológicas. Según la FAO 
los agricultores familiares son las personas que tienen las herramientas para practicar la Agroecología. Ellos son los guardianes reales del conocimiento y la sabiduría necesaria para esta disciplina. Por lo tanto, los agricultores familiares de todo el mundo son los elementos claves para la producción de alimentos de manera agroecológica. (2018).

Entonces, la conexión entre la Agricultura Familiar y la agroecología no es nueva, sino que, ha estado presente en el debate mundial sobre la relevancia de la agricultura familiar, el que ha permitido reconocer que estas distintas formas de agricultura tradicional, alrededor de todo el mundo, hacen una contribución sustancial al desarrollo sostenible global (Van der Ploeg, 2017). No obstante, para muchos de estos núcleos familiares, las condiciones de pobreza y marginalidad en que viven deben ser catalogados como inadmisibles por la sociedad, lo que hace urgente volver la mirada sobre esta categoría social y garantizar que estas familias vivan dignamente y, tengan los soportes necesarios para que puedan cumplir con las múltiples funciones que sus sistemas de producción proveen a la sociedad global. Las experiencias reseñadas en este libro evidencian cómo las familias rurales tienen la invaluable capacidad de reconfigurar sus procesos productivos, organizativos, financieros, sociales, en un contexto de autocuidado, no solo de sí mismos, sino de sus comunidades, los ecosistemas y la sociedad. Entre los aspectos centrales que se deben garantizar para el cuidado de los agricultores familiares, se incluyen:

- Construir una visión positiva de las áreas rurales, con perspectivas educativas y laborales para los jóvenes.

- Restablecer servicios públicos de extensión rural centrados en la propuesta agroecológica con estrategias de sensibilización, acompañamiento integral, capacitaciones y métodos concretos para aplicar o re-ajustar permanentemente la propuesta agroecológica.

Las experiencias presentadas en este libro se constituyen en referentes importantes para construir futuros programas que fortalezcan las organizaciones de agricultores familiares en el país.

Los gobiernos y las políticas internacionales deben corresponder al fomento de la agricultura familiar y su potencial hacia la Sustentabilidad, creando un entorno favorable para ello. Convenios del comercio libre, empresas multinacionales o también la ingeniería genética representan adversidades y altos riesgos para la 
agricultura familiar (Rossett, 2000). Al mismo tiempo, la agricultura familiar no se debe percibir como una solución romántica, sino, concretamente valorarla por su viabilidad económica, productiva y ambiental. El cambio climático requiere sistemas resilientes como los que promueve la agricultura familiar que se ven fortalecidos por la propuesta agroecológica.

Por otra parte, el acceso a la tierra es central. El recurso tierra es cada vez más limitado por razones de herencia, que disminuye la extensión o también por el asíllamado acaparamiento de tierras por empresas extranjeras (Van der Ploeg, 2009). Democratizar el acceso a la tierra, es dar espacios de maniobra a los agricultores familiares; al no hacerlo, los atributos y expectativas de la agricultura familiar se convierten en "amenazas serias” para la permanencia de las familias en la agricultura (Van der Ploeg, 2017).

La agroecología, respecto a los retos de la agricultura familiar, se enfrenta con muchos desafíos todavía, pero al mismo tiempo es cada vez más reconocida por los múltiples beneficios que genera para el desarrollo sostenible. Para productores en pequeña escala, la agroecología se constituye en una propuesta alternativa que les permite una nueva conciencia y valoración de su labor, autonomía, relaciones con los mercados y sistemas productivos que afianzan las fincas diversificadas.

Claramente, la agroecología con respecto a la agricultura familiar es mucho más que la conservación de ecosistemas y la soberanía alimentaria, porque los movimientos sociales y los procesos de incidencia política que promueven ayudan de manera global al fomento de la sustentabilidad (Rosset, 2012). Sin embargo, esta sustentabilidad debe construirse desde la misma finca. La masificación de la propuesta agroecológica a nivel de finca asegura un grado de transformaciones paulatinas a mayores niveles de sustentabilidad en la sociedad.

\section{Referencias}

Dufurnier, M. (2014). Agriculturas familiares, fertilidad de los suelos y sostenibilidad de los agroecosistemas. En F. Hidalgo, F. Houtart y P. Lizárraga (eds.), Agriculturas campesinas en Latinoamérica: propuestas y desafíos pp. 55-64. Editorial IAEN. Recuperado de https://cpalsocial.org/documentos/213.pdf

Gliessman, S (2002). Agroecología: procesos ecológicos en agricultura sostenible. Costa Rica: Turrialba. Recuperado de https://biowit.files.wordpress.com/2010 /11/ agroecologia-procesos-ecolc3b3gicos-en-agricultura-sostenible-stephen-rgliessman.pdf 
Graeub, B., Chappell, M., Wittman, H., Ledermann, S., Kerr, R., y Gemmill-Herren, B. (2015). The state of family farms in the world. World Development (87), 1-15. doi: https://doi.org/10.1016/j.worlddev.2015.05.012

Méndez, V. E., Bacon, C. M., y Cohen, R. (2013). La agroecología como un enfoque transdisciplinar, participativo y orientado a la acción. Revista Agroecología, 8(2), 9-18. Recuperado de https://revistas.um.es/agroecologia/article/view /212061

Nicholls, C. I., Altieri, M. A., y Vásquez, L. (2016). Agroecology: principles for the conversion and redesign of farming systems. Journal of Ecosystem and Geography, 5: 1-8. doi:10.4172/2157-7625.S5-010

Organización de las Naciones Unidas para la Alimentación y la Agricultura-FAO. (2014). Agricultura familiar en América Latina y el Caribe. Recomendaciones de politica. S. Salcedo y L. Guzmán (eds.). Santiago: FAO. Recuperado de http:// www.fao.org/docrep/019/i3788s/i3788s.pdf

Organización de las Naciones Unidas para la Alimentación y la Agricultura-FAO. (2018). Plataforma de conocimientos sobre agricultura familiar. Agroecología y agricultura familiar. Recuperado de http://www.fao.org/family-farming/the mes/agroecology/es/

Ortiz, W., Vilsmaier, U., y Acevedo-Osorio, Á. (2018). The diffusion of sustainable family farming practices in Colombia: an emerging sociotechnical niche? Sustainability Science, 13(3), 829-847. doi: https://doi.org/10.1007\%2Fs11625 $-017-0493-6$

Rosset, P. (2000). The multiple functions and benefits of small farm agriculture in the context of global trade negotiations. Development, 43(2),77-82. doi: https:// doi.org/10.1057/palgrave.development.1110149

Toader, M., y Roman, G. V. (2015). Family farming. Examples for rural communities development. Agriculture and agricultural science procedia, 6, 89-94. doi: https://doi.org/10.1016/j.aaspro.2015.08.043

Van der Ploeg, J. D. (2009). Peasant agriculture. En R. Kitchin y N. Thrift (eds.), International encyclopedia of human geography (pp. 108-113). Doi: https://doi. org/10.1016/B978-008044910-4.00894-4

Van der Ploeg, J. D. (2017). The importance of peasant agriculture: a neglected truth. Wageningen, Netherlands: Wageningen University and Research. Recuperado de http://edepot.wur.nl/403213

Wezel, A., Bellon, S., Doré, T., Francis, C., Vallod, D., y David, C. (2009). Agroecology as a science, a movement and a practice. A review. Agronomy for Sustainable Development, 29(4), 503-515. doi: https://doi.org/10.1051/agro/2009004 



\section{Autores}

\section{Álvaro Acevedo Osorio}

Ingeniero Agrónomo de la Universidad de Caldas (Manizales); magister en Agroecología y Desarrollo Rural Sostenible de la Universidad Internacional de Andalucía (España) y Doctor en Agroecología de la Universidad Nacional de Colombia. Cogestor y director de la Escuela Granja Agroecológica sos (Armero - Tolima). Actualmente es profesor asistente e investigador del departamento de Desarrollo Rural y Agroalimentario de la Facultad de Ciencias Agrarias de la Universidad Nacional de Colombia y profesor del programa de Especialización en Agricultura Familiar de uniminuto (Bogotá). Miembro de la Red Nacional de Agricultura Familiar, RENAF. Sus temas de interés son Agroecología, Agricultura Familiar, Extensión y Educación Rural, Agricultura Sustentable.

\section{Tarsicio Aguilar Gómez}

Ingeniero Agrónomo de la Universidad Nacional de Colombia, sede Medellín. Miembro de la Red Colombiana de Agricultura biológica ReCAB - Antioquia, Actualmente coordinador de la RECAB. Participa en el movimiento Agroecológico de América latina y el caribe maELA, en la Red Nacional de Agricultura Familiar RENAF, en la Campaña semillas de Identidad y redes de semillas libres de Colombia, en la Red de Economía solidaria de Antioquia, La Alianza por la Biodiversidad en Colombia, entre otras, donde impulsa procesos agroecológicos, de economía solidaria y el rescate de semillas criollas y nativas, y el establecimiento de sistemas participativos de garantía de calidad de la producción ecológica y de la calidad de semillas criollas y nativas.

\section{Gustavo Adolfo Alegria Fernandez}

Ingeniero Agropecuario Universidad del Cauca; Especialista gestión de proyectos; Especialista nutrición animal; Magister en Agroecología-Universidad Internacional Andalucía (España); Candidato a Doctor en Medio Ambiente 
y sociedad - Universidad Paulo de Olavide (España). Investigador junior y par académico reconocido por Colciencias; actualmente docente Universidad del Cauca; coordinador e investigador Centro de investigación CICAFICUlTURA componente agroecología; docente asesor - Universidad Indígena MISAK; Asesor técnico Comité de Integración del Macizo Colombiano CIMA; docente asesorUniversidad Autónoma Indígena Intercultural UAIIN-CRIC, miembro de la Red Gestión Territorial para el Desarrollo Rural Sustentable (México); temas de interés: Agroecología, Soberanía Alimentaria, Extensión Rural, Educación Popular, diseño de sistemas de producción sustentable.

\section{Arlex Angarita Leiton}

Campesino con formación como promotor en agroecología. Psicólogo Social Comunitario de la UnAD y Magister en Educación del Instituto Tecnológico de Estudios Superiores de Monterrey (México). Se desempeñó como instructor y director de la Escuela Granja Agroecológica sos (Armero - Tolima). Se ha desempeñado como asesor técnico-pedagógico en varias organizaciones, instituciones y entidades que desarrollan procesos sociales, comunitarios, educativos y agroecológicos rurales en Colombia. Ha sido docente, investigador y líder de proyección social en el programa de ingeniería agroecológica de UNIMINUTO en la sede principal. En la actualidad es el coordinador de la Especialización en Agricultura Familiar en UNIMINUTO. Sus temas de interés son Agroecología, Agricultura Familiar, Educación Rural y Psicología Rural.

\section{Diego Iván Ángel Sánchez}

Ingeniero agrónomo con Especialización en Agroecología, Maestría en Ciencias agrarias línea de investigación suelos y Doctorado en Agroecología de la Universidad Nacional de Colombia sede Palmira. Actualmente profesor asociado en la misma universidad y sede adscrito al departamento de Ciencias Biológicas, Facultad de Ciencias Agropecuarias, Coordinador e investigador del Doctorado y Grupo de Investigación en Agroecología. Experiencia profesional en actividades con ONG y ов en Desarrollo Rural alternativo. Miembro de la Sociedad Científica Latinoamericana de Agroecología (socla) y de la Red Nacional de Agricultura Familiar. Temas de interés Agricultura Familiar Agroecológica, investigación participativa, servicios ecosistémicos, buen vivir, cambio climático. 


\section{Carlos Arturo Aristizábal Rodríguez}

Administrador de Empresas de la Universidad Católica de Pereira; Especialista en Administración de la Universidad EAfIT (Medellín); estudiante de Doctorado en Agroecología en la Universidad Nacional de Colombia Sede Palmira; profesor de las especializaciones en Gerencia de Empresas Agropecuarias y Rurales y en Derecho Agrario de la Universidad de la Amazonia (Florencia); miembro de la Sociedad Científica Latinoamericana de Agroecología; miembro del Comité Regional de Organizaciones de Agricultura Ecológica y Comercio Justo del Valle del Cauca y de la Red Nacional de Agricultura Familiar, en representación del Grupo de Investigación en Agroecología de la Universidad Nacional de Colombia Sede Palmira.

\section{Cielo Esperanza Baez Mojica}

Agricultora de Anaime, Cajamarca - Tolima. Administradora financiera y estudiante de Licenciatura en ciencias Naturales y Educación Ambiental de la Universidad del Tolima; actualmente se desempeña como administradora de la Asociación de Productores Agroecológicos de la Cuenca del Río Anaime (APACRA); sus temas de interés son la agroecología, educación ambiental, emprenderismo y turismo rural sostenible.

\section{Gloria Inés Cárdenas Grajales}

Administradora de Empresas Cooperativas, Especialista en Agroecología Tropical Andina - UnISARC (Santa Rosa de Cabal), Magister en Sociedades Rurales - Universidad de Caldas. Profesora asociada e investigadora de la Facultad de Ciencias Administrativas y Desarrollo Rural y de la Especialización en Agroecología Tropical Andina - UnisARC . Líder del Grupo de Investigación en Estudios Rurales contextualizados al Territorio. Miembro de la Red Nacional de Agricultura Familiar RENAF, de la Red Nacional de Extensión Rural RENER y de la Red de Estudios Rurales RER. Sus temas de interés son: Ruralidad, Territorio, Enseñanza y Educación para la Agroecología y la Ruralidad, Investigación Participativa, Desarrollo Rural y Comunitario.

\section{Fernando Castrillón Zapata}

Ingeniero Agrónomo de la Universidad Nacional de Colombia (Medellín); especialista en Gerencia Ambiental de la Escuela Superior de Administración Pública. Hace parte del equipo de trabajo de la Corporación Grupo Semillas coordinando estrategias de articulación y formación orientada a la defensa y promoción de derechos territoriales y alternativas de vida digna para las comunidades de pueblos 
indígenas, afrodescendientes y campesinos del sur del Tolima y norte del Cauca, el Pacífico y los Santanderes.

\section{Neidy Lorena Clavijo Ponce}

Profesora investigadora en la Facultad de Estudios Ambientales y Rurales de la Pontificia Universidad Javeriana. Lidera la línea de investigación Agroecología e Innovación Rural Participativa. Ingeniera Agrónoma de la ESPOCH en Ecuador, Maestría en Agricultura Ecológica y especialización en Desarrollo y Extensión Rural de CATie, Costa Rica. Candidata a doctora en Agroecología por la Universidad Nacional de Colombia. Hizo parte del Centro Internacional de la Papa (CIP) en Quito y coordinó el Programa Andino de Innovación Tecnológica Participativa para Colombia a través de CORPOICA. Consultora de organismos multilaterales e integrante de redes internacionales relacionadas con sus áreas de investigación

\section{Astrid Ximena Cortés Lozano}

Ingeniera en Agroecología y especialista en Gerencia Social de la Corporación Universitaria Minuto de Dios -uniminuto, magister en Biología Aplicada de la Universidad Militar Nueva Granada, y candidata a Doctora en Agroecología de la Universidad Nacional de Colombia. Es la Directora de Investigaciones de la Gerencia de Desarrollo Rural de Uniminuto. Ha desarrollado varios fertilizantes biológicos que aportan a la producción sostenible de especies agroalimentarias. Actualmente trabaja en temas relacionados con la agricultura familiar, campesina y comunitaria, especialmente en el abordaje de la gestión social del conocimiento tradicional de Colombia, pedagogías otras y ecofeminismo.

\section{Jenny Paola Cruz Suárez}

Bióloga egresada de la Universidad Militar “Nueva Granada” (Bogotá) y magister en Ciencias Ambientales de la Universidad de Quebec en Montreal (UQAM), Canadá. Actualmente es candidata a Doctora en Ciencias Ambientales en la UQAM. Miembro del Instituto de Ciencias Ambientales ISE-UQAM y del grupo de investigación en responsabilidad social y desarrollo sostenible de la Escuela de Ciencias de la Gestión ESG-UQAM. Sus áreas de interés son la agricultura familiar, el desarrollo rural sostenible y la agroecología. 


\section{Mauricio de Jesús García Álvarez}

Ingeniero Agrónomo de la Universidad Nacional de Colombia - Sede Medellín; magister en Desarrollo Rural de la Pontificia Universidad Javeriana. Actualmente trabaja con SWISSAID Colombia en la Coordinación de la Campaña Semillas de Identidad; con experiencia de más de 20 años asesorando proyectos productivos agroecológicos con comunidades indígenas, campesinas y afrodescendientes. Adicionalmente hace parte del Movimiento Agroecológico Latino Americano - maela, la Red Semillas Libres de Colombia y la Red Nacional de Agricultura Familiar. Sus temas de interés son Agroecología, Semillas Nativas y Criollas, Agricultura Campesina, Agriculturas Alternativas.

\section{Ana María García Hoyos}

Bióloga de la Pontificia Universidad Javeriana; magister en Agricultura Orgánica y Sistemas Alimentarios de la Universidad de Hohenheim, Alemania y Sistemas Agrícolas Orgánicos y Agroecología de la Universidad de Recursos Naturales y Ciencias de la Vida (вокU), Austria. Actualmente se desempeña como consultora en el sector agropecuario y de desarrollo rural en Colombia. Sus temas de interés son Uso y Conservación de la Agrobiodiversidad, Conocimientos Tradicionales, Agricultura Ecológica, Agroecología y Redes Alimentarias Alternativas.

\section{Alvaro Idárraga Quintero}

Ingeniero Agrónomo de la Universidad de Caldas; magister en Desarrollo Regional y Planificación del territorio de la Universidad Autónoma de Manizales. Actualmente es secretario ejecutivo de la Red Comparte para el desarrollo alternativo de la Conferencia de Provinciales Jesuitas de América Latina (CPAL). Sus temas de interés son Agroecología, Gestión del Territorio y Economía Social y Solidaria.

\section{Vladymeer León Cuéllar}

Ingeniero Agrícola de la Universidad Surcolombiana (Huila); Especialista en Pedagogía de la Lúdica; Magíster en Ecología y Gestión de Ecosistemas Estratégicos y Doctor en Educación. Actualmente es profesor adscrito a la Secretaría de Educación del Huila; docente del programa de Ingeniería Ambiental de la Fundación Universitaria Navarra y catedrático de la Universidad Surcolombiana en la Facultad de Ciencias Exactas y Naturales. Coinvestigador de grupos de investigación fabenchu y ecosurc. Sus temas de interés son Agroecología, Bioindicación 
de aguas, limnología, gestión de proyectos productivos agropecuarios sostenibles, educación ambiental y ciencia ciudadana.

\section{William Bernardo Macías Orozco}

Magister en Sociología y maestrante en Economía Aplicada. Doctorado en sociología Universidad del Valle. Formación pregrado Economista y Contador Público. Especialista en formulación y gestión de proyectos-SENA. Docente y Líder de la Unidad de Investigación del Programa de Contaduría Pública de la Corporación Universitaria de Comfacauca- Unicomfacauca. Docente del Programa Trabajo Social de la Universidad del Valle y de la Corporación Universitaria Autónoma del Cauca. Como investigador cuenta con publicaciones en torno a temas relacionados con la crisis sistémica del capitalismo, movimientos sociales, economía solidaria, economía para la vida y formación-subjetivación.

\section{Willington Ortiz Orozco}

Ingeniero Mecánico de la Universidad Nacional de Colombia (Bogotá); Magister en Gestión de Tecnología y Recursos en los Trópicos y Subtrópicos de la Universidad Técnica de Colonia-Alemania. A partir de 2009 investigador asociado del Instituto Wuppertal en Alemania. Su campo general de investigación se encuentra en el papel de procesos de innovación en transformaciones sociales. En su investigación se ha enfocado particularmente en innovaciones en energías renovables y descentralizadas así como en prácticas organizativas y agroecológicas de familias agricultoras. Actualmente se encuentra finalizando su investigación de doctorado en ciencias sociales en la Universidad Leuphana de Luneburgo en Alemania.

\section{Juvenal Ruíz Pérez}

Ingeniero Agrónomo de la Universidad de Caldas (Manizales); magister en Ecología y Gestión de Ecosistemas Estratégicos de la Universidad Surcolombiana. Actualmente orienta los procesos de reconversión de sistemas productivos agrícolas hacia un manejo sustentable en el marco de la implementación del Plan de Ordenación y Manejo de la cuenca del río Las Ceibas, Neiva, Huila, con la Corporación Autónoma Regional del Alto Magdalena, CAM. Sus temas de interés son Agricultura Sustentable, Manejo y la Conservación de los Suelos, Escuela de Campo para Agricultores, Cuencas hidrográficas y medidas de mitigación y adaptación al cambio climático. 


\section{Hellen Sánchez Gil}

Ingeniera Forestal de la Universidad Distrital Francisco José de Caldas; magister en Desarrollo Rural de la Pontificia Universidad Javeriana. Actualmente se desempeña como investigadora de sistemas agroforestales en fincas del eje cafetero; adicionalmente es miembro de la BioRed Iberomérica - nodo Colombia. Sus temas de interés son Agroecología, Agricultura Familiar Campesina, Sistemas Agroforestales, Seguridad y Soberanía Alimentaria.

\section{Julia Katharina Waeger}

Pregrado en Ciencias Regionales de América Latina de la Universidad de Colonia, Alemania (Universität zu Köln) y maestría en manejo de recursos naturales en los trópicos y subtrópicos de la Universidad de Ciencias Aplicadas de Colonia, Alemania (тн Köln). Su tesis de maestría fue realizada con el Instituto Wuppertal de Clima, Medio Ambiente, Energía (Alemania), con el título “Difusión de plantas de biogás a pequeña escala bajo iniciativas dirigidas por la comunidad: análisis del caso de Asproinca, Colombia”. Actualmente es consultora de ecología en una asociación juvenil nacional en Alemania. Sus temas de interés son Agroecología, Agricultura Familiar, Política Climática Internacional. 
Este libro fue compuesto en caracteres Garamond Premier Pro 11,5 puntos, impreso en abril de 2019, en Bogotá D. C., Colombia Xpress. Estudio Gráfico y Digital S.A.S. 